\title{
WNT signalling affects cell migration, invasion and the lymphoma-endothelial interplay in Hodgkin Lymphoma
}

\author{
Doctoral Thesis \\ In partial fulfilment of the requirements for the degree \\ "Doctor rerum naturalium (Dr. rer. nat.)" \\ in the Molecular Medicine Study Programme \\ at the Georg-August University Göttingen
}

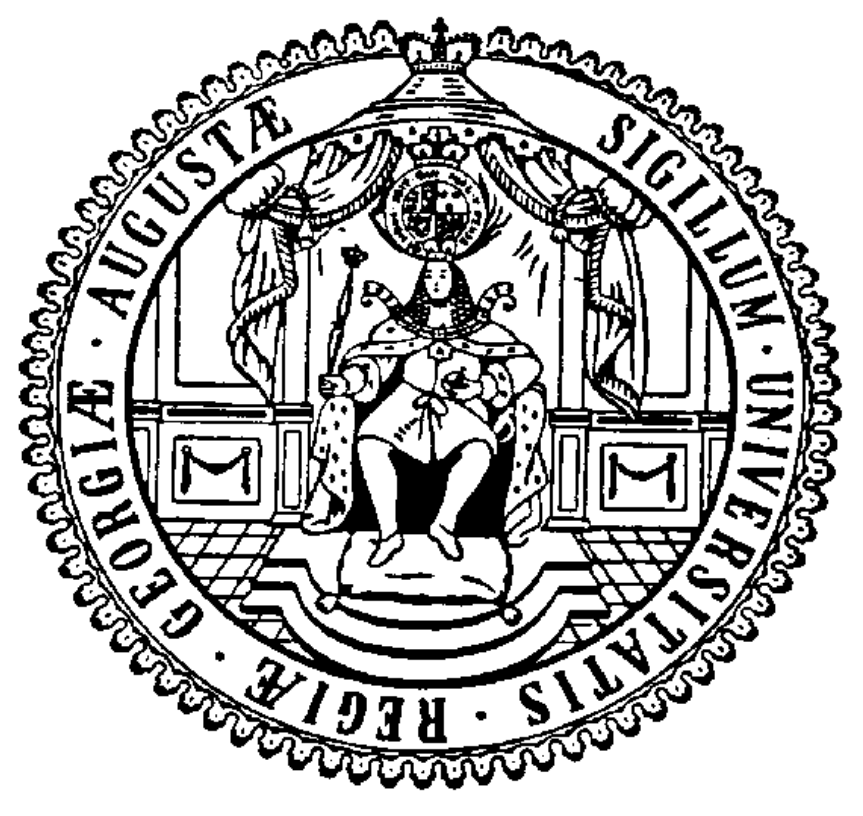

submitted by Franziska Linke

born in Cottbus

Göttingen, 2016 


\section{Members of the Thesis Committee:}

Prof. Dr. Dieter Kube (Supervisor)

$\begin{array}{ll}\text { Email } & \text { dieter.kube@med.uni-goettingen.de } \\ \text { Phone } & 0049-551-395307 \\ \text { Institute } & \text { University Medical Centre Göttingen } \\ & \text { Clinic of Haematology and Medical Oncology } \\ & \text { Robert-Koch-Str. } 40 \\ & 37075 \text { Göttingen }\end{array}$

Prof. Dr. Holger Bastians (Second member of the Thesis Committee)

Email

Phone

Institute holger.bastians@uni-goettingen.de

0049-551-3933823

University Medical Centre Göttingen

Institute for Molecular Oncology

Grisebachstr. 8

37077 Göttingen

Prof. Dr. Henning Urlaub (Third member of the Thesis Committee)

$\begin{array}{ll}\text { Email } & \text { henning.urlaub@mpi-bpc.mpg.de } \\ \text { Phone } & 0049-551-2011060 \\ \text { Institute } & \text { Max-Planck-Institute for Biophysical } \\ & \text { Chemistry } \\ & \text { Bioanalytical Mass Spectrometry Group } \\ & \text { Am Fassberg } 11 \\ & 37077 \text { Göttingen }\end{array}$

Date of Disputation: 


\section{Affidavit}

By this I declare that I independently authored the presented thesis:

"WNT signalling affects cell migration, invasion and the lymphoma-endothelial interplay in Hodgkin Lymphoma"

and that I did not use other auxiliary means than indicated. Paragraphs that are taken from other publications, by wording or by sense, are marked in every case with a specification of the literary source.

Furthermore, I declare that I carried out the scientific experiments following the principles of Good Scientific Practice according to the valid "Richtlinien der Georg-August-Universität Göttingen zur Sicherung guter wissenschaftlicher Praxis".

Franziska Linke

Göttingen, April 2016 


\section{List of publications}

\section{Original articles:}

Linke F, Zaunig S, Nietert MM, von Bonin F, Lutz S, Dullin C, Janovská P, Beissbarth T, Alves F, Bryja V, Pukrop T, Trümper L, Wilting J \& Kube D (2016) WNT5A - a motility promoting factor in Hodgkin Lymphoma. Oncogene: in revision

Linke F, Harenberg M, Nietert MM, Zaunig S, von Bonin F, Szczepanowski M, Weich HA, Lutz S, Dullin C, Janovská P, Klapper W, Beissbarth T, Alves F, Bryja V, Trümper L, Wilting J \& Kube D (2016a) Microenvironmental interactions between endothelial and lymphoma cells- a role for the canonical WNT pathway in Hodgkin's disease. Cancer Res.: submitted

Eberth S, Wilming P, Linke F, Szczepanowski M, Bayerlová M, Blumberg A, Ueberdiek S, Klingenberg M, von Bonin F, Hengst S, Klapper W, Beißbarth T, Trümper L, Wilting J, Kube D, Lymphocyte Enhancer Binding Factor 1 Supports Vascularization in a Xenograft Tumor Model for Burkitt Lymphoma. in preparation

\section{Abstracts:}

Linke F, Zaunig S, von Bonin F, Wilting J, Bryja V, Pukrop T, Trümper L, Kube D (2015) Wnt5a signaling mediates cell migration and invasion of Hodgkin Lymphoma in vitro and in xenograft models. Oncol Res Treat 38: p211.Oral presentation at the Annual Meeting of the German Society for Hematology \& Oncology, Basel, Switzerland, October 9-13.

Harenberg M.., Linke F.", Wilting J., Szczepanowski M., Klapper W., Trümper L. Kube D. (2015) Lymphocyte enhancer binding factor 1 (LEF-1) affects the interaction of Hodgkin's lymphoma with endothelial cells. Oncol Res Treat 38: p144. Poster presentation at the Annual Meeting of the German Society for Hematology \& Oncology, Basel, Switzerland, October 9-13. 
Linke F., Zaunig S., von Bonin F., Wilting J., Trümper L., Pukrop T., Kube D. (2015) A Role for Wnt signaling in Hodgkin's Lymphoma cell migration. Poster presentation at the 18th International AEK Cancer Congress, Heidelberg, Germany, March 18-20.

Linke F., Schoof N., Sieben O.M., von Bonin F., Hengst S., Wilting J., Trümper L., Pukrop T., Kube D. (2013) A Role For WNT Signaling in Hodgkin's Lymphoma. Poster presentation at the Wnt symposium, German Cancer center, Heidelberg, Germany, July 14-16. 


\section{Table of contents}

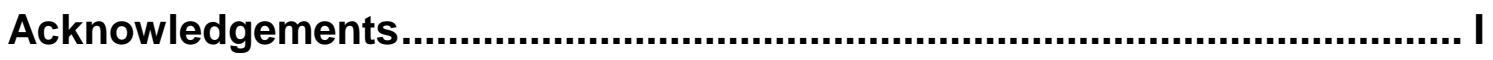

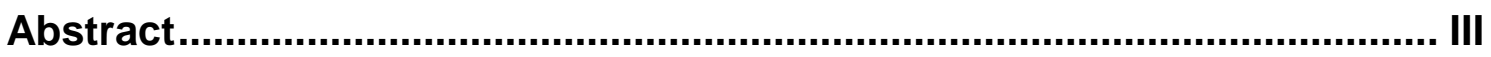

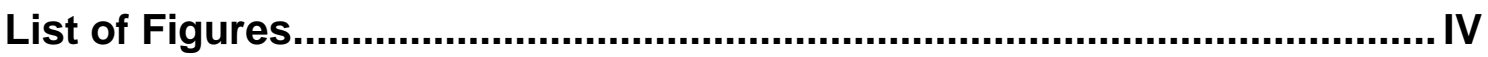

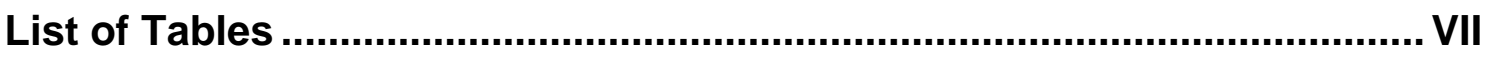

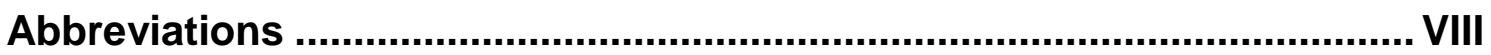

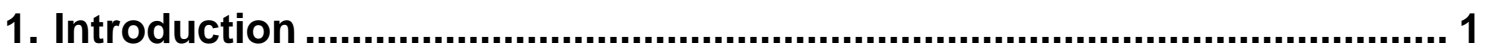

1.1 Classical Hodgkin Lymphoma (cHL) …………....................... 1

1.1.1 Histological and molecular characteristics of $\mathrm{cHL}$................. 2

1.1.2 Deregulated signalling pathways in $\mathrm{CHL}$............................... 3

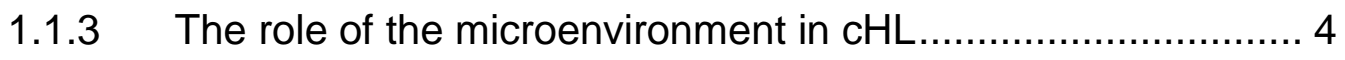

1.1.4 Therapy options, challenges and limitations........................... 5

1.2 Processes associated with lymphoma progression ……................. 7

1.2.1 Migration and invasion processes ......................................... 7

1.2.2 Induction of angiogenesis ................................................ 9

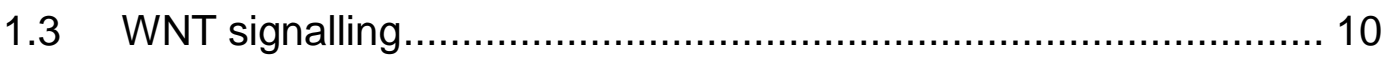

1.3.1 Canonical WNT signalling ................................................ 12

1.3.2 Non-canonical WNT signalling …………......................... 13

1.3.3 WNT signalling in cancer progression, metastasis and

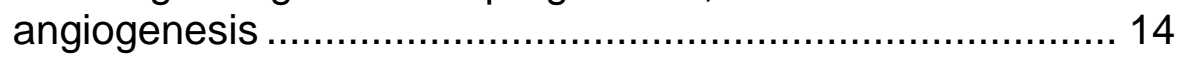

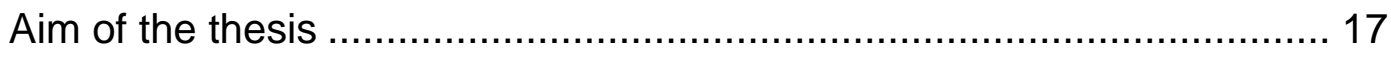

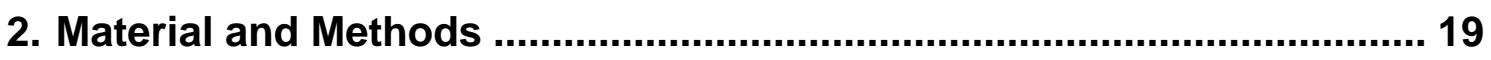

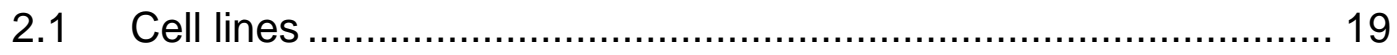

2.2 Chemicals, solutions and consumable supplies.......................... 20

2.3 Buffers and Media.................................................................... 23

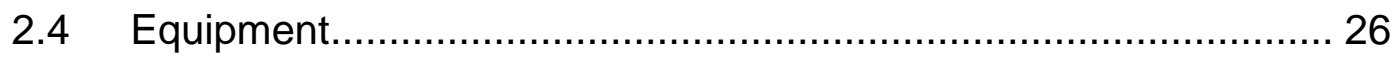

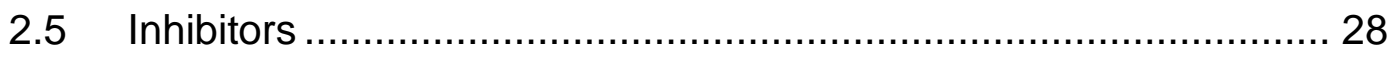




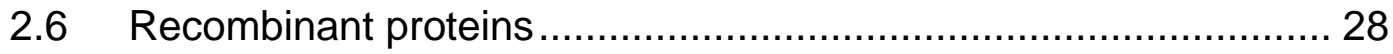

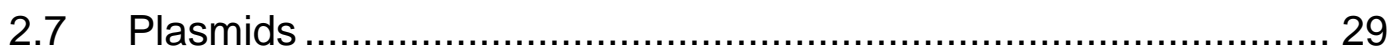

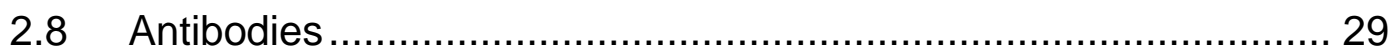

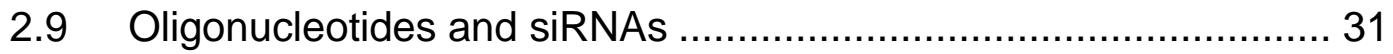

2.10 Ready to Use Reaction Systems ……….................................. 33

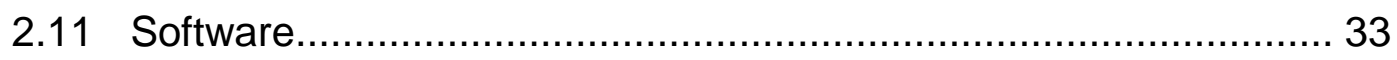

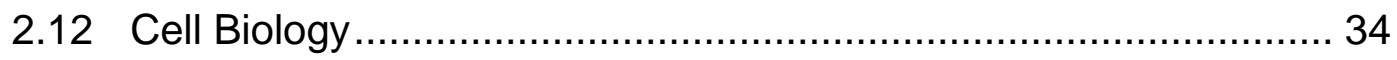

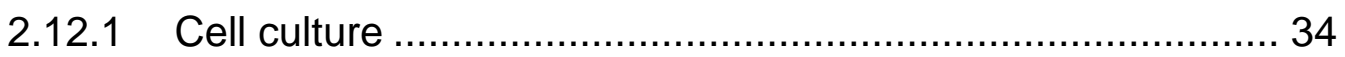

2.12.2 RNA-interference-mediated gene knockdown and gene overexpression by nucleofection ........................................... 35

2.12.3 Preparation of conditioned medium (CM) .......................... 36

2.12.4 Isolation and preparation of extracellular vesicles (EVs) ....... 36

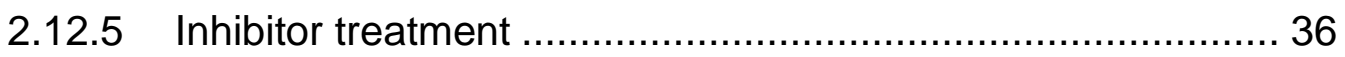

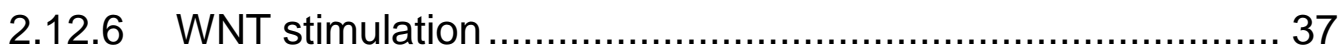

2.12.7 Lentivirus production ..................................................... 37

2.12.8 Lentiviral transduction and selection of $\mathrm{pGIPZ} \mathrm{cHL}$ cells....... 38

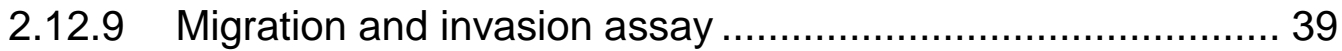

2.12.10 Time-lapse microscopy of cell chemotaxis .......................... 39

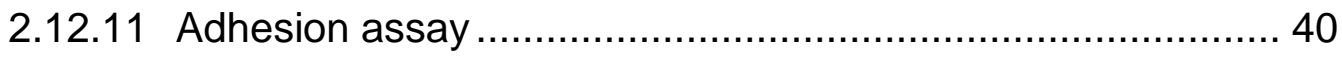

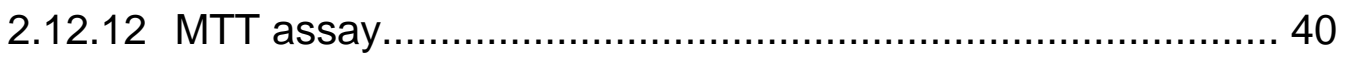

2.12.13 RHOA activity assay ....................................................... 41

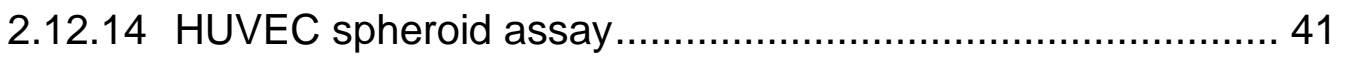

2.12.15 HUVEC tube formation assay ............................................ 41

2.12.16 Chick chorio-allantoic membrane (CAM) assay................... 42

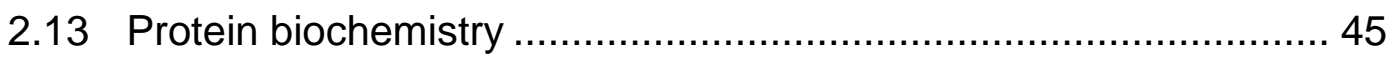

2.13.1 Whole cell lysates and cell fractionation ............................... 45 
2.13.2 SDS page and Western Blot.

2.13.3 Enzyme-linked immunosorbent assay (ELISA) of VEGFA .... 47

2.14 Molecular Biology ...................................................... 47

2.14.1 mRNA isolation......................................................... 47

2.14.2 Reverse transcription ............................................. 48

2.14.3 Quantitative real-time polymerase chain reaction (qRTPCR)

2.15 NMR spectroscopy for the quantification of intracellular metabolites

2.16 Microarray data analyses ............................................ 50

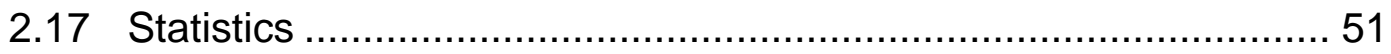

3. Results

3.1 $\mathrm{cHL}$ cell lines migrate with high rates and depend on autocrine WNTs.

3.1.1 cHL cells migrate in an amoeboid manner with special characteristics

3.1.2 Inhibition of WNT ligand secretion reduces $\mathrm{cHL}$ cell migration, invasion and adhesion

3.1.3 Intervention of JAK/STAT, MAPK or NF-KB signalling does not perturb $\mathrm{CHL}$ cell migration

3.1.4 Inhibition of the WNT ligand secretion impairs lymphoma outcome and vascularization in the in vivo CAM assay .........61 61

3.1.5 WNT5A and WNT10B are expressed by cHL cells 64

3.1.6 WNT5A signalling mediates migration and invasion in Hodgkin Lymphoma

3.1.7 Migration path characteristics depend on WNT5A signalling

3.1.8 FZD5 and DVL3 are required for $\mathrm{cHL}$ cell migration. 73

3.1.9 WNT5A on extracellular vesicles (EVs) activates DVL3 and stimulates $\mathrm{CHL}$ cell migration 
3.1.10 RHOA is activated after WNT5A stimulation

3.1.11 WNT5A expression is increased in a fraction of patients and associated with early relapse cases

3.1.12 Autocrine canonical WNT signalling is detected in $\mathrm{cHL}$ cells

3.1.13 Increased LEF-1 expression is associated with B-cell malignancies

3.1.14 Inhibition of the canonical WNT pathway reduces $\mathrm{CHL}$ cell chemotaxis

3.1.15 Migration path characteristics of $\mathrm{cHL}$ cells are impaired after LEF-1 and $\beta$-catenin knockdown.

3.2 CHL cells possess pro-angiogenic properties that depend on

WNT signalling.

3.2.1 Inhibition of the canonical WNT pathway impairs lymphoma outcome and vascularization in the in vivo CAM assay 90

3.2.2 WNT5A addition enhances $\mathrm{CHL}$ tumour hemorrhages in the in vivo CAM model

3.2.3 LEF-1 and $\beta$-catenin are important for the secreted VEGFA levels of $\mathrm{cHL}$ cells.

4. Discussion

4.1 High migration rates are a feature of $\mathrm{cHL}$ cells 96

4.2 WNT signalling is a regulator of $\mathrm{cHL}$ cell migration and invasion.

4.2.1 Autocrine secreted WNT5A is an enhancer of $\mathrm{cHL}$ cell motility 99

4.2.2 Canonical WNT signalling modifies especially collageninduced cHL motility

4.3 cHL cells possess pro-angiogenic properties that rely on WNT signalling.....

4.4 In vivo Lymphoma engraftment is significantly affected by both, canonical and non-canonical, WNT signalling 
4.5 Therapy of $\mathrm{cHL}$ and future prospects ............................... 107

5. Summary and Conclusions ................................................................. 110

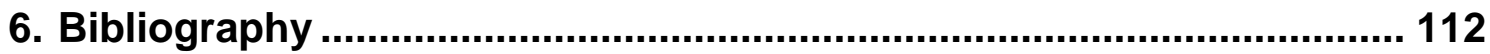

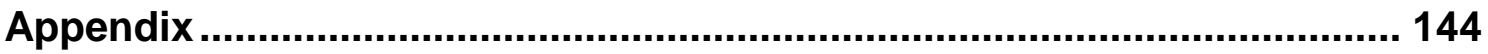

Additional figures ................................................................. 144

Supplementary Videos......................................................... 151

Additional Methods ........................................................ 152

Curriculum Vitae.......................................................................................... 154 


\section{Acknowledgements}

At first, I would like to thank Prof. Dieter Kube for his support and supervision during the last three and a half years of my thesis. I am very thankful for his advice and all the time he invested in our inspiring and motivating discussions. I also highly appreciate that he always gave me the opportunity to incorporate my own ideas and experiments into the thesis.

In addition, I am very thankful to Prof. Lorenz Trümper for the opportunity to accomplish this thesis in his department.

Furthermore, I am very grateful for the support, advice and inspiring new perspectives of my thesis committee members Prof. Holger Bastians and Prof. Henning Urlaub.

I would also like to thank all our cooperation partners for their support and contribution to our work. I gratefully acknowledge Prof. Vitezslav Bryja for his insightful suggestions and the technical support during my thesis. He and his lab members Pavlína Janovská, Michaela Krafčíková, Lukáš Trantírek and Petra Ovesná were very helpful for the analysis of microarray data sets and NMR analysis. Moreover, I want to thank Manuel M. Nietert and Prof. Tim Beißbarth for their contribution to the cell track analysis. Their cell path fingerprints opened up a new detailed way to look at cell tracks. Special thanks go to Prof. Jörg Wilting and his research group for their immunohistochemical assays and the support during the manuscript writing processes. I would also like to express my gratitude to Christian Dullin and Prof. Frauke Alves for their Micro-CT analysis, which really improved the informative value of our CAM assay data. Moreover, I want to thank Monika Szczepanowski and Wolfram Klapper for the staining of patients' tissue microarrays. Finally, I would like to acknowledge Prof. Susanne Lutz for her support and the opportunity to perform time-lapse studies of our cells in her lab.

For the successful completion of my thesis I am especially thankful to Frederike von Bonin, who was an indispensable support throughout the years. I do not know 
what I would have done without her assistance for the qRTs, plasmid preparations and of course the "millions" of chicken egg assays.

During my thesis I had the pleasure to supervise two very good medical doctor students. I would like to express my special thanks to both of them, Sebastian Zaunig and Moritz Harenberg, for their motivation, engagement and contribution to our two manuscripts.

As Aristoteles said "The whole is more than the sum of its part." I would also like to thank and acknowledge all our former and current lab members who supported and motivated me throughout the years. I want to thank Sonja Eberth, Juliane Lippert, Natalie Freytag, Susanne Hengst, Elisabeth Hand, Christina Stadler and of course especially Maren Feist, Isabel Rausch and Annekatrin Arlt for always encouraging me and the great working atmosphere.

Finally, I owe my whole family and friends a debt of gratitude for being there for me my whole life. Thanks to my parents, grand-parents, brothers, aunts and uncles for believing in me and caring so much. I am deeply grateful to be part of such a great family. In addition, I would like to thank my best friend Bettina Wagner for being such a good and reliable friend to me and also Malte Vogt for his understanding and the wonderful time I am always spending with him.

Last but not least I would like to dedicate my thesis to my parents, Gerlinde and Wolfgang, who always motivated me and believed in my goals. They achieved to give me both, roots to grow and wings to fly. 


\section{Abstract}

Classical Hodgkin Lymphoma ( $\mathrm{CHL}$ ) comprises a unique cancer where the microenvironment accounts for $99 \%$ of the whole tumour mass. In $\mathrm{cHL}$ dissemination involves functionally neighbouring lymph nodes but the underlying mechanisms for the spread of lymphoma cells are poorly understood. This thesis aims at characterizing $\mathrm{cHL}$ cell migration, invasion and pro-angiogenic properties as well as at identifying the underlying oncogenic pathways.

Herein, it is shown that $\mathrm{CHL}$ cell migration, invasion and adhesion depend on autocrine WNT signalling as revealed by the inhibition of WNT secretion with porcupine inhibitors Wnt-C59/IWP-2 but also by targeting canonical WNT signalling. Time-lapse studies identified an amoeboid type of cell migration modulated by WNT5A as well as by lymphocyte enhancer-binding factor 1 (LEF-1) and $\beta$-catenin in a $3 \mathrm{D}$ cell culture model. Application of recombinant WNT5A, WNT5A overexpression and WNT5A receptor binding inhibition by Box 5 affected $\mathrm{CHL}$ cell migration. Among the diverse WNT pathways, the WNT5A-FZD5-DVL3RHOA cascade and basal canonical WNT signalling are regulators of $\mathrm{CHL}$ cell motility. In addition to these mechanistic insights into the in vitro role of WNTs, global gene expression data revealed increased WNT5A and LEF-1 expression in primary $\mathrm{CHL}$ cells in comparison to normal B-cell subsets and other lymphomas.

The pro-angiogenic potential of $\mathrm{CHL}$ cells was revealed by sprouting and vascular tube formation assays of endothelial cells. In that context, LEF-1 and $\beta$-catenin regulated the secreted VEGFA levels of $\mathrm{cHL}$ cells. Importantly, VEGFA gene expression is prognostic for cHL. Furthermore, impaired WNT secretion or canonical WNT signalling as well as WNT5A stimulation had an impact on lymphoma development in the chick chorio-allantoic membrane (CAM) assay. The vasculature network was significantly reduced after inhibition of WNT secretion by Wnt-C59 or canonical WNT pathway inhibition.

Therefore, a model is proposed where WNT signalling plays an important role in regulating $\mathrm{cHL}$ progression-associated processes. 


\section{List of Figures}

Figure 1: Schematic overview of some known deregulated signalling pathways in $\mathrm{CHL}$ cells.

Figure 2: Overview of $\beta$-catenin-dependent and -independent WNT

pathways.

Figure 3: Examples of CAM tumours with their respective hemorrhage

score.

Figure 4: Hodgkin Lymphoma cell lines L428, KM-H2 and L1236 migrate

with higher rates compared to several NHL cell lines.

Figure 5: $\mathrm{cHL}$ cells move with an amoeboid type of migration.

Figure 6: Movements of cHL cells seem to be characterized by cell-cell

contacts with neighbouring cells.

Figure 7: Migration of cHL cell lines depends on intact WNT ligand

secretion

Figure 8: Porcupine inhibition does not significantly affect L428, KM-H2

and L1236 cell proliferation.

Figure 9: Invasion and adherence capacity of $\mathrm{cHL}$ cells is impaired after porcupine inhibition.

Figure 10: Migration of L428 cells does not depend on NF-kB, JAK/STAT

or MAPK signalling.

Figure 11: Treatment with porcupine inhibitors affects tumour size and hemorrhage scores in a chick CAM model.

Figure 12: Porcupine inhibitor-treated CAM tumours show less hemorrhages.

Figure 13: Porcupine inhibitor-treated CAM tumours contain less vessel

structures.

Figure 14: WNT5A is expressed in $\mathrm{cHL}$ cell lines on mRNA and protein level. 65

Figure 15: WNT5A is a stimulator of $\mathrm{cHL}$ cell migration.

Figure 16: Box5 inhibits WNT5A-mediated invasion, and adhesion of L428 cells. 
Figure 17: Wnt-C59, Box5 or WNT5A pre-treatment affects $L 428$ cell movement paths in a 3D collagen matrix.

Figure 18: WNT5A signalling influences cell path characteristics of $L 428$ cells in a 3D matrix.

Figure 19: L428 cell movement classes are affected by WNT5A

signalling.

Figure 20: FZD5 knockdown impairs L428 cell migration.

Figure 21: DVL3 is exclusively activated in a time-dependent manner after WNT5A stimulation in $\mathrm{CHL}$ cells.

Figure 22: DVL3 expression is required for $L 428$ cell migration..................... 75

Figure 23: WNT5A of EVs activates DVL3 and stimulates $\mathrm{CHL}$ migration. ...... 76

Figure 24: WNT5A stimulates RhoA in a DVL3 and FZD5-dependent manner.

Figure 25: L428 cell migration depends on ROCK.

Figure 26: WNT5A expression is increased in a substantial fraction of $\mathrm{cHL}$ patients.

Figure 27: Low amounts of $\beta$-catenin are already located in the nucleus of L428 cells.

Figure 28: Aberrant $L E F-1$ expression in lymphoma entities compared to physiological B-cell subsets.

Figure 29: Inhibition of the canonical WNT signalling decreases $\mathrm{cHL}$ cell migration.

Figure 30: Inhibition of the canonical WNT pathway does not affect $\mathrm{cHL}$ cell proliferation.

Figure 31: LEF-1 and $\beta$-catenin expression are necessary for $\mathrm{cHL}$ cell migration and invasion.

Figure 32: WNT5A can rescue inhibition of tankyrases but not ROCK 85

Figure 33: LEF-1 and $\beta$-catenin influence cell path characteristics of $\mathrm{cHL}$ cells in a 3D matrix.

Figure 34: LEF-1 and $\beta$-catenin influence movement classes of $\mathrm{CHL}$ cells in a $3 \mathrm{D}$ matrix. 
Figure 35: LEF-1 and $\beta$-catenin modify the influence of $\mathrm{cHL}$ cells on endothelial cell sprouting.

Figure 36: LEF-1 and $\beta$-catenin modify the influence of $\mathrm{cHL}$ cells on endothelial tube formation..

Figure 37: Impaired canonical WNT signalling by XAV939 treatment

affects lymphoma outcome in the chick CAM assay..

Figure 38: Impaired canonical WNT signalling by XAV939 treatment reduces lymphoma hemorrhages.

Figure 39: WNT5A pre-treatment positively affects tumour outcome in a chick CAM model..

Figure 40: VEGFA secreted by $\mathrm{CHL}$ cells is not regulated by WNT5A but by LEF-1/ $\beta$-catenin and high VEGFA gene expression is associated with a worse overall survival in $\mathrm{CHL}$ patients..

Figure 41: Positive LEF-1 staining was found in 3/9 (33 \%) mixed cellularity $\mathrm{cHL}$ samples.

Figure 42: Scheme of autocrine WNT5A signalling loop and canonical WNT signalling in cHLs.

Figure A-43: Additional data to time-lapse microscopy of Wnt-C59, Box5 or WNT5A pre-treated L428 cells using the IBIDI 3D chemotaxis chamber... 144 Figure A-44: KM-H2 migration depends on FZD5 and Box5 abolishes DVL3 activation in $\mathrm{HL}$ cell lines. 145

Figure A-45: Treatment with XAV939 or PF670462 abolishes nuclear $\beta$-catenin fraction. 146

Figure A-46: TCFRNA and protein level are not influenced by the LEF-1 knockdown.

Figure A-47: Cell tracks of KM-H2 LEF-1si and $\beta$-catenin si cluster separately from scr control cells. 148

Figure A-48: Metabolites of L428 and KM-H2 pGIPZ LEF-1sh cells are not different from control cells.

Figure A-49: $C C R 7$ expression is increased in $\mathrm{CHL}$ patients compared to physiological B-cell subsets 150 


\section{List of Tables}

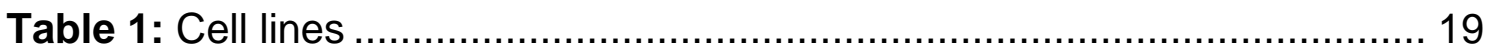

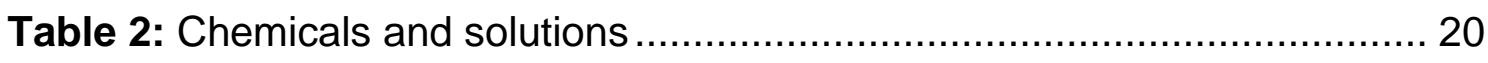

Table 3: Consumables ................................................................... 22

Table 4: Recipes of buffers and media ........................................... 23

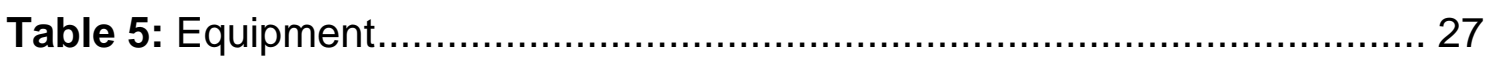

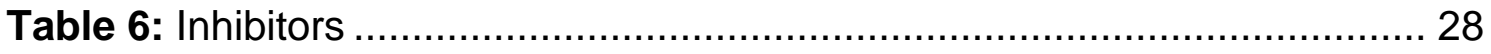

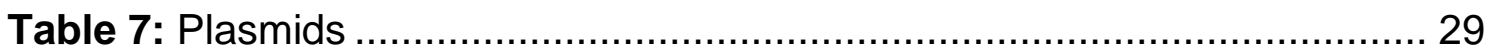

Table 8: Antibodies .......................................................................... 30

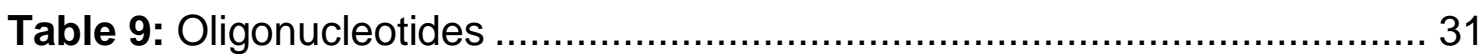

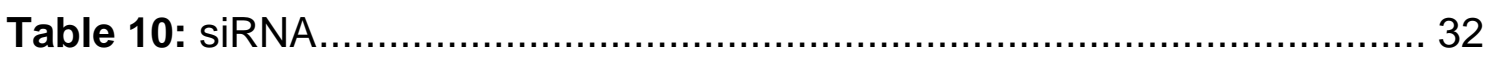

Table 11: Ready to use reaction systems ...................................... 33

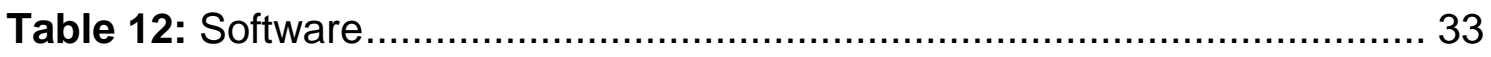

Table 13: Hemorrhage score for CAM tumours .......................................... 44

Table 14: Master mix and thermocycler programme for the reverse

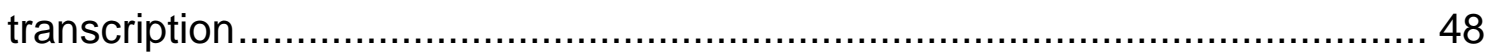

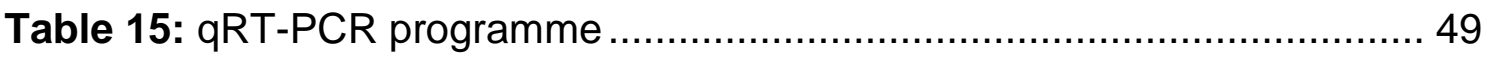




\section{Abbreviations}

\begin{tabular}{|c|c|}
\hline Abbreviation & Denotation \\
\hline ABVD & $\begin{array}{l}\text { Chemotherapy regiment of doxorubicin, bleomycin, vinblastine, } \\
\text { and dacarbazine }\end{array}$ \\
\hline AIDS & Acquired immunodeficiency syndrome \\
\hline AKT & v-Akt murine thymoma viral oncogene homolog 1 \\
\hline ALL & Acute lymphocytic leukaemia \\
\hline AML & Acute myeloid leukaemia \\
\hline Ang & Angiopoietin \\
\hline APC & Adenomatous polyposis coli \\
\hline BCL9 & B-cell CLL/Lymphoma 9 \\
\hline BCR & B-cell receptor \\
\hline BEACOPP & $\begin{array}{l}\text { Chemotherapy regiment of bleomycin, etoposide, doxorubicin, } \\
\text { cyclophosphamide, vincristine, procarbazine and prednisone }\end{array}$ \\
\hline BL & Burkitt Lymphoma \\
\hline BLNK & B-cell Linker \\
\hline BV & $\begin{array}{l}\text { Brentuximab vedotin (antibody-drug conjugate composed of } \\
\text { MMAE and anti-CD30 antibody) }\end{array}$ \\
\hline C59 & Wnt-C59 \\
\hline CAM & Chorio-allantoic membrane \\
\hline CCL & Chemokine (C-C Motif) ligand \\
\hline CCR & Chemokine (C-C Motif) receptor \\
\hline CDC42 & Cell Division Cycle 42 \\
\hline $\mathrm{cHL}$ & Classical Hodgkin Lymphoma \\
\hline CK1 & Casein kinase 1 \\
\hline CLL & Chronic lymphocytic leukaemia \\
\hline $\mathbf{C M}$ & Conditioned medium \\
\hline ctr & Control \\
\hline CXCL & Chemokine (C-X-C Motif) ligand \\
\hline DDR2 & Discoidin Domain Receptor Tyrosine Kinase 2 \\
\hline
\end{tabular}




\begin{tabular}{ll}
\hline DKK & Dickkopf \\
DLBCL & Diffuse Large B-cell Lymphoma \\
DVL & Dishevelled \\
EBV & Epstein-Barr virus \\
ECM & Extracellular matrix \\
e.g. & For example \\
EV & Extracellular vesicle \\
FGF & Fibroblast growth factor \\
fWd & Forward \\
FZD & Frizzled \\
GSK3 & Glycogen synthase kinase 3 \\
H\&E & Haematoxylin and eosin \\
HEV & High endothelial venule \\
HL & Hodgkin Lymphoma \\
HRS & Hodgkin and Reed-Sternberg \\
HUVEC & Human Umbilical Vein Endothelial Cell \\
IL & Interleukin \\
JAK & Janus kinase \\
JNK & C-Jun N-Terminal Kinase 1 \\
LEC & Lymphatic Microvascular Endothelial Cell \\
LEF-1 & Lymphocyte enhancer-binding factor 1 \\
LRP & Low-density lipoprotein receptor-related protein \\
MCL & Mantle Cell Lymphoma \\
MMAE & Monomethyl auristatin E \\
NFAT & Nuclear factor of activated T-cells \\
NF-KB & Nuclear factor kappa-light-chain-enhancer of activated B-cells \\
NHL & Non-Hodgkin Lymphoma \\
NLPHL & Nodular lymphocyte-predominant HL \\
ns & Nonsense \\
PD-1 & Programmed cell death 1 \\
PDGF & Platelet derived growth factor \\
\hline
\end{tabular}




\begin{tabular}{ll}
\hline PI3K & Phosphatidylinositol-4,5-bisphosphate 3-kinase \\
RAC & Ras-Related C3 Botulinum Toxin Substrate 1 (Rho Family, Small \\
& GTP Binding Protein Rac1) \\
REL & V-Rel Avian Reticuloendotheliosis Viral Oncogene Homolog \\
rev & Reverse \\
RHOA & Ras Homolog Family Member A \\
ROCK & Rho-Associated, Coiled-Coil Containing Protein Kinase \\
ROR & Receptor Tyrosine Kinase-Like Orphan Receptor \\
SCr & Scrambled \\
shRNA & Short hairpin RNA \\
siRNA & Small interfering RNA \\
SOCS1 & Suppressor of cytokine signalling 1 \\
STAT & Signal transducer and activator of transcription \\
TCF & Transcription Factor (T-Cell Specific, HMG-Box) \\
WNT & Wingless-Type MMTV Integration Site Family \\
WNT5A L-CM & Conditioned medium derived from WNT5A-secreting L-cells \\
wt L-CM & Conditioned medium derived from wildtype L-cells \\
XAV & XAV939
\end{tabular}




\section{Introduction}

Cancer is one of the leading cause of death worldwide and its impact will further rise due to the growing and ageing world population (Torre et al, 2015). Malignant lymphomas comprise a heterogeneous group of more than 30 subtypes divided into Non-Hodgkin (NHL) and Hodgkin Lymphoma (HL) (Swerdlow et al, 2008). Lymphoma spread often correlates with poor prognoses and challenges therapy options (Armitage, 1993; Gospodarowicz \& Sutcliffe, 1995; Yamamoto et al, 2010; Guermazi et al, 2001). In contrast to the metastasis process of solid cancers lymphoma dissemination and the underlying signalling mechanisms are only poorly understood. Therefore, an improved understanding of those mechanisms regulating lymphoma migration and their interaction with endothelial and lymphatic cells are needed.

\subsection{Classical Hodgkin Lymphoma (cHL)}

In 1832 Thomas Hodgkin described for the first time the "morbid appearances of the absorbent glands and spleen" in seven patients (Hodgkin, 1832). The observed lymphoid malignancy is named after him. HL is classified into the classical Hodgkin Lymphoma (cHL), which accounts for $95 \%$ of $\mathrm{HL}$ cases, and the less frequent nodular lymphocyte-predominant HL (NLPHL) (Lukes \& Butler, 1966; Eichenauer et al, 2014). Based on histology $\mathrm{CHL}$ is further subdivided into the nodular sclerosis $(60 \%)$, mixed cellularity $(30 \%)$, lymphocyte-rich and lymphocyte-depleted subtype (Swerdlow et al, 2008). In the European Union the annual incidence of $\mathrm{HL}$ is 2.3 cases and the corresponding mortality rate 0.4 cases per 100000 people (Ferlay et al, 2013). The age distribution at diagnosis is bimodal with a first incidence peak seen in young adults (20-35 years) and a second peak in people aged 55 years or older in the industrialized countries. While younger people are more often affected by the nodular sclerosis subtype, the mixed cellularity subtype occurs at higher frequencies in patients older than 30 years (Thomas et al, 2002). 


\subsubsection{Histological and molecular characteristics of $\mathrm{cHL}$}

In $\mathrm{cHL}$ the large malignant cells comprise mononuclear Hodgkin and bi- or multinuclear Reed Sternberg cells, which have been described first around 1900 and are called HRS cells henceforth (Sternberg, 1897; Reed, 1902). HRS cells just account for $0.2-2 \%$ of the whole tumour mass and are embedded in a background of reactive lymphatic stroma, including B- and T-cells, plasma cells, eosinophils, macrophages and granulocytes (Küppers, 2009; Liu et al, 2014) (see also chapter 1.1.3). The origin of HRS cells has been discussed for years but the detection of clonal and somatically mutated Ig heavy- and light-chain gene rearrangements support the view that HRS cells arise from germinal centre B-cells that escaped from apoptosis (Trümper et al, 1993; Küppers et al, 1994; Kanzler et al, 1996b; Marafioti et al, 2000). In only rare cases $\mathrm{HL}$ is derived from T-cells (Müschen et al, 2000; Seitz et al, 2000). HRS cells are predominantly found in the interfollicular zone or, less frequently, in the follicular mantle zone of lymph follicles in nodularinfiltrated lymph nodes (Küppers et al, 2012). One characteristic of HRS cells is the expression of CD30, a receptor of activated B- and T-cells (Stein et al, 1983, 1985). Importantly, HRS cells lost the typical B-cell identity by global reprogramming of several B-cell genes like B-Cell Linker (BLNK) (Schwering et al, 2003). HRS cells rather coexpress a mixture of various hematopoietic lineage markers like T-cell, B-cell, myeloid cell, dendritic cell or NK cell markers (Foss et al, 1999; Takahashi et al, 1995; van den Berg et al, 1999; Sahin et al, 2002). In industrialized countries HRS cells are infected by the Epstein-Barr virus (EBV) in $40 \%$ of all cases but those cases are predominantly found in the mixed-cellularity and the lymphocyte-depleted HL subtype (Kapatai \& Murray, 2006). In paediatric cases of developing countries EBV infections are found in about $90 \%$ of HL cases and if patients suffer from the acquired immunodeficiency syndrome (AIDS) a simultaneous EBV infection can be found in almost all HL cases (Dolcetti et al, 2001; Kapatai \& Murray, 2006). EBV mediates the survival of germinal centre B-cells by mimicking and thus controlling CD40 signalling (Kilger et al, 1998). 


\subsubsection{Deregulated signalling pathways in $\mathrm{cHL}$}

For the last 20 years progress has been made in understanding molecular pathway deregulations of $\mathrm{cHL}$ cells. A simplified overview on some known pathway deregulations at several pathway levels is presented in Figure 1. Deregulations due to genetic lesions have mainly been associated with the nuclear factor kappa-light-chain-enhancer of activated B-cells (NF-kB) and Janus kinase/signal transducers and activators of transcription (JAK/STAT) pathway. In approximately half of the $\mathrm{cHL}$ cases a gain-of-function mutation or amplifications involve V-Rel Avian Reticuloendotheliosis Viral Oncogene Homolog (REL), a NF-kB transcription family member (Barth et al, 2003; Joos et al, 2002). In the JAK/STAT pathway gains of JAK2 or inactivating point mutations of a negative JAK/STAT signalling regulator, suppressor of cytokine signalling 1 (SOCS1), are very frequent (Joos et al, 2000; Weniger et al, 2006). In addition to genetic lesions also autocrine and paracrine signalling cascades play a role for aberrant pathway activations in cHL. Several STAT factors including STAT3, STAT5A/B and STAT6 are activated due to autocrine interleukin signalling (Kube et al, 2001; Kapp et al, 1999; Scheeren et al, 2008; Skinnider et al, 2002; Lamprecht et al, 2008). Next to NF-KB and JAK/STAT signalling other deregulated or constitutively active pathways are the mitogen-activated protein kinase (MAPK)/ERK and phosphatidylinositol-4,5-bisphosphate 3-kinase (PI3K) pathway. In MAPK/ERK signalling ERK1, ERK2 and ERK5 and in PI3K signalling v-akt murine thymoma viral oncogene homolog 1 (AKT) are constitutively activated (Nagel et al, 2007; Zheng et al, 2003; Dutton et al, 2005). The biological outcome of these aberrant activities in multiple pathways for $\mathrm{cHL}$ cells is usually linked to cell proliferation and cell survival but lacks information on migration or invasion processes. 


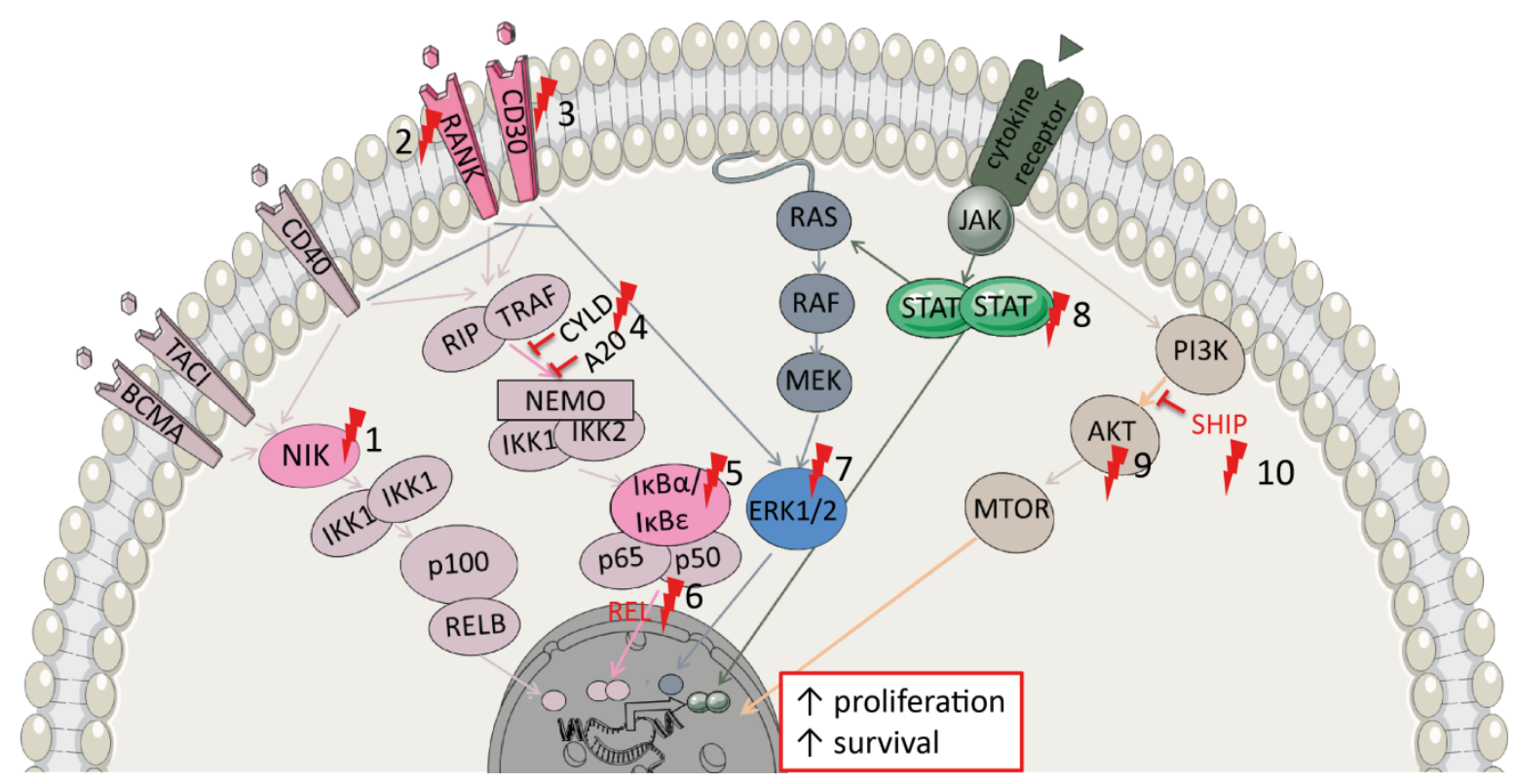

Figure 1: Schematic overview of some known deregulated signalling pathways in cHL cells. The different pathways are encoded in the following colours: NF-KB pathway in pink, MAPK pathway in blue, JAK/STAT pathway in green and PI3K pathway in orange. Pathway members with deregulations in $\mathrm{cHL}$ cells are highlighted with red flashes. References for the shown pathway modulations are as follows: (1) (Otto et al, 2012; Steidl et al, 2010b) (2) (Fiumara et al, 2001) (3) (Horie et al, 2002) (4) (Kato et al, 2009; Schmidt et al, 2010) (5) (Krappmann et al, 1999; Cabannes et al, 1999) (6) (Joos et al, 2002; Barth et al, 2003) (7) (Zheng et al, 2003) (8) (Kube et al, 2001; Skinnider et al, 2002) (9) (Dutton et al, 2005) (10) (Tiacci et al, 2012).

\subsubsection{The role of the microenvironment in $\mathrm{cHL}$}

The tumour microenvironment can initiate and promote cancer progression including tumour growth, spread and therapy resistance (Hanahan \& Weinberg, 2011). In the $\mathrm{CHL}$ tumour mass the malignant HRS cells highly depend on signals and cross talks with their surrounding cells (Aldinucci et al, 2010; Liu et al, 2014). $\mathrm{HL}$ cells actively secrete chemokines to shape their microenvironment (Maggio et al, 2002). Chemokines as chemokine (C-C Motif) ligand 5 (CCL5), CCL17/TARC or chemokine (C-X-C Motif) ligand 10 (CXCL10) are secreted by HRS cells to attract especially T-cells (Aldinucci et al, 2008; van den Berg et al, 1999; Teichmann et al, 2005; Vockerodt et al, 2005). Another example is CCL28, which is secreted to attract eosinophils and plasma cells to the $\mathrm{cHL}$ tumour infiltrate (Hanamoto et al, 2004). Importantly, the lymphoma-microenvironmental interplay does not only involve active secretion processes of $\mathrm{cHL}$ cells but also tumour- 
promoting behaviour of the surrounding cells. Until now the impact of surrounding cells has been studied for T-cells, macrophages, natural killer cells, fibroblasts, mast cells, eosinophils and dendritic cells (Pinto et al, 1996; Molin et al, 2001; Carbone et al, 1995; Schreck et al, 2009; Ohshima et al, 2002; Jundt et al, 1999). Especially small $\mathrm{CD} 4^{+} \mathrm{T}$-cells, that surround the malignant $\mathrm{CHL}$ cells in rosetteslike structures, are in close contacts with the HRS cells (Küppers, 2009). These $\mathrm{CD}^{+} \mathrm{T}$-cells express increased CD40 ligand and thus may contribute to cell survival in cHL cells (Carbone et al, 1995; Annunziata et al, 2000). In addition, mast cells and eosinophils secrete CD30 ligand thereby supporting as well $\mathrm{CHL}$ cell survival (Pinto et al, 1996; Molin et al, 2001). Mast cells can also promote cHL cell proliferation in vitro and neovascularization in vivo (Mizuno et al, 2012). The presence of microenvironmental cells has also already been adopted for prognosis. Outcome of $\mathrm{cHL}$ has been adversely correlated with the presence of CD68 and CD163 expressing macrophages/monocytes in cHL tumours (Kamper et al, 2011). Nevertheless the prognostic value of CD68 staining in $\mathrm{CHL}$ samples is still discussed (Klein et al, 2014; Agur et al, 2015). These data further underline the importance of a particular microenvironment for $\mathrm{CHL}$ cell survival.

Notably, studies highlighting Hodgkin Lymphoma-endothelial cell interactions are rare. But regarding AML, prostate and breast carcinoma, the tumour-endothelial crosstalk has been proven to influence carcinogenesis and tumour outcome and might therefore be of interest also for cHL (Cogle et al, 2014; Zhang et al, 2013; Nagaraj et al, 2015; Comito et al, 2014).

\subsubsection{Therapy options, challenges and limitations}

Over the last 50 years the therapy options for $\mathrm{CHL}$ patients improved remarkably from an incurable disease to a curation rate of $80 \%$ with modern therapies (Canellos et al, 2014). For early-stage patients usually a combined modality treatment of the standard chemotherapy regiment doxorubicin, bleomycin, vinblastine, and dacarbazine (ABVD) and radiation therapy is used leading to a 5-year overall survival of more than $90 \%$ (Armitage, 2010). Next to ABVD 


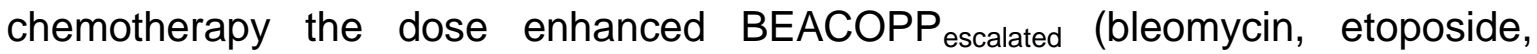
doxorubicin, cyclophosphamide, vincristine, procarbazine and prednisone) regiment is a treatment possibility for advanced-stage $\mathrm{CHL}$ patients albeit its higher toxicity is limiting especially for older patients (Engert et al, 2009). If such first-line treatment modalities fail, therapy of relapsed $\mathrm{cHL}$ cases involves platinum-based chemotherapy, followed by high-dose chemotherapy and autologous stem cell transplantation which still leads at best to curation rates of $50-60 \%$ (Clavio et al, 2005; Santoro et al, 2007). Despite these successful approaches to cure cHL future challenges will be to improve treatment modalities for advanced-stage and relapsed cases and to reduce delayed treatment toxicities without compromising the current survival rates. Since $\mathrm{CHL}$ concerns to a majority teenager and young adults (see chapter 1.1) therapy toxicities can diminish life quality and severely limit the expected life span. One serious consequence of high-dose chemotherapy and combined radiotherapy is the increased incidence of secondary malignancies which concerns especially leukaemia, breast and colon carcinoma (Aleman et al, 2003; Hodgson et al, 2007; Schellong et al, 2014). Moreover, patients report that long-term life quality is diminished compared to matched control people mainly due to dyspnoea and symptom of fatigue (Brandt et al, 2010; Rüffer et al, 2003). These side-effects of high-dose chemotherapy, the increase in secondary malignancies and decrease in life quality, further underline the request for more targeted and less toxic therapy modalities.

Therefore, new biological targets are searched for $\mathrm{cHL}$ therapy. Since the expression of CD30 is characteristic for the malignant HRS cells (see chapter 1.1.1) a tubulin inhibitor, monomethyl auristatin $E$ (MMAE), has been coupled to a mononuclear anti-CD30 antibody to target the HRS cells in a more specific manner (Katz et al, 2011; Francisco et al, 2003). This new antibody drug conjugate, brentuximab vedotin (BV), was approved in the European Union for $\mathrm{cHL}$ patients with front-line therapy failures (Gravanis et al, 2016; Younes et al, 2012). Nevertheless new approaches targeting the $\mathrm{cHL}$ microenvironment and diminishing $\mathrm{CHL}$ spread without the need of radiotherapy are discussed for years. 


\subsection{Processes associated with lymphoma progression}

One characteristic of cancer progression is the cellular ability to move and to invade into surrounding tissues. But for lymphomas the starting point is a different one regarding their specific cellular characteristics. Since lymphoma cells are derived from highly motile but strictly regulated immune cells their dissemination capacity strongly resembles physiologically conserved lymphocyte migration patterns (Pals et al, 2007). Nevertheless lymphoma dissemination displays a general challenge for therapy and long-term survival and its underlying mechanisms need to be investigated. Since HL growth in vivo requires crosstalks and interactions with the microenvironment, these interactions may also contribute to lymphoma progression (Liu et al, 2014). Especially the interaction and manipulation of endothelial cells may induce tumour angiogenesis thus permitting tumour growth, pathological tumour metabolism, inflammation and tumour cell invasion and dissemination (Wang et al, 2015). Despite this impact for lymphoma progression signalling pathways regulating angiogenesis in $\mathrm{HL}$ have only rarely been studied so far.

\subsubsection{Migration and invasion processes}

The movement patterns of lymphocytes depend on their specific maturational stage and are regulated by fine-tuned mechanisms in order to modulate immune reactions and wound healing (Butcher \& Picker, 1996; Kunkel \& Butcher, 2002). Aberrations in the corresponding migration pathways have been intensively studied mainly for solid tumour promotion (Wood et al, 2014). In contrast lymphoma dissemination in general is thought to depend on conserved homing programs and receptor expression patterns responsible for the regulation of lymphocyte trafficking (Pals et al, 1989, 2007). Both, physiological B-cell migration as well as lymphoma dissemination, is regularly observed to sites of chronic inflammation underlining the different mechanism of lymphoma dissemination compared to the metastasis of solid tumours (Shetty et al, 2012; Sakai \& Kobayashi, 2015). For example, CLL or MCL originate from small recirculating 
lymphocytes and are associated with high systemic dissemination rates at presentation as well as high cell migration rates in vitro (Lopez-Giral et al, 2004). In contrast Burkitt lymphoma (BL) and diffuse large B-cell lymphomas (DLBCL) are related to actively proliferating and differentiating lymphocytes and are more often initially detected at their sites of origin (Matasar \& Zelenetz, 2008; Pals et al, 2007). Consequently, migration capability may not directly reflect tumour progression but can be seen as conserved physiological behaviour of the cell of origin.

In $\mathrm{cHL}$ the accumulation of abundant reactive infiltrates is a result of locally produced chemokines and comparative analyses between different chemokines revealed different migration preferences of $\mathrm{HL}$ cells (Höpken et al, 2002; Aldinucci et al, 2008; van den Berg et al, 1999). Although these studies could show, that HL cells themselves migrate in a chemokine-guided manner, they missed a detailed analysis of the impact of migration and invasion properties for $\mathrm{HL}$ tumours and the mechanisms behind. But a deeper knowledge of $\mathrm{cHL}$ migration mechanisms would be necessary to understand also dissemination processes. For example, it has been shown that CLL cells migrated across high endothelial venules (HEVs) into nodes in response to CCL19 and CCL21 (Till et al, 2002). Endothelial cells of HEVs present high levels of the chemokine CCL19 and CCL21 at their luminal faces (Baekkevold et al, 2001). Consequently CCL19/CCL21-mediated chemotaxis might also be of interest for lymphoma studies.

Migration types in general are subdivided into at least three different forms: the mesenchymal and amoeboid single cell migration and the collective cell migration (Friedl \& Wolf, 2003b). The mesenchymal migration type of single epithelial cancer cells requires surface proteases to degrade and remodel the extracellular matrix $(E C M)$ in order to migrate forward via leading pseudopod formation and retraction of the cell rear (Hay, 1990; Wolf et al, 2003). The sequence of collective cell migration is similar, but several cells are interconnected by cadherins and gap junctions (Graeber \& Hülser, 1998; van Kempen et al, 2000). Amoeboid migration has been observed in leukocyte, haematopoietic stem cells and several cancer 
cells (Friedl et al, 2001; Francis et al, 2002; Wang et al, 2002). For amoeboid cell migration ECM barriers are not degraded but circumnavigated or the high cell deformability allows the cell to squeeze and glide through smallest pores (Friedl \& Wolf, 2003a). Consequently, short-lived interactions with the matrix replace stable focal contacts in the amoeboid migration type, thus allowing very fast and efficient movements. For instance, the migration of a T-cell lymphoma was not impeded by protease inhibitors underlying the independence from matrix metalloproteinases secretion (Krüger et al, 2001).

\subsubsection{Induction of angiogenesis}

According to solid cancers, growth and progress of B-cell lymphoproliferative diseases is also thought to depend on access to blood vessels, including new vessel formation (Vacca et al, 1995). For vasculogenesis endothelial cells are often switched from resting to active cells by a microenvironmental increase of positive angiogenesis regulators like vascular endothelial growth factor (VEGF), fibroblast growth factor (FGF), angiopoietins (Ang) or platelet derived growth factor (PDGF). Tumour cells actively influence this process by tipping the net balance between positive and negative angiogenesis regulators towards the proangiogenic ones (Neufeld et al, 2001). Then initial angiogenesis events involve the migration of tip cells at the vessel leading front causing vessel sprouting. Afterwards, a lumen is formed and the stabilization and maturation processes start including adhesion to the underlying matrix, basement membrane generation and blood flow (Carmeliet \& Jain, 2011). Since tumour cells create an imbalance between angiogenesis regulators, tumour vessels are characterized by an unusual leakiness involving poor coverage by vascular supportive cells, reduced functionality, perfusion and a high remodelling potential (Jain, 2005). But how and by which signalling pathway HRS cells influence and are influenced by endothelial cells is still widely unclear. 


\subsection{WNT signalling}

One pathway that has been described in tumour metastasis as well as angiogenesis processes is the WNT signalling cascade (Kurayoshi et al, 2006; Zhang et al, 2001). WNT signalling is important for embryonic development, selfrenewal of some adult tissues but it is also involved in tumourigenesis e.g. in colorectal cancer (Liu et al, 1999; Wang \& Wynshaw-Boris, 2004; Reya et al, 2003; Groden et al, 1991; Liu et al, 2000; Ge \& Wang, 2010). To our knowledge WNT signalling has never been investigated in HLs and only marginally in aggressive Non-Hodgkin lymphomas (NHLs) (Walther et al, 2013). Nevertheless, $\mathrm{NHL}$ related to small recirculating lymphocytes such as chronic lymphocytic leukaemia $(\mathrm{CLL})$ or mantle cell lymphoma $(\mathrm{MCL})$ have already been described to depend on WNT signalling (Kaucká et al, 2013; Gelebart et al, 2008; Rizzatti et al, 2005; Gutierrez et al, 2010; Gandhirajan et al, 2010; Tandon et al, 2011).

In 1982 the first WNT ligand, formerly called Int1, has been discovered as protooncogene in mice (Nusse \& Varmus, 1982). Since then 19 highly conserved different WNT ligands and 15 WNT receptors and co-receptors have been identified in humans (Niehrs, 2012). The combination of WNT ligand, WNT receptor and the particular cellular context finally determines activation of downstream pathways. In general, the $\beta$-catenin-dependent, so called canonical, pathway is distinguished from $\beta$-catenin-independent, so called non-canonical, pathways (Figure 2). Despite the complexity of combination possibilities several preferences for WNT ligands and receptors have been described. For example, WNT1, WNT3A and WNT8 are supposed to activate predominantly the canonical WNT pathway while WNT5A and WNT11 mainly activate non-canonical WNT pathways (Kikuchi et al, 2011). In addition, low-density lipoprotein receptor-related protein 5 (LRP5) and LRP6 are supposed to be primarily involved in canonical WNT signalling and receptor tyrosine kinase-like orphan receptors 1/2 (ROR1/2) in non-canonical WNT signalling (Tamai et al, 2000; Hsieh, 2004). In contrast, Frizzled (FZD) receptors and Dishevelled (DVL) adaptor proteins appear to be 
involved in all three signalling cascades (Huang \& Klein, 2004; Gao \& Chen, 2010).

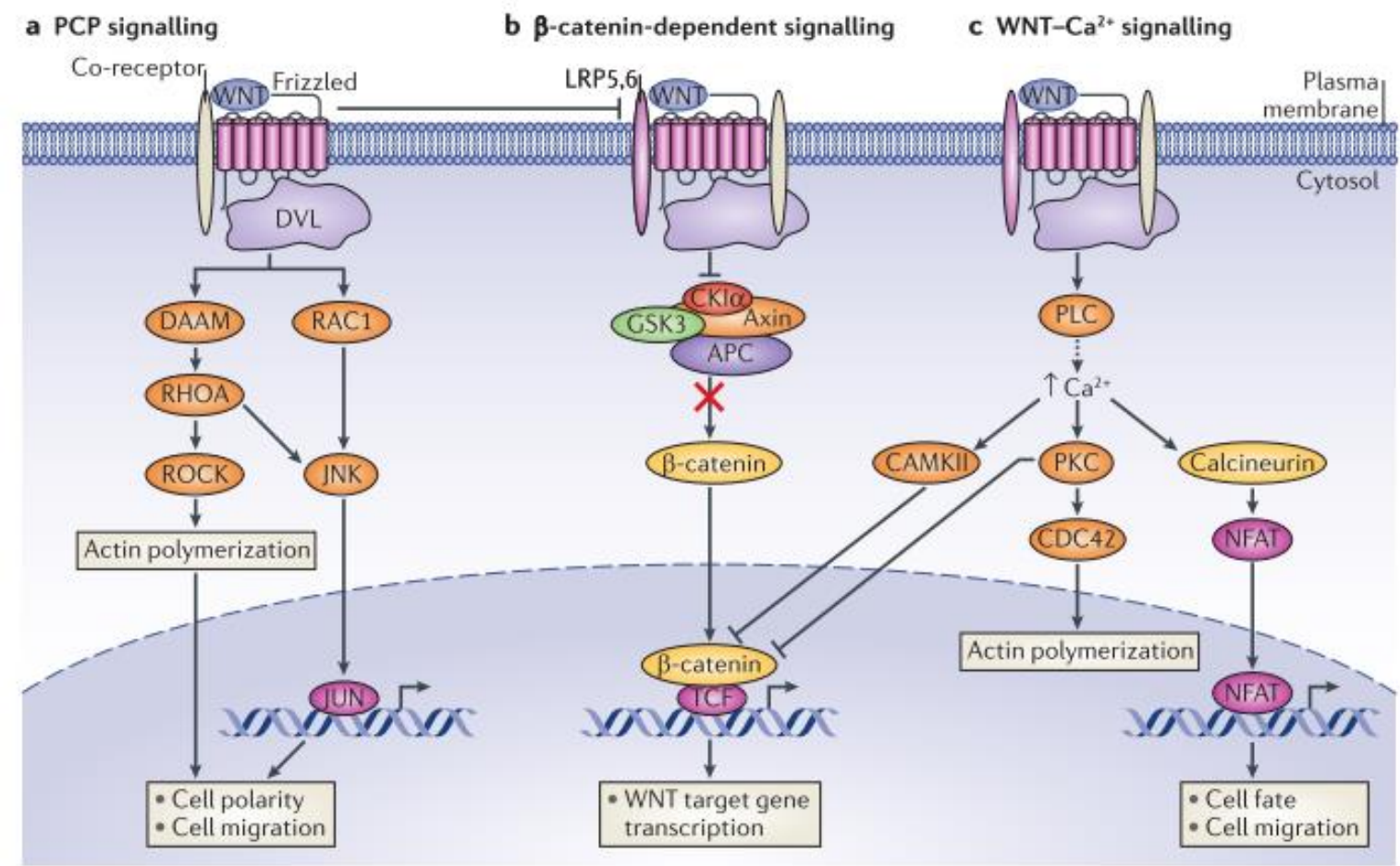

Figure 2: Overview of $\beta$-catenin-dependent and -independent WNT pathways. (A) Planar cell polarity (PCP) pathway activates small GTPases (RHOA, RAC1) to induce mainly cell polarity and motility through actin polymerization. (B) The canonical, $\beta$-catenin-dependent, WNT pathway destabilizes the $\beta$-catenin destruction complex upon activation thus enabling $\beta$-catenin to translocate to the nucleus and to induce the corresponding target gene transcription. (C) Another $\beta$-catenin-independent WNT pathway is $\mathrm{Ca}^{2+}$-dependent. $\mathrm{Ca}^{2+}$ signalling can activate $\mathrm{CDC} 42$ to induce actin polymerization like the PCP pathway or activate the nuclear factor of activated T-cells (NFAT) for gene transcription regulation. The $\mathrm{Ca}^{2+}$-dependent WNT pathway can block the $\beta$-catenin-dependent pathway at several levels. This scheme has been taken from "The complex world of WNT receptor signalling" (Niehrs, 2012).

Since WNT function depends on its local concentration, the secretion mechanism of WNT ligands, has been investigated as an important control point of WNT signalling strength (Zecca et al, 1996). In order to act as gradient morphogens WNT ligands need to be post-translationally modified involving palmitoylation which is essential for extracellular transport and binding to FZD receptors (Janda et al, 2012; Coombs et al, 2010). Porcupine is an o-acyltransferase resident at the membrane of the endoplasmic reticulum that mediates the palmitoylation of WNT ligands (Proffitt \& Virshup, 2012; Takada et al, 2006). At the Golgi apparatus 
palmitoylated WNT ligands can bind to WNTLESS (WLS) and are escorted to the plasma membrane (Kurayoshi et al, 2007; Hausmann et al, 2007). Recently it has been shown that active WNT ligands can be secreted on extracellular vesicles (EVs) (Gross et al, 2012).

A promising target of the WNT ligand secretion pathway is the enzyme porcupine which can be blocked by small molecules (Chen et al, 2009). Porcupine inhibition caused reduced viability and proliferation rates in several tumour entities like mammary tumours or gastric cancer (Proffitt et al, 2013; Mo et al, 2013).

\subsubsection{Canonical WNT signalling}

Canonical WNT signalling depends on the activation and subsequent nuclear translocation of $\beta$-catenin. The evolutionally conserved protein $\beta$-catenin belongs to the armadillo family of proteins and acts as adaptor protein for intracellular adhesion and as transcriptional regulator of the canonical WNT pathway (Peifer, 1993; Su et al, 1993; Hayashida et al, 2005).

In the absence of an activating WNT ligand, the $\beta$-catenin destruction complex, which is composed of glycogen synthase kinase 3 (GSK3), casein kinase 1 (CK1), Axin and adenomatous polyposis coli (APC), mediates the phosphorylation of $\beta$-catenin (Kimelman \& $X u, 2006$ ). This phosphorylation of $\beta$-catenin serves as signal for ubiquitylation by SKP1-cullin 1- F-box E3 ligase and the subsequent proteasomal degradation of $\beta$-catenin in the cytosol (Wu et al, 2003). Upon WNT ligand binding to the complex of FZD receptors and the LRP5/6 co-receptors DVL proteins are phosphorylated and the destruction complex is destabilized. Activated DVL is thought to phosphorylate the co-receptor LRP6 and to associate with Axin thus inactivating the destruction complex (Kishida et al, 1999; Zeng et al, 2008). This causes the accumulation and subsequent nuclear translocation of $\beta$-catenin (Figure 2) (Polakis, 1999; Tamai et al, 2000). In the nucleus $\beta$-catenin binds to a Transcription Factor (T-Cell Specific, HMG-Box)/lymphocyte enhancer-binding factor 1 (TCF/LEF-1) transcription factor. LEF-1 belongs to the TCF/LEF family of transcription factors with a clear homology to HMG group proteins (Travis et al, 
1991). In the nucleus TCF/LEF-1 binds $\beta$-catenin in a core complex with B-cell CLL/Lymphoma 9 (BCL9) and Pygopus and regulates the transcription of several targets including, amongst others, cyclin D1, C-MYC and matrix metalloproteinases (Behrens et al, 1996; Kramps et al, 2002; Shtutman et al, 1999; Yochum et al, 2008; Yochum, 2011; Brabletz et al, 1999; Wu et al, 2007).

\subsubsection{Non-canonical WNT signalling}

For the non-canonical or $\beta$-catenin-independent WNT pathway WNT/FZD complexes initiate signalling with the help of heterotrimeric G proteins and DVL to regulate the cytoskeleton (planar cell polarity pathway; PCP) or to increase the intracellular calcium concentration (calcium-dependent WNT signalling) (Figure 2) (Veeman et al, 2003).

In vertebrates the PCP pathway regulates convergent extension movements of epithelial cells, and is of great importance during early embryonic development, the gastrulation process, cochlear cell polarity and during neuronal tube development and axon guidance (Habas et al, 2001; Dabdoub \& Kelley, 2005; Goodrich, 2008; Wallingford et al, 2002). The PCP pathway involves DVL, Ras Homolog Family Member A (RHOA) and Rho-Associated, Coiled-Coil Containing Protein Kinase (ROCK) and was first described as polarity pathway in drosophila (Nübler-Jung, 1987; Boutros \& Mlodzik, 1999; Strutt et al, 1997; Winter et al, 2001). Binding of WNTs to their corresponding receptors is associated with the activation of one of the three DVL molecules (Wong et al, 2003; Gonzalez-Sancho et al, 2004). Thereby DVL binds to FZD receptors via its central PDZ domain and gets activated (Wong et al, 2003). Activated DVL forms a complex with the DVLassociated activator of morphogenesis (DAAM) and RHOA which causes activation of RHOA and subsequently of its effector ROCK (Habas et al, 2001; Ishizaki et al, 1997).

One prominent non-canonical WNT is WNT5A. WNT5A has been discovered together with other WNTs in mouse development in 1990 (Gavin et al, 1990). Soon it emerged that WNT5A plays pivotal roles in germ cell differentiation, 
repopulation and maintenance of haematopoietic stem cells and regulation of chondrogenesis (Danielson et al, 1995; Nemeth et al, 2007; Hartmann \& Tabin, 2000; Yang et al, 2003). WNT5A encodes two isoforms through an alternative exon one (Katoh \& Katoh, 2009). WNT ligands bind specifically to FZD receptors, which are a distinct group of G-protein-coupled receptors sharing structural similarities with chemokine and sphingosine receptors (Schulte \& Bryja, 2007). Studies on the binding of WNT ligands to FZD receptors revealed the high specificity of WNT5A for FZD5 (Dijksterhuis et al, 2015). But depending on the particular cellular receptor setting, WNT5A can not only activate calciumdependent or PCP non-canonical WNT signalling but also block or activate $\beta$-catenin-dependent canonical WNT signalling (Mikels \& Nusse, 2006). Due to this broad spectrum of regulated pathways by WNT5A it is not only associated with physiological processes but also with inflammatory disorders like rheumatoid arthritis or atherosclerosis and tumourigenesis (Sen et al, 2000; Christman et al, 2008; Bhatt et al, 2012; Kurayoshi et al, 2006). To target WNT5A an agonist, Foxy-5, and the corresponding antagonist, Box5, have been developed (Jenei et al, 2009; Blagodatski et al, 2014).

The calcium-dependent non-canonical WNT signalling involves the activation of calcium-sensitive kinase protein kinase $C$ (PKC) and the calcium-responsive transcription factor nuclear factor of activated T-cells (NFAT) (Sheldahl et al, 1999; Saneyoshi et al, 2002). Since the calcium-dependent pathway is not subject to this thesis it will not be introduced in further detail.

\subsubsection{WNT signalling in cancer progression, metastasis and angiogenesis}

The WNT pathway is strictly balanced in physiology and disruptions of this homeostasis can directly promote pathogenic processes (Clevers, 2006). The dramatic impact of canonical WNT signalling for tumourigenesis has been described best for colon carcinoma regarding APC mutations (Nishisho et al, 1991; Kinzler et al, 1991; Kinzler \& Vogelstein, 1996). Axin mutations are often found in hepatocellular cancers while mutations of $\beta$-catenin have been found 
amongst others in medulloblastoma, ovarian carcinoma, gastric cancer and also colon carcinoma (Satoh et al, 2000; Zurawel et al, 1998; Wright et al, 1999; Clements et al, 2002; Morin et al, 1997). High LEF-1 expression is correlated with tumourigenesis e.g. in colon cancer, lymphomas, CLL, acute lymphocytic leukaemia (ALL), acute myeloid leukaemia (AML) and metastatic melanoma (Hovanes et al, 2001; Gelebart et al, 2008; Spaulding et al, 2007; Gutierrez et al, 2010; Petropoulos et al, 2008; Wang et al, 2005; Simon et al, 2005; Murakami et al, 2001).

Among the various WNT ligands, evidence has accumulated that WNT5A is a key player for tumour metastasis by modulating cell motility (Kurayoshi et al, 2006; Qin et al, 2015; Klemm et al, 2011). WNT signalling and especially WNT5A have been correlated to tumour migration and invasion in several tumour entities like hepatocellular carcinoma, gastric cancer or lung cancer bone metastasis (Qin et al, 2007; Kurayoshi et al, 2006; Nguyen et al, 2009). Recent studies on CLL and multiple myeloma have also revealed an involvement of non-canonical WNT signalling in migration and invasion of the disease (Kaucká et al, 2013; Qiang et al, 2005).

However, WNT signalling plays not only a role for tumour progression and metastasis but also regulates angiogenesis processes. In physiological angiogenesis processes WNT signalling has already been shown to be important for the developing retina, the placenta and ovaries (Xu et al, 2004; Hsieh et al, 2005; Luhmann et al, 2005). A direct migration stimulating effect of the canonical WNT3A on Human Umbilical Vein Endothelial Cells (HUVECs) has been reported by Samarzija et al (Samarzija et al, 2009). In addition, also canonical WNT signalling of the tumour cells themselves can regulate angiogenesis. In colonic neoplasia canonical $\beta$-catenin-dependent WNT signalling has been reported to regulate VEGF and therefore angiogenesis in a pre-malignant disease (Zhang et al, 2001).

Since deregulated WNT signalling plays a role in several cancer entities inhibiting canonical pathway members is subject of research as well as clinical trials. Among 
the secreted canonical WNT antagonists the Dickkopf (DKK) protein family is the best described (Niehrs, 2006). Both, DKK1 and DKK2, specifically inhibit the canonical WNT pathway by antagonizing the co-receptors LRP5/6 (Semënov et al, 2001; Mao \& Niehrs, 2003; Zhu et al, 2012). Nevertheless there is evidence that DKK2 can also activate canonical WNT signalling depending on the particular cellular context (Wu et al, 2000). In addition, DKK1 levels are elevated in oesophageal adenocarcinoma and hepatocellular cancer, leading to the hypothesis that aberrant as well as downregulated WNT signalling can ultimately cause cancer or other pathogenic processes (Darlavoix et al, 2009; Yu et al, 2009). The application of small molecules or neutralizing antibodies can provide possibilities to restore balanced WNT signalling (NCT02013154; NCT02375880) (Zhao et al, 2009). Targeting the $\beta$-catenin destruction complex is another attempt to downregulate aberrant $\beta$-catenin activity in cancer. For years axin inhibition has been investigated as auspicious target of canonical WNT signalling. Several inhibitors targeting the axin inhibitors, tankyrases, have been chemically designed like XAV939 (Novartis) or G007-LK (Roche) but so far none of those was approved for clinical trials (Yeh \& Peterson, 2009; Lehtiö et al, 2013; Huang et al, 2009; Lau et al, 2013). Targeting the non-canonical WNT pathway still remains difficult since e.g. FZD receptors share high homologies and can function interchangeably (Curtin \& Lorenzi, 2010). Other inhibitors like Y-27632 targeting ROCK are not yet specific enough for clinical trials.

Of note, there is so far no detailed knowledge about WNT signalling in cHL cells despite its impact for the above mentioned lymphoma and leukaemia entities. Consequently a deeper understanding of WNT signalling cascades in CHL cells could also contribute to the general comprehension of $\mathrm{cHL}$ progression and thus might increase therapy options. 


\section{Aim of the thesis}

In $\mathrm{cHL}$, the accumulation of reactive infiltrate is a result of locally produced chemokines. Although studies could show that $\mathrm{cHL}$ cells, too, migrate in a chemokine-dependent manner, fundamental questions about the impact of the migratory and invasive properties of $\mathrm{cHL}$ cells for the microenvironment and for tumour motility within the process of dissemination and progression have not yet been investigated.

Lymphoma dissemination in general is thought to depend on conserved homing factors and receptors, which regulate lymphocyte trafficking in health and disease and thus follows characteristic patterns. Recent studies on CLL and multiple myeloma have revealed an involvement of non-canonical WNT signalling in migration and invasion of the disease. The underlying signalling mechanism for movements towards appropriate chemokine gradients and therefore towards favourable niches as well as the manipulation of the own microenvironment of $\mathrm{cHL}$ cells is subject to this thesis.

Therefore, the thesis aims at (i) characterizing migration and invasion of $\mathrm{CHL}$ cells and (ii) at investigating the lymphoma-endothelial interplay in the context of WNT signalling. In order to get deeper insight into $\mathrm{cHL}$ cell migration properties the following questions have to be answered:

1. How do $\mathrm{CHL}$ cells migrate in comparison to other lymphoma cells in defined chemokine gradients?

2. Is autocrine WNT signalling important for $\mathrm{CHL}$ cell migration and invasion?

3. How do PCP and/or $\beta$-catenin-dependent WNT signalling contribute to $\mathrm{CHL}$ cell motility?

To answer these questions the migration of $\mathrm{CHL}$ cells was characterized in $2 \mathrm{D}$ and $3 \mathrm{D}$ cell migration models first. The role of WNT signalling was analysed by RNA interference-mediated knockdowns of specific pathway components and the 
application of chemical inhibitors. For confirmation microarray data of cHL patients were tested for the expression of particular WNT pathway members.

To get further insight into the interplay of $\mathrm{cHL}$ cells with endothelial cells and the impact of WNT signalling the following questions have to be answered:

1. Do cHL cells possess pro-angiogenic properties?

2. Does WNT signalling of $\mathrm{cHL}$ cells affect the interplay with endothelial cells in vitro and in vivo?

Therefore, the initial capacity of $\mathrm{cHL}$ cells to induce angiogenesis in vitro and the influence of WNT signalling on these processes were measured in vivo in a chicken model system. 


\section{Material and Methods}

\subsection{Cell lines}

Cell lines used in this study are listed in Table 1.

Table 1: Cell lines

\begin{tabular}{|l|l|l|}
\hline Cell line & Source & Reference \\
\hline BL-2 & Burkitt Lymphoma (B-cell, EBV') & $\begin{array}{l}\text { (Bertrand et al, 1981; } \\
\text { Kube et al, 1995) }\end{array}$ \\
\hline BL-30 & Burkitt Lymphoma (B-cell, EBV') & (Philip et al, 1984) \\
\hline Carnaval & $\begin{array}{l}\text { Diffuse Large B-cell lymphoma (B-cell, } \\
\text { EBV') }\end{array}$ & $\begin{array}{l}\text { established 2010 } \\
\text { (unpublished) }\end{array}$ \\
\hline HEK293T & human primary embryonal kidney cells & $\begin{array}{l}\text { (Graham et al, 1977; } \\
\text { DuBridge et al, 1987) }\end{array}$ \\
\hline HUVEC & $\begin{array}{l}\text { Human Umbilical Vein Endothelial } \\
\text { Cells }\end{array}$ & $\begin{array}{l}\text { primary cells (Lonza, } \\
\text { Basel, CH) }\end{array}$ \\
\hline JeKo-1 & Mantle Cell Lymphoma (B-cell, EBV') & (Jeon et al, 1998) \\
\hline Karpas-422 & $\begin{array}{l}\text { Diffuse Large B-cell lymphoma (B-cell, } \\
\text { EBV') }\end{array}$ & (Dyer et al, 1990) \\
\hline KM-H2 & Hodgkin Lymphoma (EBV-) & (Kamesaki et al, 1986) \\
\hline L1236 & Hodgkin Lymphoma (EBV') & (Wolf et al, 1996) \\
\hline L428 & Hodgkin Lymphoma (EBV-) & (Schaadt et al, 1979) \\
\hline L-cell wildtype & mouse fibroblasts & (Willert et al, 2003) \\
\hline L-cell WNT3a & $\begin{array}{l}\text { mouse fibroblasts (stable expression of } \\
\text { WNT-3A vector, G418 resistance) }\end{array}$ & (Willert et al, 2003) \\
\hline L-cell WNT5a & $\begin{array}{l}\text { mouse fibroblasts (stable expression of } \\
\text { WNT-5A vector, G418 resistance) }\end{array}$ & (Chen et al, 2003) \\
\hline Mino & Mantle Cell Lymphoma (B-cell, EBV') & (Lai et al, 2002) \\
\hline Oci-Ly1 & $\begin{array}{l}\text { Diffuse Large B-cell lymphoma (B-cell, } \\
\text { EBV') }\end{array}$ & (Tweeddale et al, 1987) \\
\hline
\end{tabular}




\subsection{Chemicals, solutions and consumable supplies}

Chemicals, solutions and consumables used in the study are listed in Table 2 and Table 3.

Table 2: Chemicals and solutions

\begin{tabular}{|l|l|}
\hline Chemical or solution & Manufacturer \\
\hline 4-IPBA & Sigma-Aldrich, Munich, DE \\
\hline Acetic acid & Roth, Karlsruhe, DE \\
\hline Acrylamide/bisacrylamide 40\% & BioRad, Munich, DE \\
\hline Ammonium persulphate & Sigma-Aldrich, Munich, DE \\
\hline Bovine serum albumin (BSA) & Serva, Heidelberg, DE \\
\hline Bradford solution & RotiQuant-Roth, Karlsruhe, DE \\
\hline Bromophenol blue & Sigma-Aldrich, Munich, DE \\
\hline Calcium chloride & Merck Millipore, Billerica, US \\
\hline Chicken eggs & $\begin{array}{l}\text { Valo BioMedia GmbH, Osterholz- } \\
\text { Scharmbeck, DE }\end{array}$ \\
\hline Collagen (type-I) & Trevigen, Gaithersburg, US \\
\hline Deoxyribonucleoside triphosphates & PrimeTech LTD, Minsk, BY \\
(dATP, dCTP, dGTP, dTTP) & Sigma-Aldrich, Munich, DE \\
\hline Dimethyl sulfoxide (DMSO) & Biochrom AG, Berlin, DE \\
\hline DMEM & Roth, Karlsruhe, DE \\
\hline Eosin & J.T. Baker, Deventer, NL \\
\hline Ethanol (100 \%) & Riedel-de Haën, Seelze, DE \\
\hline Ethylenediaminetetraacetic acid (EDTA & $\begin{array}{l}\text { System Biosciences, Mountain View, } \\
\text { US }\end{array}$ \\
\hline ExoQuick-TC Solution & Sigma-Aldrich, Munich, DE \\
\hline Formaldehyde & GE Healthcare, Munich, DE \\
\hline Full Range Rainbow Molecular Weight \\
Marker & Roche, Basel, CH \\
\hline G418 & \\
\hline
\end{tabular}




\begin{tabular}{|l|l|}
\hline Glutaraldehyde & Roth, Karlsruhe, DE \\
\hline Glycerol & Roth, Karlsruhe, DE \\
\hline Glycine & Roth, Karlsruhe, DE \\
\hline HEPES & Sigma-Aldrich, Munich, DE \\
\hline Hot FIREpol DNA polymerase & PrimeTech LTD, Minsk, BY \\
\hline Hydrogen peroxide & Sigma-Aldrich, Munich, DE \\
\hline Isopropanol & Sigma-Aldrich, Munich, DE \\
\hline Luminol & Sigma-Aldrich, Munich, DE \\
\hline Magnesium chloride & PrimeTech LTD, Minsk, BY \\
\hline Matrigel & BD Biosciences, Franklin Lakes, US \\
\hline Mayer's alum haematoxylin solution & Roth, Karlsruhe, DE \\
\hline Methanol 100 \% (p.a.) & J.T. Baker, Deventer, NL \\
\hline Methyl cellulose & Sigma-Aldrich, Munich, DE \\
\hline Milk powder & Roth, Karlsruhe, DE \\
\hline MTT reagent & Sigma-Aldrich, Munich, DE \\
\hline Nonidet P-40 & Sigma-Aldrich, Munich, DE \\
\hline Osmium tetraoxide & Roth, Karlsruhe, DE \\
\hline Paraformaldehyde & Roth, Karlsruhe, DE \\
\hline PBS pH 7.4 (cell culture grade) & PAN-Biotech GmbH, Aidenbach, DE \\
\hline Phenylmethylsulfonyl fluoride (PMSF) & Sigma-Aldrich, Munich, DE \\
\hline Phosphatase inhibitor phospho-STOP & Roche, Mannheim, DE \\
\hline Picric acid & Merck Millipore, Billerica, US \\
\hline Potassium dihydrogen phosphate & Roth, Karlsruhe, DE \\
\hline (KH ${ }_{2}$ PO ${ }_{4}$ ) & Sigma-Aldrich, Munich, DE \\
\hline Protamine sulfate & Roche, Mannheim, DE \\
\hline Proteaseinhibitor-mix complete ${ }^{\text {TM }}$ & Invivogen, San Diego, US \\
\hline Puromycin & Merck Millipore, Billerica, US \\
\hline ReBlot plus mild & Roth, Karlsruhe, DE \\
\hline Roti®-Load 4x loading buffer & Lonza, Basel, CH \\
\hline RPMI-1640 & \\
\hline
\end{tabular}




\begin{tabular}{|l|l|}
\hline Sodium chloride & Merck KGaA, Darmstadt, DE \\
\hline Sodium deoxycholate & Merck KGaA, Darmstadt, DE \\
\hline $\begin{array}{l}\text { Sodium dihydrogen phosphate } \\
\left(\mathrm{Na}_{2} \mathrm{HPO}_{4}\right)\end{array}$ & Roth, Karlsruhe, DE \\
\hline Sodium dodecyl sulfate (SDS) & Merck KGaA, Darmstadt, DE \\
\hline Sodium phosphate dibasic & Sigma-Aldrich, Munich, DE \\
\hline SYBR Green I Nucleic Acid Gel Stain & Roche, Mannheim, DE \\
\hline Tetramethylethylenediamine (TEMED) & Sigma-Aldrich, Munich, DE \\
\hline Tissue Tek & Poysciences Inc., Warrington, US \\
\hline Tris base & Sigma-Aldrich, Munich, DE \\
\hline TritonX-100 & Roth, Karlsruhe, DE \\
\hline Trypan blue 0.4 \% in PBS & Life Technologies, Carlsbad, US \\
\hline Trypsin/EDTA (cell culture grade) & Biochrom AG, Berlin, DE \\
\hline Tween-20 & Merck KGaA, Darmstadt, DE \\
\hline Water HPLC grade & Merck KGaA, Darmstadt, DE \\
\hline
\end{tabular}

Table 3: Consumables

\begin{tabular}{|l|l|}
\hline Consumable & Manufacturer \\
\hline $\begin{array}{l}\text { ABI PRISM® 384-well clear optical } \\
\text { reaction plate }\end{array}$ & Applied Biosystems, Foster City, US \\
\hline ABI PRISM® optical adhesive covers & Applied Biosystems, Foster City, US \\
\hline Cell culture flasks & Sarstedt, Nümbrecht, DE \\
\hline Cryo tubes & Nunc, Wiesbaden, DE \\
\hline Diethylaminoethyl-cellulose & Whatman®, International Ltd, UK \\
\hline Falcon tubes $15 \mathrm{ml}, 50 \mathrm{ml}$ & Sarstedt, Nümbrecht, DE \\
\hline Filter tips, $10 \mu \mathrm{l}, 100 \mu \mathrm{l}, 200 \mu \mathrm{l}, 1000 \mu \mathrm{l}$ & Starlab, Ahrensburg, DE \\
\hline Immobilon PVDF membranes & Merck Millipore, Billerica, US \\
\hline $\begin{array}{l}\text { Membranes for Boyden chamber }(8 \mu \mathrm{m}, \\
10 \mu \mathrm{m} \text { pores) }\end{array}$ & Neuroprobe Inc, Gaithersburg, US \\
\hline Nitrocellulose membrane & Life Technologies, Carlsbad, US \\
\hline
\end{tabular}




\begin{tabular}{|l|l|}
\hline Nucleofection cuvettes & Lonza, Basel, CH \\
\hline Pasteur pipettes & Sarstedt, Nümbrecht, DE \\
\hline Pipette tips (w/o filters) $100 \mu \mathrm{l}, 1000 \mu \mathrm{l}$ & Sarstedt, Nümbrecht, DE \\
\hline Reaction tubes $0.5 \mathrm{ml}, 1.5 \mathrm{ml}, 2 \mathrm{ml}$ & Sarstedt, Nümbrecht, DE \\
\hline Serological pipettes $5 \mathrm{ml}, 10 \mathrm{ml}, 25 \mathrm{ml}$ & Sarstedt, Nümbrecht, DE \\
\hline $\begin{array}{l}\text { Sterling nitrile powder-free examination } \\
\text { gloves }\end{array}$ & Kimberly-Clark, Zaventem, BE \\
\hline $\begin{array}{l}\text { Tissue culture dish } \\
\text { Tissue culture plates, } 6 \text { well, 12 well, }\end{array}$ & Sarstedt, Nümbrecht, DE \\
\hline$\mu$ well & Nunc, Wiesbaden, DE \\
\hline
\end{tabular}

\subsection{Buffers and Media}

Recipes of buffers and media used for this study are listed in Table 4.

Table 4: Recipes of buffers and media

\begin{tabular}{|l|l|}
\hline Liquid & Receipt/Manufacturer \\
\hline 2x Hepes-buffered $\mathrm{NaCl}$ & $0.28 \mathrm{M} \mathrm{NaCl}$ \\
solution (lentivirus & $0.05 \mathrm{M} \mathrm{HEPES}$ \\
production) & $1.5 \mathrm{mM} \mathrm{Na}_{2} \mathrm{HPO}_{4}$ \\
& adjust to $\mathrm{pH} 7.0 ;$ sterile-filtered \\
\hline \multirow{3}{*}{ Acidic MTT solution } & $33 \% \mathrm{DMSO}$ \\
& $62 \%$ isopropanol \\
& $5 \%$ formic acid \\
\hline Bouin's solution & $5 \%$ acetic acid \\
& $9 \%$ formaldehyde \\
& $0.9 \%$ picric acid \\
\hline
\end{tabular}




\begin{tabular}{|c|c|}
\hline $\begin{array}{l}\text { Cell culture medium I } \\
\text { (cHL cell lines) }\end{array}$ & $\begin{array}{l}\text { RPMI-1640 } \\
10 \%(\mathrm{v} / \mathrm{v}) \text { FCS (Biochrom AG, Berlin, DE) } \\
200 \mathrm{U} / \mathrm{ml} \text { penicillin + } 200 \mu \mathrm{g} / \mathrm{ml} \text { streptomycin + } \\
4 \mathrm{mM} \mathrm{L-glutamine} \mathrm{(PSG)} \mathrm{(Sigma-Aldrich,} \mathrm{Munich,} \mathrm{DE)}\end{array}$ \\
\hline $\begin{array}{l}\text { Cell culture medium II } \\
\text { (NHL cell lines) }\end{array}$ & $\begin{array}{l}\text { RPMI-1640 } \\
10 \%(\mathrm{v} / \mathrm{v}) \text { FCS (Sigma-Aldrich, Munich, DE) } \\
200 \mathrm{U} / \mathrm{ml} \text { penicillin + } 200 \mu \mathrm{g} / \mathrm{ml} \text { streptomycin + } \\
4 \mathrm{mM} \mathrm{L-glutamine} \mathrm{(PSG)} \mathrm{(Sigma-Aldrich,} \mathrm{Munich,} \mathrm{DE)}\end{array}$ \\
\hline $\begin{array}{l}\text { Cell culture medium III } \\
\text { (HUVEC) }\end{array}$ & $\begin{array}{l}\text { EBM2 medium } \\
10 \% \text { (v/v) FCS plus EGM-2 SingleQuot Kit Suppl. \& } \\
\text { growth factors (all Lonza, Basel, CH) }\end{array}$ \\
\hline $\begin{array}{l}\text { Cell culture medium IV } \\
\text { (cHL pGIPZ cell lines) }\end{array}$ & $\begin{array}{l}\text { RPMl-1640 } \\
10 \% \text { (v/v) FCS (Biochrom AG, Berlin DE) } \\
200 \mathrm{U} / \mathrm{ml} \text { penicillin }+200 \mu \mathrm{g} / \mathrm{ml} \text { streptomycin + } \\
4 \mathrm{mM} \mathrm{L-glutamine} \mathrm{(PSG)} \mathrm{(Sigma-Aldrich,} \mathrm{Munich,} \mathrm{DE)} \\
2 \mu \mathrm{g} / \mathrm{ml} \text { puromycin }\end{array}$ \\
\hline $\begin{array}{l}\text { Cell culture medium V } \\
\text { (mouse fibroblasts; } \\
\text { L-cells; HEK293T) }\end{array}$ & $\begin{array}{l}\text { DMEM (Biochrom AG, Berlin, DE) } \\
10 \% \text { (v/v) FCS (Sigma-Aldrich, Munich, DE) }\end{array}$ \\
\hline $\begin{array}{l}\text { Cell culture medium VI } \\
\text { (selection medium for } \\
\text { L-cells) }\end{array}$ & $\begin{array}{l}\text { DMEM (Biochrom AG, Berlin, DE) } \\
10 \% \text { (v/v) FCS (Sigma-Aldrich, Munich, DE) } \\
0.4 \mathrm{mg} / \mathrm{ml} \mathrm{G-418}\end{array}$ \\
\hline Freezing medium & $\begin{array}{l}90 \%(v / v) \text { FCS } \\
10 \%(v / v) \text { DMSO }\end{array}$ \\
\hline Karnovsky's fixative & $\begin{array}{l}0.3 \text { M Soerensen-Buffer } \\
3 \% \text { paraformaldehyde } \\
3 \% \text { glutaraldehyde }\end{array}$ \\
\hline
\end{tabular}




\begin{tabular}{|c|c|}
\hline NP-40 lysis buffer & $\begin{array}{l}50 \mathrm{mM} \text { Tris } \mathrm{pH} 7.4 \\
150 \mathrm{mM} \mathrm{NaCl} \\
1 \mathrm{mM} \text { EDTA } \\
0.5 \% \text { NP-40 } \\
1 \times \text { Complete Mini Protease Inhibitor } \\
1 \times \text { PhosStop }\end{array}$ \\
\hline Nuclear Extract Buffer A & $\begin{array}{l}10 \text { mM HEPES pH } 7.9 \\
10 \text { mM KCl } \\
100 \mu \mathrm{M} \text { EDTA } \\
100 \mu \mathrm{M} \text { EGTA } \\
1 \text { mM DTT } \\
1 \times \text { Complete Mini Protease Inhibitor } \\
1 \times \text { PhosStop }\end{array}$ \\
\hline Nuclear Extract Buffer B & $\begin{array}{l}20 \mathrm{mM} \text { HEPES pH } 7.9 \\
400 \mathrm{mM} \mathrm{KCl} \\
1 \mathrm{mM} \text { EDTA } \\
1 \mathrm{mM} \text { EGTA } \\
1 \mathrm{mM} \text { DTT } \\
1 \times \text { Complete Mini Protease Inhibitor } \\
1 \times \text { PhosStop }\end{array}$ \\
\hline PCR buffer (10x) & $\begin{array}{l}750 \mathrm{mM} \text { Tris- } \mathrm{HCl} \mathrm{pH} 8.8 \\
200 \mathrm{mM} \text { Ammonium sulfate } \\
0.1 \% \text { Tween-20 }\end{array}$ \\
\hline Running buffer (1x) & $\begin{array}{l}25 \text { mM Tris-Base } \\
192 \text { mM Glycin } \\
34.67 \text { mM SDS }\end{array}$ \\
\hline Separation Gel Mix & $\begin{array}{l}31.3 \% \text { (v/v) Acrylamide/Bis Solution (40 \%) } \\
332 \mathrm{mM} \text { Tris Base, } \mathrm{pH} 8.9 \\
3.33 \mathrm{mM} \text { EDTA }\end{array}$ \\
\hline Soerensen-Buffer & $\begin{array}{l}54.6 \mathrm{mM} \mathrm{KH}_{2} \mathrm{PO}_{4} \\
245.4 \mathrm{mM} \mathrm{Na}_{2} \mathrm{HPO}_{4}\end{array}$ \\
\hline
\end{tabular}




\begin{tabular}{|c|c|}
\hline $\begin{array}{l}\text { Solution } 1 \\
\text { Chemiluminescence - } \\
\text { Luminol }\end{array}$ & $\begin{array}{l}100 \mathrm{mM} \text { Tris/HCl } \mathrm{pH} 8.8 \\
2.5 \mathrm{mM} \text { Luminol } \\
4 \mathrm{mM} 4 \text {-IPBA }\end{array}$ \\
\hline $\begin{array}{l}\text { Solution } 2 \\
\text { Chemiluminescence - } \\
\text { Peroxide }\end{array}$ & $\begin{array}{l}100 \mathrm{mM} \text { Tris/ } \mathrm{HCl} \mathrm{pH} 8.8 \\
10.6 \mathrm{mM} \mathrm{H}_{2} \mathrm{O}_{2}\end{array}$ \\
\hline Stacking Gel Mix & $\begin{array}{l}15 \%(\mathrm{v} / \mathrm{v}) \text { Acrylamide/Bis Solution (40\%) } \\
125 \mathrm{mM} \text { Tris base } \mathrm{pH} 6.8 \\
0.1 \%(\mathrm{w} / \mathrm{v}) \text { SDS } \\
5 \mathrm{mM} \text { EDTA }\end{array}$ \\
\hline SYBRGreenMix & $\begin{array}{l}1 \times \text { PCR buffer } \\
3 \mathrm{mM} \mathrm{MgCl}_{2} \\
1: 80.000 \text { SYBRGreen } \\
0.2 \mathrm{mM} \text { dNTP each } \\
20 \mathrm{U} / \mathrm{ml} \text { Hot FIREpol DNA polymerase } \\
0.25 \% \text { TritonX-100 } \\
0.5 \mathrm{mM} \text { Trehalose in depc water }\end{array}$ \\
\hline TBS (1x) & $\begin{array}{l}20 \text { mM Tris-base } \\
137 \text { mM Sodium Chloride, } \mathrm{pH} 7.6\end{array}$ \\
\hline TBS-T & $\begin{array}{l}1 \times \text { TBS } \\
0.1 \%(v / v) \text { Tween-20 }\end{array}$ \\
\hline Transfer buffer $(1 \mathrm{x})$ : & $\begin{array}{l}25 \text { mM Tris-base } \\
192 \text { mM Glycine } \\
15 \%(v / v) \mathrm{MeOH}\end{array}$ \\
\hline
\end{tabular}

\subsection{Equipment}

Equipment used for this study is listed in Table 5. 
Table 5: Equipment

\begin{tabular}{|l|l|}
\hline Instrument & Manufacturer \\
\hline $\begin{array}{l}\text { ABI PRISM 7900HT Fast Real-time } \\
\text { PCR System }\end{array}$ & Thermo Fisher Scientific, Waltham, US \\
\hline Accu-jet & Brand, Hamburg, DE \\
\hline Biofuge Pico, Primo R & Heraeus Instruments, Hanau, DE \\
\hline Boyden chamber & Neuroprobe Inc, Gaithersburg, US \\
\hline CAT RM 5 horizontal roller & CAT M Zipperer, Staufen, DE \\
\hline Centrifuge 5451D & Eppendorf, Hamburg, DE \\
\hline Consort E734 Power Supply & Schütt Labortechnik, Göttingen, DE \\
\hline FACS Aria II & BD Biosciences, Franklin Lakes, US \\
\hline Hera freeze -80C freezer & Heraeus Instruments, Hanau, DE \\
\hline IKA KS 260 shaker & IKA, Staufen, DE \\
\hline IKAMAG RCT magnetic stirrer & IKA, Staufen, DE \\
\hline Incubator Cytoperm & Heraeus Instruments, Hanau, DE \\
\hline Incudrive incubator & Schütt Labortechnik, Göttingen, DE \\
\hline LAS-4000 Image Reader & Fujifim, Düsseldorf, DE \\
\hline Leica DM 5000B with camera: DFC290 & Leica Microsystems GmbH, Wetzlar, DE \\
\hline Microcoolcentrifuge 1-15k & Sigma, Munich, DE \\
\hline $\begin{array}{l}\text { Microflow Laminar Downflow } \\
\text { Workstation: Telstar Bio-II-A }\end{array}$ & $\begin{array}{l}\text { Azbil Telstar Technologies, Terrassa, } \\
\text { ES }\end{array}$ \\
\hline $\begin{array}{l}\text { Motic SMZ-161 with Moticam 3.0 } \\
\text { camera (CAM overviews) }\end{array}$ & Motic Asia, Hong Kong, CN \\
\hline Multifuge 3 L-R & Heraeus Instruments, Hanau, DE \\
\hline ND-1000 UV/Vis-Spectrophotometer & Thermo Fisher Scientific, Waltham, US \\
\hline Neubauer Counting Chamber Improved & Lo Labor Optik, Friedrichsdorf, DE \\
\hline Nucleofector 2b Device & Lonza, Basel, CH \\
\hline Olympus IX81 with Olympus XM-10 \\
camera (time-lapse microscopy) & Olympus, Shinjuka, JP \\
\hline Power Pac 300 Power Supply & Bio-Rad, Munich, DE \\
\hline
\end{tabular}




\begin{tabular}{|l|l|}
\hline Tecan Infinite F50 Reader & Tecan Group Ltd., Männedorf, CH \\
\hline Thermocycler T3000 & Biometra, Göttingen, DE \\
\hline Thermomixer Compact & Eppendorf, Hamburg, DE \\
\hline Vortex Genie 2 & $\begin{array}{l}\text { Schütt Labortechnik, Göttingen, DE } \\
\text { Wäter bath }\end{array}$ \\
\hline & KE \\
\hline
\end{tabular}

\subsection{Inhibitors}

Inhibitors used in this study are listed in Table 6.

Table 6: Inhibitors

\begin{tabular}{|c|c|c|}
\hline Inhibitor (target) & Manufacturer & $\begin{array}{l}\text { Final } \\
\text { concentration }\end{array}$ \\
\hline $\mathrm{ACHP}(\mathrm{IKK} / \beta)$ & Merck Millipore, Billerica, US & $7 \mu \mathrm{M}$ \\
\hline Box5 (WNT5A antagonist) & Merck Millipore, Billerica, US & $100 \mu \mathrm{M}$ \\
\hline DKK1 (LRP5/6) & R\&D Systems, Minneapolis, US & $100 \mathrm{ng} / \mathrm{ml}$ \\
\hline DKK2 (LRP5/6) & R\&D Systems, Minneapolis, US & $100 \mathrm{ng} / \mathrm{ml}$ \\
\hline H1152P (ROCK) & Tocris, Bristol, UK & $0.5 \mu \mathrm{M}$ \\
\hline IWP-2 (porcupine) & StemRD, Burlingame, US & $5 \mu \mathrm{M}$ \\
\hline PF670462 (CKع/ठ) & Merck Millipore, Billerica, US & $50 \mathrm{nM}$ \\
\hline Wnt-C59 (porcupine) & Selleck Chemicals, Houston, US & $5 \mu \mathrm{M}$ \\
\hline XAV-939 (tankyrases) & Merck Millipore, Billerica, US & $5 \mu \mathrm{M}$ \\
\hline Y-27632 (ROCK) & Merck Millipore, Billerica, US & $5 \mu \mathrm{M}$ \\
\hline
\end{tabular}

\subsection{Recombinant proteins}

The $\mathrm{cHL}$ cell lines were stimulated with $100 \mathrm{ng} / \mathrm{ml}$ recombinant WNT5A protein (R\&D Systems, Minneapolis, US) for 24 hours. As chemoattractant for migration and invasion assays recombinant human MIP-3ß/CCL19 (R\&D Systems, Minneapolis, US) has been used. 


\subsection{Plasmids}

Plasmids used for virus generation or protein overexpression are listed in Table 7.

Table 7: Plasmids

\begin{tabular}{|c|c|c|}
\hline Plasmid & Description & Source \\
\hline $\begin{array}{l}\text { pcDNA3.2/V5-DEST } \\
\text { (WNT5A, WNT10A, } \\
\text { WNT10B, WNT16) }\end{array}$ & $\begin{array}{l}\text { expression vector of V5 } \\
\text { tagged active WNTs }\end{array}$ & $\begin{array}{l}\text { Addgene, Cambridge, US } \\
\text { The plasmid kit was a gift } \\
\text { from Marian Waterman, } \\
\text { David Virshup and Xi He } \\
\text { (Najdi et al, 2012; } \\
\text { MacDonald et al, 2014). }\end{array}$ \\
\hline $\begin{array}{l}\text { pCDNA-DVL3K435M- } \\
\text { FLAG }\end{array}$ & $\begin{array}{l}\text { expression vector of } \\
\text { mutant K435M DVL3 } \\
\text { variant }\end{array}$ & $\begin{array}{l}\text { kindly provided by } \\
\text { Vitezslav Bryja (Bernatík } \\
\text { et al, 2014) }\end{array}$ \\
\hline pCDNA-DVL3wt-FLAG & DVL3 expression vector & $\begin{array}{l}\text { kindly provided by } \\
\text { Vitezslav Bryja (Bernatík } \\
\text { et al, 2014) }\end{array}$ \\
\hline pCMV delta R8.2 & $\begin{array}{l}\text { packaging plasmid for } \\
\text { lentivirus production }\end{array}$ & Addgene, Cambridge, US \\
\hline pGIPZ LEF-1 shRNA & $\begin{array}{l}\text { lentiviral vector containing } \\
\text { LEF-1sh sequence }\end{array}$ & $\begin{array}{l}\text { Thermo Fisher Scientific, } \\
\text { Waltham US }\end{array}$ \\
\hline $\begin{array}{l}\text { pGIPZ non-silencing } \\
\text { control shRNA }\end{array}$ & $\begin{array}{l}\text { lentiviral vector containing } \\
\text { non-silencing control } \\
\text { sequence }\end{array}$ & $\begin{array}{l}\text { Thermo Fisher Scientific, } \\
\text { Waltham, US }\end{array}$ \\
\hline pMD.2G & $\begin{array}{l}\text { envelope plasmid for } \\
\text { lentivirus production }\end{array}$ & Addgene, Cambridge, US \\
\hline
\end{tabular}

\subsection{Antibodies}

Antibodies used for immunoblotting are listed in Table 8. 
Table 8: Antibodies

\begin{tabular}{|c|c|c|}
\hline Antibody & Source & Working solution \\
\hline $\begin{array}{l}\text { goat anti mouse HRP } \\
\text { polyclonal (sc-2005) }\end{array}$ & Santa Cruz, Dallas, US & $\begin{array}{l}1: 5000 \text { in } 5 \% \text { BSA or } 5 \% \\
\text { milk powder in TBS-T }\end{array}$ \\
\hline $\begin{array}{l}\text { goat anti rabbit HRP } \\
\text { polyclonal (sc-2004) }\end{array}$ & Santa Cruz, Dallas, US & $\begin{array}{l}1: 5000 \text { in } 5 \% \text { BSA or } 5 \% \\
\text { milk powder in TBS-T }\end{array}$ \\
\hline $\begin{array}{l}\text { goat anti rat HRP } \\
\text { polyclonal (sc-2006) }\end{array}$ & Santa Cruz, Dallas, US & $\begin{array}{l}1: 5000 \text { in } 5 \% \text { BSA or } 5 \% \\
\text { milk powder in TBS-T }\end{array}$ \\
\hline mouse anti FLAG (8146) & $\begin{array}{l}\text { Cell Signalling } \\
\text { Technology, Danvers, US }\end{array}$ & $\begin{array}{l}1: 1000 \text { in } 5 \% \text { BSA in } \\
\text { TBS-T }\end{array}$ \\
\hline $\begin{array}{l}\text { mouse anti GAPDH } \\
\text { (ab8245) }\end{array}$ & abcam, Cambridge, UK & $\begin{array}{l}1: 20000 \text { in } 5 \% \text { BSA in } \\
\text { TBS-T }\end{array}$ \\
\hline $\begin{array}{l}\text { mouse anti HSP90 (sc- } \\
13119)\end{array}$ & Santa Cruz, Dallas, US & $\begin{array}{l}1: 1000 \text { in } 5 \% \text { BSA in } \\
\text { TBS-T }\end{array}$ \\
\hline $\begin{array}{l}\text { mouse anti RHOA } \\
(\mathrm{ARH03)}\end{array}$ & $\begin{array}{l}\text { Cytoskeleton Inc., } \\
\text { Denver, US }\end{array}$ & 1:500 in TBS- $T$ \\
\hline mouse anti TCF4 & $\begin{array}{l}\text { Merck Millipore, Billerica, } \\
\text { US }\end{array}$ & $\begin{array}{l}\text { 1:1000 in } 5 \% \text { milk } \\
\text { powder in TBS-T }\end{array}$ \\
\hline $\begin{array}{l}\text { mouse anti Tubulin } \\
(05-829)\end{array}$ & $\begin{array}{l}\text { Merck Millipore, Billerica, } \\
\text { US }\end{array}$ & $\begin{array}{l}\text { 1:5000 in } 5 \% \text { BSA in } \\
\text { TBS-T }\end{array}$ \\
\hline $\begin{array}{l}\text { mouse anti } \beta \text {-catenin } \\
(610153)\end{array}$ & $\begin{array}{l}\text { BD Biosciences, Franklin } \\
\text { Lakes, US }\end{array}$ & $\begin{array}{l}1: 1000 \text { in } 5 \% \text { BSA in } \\
\text { TBS-T }\end{array}$ \\
\hline $\begin{array}{l}\text { rabbit anti DVL1 } \\
(\text { ab106844) }\end{array}$ & abcam, Cambridge, UK & $\begin{array}{l}1 \mu \mathrm{g} / \mathrm{ml} \text { in } 5 \% \mathrm{BSA} \text { in } \\
\text { TBS-T }\end{array}$ \\
\hline rabbit anti DVL2 (3216) & $\begin{array}{l}\text { Cell Signalling } \\
\text { Technology, Danvers, US }\end{array}$ & $\begin{array}{l}\text { 1:1000 in } 5 \% \text { milk } \\
\text { powder in TBS-T }\end{array}$ \\
\hline rabbit anti DVL3 (3218) & $\begin{array}{l}\text { Cell Signalling } \\
\text { Technology, Danvers, US }\end{array}$ & $\begin{array}{l}1: 1000 \text { in } 5 \% \text { BSA in } \\
\text { TBS-T }\end{array}$ \\
\hline rabbit anti FZD5 (5266) & $\begin{array}{l}\text { Cell Signalling } \\
\text { Technology, Danvers, US }\end{array}$ & $\begin{array}{l}1: 1000 \text { in } 5 \% \text { BSA in } \\
\text { TBS-T }\end{array}$ \\
\hline
\end{tabular}




\begin{tabular}{|l|l|l|}
\hline rabbit anti HDAC (2062) & $\begin{array}{l}\text { Cell Signalling } \\
\text { Technology, Danvers, US }\end{array}$ & $\begin{array}{l}\text { 1:1000 in 5 \% BSA in } \\
\text { TBS-T }\end{array}$ \\
\hline rabbit anti IKK1 (2682) & $\begin{array}{l}\text { Cell Signalling } \\
\text { Technology, Danvers, US }\end{array}$ & $\begin{array}{l}1: 1000 \text { in 5 \% BSA in } \\
\text { TBS-T }\end{array}$ \\
\hline rabbit anti LEF-1 (2286) & $\begin{array}{l}\text { Cell Signalling } \\
\text { Technology, Danvers, US }\end{array}$ & $\begin{array}{l}1: 1000 \text { in 5 \% BSA in } \\
\text { TBS-T }\end{array}$ \\
\hline rabbit anti p38 (9212) & $\begin{array}{l}\text { Cell Signalling } \\
\text { Technology, Danvers, US }\end{array}$ & $\begin{array}{l}1: 1000 \text { in 5 \% BSA in } \\
\text { TBS-T }\end{array}$ \\
\hline rabbit anti STAT3 (9132) & $\begin{array}{l}\text { Cell Signalling } \\
\text { Technology, Danvers, US }\end{array}$ & $\begin{array}{l}1: 1000 \text { in 5 \% BSA in } \\
\text { TBS-T }\end{array}$ \\
\hline rabbit anti TCF3 & $\begin{array}{l}\text { Merck Millipore, Billerica, } \\
1: 1000 \text { in 5 \% milk } \\
\text { powder in TBS-T }\end{array}$ \\
\hline rabbit anti V5 (13202S) & $\begin{array}{l}\text { Cell Signalling } \\
\text { Technology, Danvers, US }\end{array}$ & $\begin{array}{l}1: 1000 \text { in 5 \% BSA in } \\
\text { TBS-T }\end{array}$ \\
\hline rat anti WNT5A & R\&D Systems, & $\begin{array}{l}1: 1000 \text { in 5 \% milk } \\
\text { powder in TBS-T }\end{array}$ \\
\hline (MAB645) & Minneapolis, US & \multicolumn{2}{|l}{} \\
\hline
\end{tabular}

\subsection{Oligonucleotides and siRNAs}

Primers used for quantitative real-time PCR (qRT) are listed in Table 9 and siRNAs used for transient gene knockdowns are listed in Table 10. Primers as well as random hexamer primers have been generated by IBA GmbH (Göttingen, DE).

Table 9: Oligonucleotides

\begin{tabular}{|l|l|}
\hline Oligonucleotides & Sequence \\
\hline ABL & $\begin{array}{l}\text { fwd: 5' AGC CTG GCC TAC AAC AAG TTC TC 3' } \\
\text { rev: 5' GAC ATG CCA TAG GTA GCA ATT TCC 3' }\end{array}$ \\
\hline FZD5 & $\begin{array}{l}\text { fwd: 5' GTC ACA CCC GCT CTA CAA CA 3' } \\
\text { rev: 5' GGA CGT GGA GAT GAA GCA CA 3' }\end{array}$ \\
\hline LEF-1 & $\begin{array}{l}\text { fwd: 5' TAA TGC ACG TGA AGC CTC AGC 3' } \\
\text { rev: 5' TTA ATG TGA GGT CTT TTT GGC TCC 3' }\end{array}$ \\
\hline
\end{tabular}




\begin{tabular}{|l|l|}
\hline TCF7 & $\begin{array}{l}\text { fwd: 5’ AAC CTG AAG ACA CAA GCA GAG TCC 3' } \\
\text { rev: 5' AAC CTG AAG ACA CAA GCA GAG TCC 3' }\end{array}$ \\
\hline TCF7L1 & $\begin{array}{l}\text { fwd: 5' CGC GGG ACT ATT TCG CCG AAG 3' } \\
\text { rev: 5' TGG AGA GGT ACG GGC TGC TCA G 3' }\end{array}$ \\
\hline TCF7L2 & $\begin{array}{l}\text { fwd: 5' CAT CAC CGG CAC ACA TTG TC 3' } \\
\text { rev: 5' GTT CAT TGC TGT ACG TGA TAA GAG GC 3' }\end{array}$ \\
\hline WNT3A & $\begin{array}{l}\text { fwd: 5' CAG GAA CTA CGT GGA GAT CAT GC 3' } \\
\text { rev: 5' TCC TGG ATG CCA ATC TTG ATG 3' }\end{array}$ \\
\hline WNT5A & $\begin{array}{l}\text { fwd: 5' AGG GCT CCT ACG AGA GTG CT 3' } \\
\text { rev: 5' GAC ACC CCA TGG CAC TTG 3' }\end{array}$ \\
\hline WNT10A & $\begin{array}{l}\text { fwd: 5' CCA GGT CAG CAC CCA ATG ACA TT 3' } \\
\text { rev: 5' CCT GGC AAT GTT AGG CAC ACT GTG 3' }\end{array}$ \\
\hline WNT10B & $\begin{array}{l}\text { fwd: 5' CTG TGT GAT GAG TGC AAG GTT ACA G 3' } \\
\text { rev: 5' CCC TCA CTT ACA CAC ATT CAC CC 3' }\end{array}$ \\
\hline fwd: 5' GGC TAC GAG CTG AGC AGC G 3' \\
rev: 5' CAT GAC CTG GTC ACA GAA TGC A 3'
\end{tabular}

Table 10: siRNA

\begin{tabular}{|l|l|}
\hline siRNA & Manufacturer \\
\hline DVL3si (s675) & Life Technologies, Carlsbad, US \\
\hline $\begin{array}{l}\text { FZD5si (pool of HSS111796, } \\
\text { HSS111798, HSS187902) }\end{array}$ & Life Technologies, Carlsbad, US \\
\hline $\begin{array}{l}\text { LEF-1si (pool of ID108840, IDs27618, } \\
\text { IDs27617, IDs27616) }\end{array}$ & Life Technologies, Carlsbad, US \\
\hline $\begin{array}{l}\text { MAPK14si (SMARTpool: ON- } \\
\text { TARGETplus MAPK14 siRNA, L- } \\
\text { 003512-00) }\end{array}$ & $\begin{array}{l}\text { GE Healthcare Dharmacon, Lafayette, } \\
\text { US }\end{array}$ \\
\hline scrambled si control (scr, AM4611) & Life Technologies, Carlsbad, US \\
\hline
\end{tabular}




\begin{tabular}{|l|l|}
\hline $\begin{array}{l}\text { STAT3si (SMARTpool: ON- } \\
\text { TARGETplus STAT3 siRNA, } \\
\text { L-003544-00) }\end{array}$ & $\begin{array}{l}\text { GE Healthcare Dharmacon, Lafayette, } \\
\text { US }\end{array}$ \\
\hline $\begin{array}{l}\beta \text {-catenin si (pool of ID J-003482-09, ID } \\
\text { J-003482-12) }\end{array}$ & $\begin{array}{l}\text { GE Healthcare Dharmacon, Lafayette, } \\
\text { US }\end{array}$ \\
\hline
\end{tabular}

\subsection{Ready to Use Reaction Systems}

Ready to use reaction systems and kits used in this study are listed in Table 11.

Table 11: Ready to use reaction systems

\begin{tabular}{|l|l|}
\hline Ready to use reaction system & Manufacturer \\
\hline $\begin{array}{l}\text { Cell Line Nucleofector }{ }^{\circledR} \text { Kit L (for L428)/ } \\
\text { Kit T (for KM-H2) }\end{array}$ & Lonza, Basel, CH \\
\hline Nucleo Spin RNA II & Machery+Nagel, Düren, DE \\
\hline $\begin{array}{l}\text { RHOA Pull-down Activation Assay } \\
\text { Biochem Kit }\end{array}$ & Cytoskeleton Inc., Denver, US \\
\hline Superscript II ${ }^{\text {TM }}$ RT Kit & Invitrogen, Karlsruhe, DE \\
\hline
\end{tabular}

\subsection{Software}

Software used for this study is listed in Table 12.

Table 12: Software

\begin{tabular}{|l|l|}
\hline Software & Developer \\
\hline $\begin{array}{l}\text { ABI 7900HT Sequence Detection } \\
\text { Systems Ver. 2.4 }\end{array}$ & Thermo Fisher Scientific, Waltham, US \\
\hline Adobe Illustrator CS6 Ver 16.0.3 & Adobe Systems Inc. San José, US \\
\hline Adobe Photoshop CS2 Ver 9.0 & Adobe Systems Inc. San José, US \\
\hline Chemotaxis and Migration Tool & Ibidi, Martinsried, DE \\
\hline GraphPad Prism 6.04 & GraphPad Software Inc., La Jolla, US \\
\hline ImageJ software 1.45s & National Institutes of Health, Bethesda, US \\
\hline
\end{tabular}




\begin{tabular}{|l|l|}
\hline Leica Application Suite Ver 3.8.0 & Leica Microsystems GmbH, Wetzlar, DE \\
\hline Magellan for F50 7.0 & Tecan Group Ltd., Männedorf, CH \\
\hline Mendeley Desktop Ver 1.15.2 & Mendeley Ltd, London, UK \\
\hline $\begin{array}{l}\text { Microsoft Office (Word, Excel, } \\
\text { PowerPoint) }\end{array}$ & Microsoft Corporation, Redmont, US \\
\hline ND-1000 V3.8.1 & Thermo Fisher Scientific, Waltham, US \\
\hline Oncomine web platform & Life Technologies, Carlsbad, US \\
\hline RQ Manager Ver. 1.2.1 & Thermo Fisher Scientific, Waltham, US \\
\hline $\begin{array}{l}\text { Servier Medical Art (licensed under a } \\
\text { Creative Commons Attribution 3.0 } \\
\text { Unported License) }\end{array}$ & $\begin{array}{l}\text { Les Laboratoires Servier, Neuilly-sur- } \\
\text { Seine, FR }\end{array}$ \\
\hline $\begin{array}{l}\text { Xcellence Imaging Software for Life } \\
\text { Science Microscopy }\end{array}$ & Olympus, Shinjuka, JP \\
\hline
\end{tabular}

\subsection{Cell Biology}

\subsubsection{Cell culture}

The $\mathrm{CHL}$ cell lines $\mathrm{L} 428, \mathrm{KM}-\mathrm{H} 2$ and $\mathrm{L} 1236$ were cultured in cell culture medium I while the BL cell lines BL-2 and BL-30, the MCL cell lines JeKo-1 and Mino and the DLBCL cell lines OciLy1, Carnaval and Karpas-422 were cultured in cell culture medium II. All cells were maintained at $37^{\circ} \mathrm{C}$ in $5 \% \mathrm{CO}_{2}$. The $\mathrm{cHL}$, MCL and DLBCL cells were seeded at a density of $5 \times 10^{5} \mathrm{celll} / \mathrm{ml}$ the day before the experiment while $\mathrm{BL}$ cell lines were seeded at a density of $3 \times 10^{5}$ cells $/ \mathrm{ml}$. For cell number measurement cells were mixed in an equal ratio with $0.4 \%$ Trypan blue and counted using the Neubauer counting chamber.

Human Umbilical Vein Endothelial Cells (HUVECs) were cultured in cell culture medium III. For the experiments HUVEC cells with a confluence of $80-90 \%$ and from passage two till six have been used. 
Mouse fibroblasts (WNT3ANNT5A) have been cultured in cell culture medium VI and wildtype L-cells in cell culture medium V. Approximately every three days L-cells were subcultivated (ratio: $1: 4$ to $1: 10$ ).

HEK293T cells have been cultured in cell culture medium V. Approximately 2-3 $\times 10^{6}$ cells $/ 80 \mathrm{~cm}^{2}$ have been seeded and subcultivated (ratio: 1:4 to $1: 5$ ) every three days.

All cell lines have been tested regularly for mycoplasma contamination. Cells were no longer than four weeks continuously cultivated. For cell freezing $3 \times 10^{6}$ till $5 \times 10^{6}$ cells were centrifuged at $100 \times \mathrm{g} / 7 \mathrm{~min}$ and resuspended in $1 \mathrm{ml}$ freezing medium. For the freezing process cryo boxes which contain isopropanol were used to ensure a constant cooling of approximately $1^{\circ} \mathrm{C} / \mathrm{min}$. Cryo boxes were stored immediately at $-80^{\circ} \mathrm{C}$ for 24 hours before they were transferred to $-150^{\circ} \mathrm{C}$ for long-term storage. For thawing cells were washed with their corresponding culture medium, counted and seeded in new culture medium (cHLs, DLBCLs, MCLs: $5 \times 10^{5}$ cells $/ \mathrm{ml}$; BLs: $3 \times 10^{5}$ cells $/ \mathrm{ml}$ ).

\subsubsection{RNA-interference-mediated gene knockdown and gene overexpression by nucleofection}

Small-interfering RNA (siRNA) against the indicated target genes or nonsense controls (ns ctr) were transfected into the cells using Cell Line Nucleofector Kit (L428: Kit L; KM-H2: Kit T) and the Nucleofector 2b Device (2 $\mu \mathrm{g}$ siRNA/plasmid per two million cells) according to the manufacturer's instructions (programme X001 for L428 and T-001 for KM-H2). After the nucleofection process cells were incubated in pre-warmed RPMI 1640 supplemented with $10 \%$ (v/v) FCS, $200 \mathrm{U} / \mathrm{ml}$ penicillin, $200 \mu \mathrm{g} / \mathrm{ml}$ streptomycin, $1 \mathrm{mM}$ sodium pyruvate and $10 \mathrm{mM}$ Hepes for 48 hours at $37^{\circ} \mathrm{C}$ in $5 \% \mathrm{CO}_{2}$. Knockdown quality was verified with qRT-PCR and immunoblotting.

For WNT overexpression pCDNA3.2 plasmids containing corresponding V5tagged WNT ligands were used from the WNT Open Source Kit. pCDNA-DVL3wt- 
FLAG and pCDNA-DVL3K435M-FLAG plasmids have been described recently (Bernatík et al, 2014).

\subsubsection{Preparation of conditioned medium (CM)}

For the preparation of conditioned HL medium $\mathrm{L} 428, \mathrm{KM}-\mathrm{H} 2$ or $\mathrm{L} 1236$ have been seeded at a density of $5 \times 10^{5}$ cells $/ \mathrm{ml}$ and incubated in cell culture medium I for two days. Cell supernatant was centrifuged at $300 \times \mathrm{g}$ for $10 \mathrm{~min}$ at $4^{\circ} \mathrm{C}$, sterile filtered and stored at $4^{\circ} \mathrm{C}$ for a maximum of two weeks.

For the preparation of conditioned L-cell medium mouse fibroblasts (L-cell wildtype/WNT3A/WNT5A) have been seeded at a density of 8000 cells $/ \mathrm{cm}^{2}$ and incubated in cell culture medium $V$ for four days. Cell supernatant was centrifuged at $300 \times \mathrm{g}$ for $10 \mathrm{~min}$ at $4^{\circ} \mathrm{C}$ and stored at $4^{\circ} \mathrm{C}$. New cell culture medium $\mathrm{V}$ was added to the L-cells for three more days. The second supernatant was added to the first one after centrifugation in an equal ratio. Finally the conditioned medium was sterile filtered and stored at $4^{\circ} \mathrm{C}$ for a maximum of two months.

\subsubsection{Isolation and preparation of extracellular vesicles (EVs)}

EVs have been isolated using ExoQuick-TC Solution following the manufacturer's instructions. Shortly, ExoQuick-TC Precipitation Solution has been added to the cell supernatant, mixed and incubated at $4^{\circ} \mathrm{C}$ overnight. The mixture has been centrifuged at $1500 \times \mathrm{g}$ twice and the dry pellet has been resuspended in PBS for stimulation assays or NP-40 lysis buffer for Western Blot analysis.

As another possibility ultracentrifugation has been used for EV preparation as described recently (Menck et al, 2013).

\subsubsection{Inhibitor treatment}

For porcupine inhibition the chemical compounds Wnt-C59 or IWP-2 have been added to the cell culture medium at a final concentration of $5 \mu \mathrm{M}$ in DMSO for 
72 hours. Each 24 hours the inhibitor and the corresponding DMSO control were renewed.

For inhibition of the canonical WNT pathway the CK1 inhibitor PF670462, the tankyrases inhibitor XAV939 or DKK1 and DKK2 have been added to the cell culture medium at a final concentration of $50 \mathrm{nM}$ (PF670462) or $5 \mu \mathrm{M}$ (XAV939) or $100 \mathrm{ng} / \mathrm{ml}$ (DKK1, DKK2) in DMSO (PF670462, XAV939), PBS (DKK2) or PBS with $0.1 \%$ BSA (DKK1) respectively for 24 hours.

For inhibition of ROCK the inhibitors Y-27632 or H1152P have been added to the cell culture medium at a final concentration of $5 \mu \mathrm{M}(\mathrm{Y}-27632)$ or $0.5 \mu \mathrm{M}(\mathrm{H} 1152 \mathrm{P})$ in DMSO respectively for 24 hours.

For IKK2 inhibition ACHP has been applied at a final concentration of $7 \mu \mathrm{M}$ in DMSO for 24 hours.

For antagonizing WNT5A Box5 has been applied at a final concentration of $100 \mu \mathrm{M}$ in DMSO for 24 hours.

\subsubsection{WNT stimulation}

Before stimulation $\mathrm{cHL}$ cells were serum-starved and treated with the Porcupine inhibitor Wnt-C59 $(5 \mu \mathrm{M})$ for 48 hours. $\mathrm{cHL}$ cell lines were either stimulated with $100 \mathrm{ng} / \mathrm{ml}$ recombinant WNT5A ligand or with corresponding WNT ligand containing L-cell conditioned medium for the indicated times.

For migration and chorio-allantoic membrane (CAM) experiments $\mathrm{CHL}$ cells have not been serum-starved before.

\subsubsection{Lentivirus production}

For lentivirus production $5 \times 10^{6}$ HEK293T cells have been seeded per $10 \mathrm{~cm}^{2}$ cell culture dish and grown to $80 \%$ confluence. Two hours prior to the experiment HEK293T medium has been renewed without disturbing cell confluence. 
Expression vector (pGIPZ LEF1 shRNA or pGIPZ non-silencing control), packaging plasmid (pCMV delta R8.2) and envelope plasmid (pMD.2G) have been mixed in the ratio 3:2:1. Calcium chloride solution has been added to a final concentration of $0.5 \mathrm{M}$. While the calcium chloride-plasmid mixture has been mixed thoroughly the same volume of $2 x$ Hepes-buffered $\mathrm{NaCl}$ solution has been added drop by drop. The final mixtures have been incubated for $3 \mathrm{~min}$ at room temperature, mixed again and then carefully been added drop by drop to the HEK293T cells. The next day cell supernatant has been removed and $5 \mathrm{ml}$ of cell culture medium $V$ have been added carefully to each dish. HEK293T cells have been incubated for 24 hours at $37^{\circ} \mathrm{C}$ in $5 \% \mathrm{CO}_{2}$ before the first virus harvest has been performed. For that purpose HEK293T cell supernatant has been taken off and stored at $4^{\circ} \mathrm{C}$ and HEK293T cells have been covered again with $5 \mathrm{ml}$ of cell culture medium $\mathrm{V}$ per dish. After another day of incubation the second supernatants have been taken off and mixed with the respective first supernatants. The resulting virus solutions have been centrifuged at $2000 \mathrm{xg}$ for $10 \mathrm{~min}$ at $4^{\circ} \mathrm{C}$. To remove residual cell debris supernatants have been transferred to new tubes and sterile filtered. Virus solution has either been used immediately for transfection controls or $\mathrm{CHL}$ cell transduction or stored at $-80^{\circ} \mathrm{C}$.

\subsubsection{Lentiviral transduction and selection of $\mathrm{pGIPZ} \mathrm{cHL}$ cells}

Cell concentration of $\mathrm{L} 428$ and $\mathrm{KM}-\mathrm{H} 2$ cells has been adjusted to $1 \times 10^{6} \mathrm{cells} / \mathrm{ml}$ in RPMI1640 medium supplemented with $20 \%(\mathrm{v} / \mathrm{v}) \mathrm{FCS}, 200 \mathrm{U} / \mathrm{ml}$ penicillin, $200 \mu \mathrm{g} / \mathrm{ml}$ streptomycin, $4 \mathrm{mM} \mathrm{L-glutamine}$ and $10 \mu \mathrm{g} / \mathrm{ml}$ protamine sulfate. Virus solution and cell suspension have been mixed in an equal ratio and centrifuged at $300 \times \mathrm{g}$ for $90 \mathrm{~min}$ at $37^{\circ} \mathrm{C}$. The $\mathrm{cHL}$ cell-virus suspensions have been incubated for 48 hours. Since the pGIPZ plasmid contains an additional puromycin resistance selection process has been started by adding puromycin to a final concentration of $2 \mu \mathrm{g} / \mathrm{ml}$ to the cells on the second day after transduction. To control the selection process $\mathrm{L} 428$ and $\mathrm{KM}-\mathrm{H} 2$ cells without virus addition also have been treated with puromycin but those cells died within two days. Lentiviral transduced L428 and KM-H2 cells have been grown in cell culture medium IV and 
frozen for long-term storage as described in 2.12.1. LEF-1 knockdown has been regularly confirmed using qRT-PCR and immunoblot techniques (2.13.2 and 2.14.3).

\subsubsection{Migration and invasion assay}

The migratory potential of the $\mathrm{CHL}$ and $\mathrm{NHL}$ cells was assessed using the Boyden chamber with defined porous membranes (for cHLs, MCLs: $8 \mu \mathrm{m}$, for BLs, DLBCLs: $10 \mu \mathrm{m}$ ). In short, the lower chamber was filled with RPMI 1640 alone (undirected migration) and RPMI 1640 supplemented with $10 \%$ (v/v) FCS and $50 \mathrm{nM}$ MIP-3 $\beta / C C L 19$, the membrane was applied free from air bubbles and the upper chamber was filled with 50.000 untreated, inhibitor-treated or nucleofected cells per well in RPMI 1640 medium. After 6 hours of migration time (cHLs and MCLs) or 16 hours (BLs, DLBCLs) cells from the upper chamber were removed and the migrated cells in the lower chamber were counted. Basal cell migration towards RPMI 1640 medium only was set one. For stimulation experiments the lower chamber was filled with RPMI 1640 supplemented with $1 \%$ (v/v) FCS. Six wells per condition were used in every experiment.

For invasion assays $8 \mu \mathrm{m}$ porous membranes were coated with $1 \mathrm{mg} / \mathrm{ml}$ type-I-collagen and invasion was measured after 16 hours as described above.

\subsubsection{Time-lapse microscopy of cell chemotaxis}

For monitoring real-time cell movements $\mathrm{cHL}$ cells $\left(3 \times 10^{6}\right.$ cells $\left./ \mathrm{ml}\right)$ were added into the $\mu$-Slide chemotaxis ${ }^{3 \mathrm{D}}$ chamber in $1.5 \mathrm{mg} / \mathrm{ml}$ type-I-collagen. Chemotaxis towards $10 \%(\mathrm{v} / \mathrm{v})$ FCS and $50 \mathrm{nM}$ MIP-3B/CCL19 was documented for 6 hours with one photo per 5 min by time-lapse microscopy. For trajectory analysis of 50 cells per condition ImageJ 1.45s (plugin: manual tracking) and the lbidi software "Chemotaxis and Migration Tool" were used.

Cell track analysis using shape fingerprint descriptors has been performed by Manuel M. Nietert (Department of Medical Statistics, University Medical Centre of 
the Georg-August University of Göttingen, Göttingen). A detailed description of the method can be found in the Appendix.

\subsubsection{Adhesion assay}

Adhesion assays have been performed as described recently (Zepeda-Moreno et al, 2014). Shortly, 96 well plates have been coated with $1 \mathrm{mg} / \mathrm{ml}$ type-I-collagen or seeded with HUVEC cells overnight. Inhibitor-treated or transfected $\mathrm{cHL}$ cells have been added to the wells $(75.000$ cells/well/320 $\mu$ l) in quadruplicates and incubated for 1 hour at $37^{\circ} \mathrm{C}$ in $5 \% \mathrm{CO}_{2}$. For discrimination between adherent and nonadherent cells the plate has been turned up-side down and incubated for two more hours at $37^{\circ} \mathrm{C}$ in $5 \% \mathrm{CO}_{2}$. While holding the plate still up-side down the supernatant with the non-adherent cells has been carefully transferred to a second plate. Additionally, five different known numbers of cells have been added for each condition in duplicates to this second plate for the standard curve calculation. For cell number quantification MTT solution has been added to a final concentration of $0.5 \mathrm{mg} / \mathrm{ml}$ and incubated with the non-adherent cells and the cells for the standard curve for 3 hours at $37^{\circ} \mathrm{C}$ in $5 \% \mathrm{CO}_{2}$. Optical density has been determined at $560 \mathrm{~nm}$ using the Tecan Infinite F50 Reader. Standard curves have been calculated for each condition and the amount of adherent cells has been presented in percentage of the total number.

\subsubsection{MTT assay}

For cell viability tests cell lines have been pretreated with inhibitor as described above and subsequently seeded into a 96 well plate. After the addition of $0.5 \mathrm{mg} / \mathrm{ml}$ MTT reagent, cells have been incubated for four hours at $37^{\circ} \mathrm{C}$ in $5 \% \mathrm{CO}_{2}$ followed by centrifugation and resuspension of the cell pellet in the acidic MTT solution. Optical density has been determined at $560 \mathrm{~nm}$ using Tecan Infinite F50 Reader. 


\subsubsection{RHOA activity assay}

RHOA Activity has been measured with the RHOA Pull-down Activation Assay Biochem Kit following the manufacturer's instructions. Shortly, stimulated cells have been lysed and snap-frozen in liquid nitrogen. For positive and negative controls lysate was incubated with GDP or the GTP analogue GTPYS before the pull-down started. Equal lysate amounts were incubated with $50 \mu \mathrm{g}$ rhotekin-RBD beads at $4^{\circ} \mathrm{C}$ for one hour. Beads were washed, resuspended in Roti-Load loading dye and boiled at $95^{\circ} \mathrm{C}$ for $5 \mathrm{~min}$. The following SDS page and immunoblotting is described in 2.13.2 SDS page and Western Blot.

\subsubsection{HUVEC spheroid assay}

For spheroid generation HUVEC cells have been mixed with $1.2 \%$ methylcellulose in cell culture medium III and incubated in 96 well plates for 24 hours. Roundly formed spheroids have been harvested and seeded with one part matrigel and two parts $\mathrm{KM}-\mathrm{H} 2$ conditioned medium in 96 well plates for 48 hours. At least 12 spheroids have been seeded per condition. For positive controls spheroids have been seeded with cell culture medium III. Photos of each spheroid have been taken after 48 hours and sprouting frequency has been calculated as relation between sprouted spheroids and totally seeded spheroids per condition. From every sprouted spheroid total sprout length and tip number have been calculated using ImageJ software 1.45s.

\subsubsection{HUVEC tube formation assay}

HUVEC cells have been seeded as single cell suspension in matrigel mixed with two parts of the particular $\mathrm{cHL}$ conditioned medium and one part cell culture medium III in 96 well plates. Four wells per condition have been used. After 16 hours tubes have been formed throughout the well. Three photos per well have been taken and total tube lengths have been measured using ImageJ software $1.45 \mathrm{~s}$ 


\subsubsection{Chick chorio-allantoic membrane (CAM) assay}

The CAM assay has been performed by Frederike von Bonin including sawing the egg shells, cell inoculation, the tumour harvest, fixation and eventually H\&E staining. The prior cell treatment and the later evaluation including development of the haemorrhage score, assessment of the results, microscoping $\mathrm{H} \& \mathrm{E}$ stained slices and statistics have been performed by me.

In short, chicken eggs have been bred and regularly turned around for 4 days at $37.8^{\circ} \mathrm{C}$ and $80 \%$ air humidity. For the in ovo assay a $0.75 \mathrm{~cm}^{2}$ window has been sawed into the egg shell at the fourth day of chicken embryo development. At day eleven of chicken embryo development $2 \times 10^{6}$ pretreated L428 cells embedded in $20 \mu \mathrm{l}$ Matrigel have been added on the CAM. After 4 days of incubation on the CAM, tumours have been cut out, evaluated, photographed and fixed either in Bouin's solution or $4 \%$ paraformaldehyde solution with a subsequent ascending series of saccharose. For histological analysis tumours were embedded in paraffin or Tissue Tek and cut. Tumour areas have been measured using the light microscopy photos and ImageJ software 1.45s.

\subsubsection{Haematoxylin and eosin (H\&E) staining}

Tumour sections have been fixed in $100 \%$ methanol for 5 min. After 2 min of washing with distilled water, sections were incubated in Mayer's alum haematoxylin solution for $2 \mathrm{~min}$, rinsed in running tap water, incubated in eosin for 7 min and again washed with distilled water. For dehydration an ascending ethanol series with a final incubation in xylol has been used. Dried and mounted sections have been analysed using light microscopy (Leica DM 5000B, camera: DFC290).

\subsubsection{Semi-thin and ultra-thin sections}

Semi-thin and ultra-thin sections have been performed in the Department of Anatomy and Cell Biology of the University Medical Centre of the Georg-August University of Göttingen by the working group of Prof. Dr. Jörg Wilting. 
Shortly, tumours have been fixed in Karnovsky's fixative, post-fixed in osmium tetroxide solution and embedded in Epon resin according to standard techniques. Semi-thin sections of $750 \mathrm{~nm}$ were stained with Richardson solution and studied with a light microscope. For transmission electron microscopy ultra-thin sections of $70 \mathrm{~nm}$ were contrasted with lead citrate and uranyl acetate.

\subsubsection{Micro-CT scans of CAM tumours}

Micro-CT scans of CAM tumours have been performed by Christian Dullin (Institute of Diagnostic and Interventional Radiology; University Medical Centre of the Georg-August University of Göttingen, Göttingen).

In short, CT scans of the PTA stained and agarose gel embedded samples have been performed using the GE eXplore Locus SP specimen CT (TriVoil, USA) (Verdelis et al, 2011). The system was operated with the following parameters: tube voltage $70 \mathrm{kVp}$, tube current $50 \mathrm{~mA}, 270^{\circ}$ rotation with 667 projection images, exposure time per projection $1600 \mathrm{~ms}$, detector binning $2 \times 2$ resulting in a pixel size of $14 \mu \mathrm{m}$. In order to increase the signal-to-noise ratio every projection data has been acquired twice and averaged.

\subsubsection{Scoring hemorrhages in CAM tumours}

The haemorrhage score is based on three criteria: appearance of hemorrhages, intensity of hemorrhages and relative area covered by hemorrhages. In each criterion zero to three points can be given leading to a maximum of nine points per tumour. Examples for each criterion as well as tumour examples for the total points are shown in Table 13 and Figure 3. For the evaluation process light microscopy pictures of each tumour have been blinded and then evaluated by another group member who was not involved in the experiments. 
Table 13: Hemorrhage score for CAM tumours

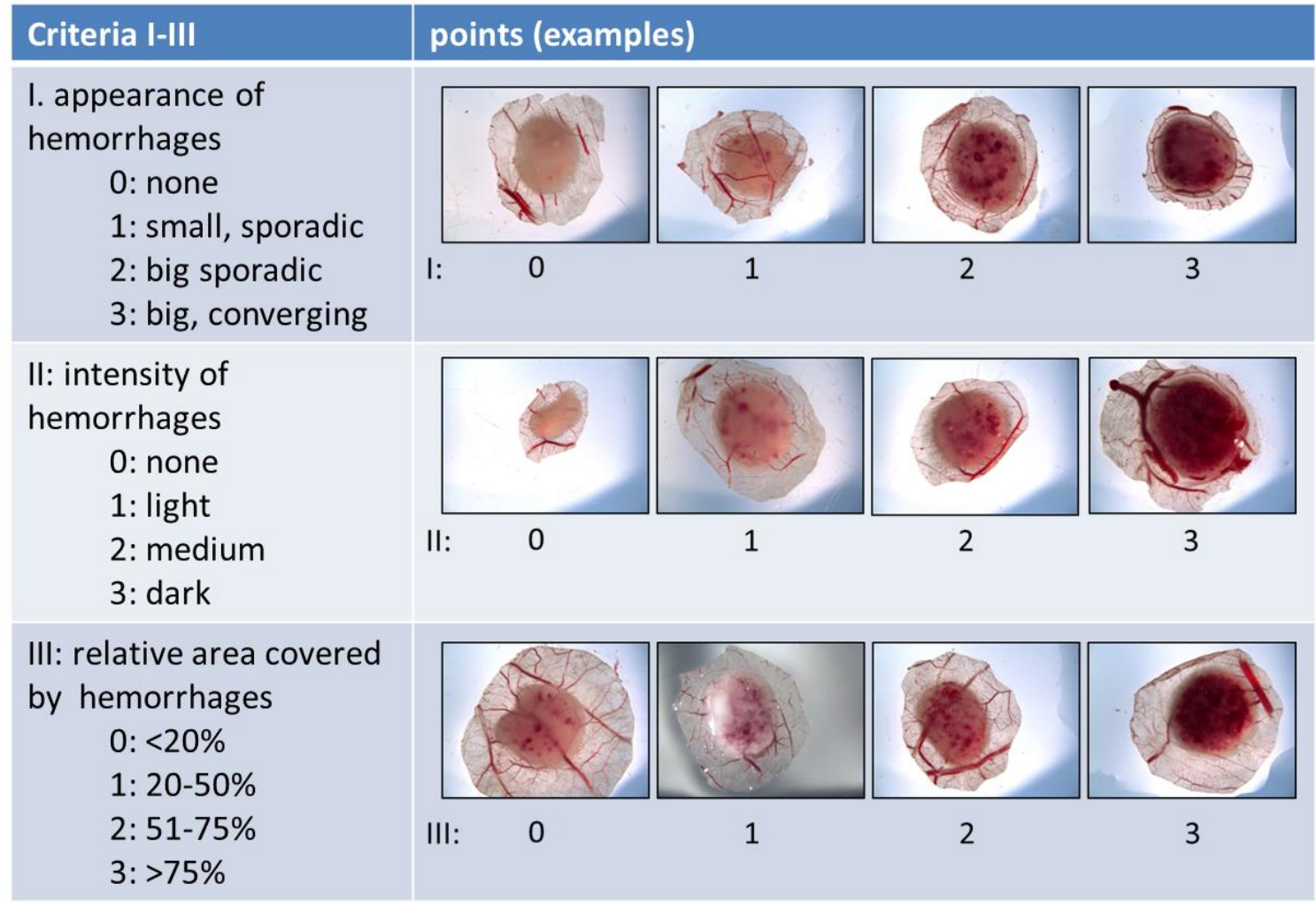




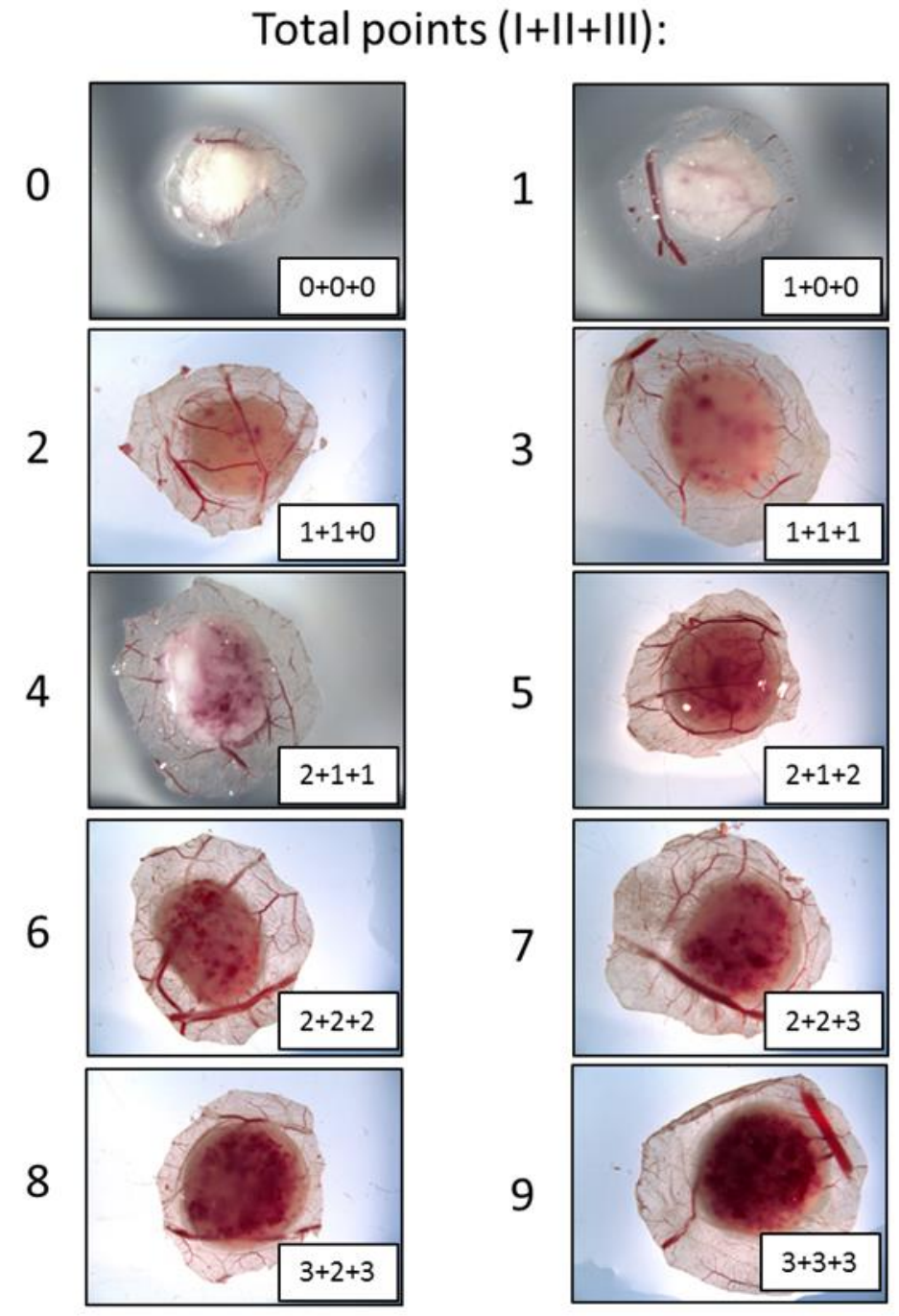

Figure 3: Examples of CAM tumours with their respective hemorrhage score.

\subsection{Protein biochemistry}

\subsubsection{Whole cell lysates and cell fractionation}

Cells were harvested, centrifuged at $300 \times \mathrm{g} / 5 \mathrm{~min} / 4^{\circ} \mathrm{C}$ and washed once with PBS.

For whole cell lysates cell pellets of $1 \times 10^{6}$ to $2 \times 10^{6}$ cells have been resuspended in $50 \mu \mathrm{l}$ or $100 \mu \mathrm{l} \mathrm{NP}-40$ lysis buffer respectively and incubated on ice for $30 \mathrm{~min}$. Subsequently, residual cell debris was lost by centrifuging cell suspensions at 
$14.000 \times \mathrm{g} / 15 \mathrm{~min} / 4^{\circ} \mathrm{C}$. Supernatants were transferred to new reaction tubes and total protein amount was measured using the RotiQuant assay and the Tecan Infinite F50 Reader.

Cell fractionation has been performed as described by Schreiber et al. (Schreiber et al, 1989). In short, cell pellets of $1 \times 10^{6}$ to $2 \times 10^{6}$ cells were resuspended in $400 \mu \mathrm{l}$ Nuclear Extract Buffer A and incubated on ice for $15 \mathrm{~min}$. Afterwards $25 \mu \mathrm{l}$ $10 \%$ NP-40 solution was added to each tube, mixed thoroughly and centrifuged at $13.000 \times \mathrm{g} / 5 \mathrm{~min} / 4^{\circ} \mathrm{C}$. The supernatant containing the cytosolic fraction was transferred to a new tube and the pellets were resuspended in each $50 \mu$ Nuclear Extract Buffer $B$ and shaken thoroughly for $25 \mathrm{~min}$ at $4^{\circ} \mathrm{C}$. After centrifugation at $13.000 \times \mathrm{g} / 5 \mathrm{~min} / 4^{\circ} \mathrm{C}$ the supernatant containing the nuclear fraction was transferred to a new tube and protein amount of both fractions was measured using the RotiQuant assay and the Tecan Infinite F50 Reader.

\subsubsection{SDS page and Western Blot}

Sodium dodecyl sulphate polyacrylamide gel electrophoresis (SDS-PAGE) was used for size-fractionation of the proteins (Laemmli, 1970). Polyacrylamide gels were composed of a $5 \%$ stacking gel and a $7.5 \%$ to $15 \%$ ranging separation gel (DVL: 7.5\%; RHOA: $15 \%$; cell fractions and knockdown controls: 10\%). For SDS page $15 \mu \mathrm{g}$ to $20 \mu \mathrm{g}$ of protein was mixed with $4 \mathrm{x}$ RotiLoad loading dye, denaturized at $95^{\circ} \mathrm{C}$ for $5 \mathrm{~min}$ and loaded onto the gel. Additionally, Rainbow Fullrange marker was used to determine protein sizes. The gel was run at $20 \mathrm{~mA}$ for approximately one hour. Then the stacking gel was separated from the separation gel and the separation gel, whatman papers and the methanol-activated PVDF membrane were equilibrated in transfer buffer. For the transfer the BioRad Tank Blot System was used with the following arrangement: Cathode (-); 2 whatman papers; polyacrylamide gel; PVDF membrane; 2 whatman papers; Anode (+). The transfer was conducted at $100 \mathrm{~V}$ for 1 hour at $4^{\circ} \mathrm{C}$. Blots were air-dried, rehydrated in TBS-T buffer and incubated in blocking buffer (5\% BSA or milk powder, $0.1 \%$ Tween in tris-buffered saline) at room temperature for one hour and afterwards 
incubated with primary antibody in the respective blocking buffer overnight at $4^{\circ} \mathrm{C}$. After washing blots were incubated with the respective peroxidase-coupled secondary antibody for 1 hour at room temperature. Enhanced chemiluminescence detection was used to visualize the immune reaction. Therefore, the membrane was incubated with chemiluminescence solution 1 and 2 in equal amounts for $1 \mathrm{~min}$ and afterwards proteins were detected using chemiluminescence camera LAS-4000 Image Reader. For reprobing with another antibody blots were incubated in Reblot Mild Plus Buffer at room temperature for $15 \mathrm{~min}$.

For WNT5A immunoblotting lysates have not been boiled for SDS page but transferred semi-dry onto a nitrocellulose membrane.

\subsubsection{Enzyme-linked immunosorbent assay (ELISA) of VEGFA}

To estimate the VEGFA level in the supernatant of $\mathrm{cHL}$ cells Human VEGF Quantikine ELISA Kit has been used. VEGFA ELISA has been performed with the indicated CMs of WNT5A-stimulated or siRNA transfected L428 and KM-H2 cells according to the manufacturer's instructions. The absorption of the samples has been detected at a wavelength of $450 \mathrm{~nm}$ (wavelength correction: $540 \mathrm{~nm}$ ) using the Tecan Infinite F50 microplate Reader.

\subsection{Molecular Biology}

\subsection{1 mRNA isolation}

Total RNA of cell pellets was isolated using the NucleoSpin RNA Kit according to the manufacturer's instructions. RNA was eluted in $40 \mu \mathrm{l}$ RNAse free water and the corresponding concentration has been determined using the NanoDrop. 


\subsubsection{Reverse transcription}

The Superscript II first-strand synthesis kit and random hexamer primers have been used for the reverse transcription of mRNA to cDNA. For the cDNA synthesis in each tube $1 \mu \mathrm{g}$ to $2 \mu \mathrm{g}$ mRNA have been mixed with RNAse free water to a final volume of $10 \mu \mathrm{l}$ and $2 \mu \mathrm{l}$ random hexamer primers $(100 \mu \mathrm{M})$ have been added. The mix has been incubated at $70^{\circ} \mathrm{C}$ for $10 \mathrm{~min}$ in a thermocycler. Subsequently, the tubes have been cooled on ice, $8 \mu$ master mix have been added to each tube and the complete mixtures have been incubated in a thermocycler with the programme shown in Table 14.

Table 14: Master mix and thermocycler programme for the reverse transcription

\begin{tabular}{|l|l|}
\hline Master mix & Thermocycler programme \\
\hline $4 \mu \mathrm{l}$ 5x First Strand Buffer & $42^{\circ} \mathrm{C} 60 \mathrm{~min}$ \\
\hline $2 \mu \mathrm{DTT}(0.1 \mathrm{M})$ & $65^{\circ} \mathrm{C} 10 \mathrm{~min}$ \\
\hline $1 \mu \mathrm{l}$ dNTPs $(10 \mathrm{mM}$ each) & $4^{\circ} \mathrm{C} \infty$ \\
\hline $1 \mu \mathrm{l}$ SuperScript RT II & \\
\hline
\end{tabular}

\subsubsection{Quantitative real-time polymerase chain reaction (qRT-PCR)}

For relative transcript quantification the fluorescent DNA binding dye SYBR Green has been applied. If SYBR Green binds double-stranded DNA, this complex of DNA and the SYBR Green dye will absorb blue light $\left(\lambda_{\max }=488 \mathrm{~nm}\right)$ and emit green light $\left(\lambda_{\max }=522 \mathrm{~nm}\right)$. Therefore, the increasing fluorescence is used to quantify the amount of transcripts over the PCR cycles which corresponds to the number of PCR cycles with an exponential increase of fluorescence (cycle threshold $=\mathrm{Ct}$-value). For the $\mathrm{PCR}$ reaction and the simultaneous fluorescence detection the ABI PRISM 7900HT sequence detection system and corresponding 384 well clear optical plates and SYBR Green mix (Table 4) was used. For each reaction $5.6 \mu \mathrm{l}$ SYBR Green mix, $0.3 \mathrm{pmol} / \mu \mathrm{l}$ of each primer and cDNA which correlates to $10 \mathrm{ng}$ mRNA has been mixed in a final volume of $10 \mu \mathrm{l}$. Each 
analysis has been performed in triplets. The corresponding qRT-PCR programme is shown in Table 15.

Table 15: qRT-PCR programme

\begin{tabular}{|l|l|}
\hline qRT-PCR step & \\
\hline $\begin{array}{l}\text { Initial Denaturation and activation of the } \\
\text { polymerase }\end{array}$ & $95^{\circ} \mathrm{C} / 15 \mathrm{~min}$ \\
\hline Denaturation & $95^{\circ} \mathrm{C} / 15 \mathrm{sec}$ \\
Elongation & $60^{\circ} \mathrm{C} / 1 \mathrm{~min} \quad(40$ cycles $)$ \\
\hline & $95^{\circ} \mathrm{C} / 15 \mathrm{sec}$ \\
Dissociation & $60^{\circ} \mathrm{C} / 15 \mathrm{sec}$ \\
& $95^{\circ} \mathrm{C} / 15 \mathrm{sec}$ \\
\hline Pause & $4^{\circ} \mathrm{C} / \infty$ \\
\hline
\end{tabular}

Gene expression was evaluated relative to $A B L$ using the SDS 2.4 and the $R Q$ Manager 1.2.1 software. Target gene transcript abundance was calculated using the $\Delta \mathrm{CT}$ method. Therefore, the actual Ct-values of genes of interest have been normalized to the Ct-values of $A B L$ :

$$
\Delta C T=C T_{\text {gene } \text { of interest }}-C T_{A B L}
$$

\subsection{NMR spectroscopy for the quantification of intracellular metabolites}

NMR spectroscopy analysis of L428 and KM-H2 pGIPZ cells has been performed by our cooperation partners from the Masaryk University (Brno; CZ). Michaela Krafčíková and Lukáš Trantírek performed NMR analysis and Petra Ovesná the corresponding cluster analysis.

Sample preparation: Acetonitrile extraction (Dietmair et al, 2010) was employed to quench cell metabolism and to quantitatively extract low molecular weight 
compounds from $\mathrm{HL}$ cell lines. Acetonitrile fraction was subjected to overnight lyophilisation. Dried extracts were resuspended in $550 \mu \mathrm{l}$ of $\mathrm{D}_{2} \mathrm{O}$ containing $0.005 \%$ sodium 3-(trimethylsilyl)propionate-2,2,3,3-d4 (TSP) as both chemical shift reference and internal standard for metabolite quantification.

NMR spectroscopy: Information on concentration of metabolites in individual samples was derived from volumes of corresponding signals in 1D $1 \mathrm{H}$ NMR spectrum. Assignment of signals in NMR spectra of individual samples to particular metabolite was achieved via comparison of a sample spectrum with spectra of pure metabolites. The 1D $1 \mathrm{H}$ spectra were measured at $700 \mathrm{MHz}$ using a Bruker Avance III NMR spectrometer equipped with a triple resonance room temperature probe using the WATERGATE pulse sequence (Piotto et al, 1992), including $1 \mathrm{~ms}$ rectangular selective pulses to suppress the residual signal of water. All spectra were acquired at $20^{\circ} \mathrm{C}$ and processed using TopSpin 3.2 (Bruker, USA). To compare the metabolite concentration profiles among various samples the signal intensities in individual samples were normalized to total protein concentration.

\subsection{Microarray data analyses}

Analysis of available microarray mRNA expression data was conducted using the Oncomine web platform (Rhodes et al, 2004). The Steidl Lymphoma, Brune Lymphoma and Basso Lymphoma datasets have been used (Steidl et al, 2010a; Brune et al, 2008; Basso et al, 2005). In the Steidl study $130 \mathrm{HL}$ samples were analysed using Human Genome U133 Plus 2.0 Array (19 574 genes, 54675 reporters). In the Brune study 42 malignant lymphoma samples and 25 normal B-cell samples of various types were analysed using as well the Human Genome U133 Plus 2.0 Array. In the Basso study 336 B-cell samples (normal, tumour, cell line, and cell line perturbation samples) were analysed using the Affymetrix U95Av2 Array (8,603 genes, 12,651 reporters). Data were analysed using GraphPad Prism 6.04 and with the friendly support of Pavlína Janovská (Faculty of Science, Institute of Experimental Biology, Masaryk University, Brno, CZ). 


\subsection{Statistics}

Results are shown as mean or as mean \pm standard deviation (mean \pm SD) of the indicated number of samples. The statistical significance of the values was determined using the Student's t-test. If applicable group results were compared using the ANOVA-method (One-way or Two-way Analysis of Variance) with a subsequent Bonferroni's post-hoc test to correct for multiple comparisons as indicated. Normal distribution and homogeneity of variance has been tested using the Kolmogorov-Smirnov Test and the F-test. For nonparametric group results Kruskal-Wallis test with Dunn's post-hoc test has been performed. Significance levels are indicated as ${ }^{*}=p<0.05,{ }^{* *}=p<0.01,{ }^{* * *}=p<0.001$. All statistical analyses and plots were done with GraphPad Prism 6.04. 


\section{Results}

The aim of this thesis was the analysis of the $\mathrm{cHL}$ cell motility and the interplay with endothelial cells regarding WNT signalling.

At first, the general migration rates of $\mathrm{CHL}$ cell lines in comparison to NHL cell lines and their particular characteristics were investigated. In this context the impact of WNT signalling on in vitro $\mathrm{cHL}$ cell migration and in vivo lymphoma engraftment were analysed using porcupine inhibitors. The WNT5A-mediated non-canonical WNT signalling on $\mathrm{CHL}$ cell motility was analysed in more detail. The WNT5A signalling cascade was dissected regarding the involved FZD receptor, DVL adaptor protein and the small GTPase protein RHOA. In addition, the activation status and impact of canonical WNT signalling was investigated. Therefore, inhibitors of canonical pathway members were applied and knockdowns of LEF-1 and $\beta$-catenin were performed for migration and invasion assays. Most of these data are to be published in (Linke et al, 2016a, 2016b).

Finally, the last part focuses on the interplay with endothelial cells using angiogenesis assays. Therefore, the supernatant of $\mathrm{cHL}$ cells were used to evaluate the influence of $\mathrm{cHL}$ cells on endothelial cells regarding sprouting, tube formation and in vivo lymphoma engraftment. Most of these data are also to be published in (Linke et al, 2016a, 2016b).

\section{$3.1 \mathrm{cHL}$ cell lines migrate with high rates and depend on autocrine WNTs}

At first, the migration rates of different lymphoma entities were compared in Boyden chamber assays. Since the high migration potential of CLL and MCL cells was shown previously (Xargay-Torrent et al, 2013; Kaucká et al, 2013), the question emerged how effective $\mathrm{CHL}$ cells migrate compared to $\mathrm{CLL}$ and $\mathrm{MCL}$ cells. Moreover, so far there is no quantitative comparison for $B L$ and DLBCL cells available. Therefore, NHL cell lines including MCL cell lines related to small-cell B- 
cell lymphomas such as CLL, as well as BL and DLBCL cell lines belonging to initially localized lymphoma were tested in Boyden chamber assays. Figure 4 shows the results of the migration experiments performed with $\mathrm{cHL}$ and MCL cells using membranes with $8 \mu \mathrm{m}$ pores for 6 hours. For BL and DLBCL cells the membrane pore size as well as the migration time had to be extended to $10 \mu \mathrm{m}$ pore size and 16 hours migration time to yield evaluable migration rates. The $\mathrm{cHL}$ cell lines L428, KM-H2 and L1236 showed the highest migration rates with at least 12 to 20 fold enhanced migration towards the chemoattractant compared to pure RPMI medium. Interestingly, MCLs migrated efficiently as expected but with approximately almost half the rates compared to $\mathrm{cHL}$ cells. In contrast, only little enhanced migration rates towards the chemoattractant were detected for $\mathrm{BL}$ and DLBCL cells despite the simplified migration conditions. Consequently, these remarkable migration rates of $\mathrm{cHL}$ cells prompted us to investigate the $\mathrm{cHL}$ cell movements in greater detail and the underlying signalling mechanism.

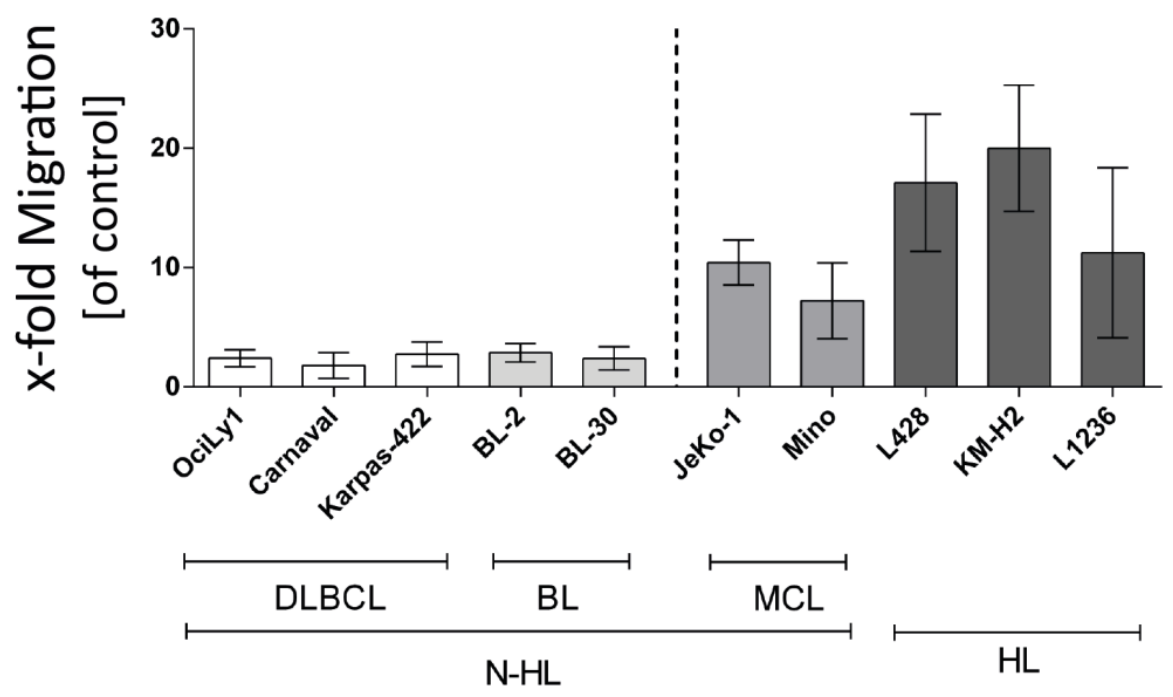

Figure 4: Hodgkin Lymphoma cell lines L428, KM-H2 and L1236 migrate with higher rates compared to several NHL cell lines. Migration of $\mathrm{HL}$ cell lines and $\mathrm{NHL}$ cell lines were measured in Boyden chamber assays (mean $\pm S D, n=3$; DLBCL, $B L$ : $16 \mathrm{~h}$ migration through $10 \mu \mathrm{m}$ pores; $\mathrm{MCL}, \mathrm{HL}$ : $6 \mathrm{~h}$ migration through $8 \mu \mathrm{m}$ pores). Note the high migration rates of $\mathrm{MCL}$ and $\mathrm{HL}$ cell lines. From (Linke et al, 2016b). 


\subsection{1 cHL cells migrate in an amoeboid manner with special characteristics}

Since the above used assay for migration only measures endpoints of complex and very dynamic processes, time-lapse microscopy was applied to characterize $\mathrm{cHL}$ cell motility within a chemotactic gradient in greater detail and on single cell level. In 3D chemotaxis chambers L428 cells were completely embedded in type-I-collagen and their movements were monitored. L428 cells moved in an amoeboid way, which is composed of blebbing, polarization, deformation and translocation events (Figure 5). In detail, the cell started turning around quickly thereby forming short and long blebs in all directions as an initial part of movement. Then the cell appeared to concentrate with its cell body to a concrete point and formed a long and stretched constriction ring (barbell-like form). While the constriction ring formation appeared to require several minutes, the cell slipped forwards very fast from a particular point on and started blebbing again.
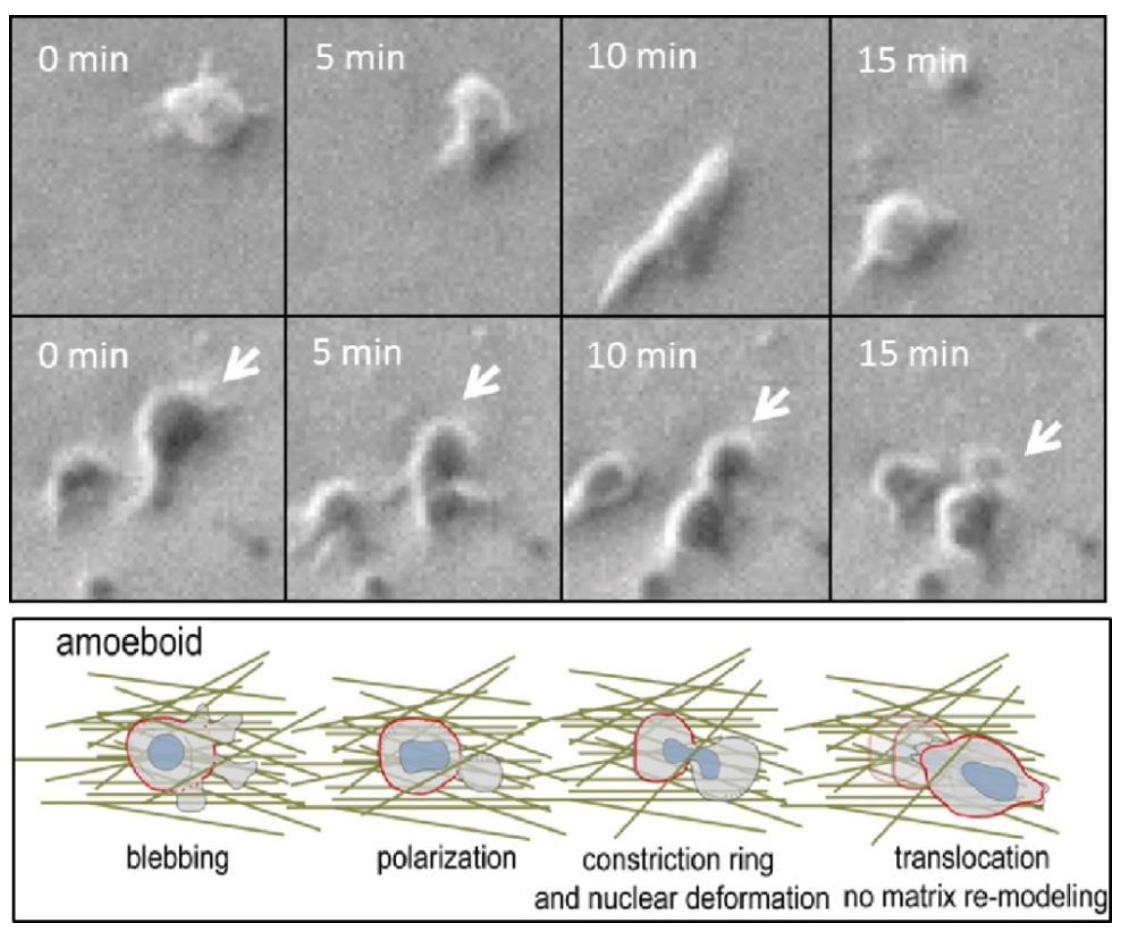

Figure 5: $\mathrm{cHL}$ cells move with an amoeboid type of migration. Typical amoeboid type of migration of L428 cells is shown with two exemplary cells. Pictures were taken at 5 min intervals. Lower row: Schematic representation of the migration process consisting of blebbing, polarization, constriction ring formation and translocation (courtesy of Dr. Aldo Ferrari, ETH, Zurich) as introduced by (Friedl et al, 2001; Friedl \& Wolf, 2003b). From (Linke et al, 2016b). 
The observation of $\mathrm{cHL}$ single cell movements in connection with surrounding cells revealed additional characteristics. L428 cells seemed to be influenced by each other in their migration steps. For example, one initially non-moving cell (Figure 6 A-G, black arrow) started moving towards another cell (white asterisk) in the moment this cell appeared in its z-axis (Figure $6 \mathrm{H}$ ). But cHL cells did not only appear to be attracted by each other, also cell-cell contacts seem to characterize their sequence of movements. One exemplary cell was frequently in close contact with surrounding cells before finally moving away (Figure 6 C-D, F-G, J, P; white arrow). Thus, mutual attraction and cell-cell contacts seem to be general characteristics of $\mathrm{cHL}$ cell movements and can be observed in all supplementary videos of control cells (Appendix; Supplementary Videos 1 and 5). 


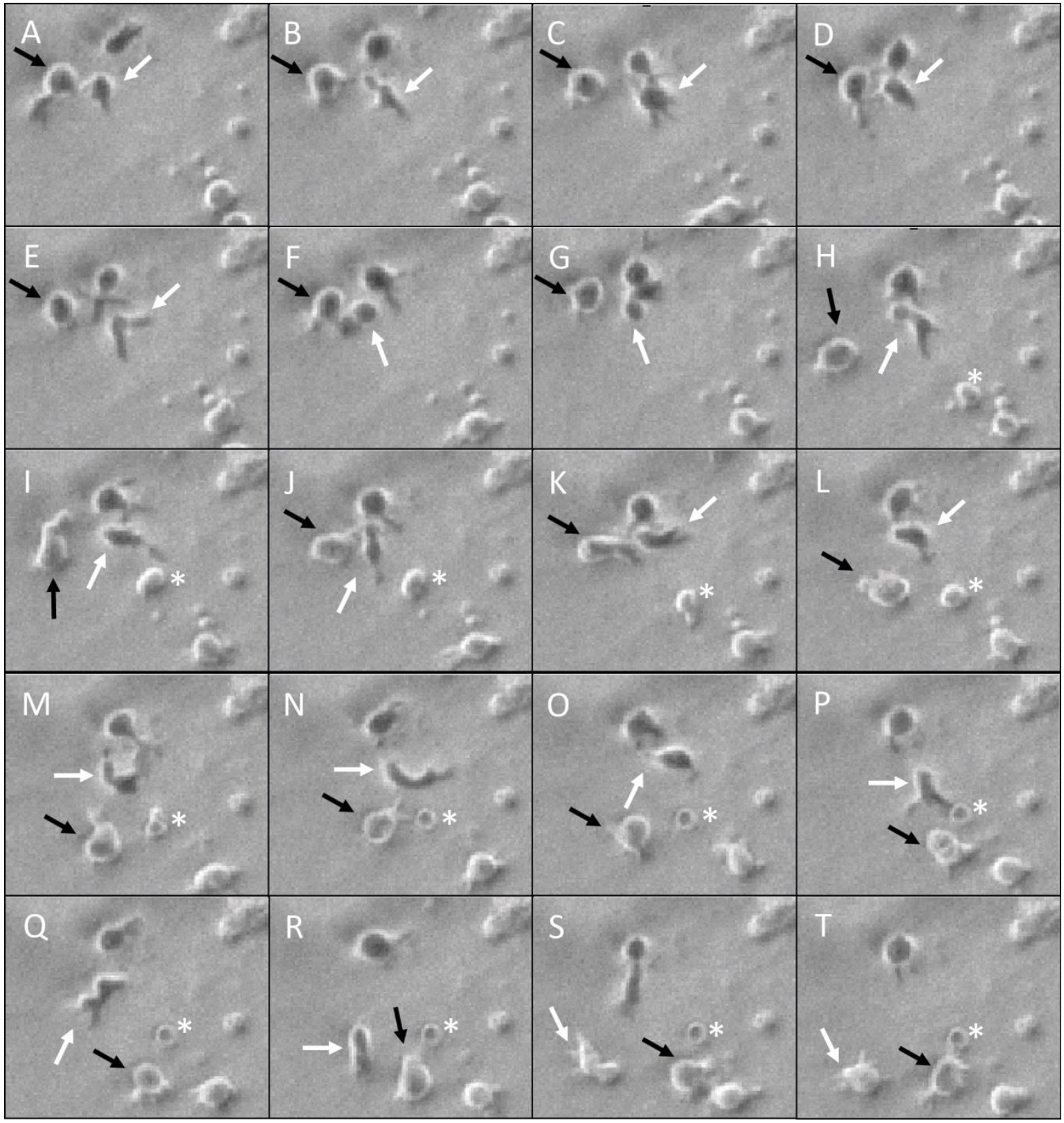

Figure 6: Movements of $\mathrm{cHL}$ cells seem to be characterized by cell-cell contacts with neighbouring cells. Time-lapse microscopy of exemplary L428 cells over $230 \mathrm{~min}(\mathrm{~A}-\mathrm{T})$ revealed a typical behaviour of $\mathrm{cHL}$ cells. The marked cell (white arrow) continually contacts surrounding cells (e.g. in C, F, G, J) before moving ahead. One cell (white asterisk) moves into the frame (from $\mathrm{H}$ on) but starts leaving the frame in the $\mathrm{z}$-axis direction from frame $\mathrm{M}$ on. The appearance of this cell (white asterisk) seems to initiate movements of another cell (black arrow) to that direction. 


\subsubsection{Inhibition of WNT ligand secretion reduces $\mathrm{cHL}$ cell migration, invasion and adhesion}

In order to analyse whether the observed high migration rates of $\mathrm{CHL}$ cells are associated with the WNT pathway the porcupine inhibitors, Wnt-C59 and IWP-2, were each applied to L428, KM-H2 and L1236 cells. Wnt-C59 as well as IWP-2 block the palmitoylation of WNT ligands thus preventing their secretion and therefore autocrine signalling cascades (Proffitt \& Virshup, 2012; Proffitt et al, 2013).

The migration rates of all three Wnt-C59- or IWP-2-treated $\mathrm{cHL}$ cell lines were at least reduced by up to $50 \%$ compared to DMSO controls (Figure 7 A-F). By adding conditioned medium (CM) of untreated $\mathrm{CHL}$ cells the effects of porcupine inhibition were rescued. The $\mathrm{cHL}$ cells that were treated with both, the porcupine inhibitor and their respective $\mathrm{CM}$, migrated with similar rates as the DMSO-treated or untreated cells (Figure $7 \mathrm{~A}-\mathrm{F}$ ).

To exclude potential effects of the Wnt-C59 treatment on $\mathrm{cHL}$ cell viability and cell proliferation, MTT assays and cell doubling counting were performed. In contrast to the strong effect on cell migration Wnt-C59 and IWP-2 had no significant influence on cHL cell viability and proliferation with the applied concentrations (Figure 8 A-E). 
A

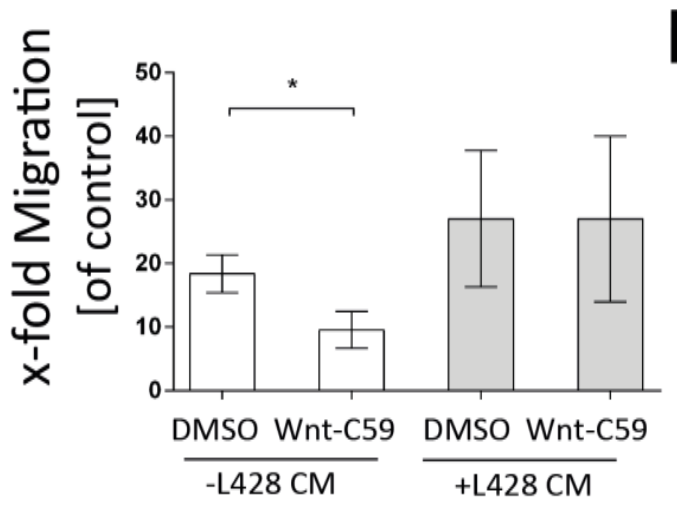

B

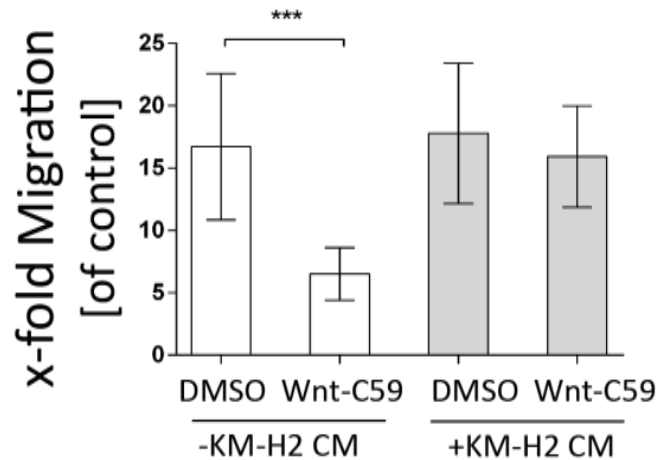

C

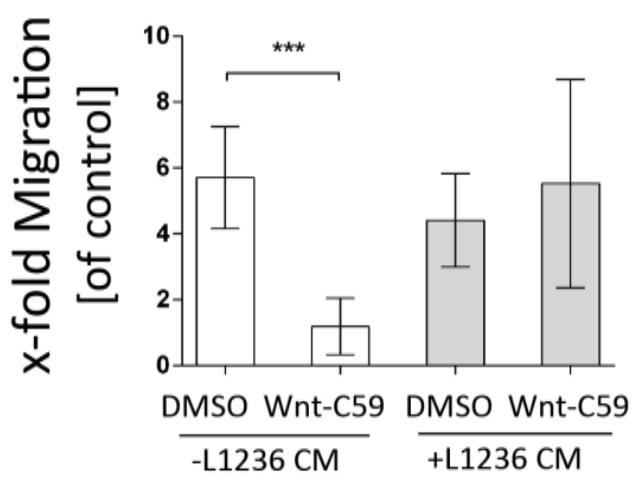

$\mathrm{D}$

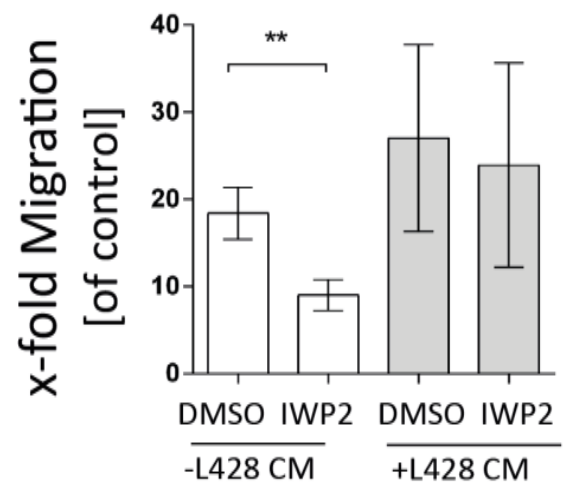

E

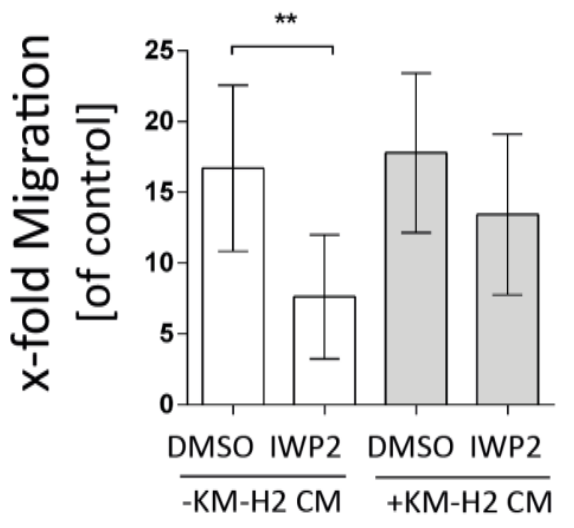

$\mathrm{F}$

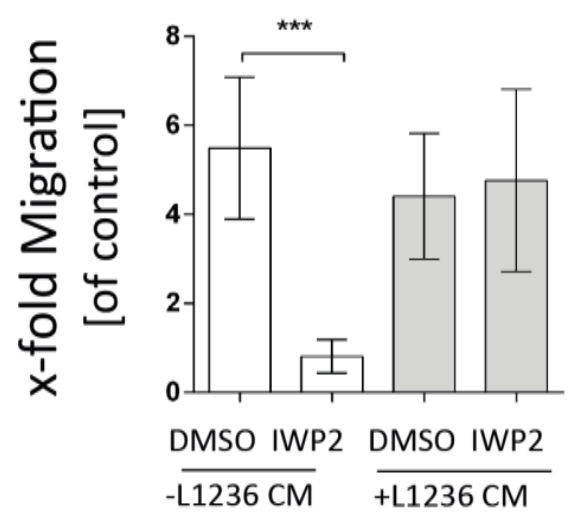

Figure 7: Migration of $\mathrm{cHL}$ cell lines depends on intact WNT ligand secretion. Migration of L428 (A), KM-H2 (B) and L1236 (C) cells after $72 \mathrm{~h}$ pre-treatment with $5 \mu \mathrm{M}$ Wnt-C59 or DMSO is shown with $(+C M)$ or without $(-C M)$ the simultaneous stimulation with the respective cHL-conditioned medium for $24 \mathrm{~h}$. Migration of L428 (D), KM-H2 (E) and L1236 (F) cells after $72 \mathrm{~h}$ pre-treatment with $5 \mu \mathrm{M}$ IWP-2 or DMSO is presented with or without the simultaneous stimulation with the respective $\mathrm{CHL}$-conditioned medium for $24 \mathrm{~h}$. (mean $\pm \mathrm{SD}, \mathrm{n}=3,1$-way ANOVA and Dunn's post-hoc test). Note that the inhibition of migration by porcupine inhibitors is rescued by CM addition $\left({ }^{*} P<0.05,{ }^{* *} P<0.01\right.$ and $\left.{ }^{* *} P<0.001\right)$. Modified from (Linke et al, 2016b). 

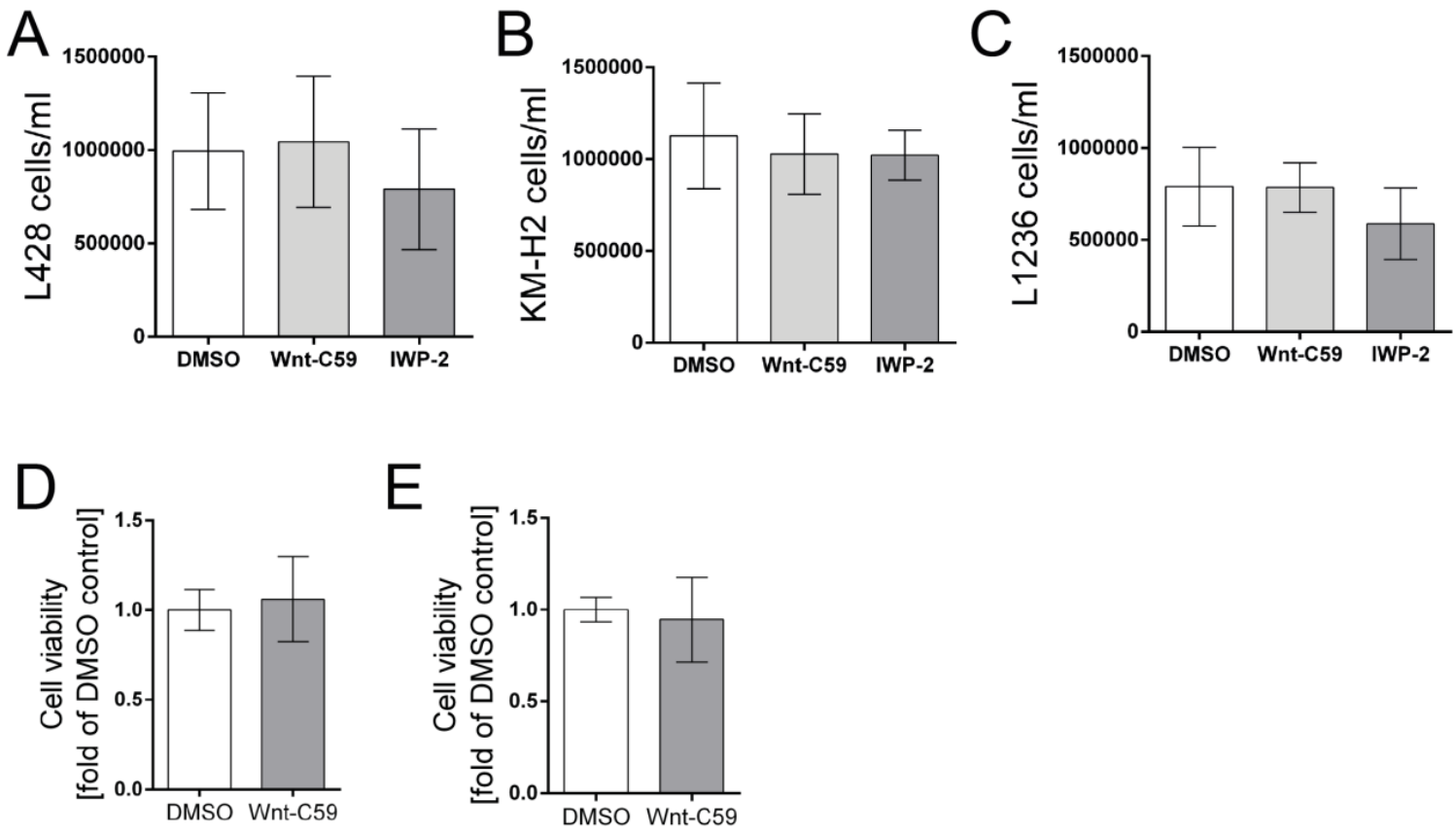

Figure 8: Porcupine inhibition does not significantly affect L428, KM-H2 and L1236 cell proliferation. Cell numbers of L428 (A), KM-H2 (B) and L1236 (C) cells are displayed after treatment with $5 \mu \mathrm{M}$ Wnt-C59 or $5 \mu \mathrm{M}$ IWP-2 for 72 hours. (mean \pm SD, $\mathrm{n}=10$ (L428; Wnt-C59 $p>0.99$, IWP-2 $p=0.723), n=8$ (KM-H2, Wnt-C59 p=0.855, IWP-2 p>0.99), $n=3$ (L1236, Wnt-C59 $\mathrm{p}>0.99$, IWP-2 $\mathrm{p}=0.455$ ), 1 -way ANOVA and Bonferroni's post-hoc test). MTT data of L428 (D) and $\mathrm{KM}-\mathrm{H} 2$ (E) cells is shown after treatment with $5 \mu \mathrm{M}$ Wnt-C59 for 72 hours. OD values of DMSO control were set as 1 (mean $\pm S D, n=4$ (L428; $p=0.4795), n=5(K M-H 2, p=0.2746)$, unpaired 2-tailed t-test with Welch's correction). Modified from (Linke et al, 2016b).

Moreover, invasion of $\mathrm{L} 428$ and $\mathrm{KM}-\mathrm{H} 2$ cells was measured after Wnt-C59 treatment (Figure 9 A). Invasion rates through type-I-collagen significantly decreased to $50 \%$ by porcupine inhibition. Since the adhesion capacity is an additional part of the whole invasion process adhesion of Wnt-C59-pre-treated L428 cells on endothelial cells as well as on type-I-collagen were also analysed (Figure 9 B). The amount of adherent cells on endothelial cells dropped to $30 \%$ following Wnt-C59 treatment and to $40 \%$ on type-I-collagen. These results indicate that $\mathrm{CHL}$ cells secrete WNT ligands in a porcupine dependent manner and these WNT ligands function in an autocrine way to stimulate cHL cell migration, invasion, and are also involved in adhesion processes. 


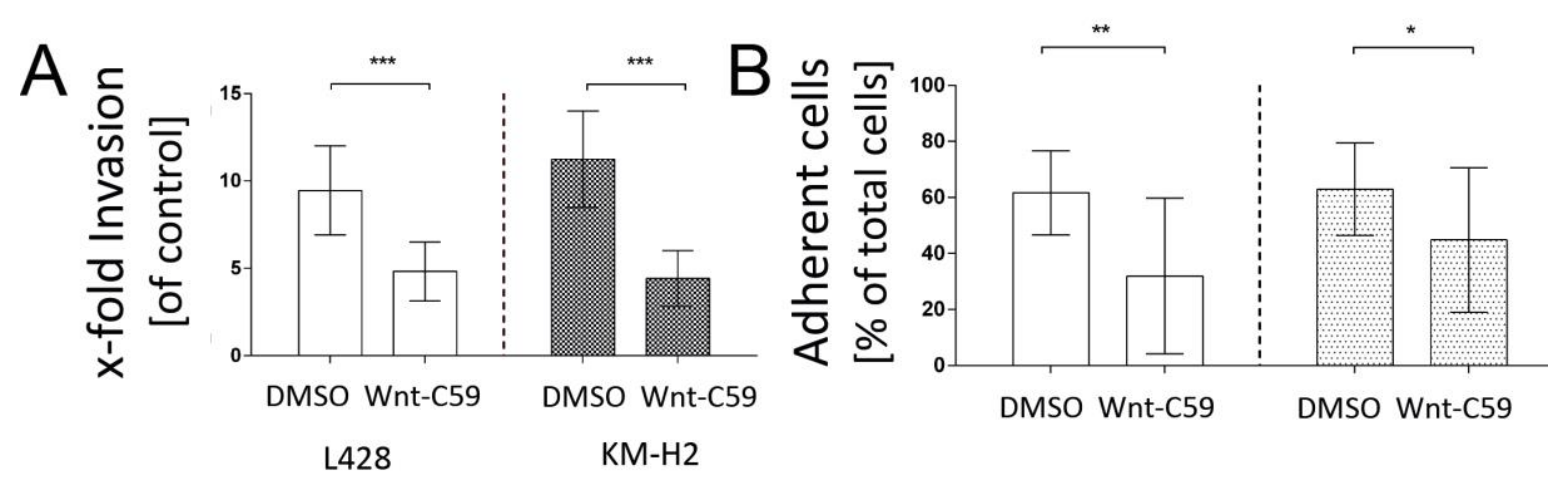

Figure 9: Invasion and adherence capacity of $\mathrm{cHL}$ cells is impaired after porcupine inhibition. (A) Invasion of $\mathrm{L} 428$ or $\mathrm{KM}-\mathrm{H} 2$ cells is presented after $72 \mathrm{~h}$ pre-treatment with $5 \mu \mathrm{M}$ Wnt-C59 or DMSO (mean \pm SD, $n=32$-way ANOVA and Bonferroni's post-hoc test). (B) Adhesion of DMSO or Wnt-C59-pre-treated L428 cells is shown on either HUVEC (white) or type-I-collagen (grey) (mean $\pm \mathrm{SD}, \mathrm{n}=5$, 2-way ANOVA and Bonferroni's post-hoc test). Note the decrease of cell invasion and adhesion after WNT secretion inhibition $\left({ }^{*} P<0.05,{ }^{* *} P<0.01\right.$ and $\left.{ }^{* * *} P<0.001\right)$. From (Linke et al, 2016b).

\subsubsection{Intervention of JAK/STAT, MAPK or NF-KB signalling does not perturb cHL cell migration}

To further evaluate the specificity of WNT signalling for $\mathrm{cHL}$ cell migration in comparison with other deregulated pathways of $\mathrm{cHL}$ cells, various chemical inhibitors or siRNAs were applied. The NF-KB, JAK/STAT and MAPK pathway were blocked at different levels. For the NF-KB pathway an IKK2 inhibitor (ACHP) was used and also IKK1 knockdown was performed. In addition, STAT3 was knocked down to test for the JAK/STAT pathway and, correspondingly, p38 knockdown was performed to test for MAPK signalling. None of these interventions showed any effect on L428 cell migration (Figure 10) suggesting that WNT signalling is a highly specific regulator of $\mathrm{CHL}$ cell migration. 


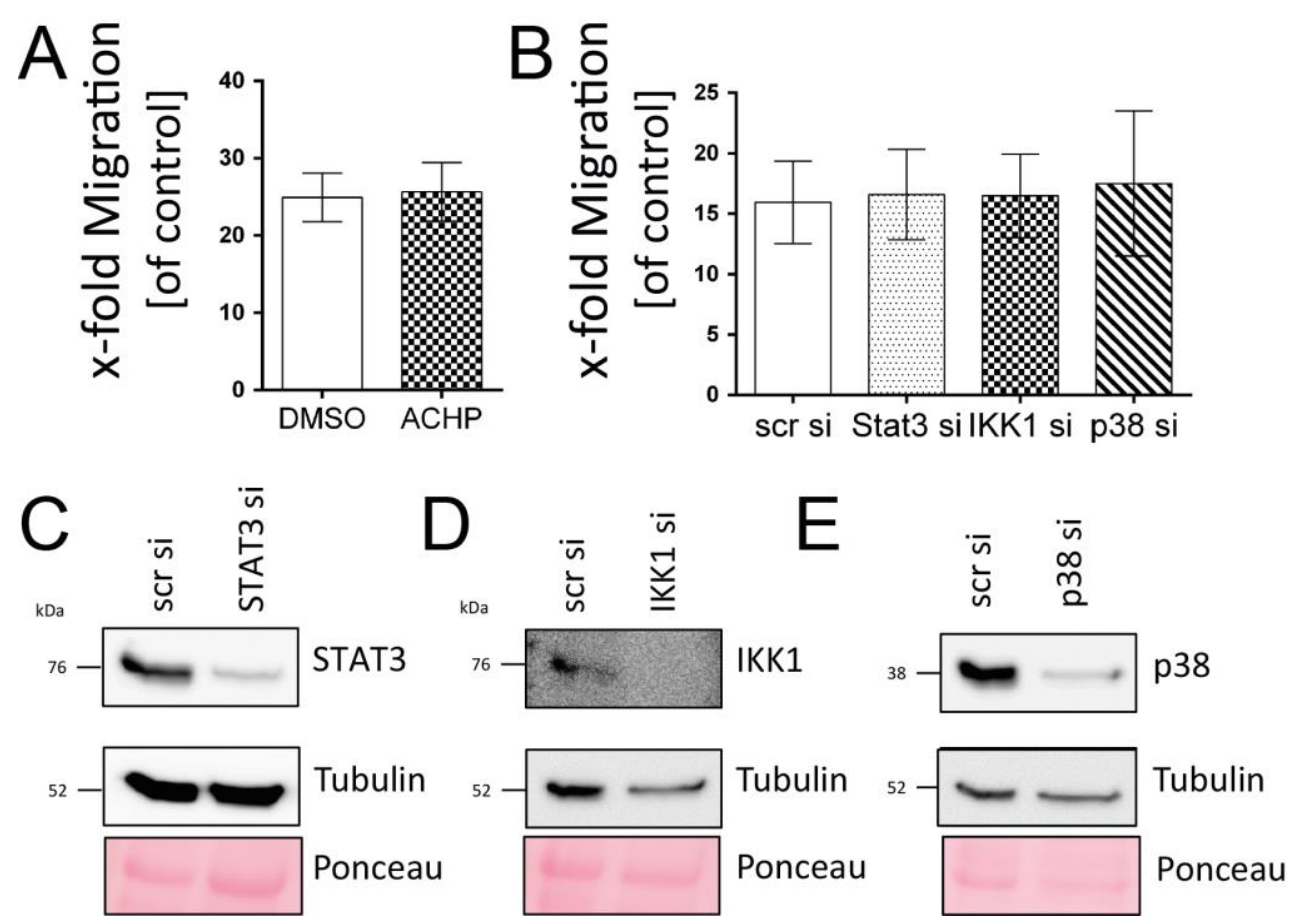

Figure 10: Migration of L428 cells does not depend on NF-KB, JAK/STAT or MAPK signalling. (A) L428 migration was performed after 24 hours of treatment with $7 \mu \mathrm{M}$ IKK2 inhibitor ACHP and 48 hours after IKK1, STAT3 or p38 (B) knockdown (mean \pm SD, $n=3$, One-way ANOVA and Bonferroni's post-test). Knockdown of STAT3 (C), IKK1 (D) and p38 (E) was evaluated with immunoblot assays using specific antibodies against STAT3 (C), IKK1 (D) or p38 (E) respectively. As loading control a specific antibody against tubulin was used (C-E). From (Linke et al, 2016b).

\subsubsection{Inhibition of the WNT ligand secretion impairs lymphoma outcome and vascularization in the in vivo CAM assay}

To test whether inhibition of Porcupine and consequently inhibition of autocrine WNT signalling affects not only migration and invasion of $\mathrm{cHL}$ cells in vitro but also $\mathrm{CHL}$ tumour outcome in vivo, the chick chorio-allantoic membrane (CAM) assay was applied as xenograft model. Wnt-C59-pre-treated L428 cells were inoculated on the CAM and four days later corresponding lymphomas were harvested. Lymphomas from L428 cells pre-treated with Wnt-C59 were significantly smaller compared to DMSO-pre-treated cells (Figure $11 \mathrm{~A}$ ). To quantify lymphoma vascularization at the macroscopic level a vascularization score was established taking into account the appearance, intensity and relative area covered by the hemorrhage areas (Scoring hemorrhages in CAM tumours in chapter 2.12.16.4). 
Based on this score the lymphomas developed from porcupine inhibitor-pretreated $\mathrm{cHL}$ cells were characterized by a lower degree of vascularization (Figure $11 \mathrm{~B})$.
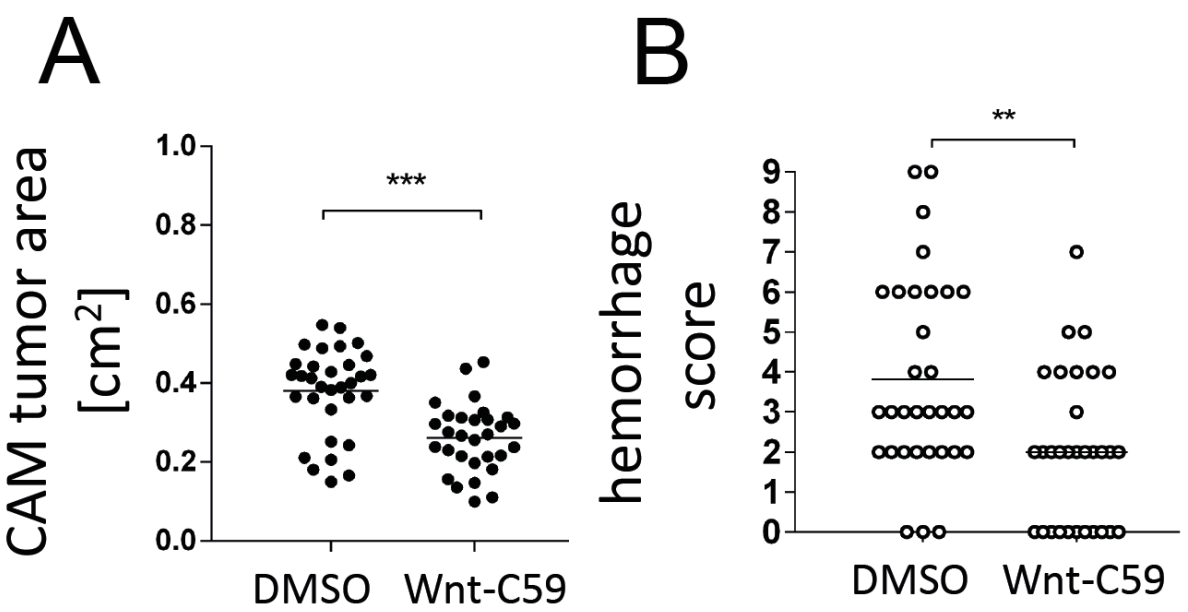

Figure 11: Treatment with porcupine inhibitors affects tumour size and hemorrhage scores in a chick CAM model. Tumour areas (A) of L428 tumours were measured and their corresponding hemorrhage scores (B) determined after three days of Wnt-C59 pre-treatment followed by four days of tumour growth on the CAM. Note the reduced tumour size and hemorrhages after porcupine inhibition. Exemplary tumour pictures are presented in Figure 12 und examples for the hemorrhage score in chapter 2.12.16.4 (DMSO, n=32; Wnt-C59, n=30; 2-way ANOVA and Bonferroni's post-hoc test) $\left({ }^{* *} P<0.01\right.$ and $\left.{ }^{* *} P<0.001\right)$. From (Linke et al, 2016b).

In Figure 12 typical lymphomas derived from DMSO (A) or Wnt-C59 (B)-pre-treated L428 cells are presented, using $2 \times 10^{6}$ cells for inoculation. The H\&E staining's of these tumours (Figure 12 A-B) support the macroscopic observation of smaller tumour size and differences in vascularization. Bleeding, that was regularly observed in control tumours, was reduced in WntC59-pre-treated tumours. For detailed microscopic analysis ultra-thin sections were performed. As shown in Figure 12 C-D, DMSO control tumours showed massive signs of bleeding (asterisk) but still contained some perfused capillaries (red arrows). Wnt-C59-treated tumours contained low numbers of capillaries and, although vessels showed signs of disintegration (black arrow), hemorrhage was rarely visible.

In addition to the classical analysis of morphology selected lymphoma were analysed by Micro-CT. In Figure $\mathbf{1 3}$ corresponding examples of DMSO or 
Wnt-C59 pre-treated L428 lymphoma are shown. Both developed in close proximity to major vessels from the CAM. The CT scan revealed the existence of vessels with numerous branches in the DMSO controls (inlet Figure 3-10 A). Signs of vessel residuals as cause for large bleeding areas are indicated with black arrows. The Wnt-C59-pre-treated tumour showed no dominant branches although much smaller vessels were visible (inlet Figure 3-10 B). Micro-CT technique provides the view on many different virtual section planes thus visualizing vessel structures and their origin that would have been hardly to interpret with classical histology. Using H\&E staining, ultra-thin sections and Micro-CT scans it can be concluded that autocrine WNT signalling is involved in lymphoma engraftment, affects lymphoma vascularization and suggests an additional paracrine WNT effect in cHLs.
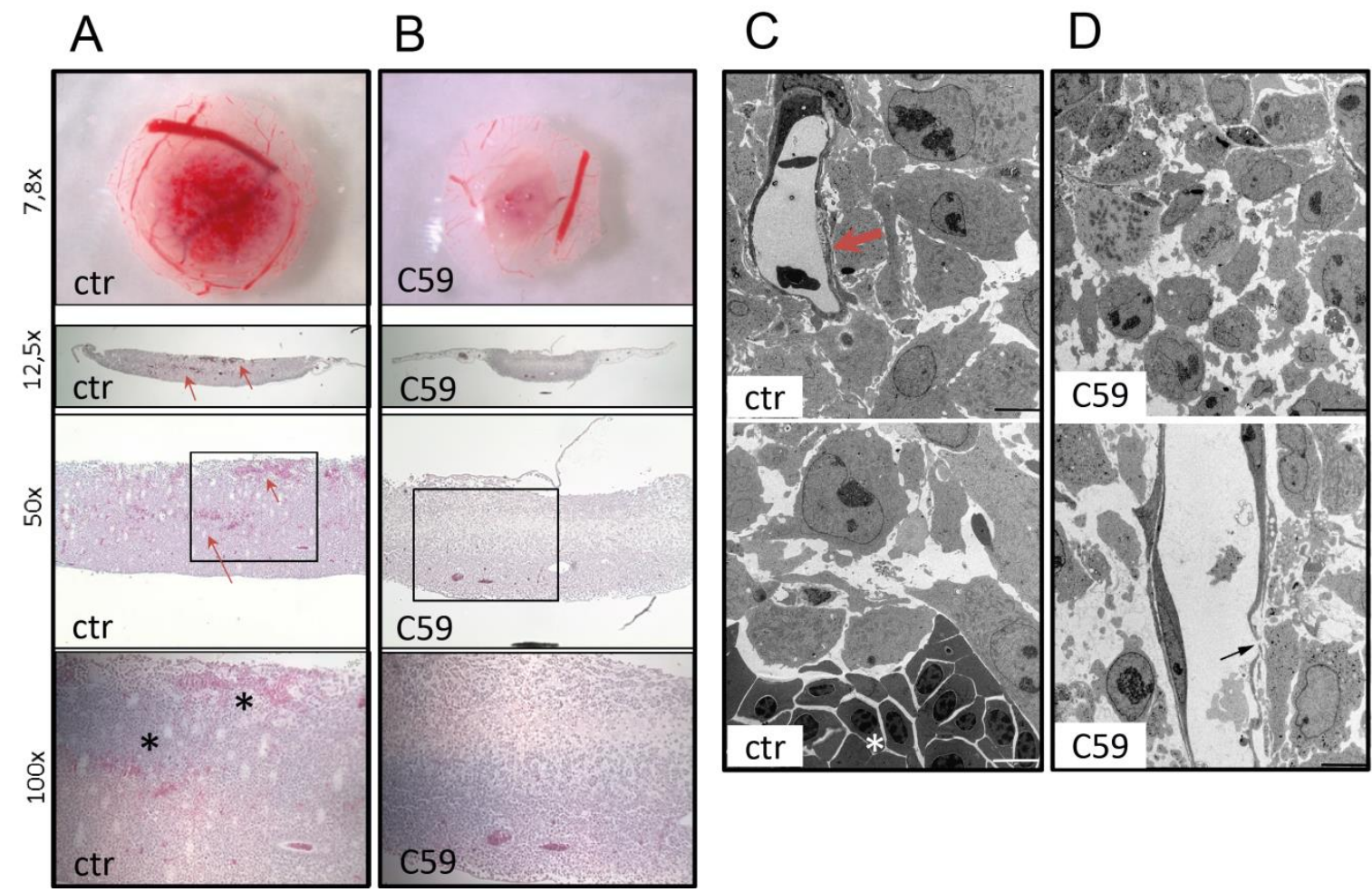

Figure 12: Porcupine inhibitor-treated CAM tumours show less hemorrhages. $(A, B)$ Representative stereo-microscopic (7.8 x magnification) and H\&E stained pictures of L428 tumours and $(\mathbf{C}, \mathbf{D})$ ultra-thin sections (bar= $5 \mu \mathrm{m}$ ) of KM-H2 cells treated with DMSO (A, C; ctr) or Wnt-C59 (B, D; C59) are shown. Note strong bleedings (asterisk) and increased vessel numbers (red arrow) of control tumours and fragile vessels (black arrow) after porcupine inhibition. Modified from (Linke et al, 2016b). 


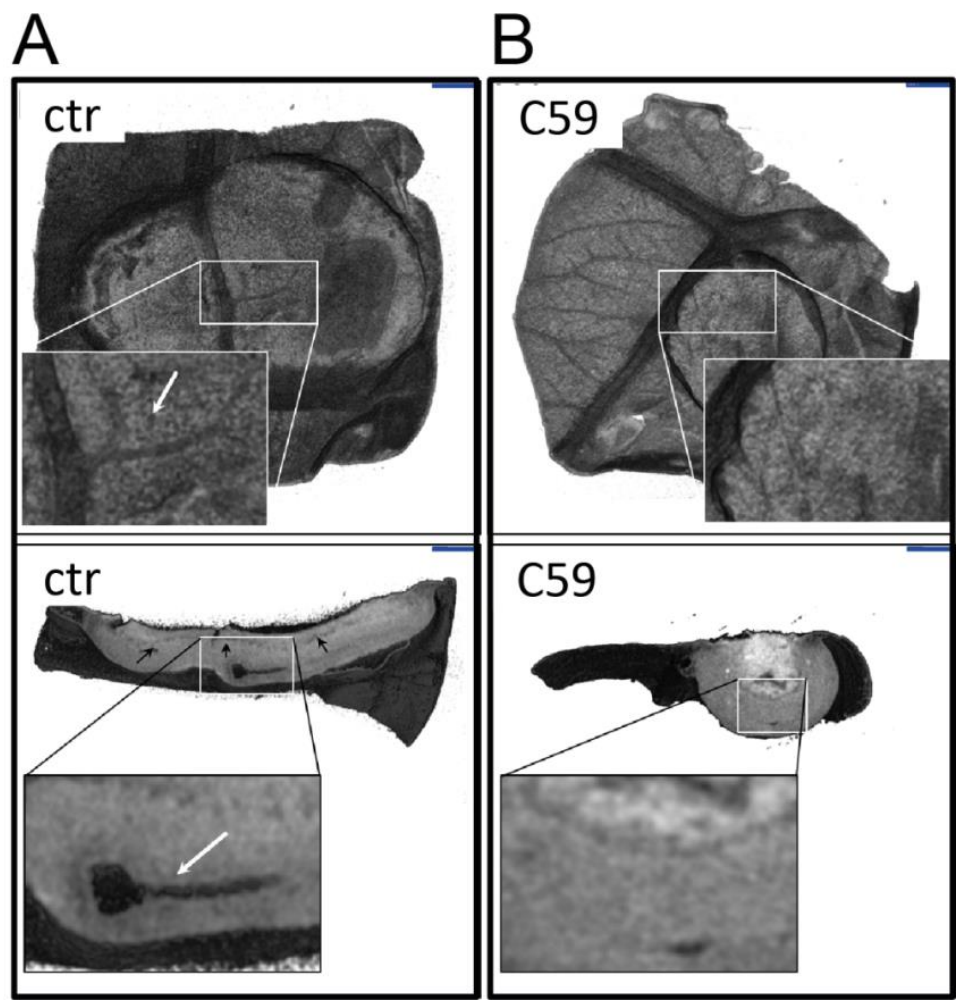

Figure 13: Porcupine inhibitor-treated CAM tumours contain less vessel structures. Micro-CT photos of selected L428 tumours that were treated with DMSO (A; ctr) or Wnt-C59 (B; C59) are displayed. The white arrow points at a tumour-vessel which branches off a major CAM vessel in a control tumour. Black arrows show at vessel residuals in the control tumour (bar= $1 \mathrm{~mm}$ ). From (Linke et al, 2016b).

\subsubsection{WNT5A and WNT10B are expressed by cHL cells}

Since porcupine inhibition caused significantly reduced $\mathrm{cHL}$ migration rates (see chapter 3.1.1), the expression level of several WNT ligands that have already been correlated with an enhanced cell motility were tested (Qiang et al, 2005; Weeraratna et al, 2002; Long et al, 2015; Aprelikova et al, 2013). Therefore, the expression of WNT3A, WNT5A, WNT10A, WNT10B and WNT16 was analysed by qRT-PCR (Figure 14 A). L428 and KM-H2 cells expressed WNT5A and WNT10B, whereas WNT3A, WNT10A and WNT16 were not found. In addition, the amount of WNT5A was estimated by immunoblot assays as presented in Figure 14 B. WNT5A protein was detected in all tested HL cell lines with L1236 cells expressing the highest amounts. 

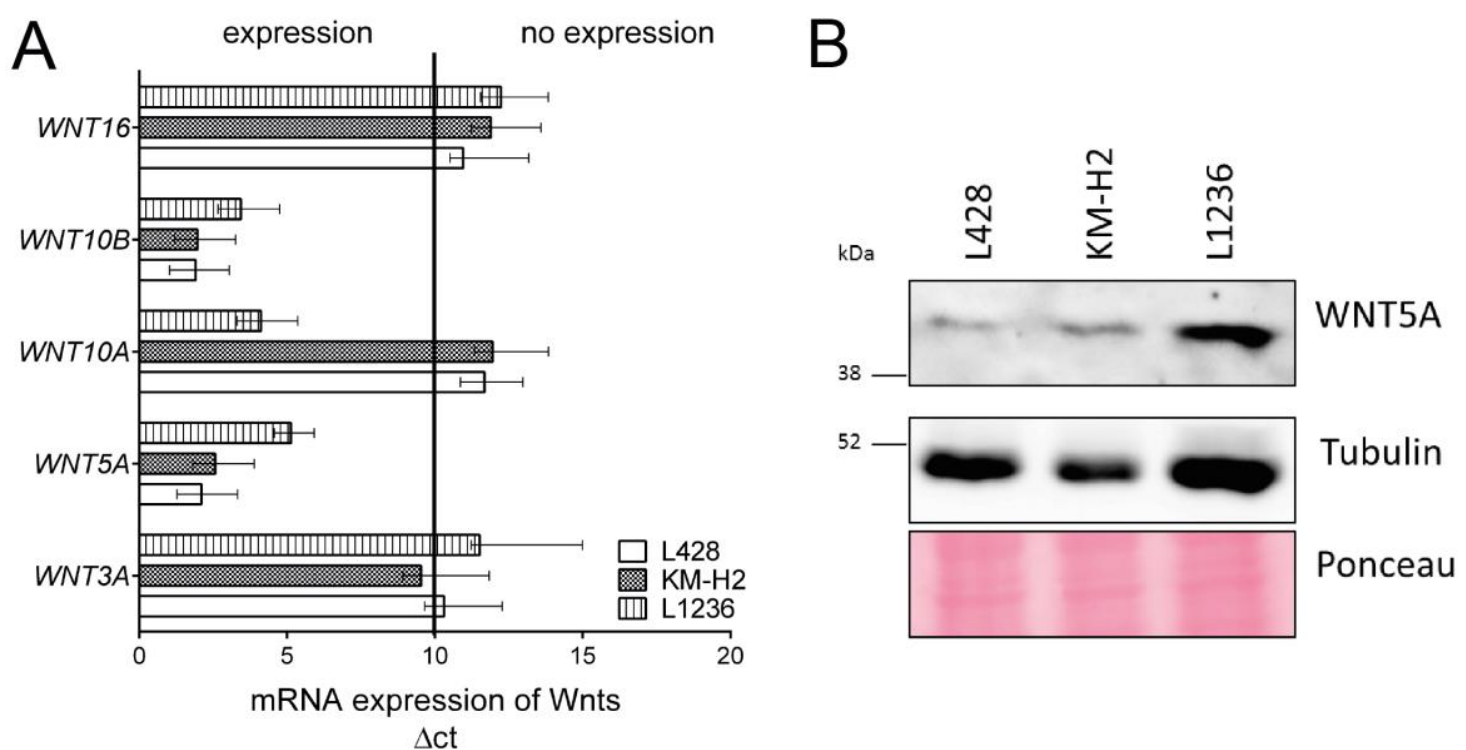

Figure 14: WNT5A is expressed in cHL cell lines on mRNA and protein level. (A) Relative WNT3A, WNT5A, WNT1OA, WNT10B and WNT16 gene expression of L428, KM-H2 and L1236 cells were measured by SYBRGreen qRT-PCR (mean \pm errors, $\mathrm{n}=3$, endogenous control: $A B L$ ). Note the high WNT5A and WNT10B expression in all three cell lines. (B) Western Blot reveals WNT5A protein expression in CHL cell lines using a specific antibody against WNT5A and against tubulin as loading control. From (Linke et al, 2016b).

\subsubsection{WNT5A signalling mediates migration and invasion in Hodgkin Lymphoma}

In order to identify migration-stimulating WNTs L428 cells were transfected with WNT-V5tag-containing pCDNA plasmids and subsequently their migration rates were determined. WNT5A, WNT10A, WNT10B and WNT16 were overexpressed in L428 cells. WNT5A overexpression increased L428 cell migration significantly by up to $50 \%$ compared to vector controls (Figure $15 \mathrm{~A}$ ). The overexpression of other migration-affecting WNTs like WNT10A, WNT10B and WNT16 had no effect on L428 migration (Figure $15 \mathrm{~A}$ ). This highlights the dominant role of WNT5A for $\mathrm{cHL}$ migration.

As proof-of-principle and to further confirm the special role of WNT5A for cHL cell motility, porcupine inhibitor-treated L428 cells were stimulated simultaneously with WNT5A L-cell-conditioned medium (WNT5A L-CM) in comparison to wildtype Lcell-conditioned medium (L-CM) (Figure 15 B). WNT5A L-CM alone increased 
L428 cell migration by approximately $75 \%$. The addition of WNT5A L-CM reversed the porcupine inhibitor-mediated inhibition of $\mathrm{cHL}$ cell migration significantly from $30 \%$ back to almost $80 \%$ of the controls. Consequently WNT5A can account for a major part of the porcupine-inhibitor rescue effect observed in Figure 7 albeit the rescue by the $\mathrm{cHL}$ conditioned medium was even stronger.

As additional approach the WNT5A antagonist Box5 was used in $\mathrm{CHL}$ Boyden chamber assays. The treatment with Box5 reduced migration of $\mathrm{L} 428, \mathrm{KM}-\mathrm{H} 2$ and L1236 cells by 25 to $50 \%$ (Figure 15 C-E). Since porcupine inhibition did not only affect migration but also invasion and adhesion of $\mathrm{cHL}$ cells, additional invasion and adhesion assays were performed using Box5-pre-treated cells. Box5 treatment reduced the invasion rates of $L 428$ cells to $50 \%$, whereas exogenous recombinant WNT5A further increased invasiveness by 30-60\% (Figure 16 A). In addition, the specific WNT5A effect on the adhesion of L428 cells on endothelial cells (HUVEC) as well as type-I-collagen was tested with Box5. The fraction of adherent cells significantly decreased from $70 \%$ to $40-30 \%$ on HUVEC and to $50 \%$ on type-I-collagen when L428 cells were pre-treated with the WNT5A antagonist Box5 (Figure 16 B). These data suggest that WNT5A secreted by HL cells is at least one major activator of $\mathrm{cHL}$ cell migration, invasion and adherence. 


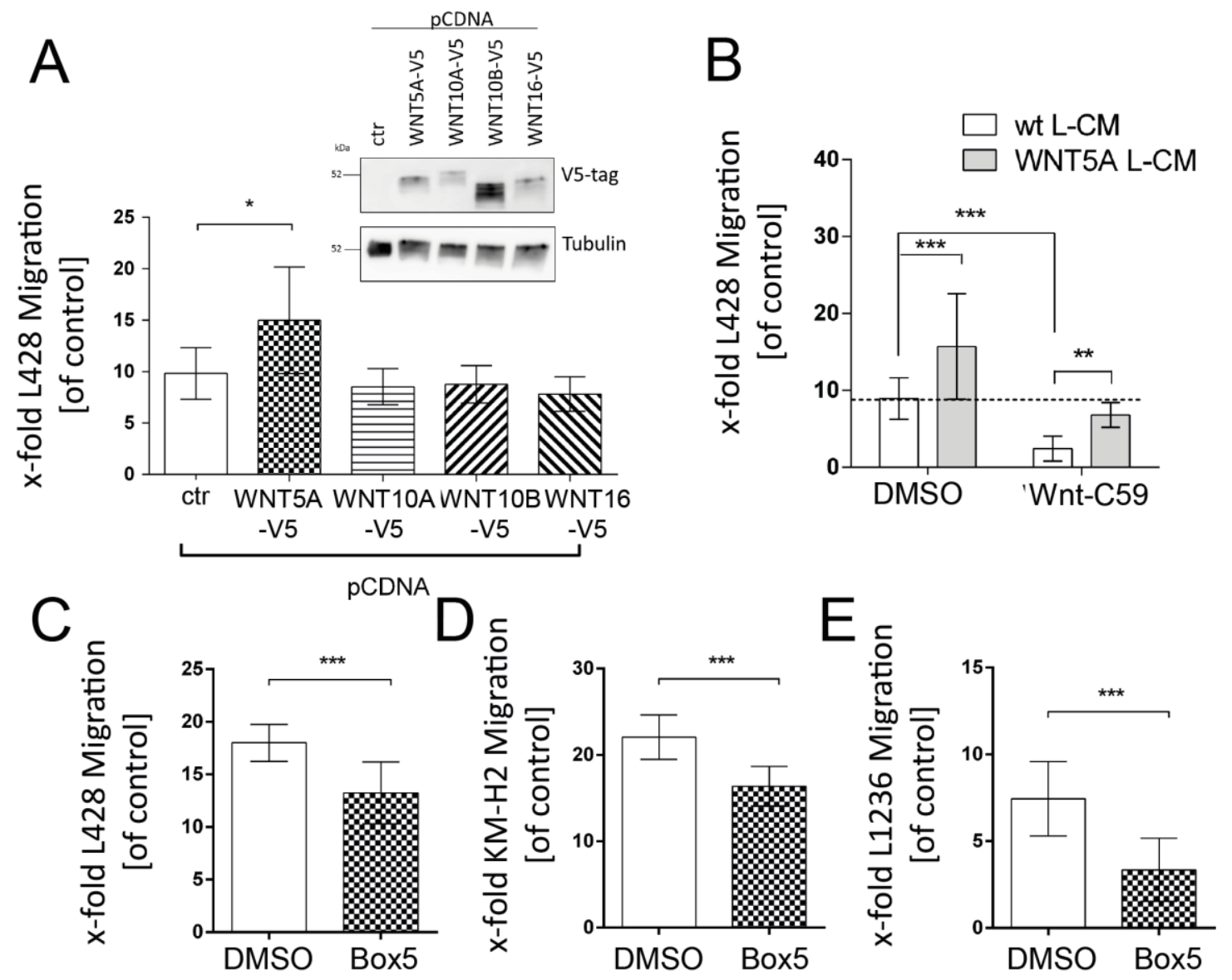

Figure 15: WNT5A is a stimulator of $\mathrm{cHL}$ cell migration. (A) Migration and Western Blot were performed with L428 cells transfected with pCDNA vector containing either WNT5A-V5-tag, WNT10A-V5, WNT10B-V5, WNT16-V5, or without insert. For protein detection specific antibodies against the V5-tag and against tubulin as loading control were used. (mean $\pm S D, n=3,1$-way ANOVA and Dunn's post-hoc test). Note the exclusive effect of WNT5A. (B) Migration of L428 cells after Wnt-C59 treatment and application of wildtype (wt) or WNT5A L-cell-conditioned medium was analysed. Note the rescue effect observed with the simultaneous WNT5A L-CM treatment (mean \pm SD, $n=3,2$-way ANOVA and Bonferroni's post-hoc test). L428 (C), KM-H2 (D) and L1236 (E) cells showed decreased migration rates after Box5 treatment $(1 \mathrm{~d}, 100 \mu \mathrm{M})$ (mean $\pm \mathrm{SD}, \mathrm{n}=3$, unpaired 2-tailed t-test; for L428 with Welch's correction) $\left({ }^{*} P<0.05,{ }^{* *} P<0.01\right.$ and $\left.{ }^{* * *} P<0.001\right)$. Modified from (Linke et al, 2016b). 

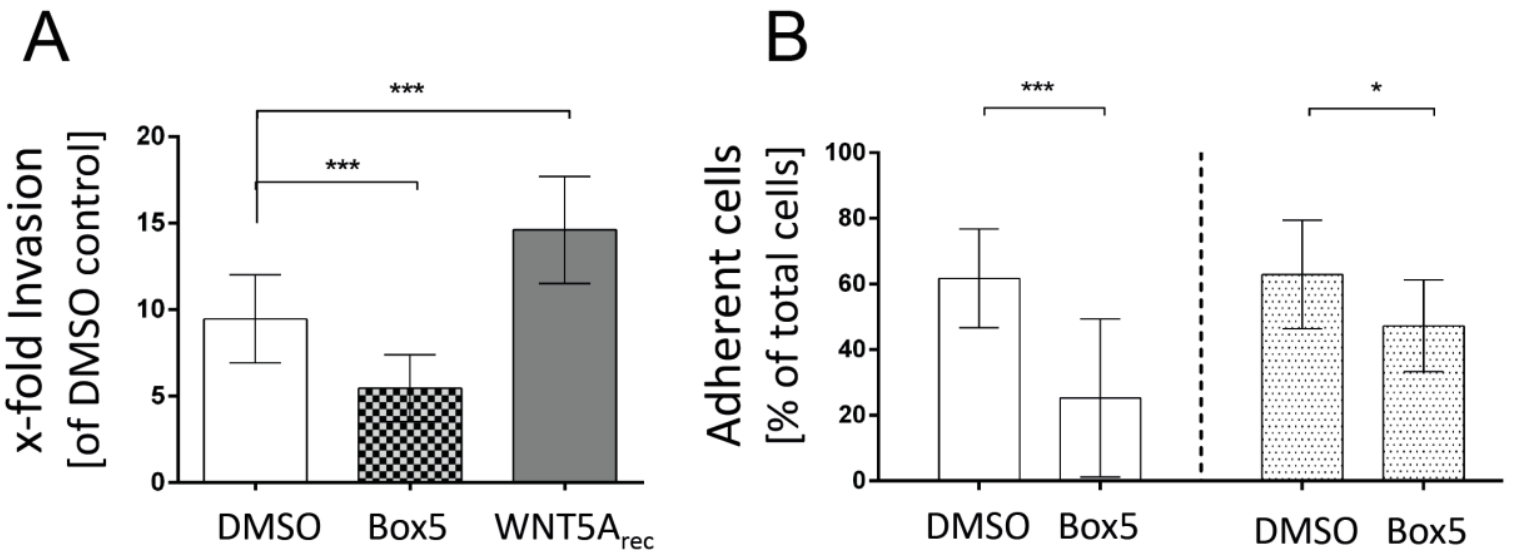

Figure 16: Box5 inhibits WNT5A-mediated invasion and adhesion of L428 cells. (A) Invasion of L428 cells was reduced after Box5 treatment $(1 \mathrm{~d}, 100 \mu \mathrm{M})$ but increased by WNT5A stimulation $(1 \mathrm{~d}, 100 \mathrm{ng} / \mathrm{ml})$ (mean $\pm \mathrm{SD}, \mathrm{n}=3,1$-way ANOVA and Bonferroni's post-hoc test). (B) Adhesion of Box5 pre-treated L428 cells was reduced on either HUVEC cells (white) or type-I-collagen (grey) (mean $\pm S D, n=5,2$ way ANOVA and Bonferroni's post-hoc test) $\left({ }^{*} P<0.05\right.$, $\left.{ }^{* \star *} P<0.001\right)$.

\subsubsection{Migration path characteristics depend on WNT5A signalling}

To further elucidate the effect of WNT5A signalling on $\mathrm{cHL}$ cell movements time-lapse studies of L428 cells in a three-dimensional collagen matrix were performed (Figure 17; overview images in the Appendix Figure A-43 A; Supplementary Videos 1-4). The majority of DMSO-treated control L428 cells migrated towards CCL19. However, numerous control cells moved slow or just turned in cycles while mostly actively blebbing. Others attracted attention due to high-speed movements. While the control cells showed a broad spectrum of these diverse types of movements, the inhibition of autocrine WNT signalling with Box5 or Wnt-C59 was associated with an increase in the number of static cells and rare blebbing events. In contrast, stimulation with recombinant WNT5A further enhanced the degree of motility of all investigated cells. Blebbing and transformation events occurred with high dynamics. 


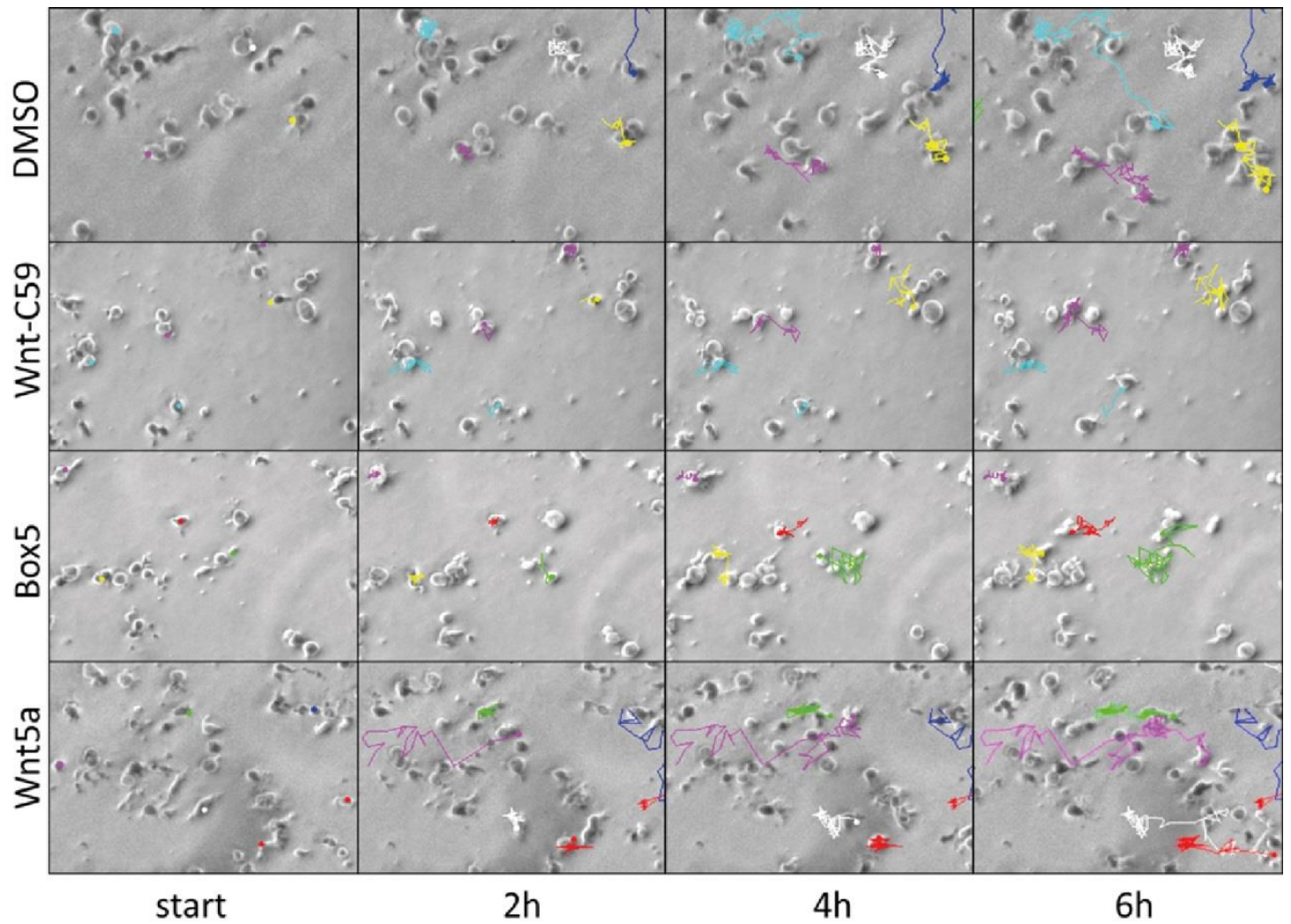

Figure 17: Wnt-C59, Box5 or WNT5A pre-treatment affects L428 cell movement paths in a 3D collagen matrix. Time-lapse microscopy of Wnt-C59, Box5 or WNT5A-pre-treated L428 cells was performed using IBIDI 3D chemotaxis chambers. Photos were taken every 5 min for $6 \mathrm{~h}$. Representative coloured trajectories of single cells towards the chemoattractant are shown at indicated intervals. The chemokine was located on the right side. Corresponding Videos 1-4 can be found in the Appendix on page 151.

Quantitative data analyses using trajectory dot plots support the video observations. The different treatments affected the directionality of $\mathrm{cHL}$ cell movements. The mean centres of masses of the track endpoints were significantly shifted towards the chemokine in the DMSO control and the WNT5A treatment groups, whereas they remained near the starting point in the Wnt-C59 and Box5 treatment groups (Figure 18 A-D). Impaired WNT5A signalling also negatively affected the mean euclidean distances, accumulated distances and velocities (Figure $18 \mathrm{E}-\mathrm{G}$ ). WNT5A stimulation further enhanced velocity from a mean of $1.2 \mu \mathrm{m} / \mathrm{min}$ to $1.5 \mu \mathrm{m} / \mathrm{min}$. 


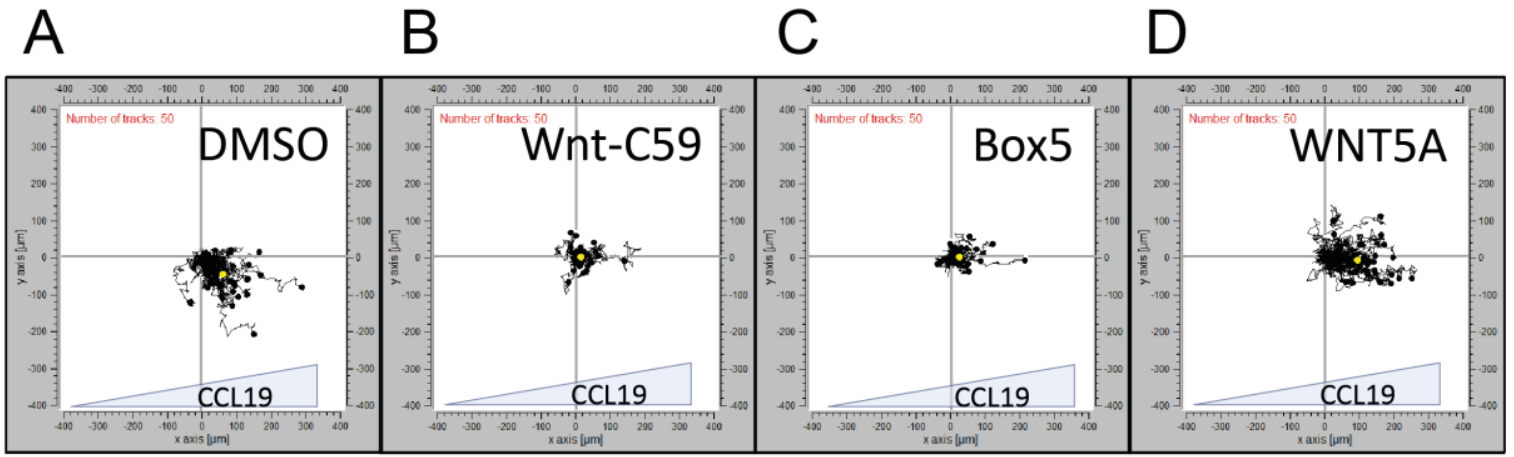

$E$
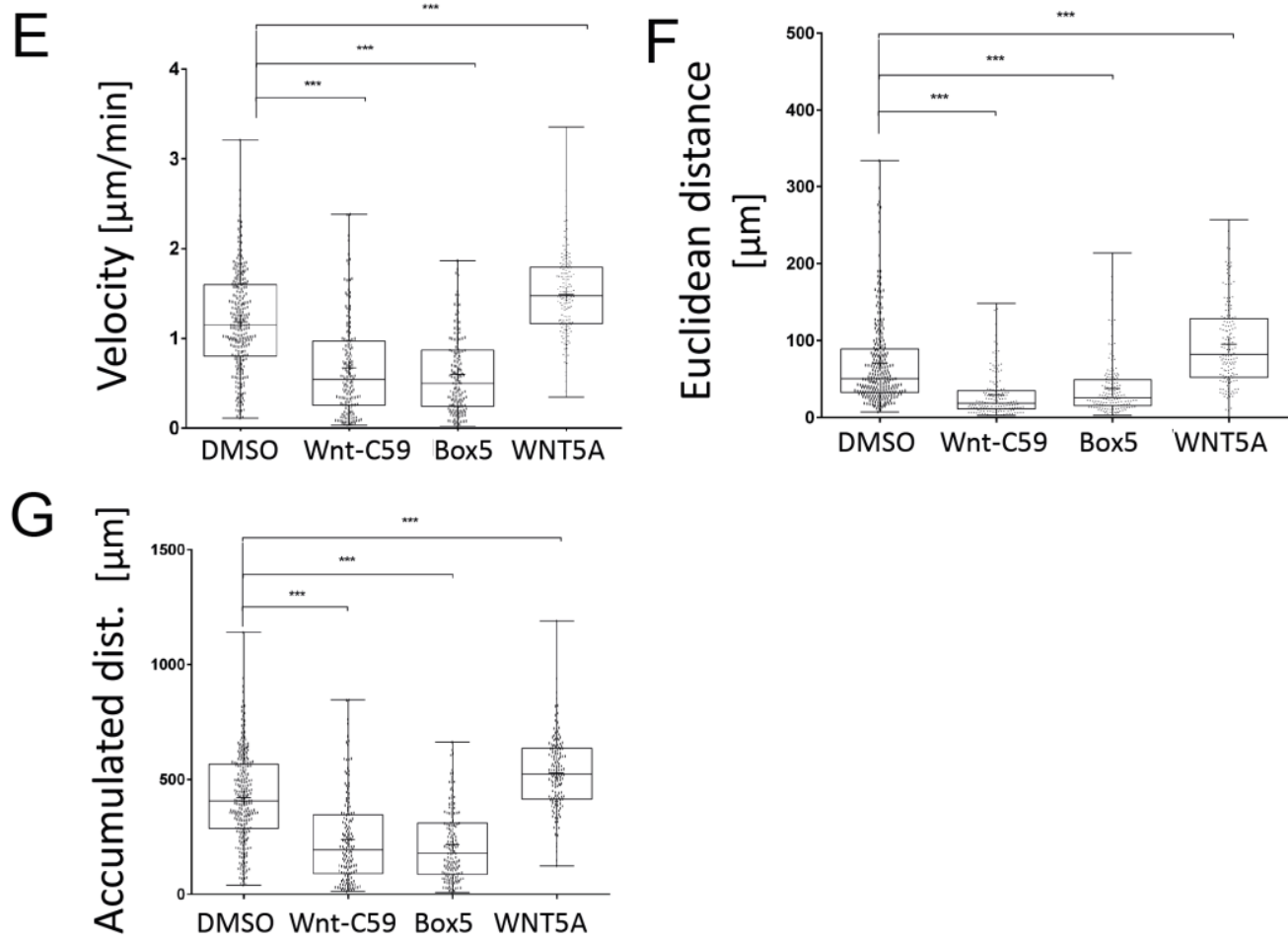

Figure 18: WNT5A signalling influences cell path characteristics of L428 cells in a 3D matrix. Representative trajectory dot plots show the sector distribution of the L428 cells treated with DMSO (A), Wnt-C59 (B), Box5 (C) and WNT5A (D). For group directionality the centre of masses after $6 \mathrm{~h}$ is shown as yellow dot. CCL19 source was located on the right side. Velocities (E), euclidean (F) and accumulated $(\mathbf{G})$ distances of DMSO, Wnt-C59, Box5 and WNT5A-pre-treated L428 cells were analysed (mean \pm SD; DMSO, $n=5$; Wnt-C59, Box5, WNT5A, $n=3$ of each 50 trajectories; KruskalWallis test, $\left.{ }^{* \star *} P<0.001\right)$. Note the inhibitory effects of Wnt-C59 and Box5 treatment while WNT5A stimulation enhances cell path characteristics. Corresponding Videos 1-4 can be found in the Appendix on page 151. Modified from (Linke et al, 2016b).

In a next step the movement patterns of each cell towards the chemokine were converted into biostatistical fingerprints. The fingerprints of the inhibitor-treated (Wnt-C59, Box5) or WNT5A-stimulated groups were hierarchically ordered 
according to highest similarities (Figure $19 \mathrm{~A}$ ). Next to the similarity-dendrogram examples of the movement classes belonging to the corresponding subgroups are plotted. In the heat map the movement patterns of the Wnt-C59 (black) and Box5 (green) inhibitor-treated groups clearly separate from the WNT5A group (orange) as shown in Figure $19 \mathrm{~A}$ (heat map including DMSO datasets are presented in the appendix Figure A-43 B).

To further dissect the influence of WNT5A on cellular movement patterns the relative distribution of each treatment group within the six most different movement classes was calculated (Figure 19 B). These classes include non-moving (class 1), turning (class 2), initially not moving (class 3 ), short (class 4 ) and long distances (class 5, class 6 with twists) covering cells. Movement classes 3 and 6 occurred only rarely and were almost only seen in the control and WNT5Astimulated groups. $37 \%$ of DMSO control cells covered short distances (class 4) within 6 hours whereas approximately $20 \%$ had not moved (class 1 ) or covered long distances in a directed manner (class 5). This distribution shifted after Wnt-C59 or Box5 treatment. In the inhibitor-treated groups $60-70 \%$ of the cells belonged to movement class 1, or had mainly turned around (class 2). Long distance tracks occurred less than half as often as in the control group (classes 5 , 6). In contrast the WNT5A stimulation shifted the group distribution towards the long-distance track groups (classes 5,6). Approximately half of the cells of the WNT5A group covered directed long distances (classes 5 and 6), while the number of non-moving cells was cut by half compared to the DMSO controls. Thus, time-lapse microscopy further underlines the motility shaping properties of WNT5A for cHL cells. 
A
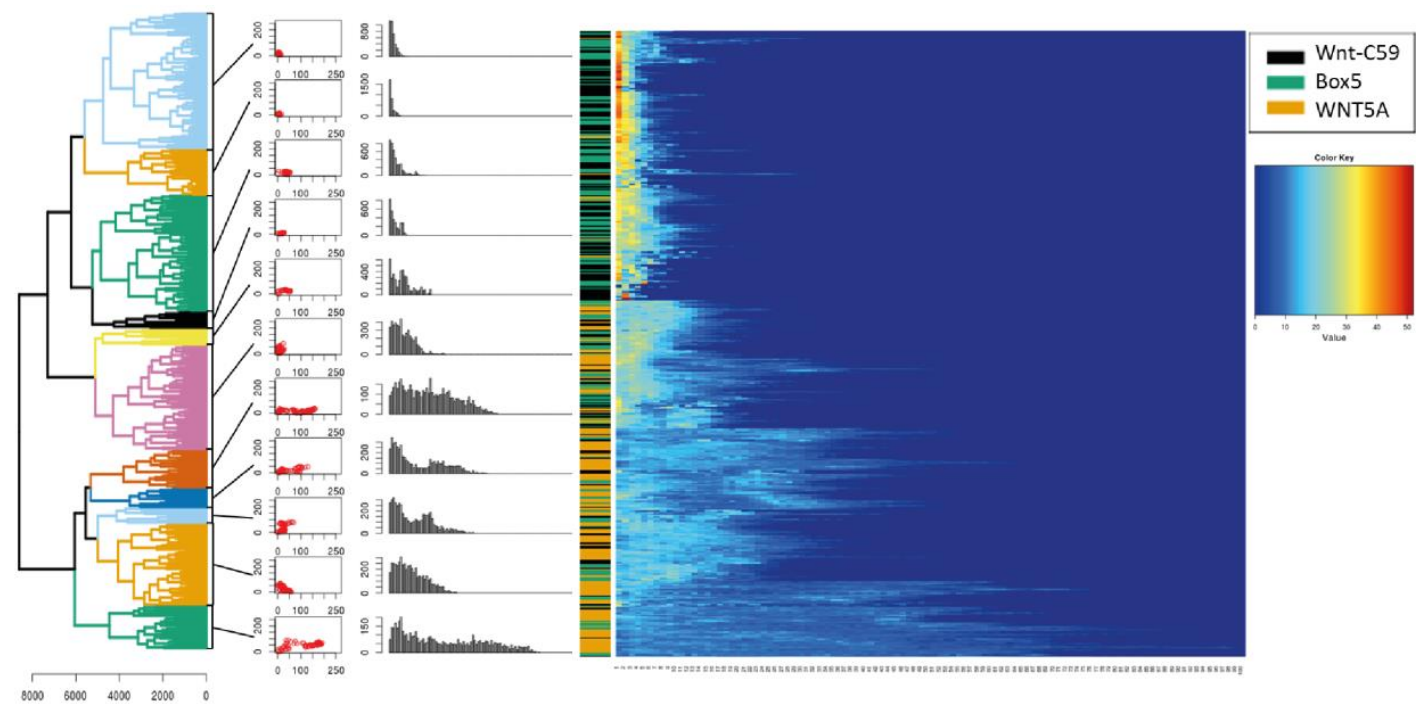

$8000 \quad 600040002000$

B
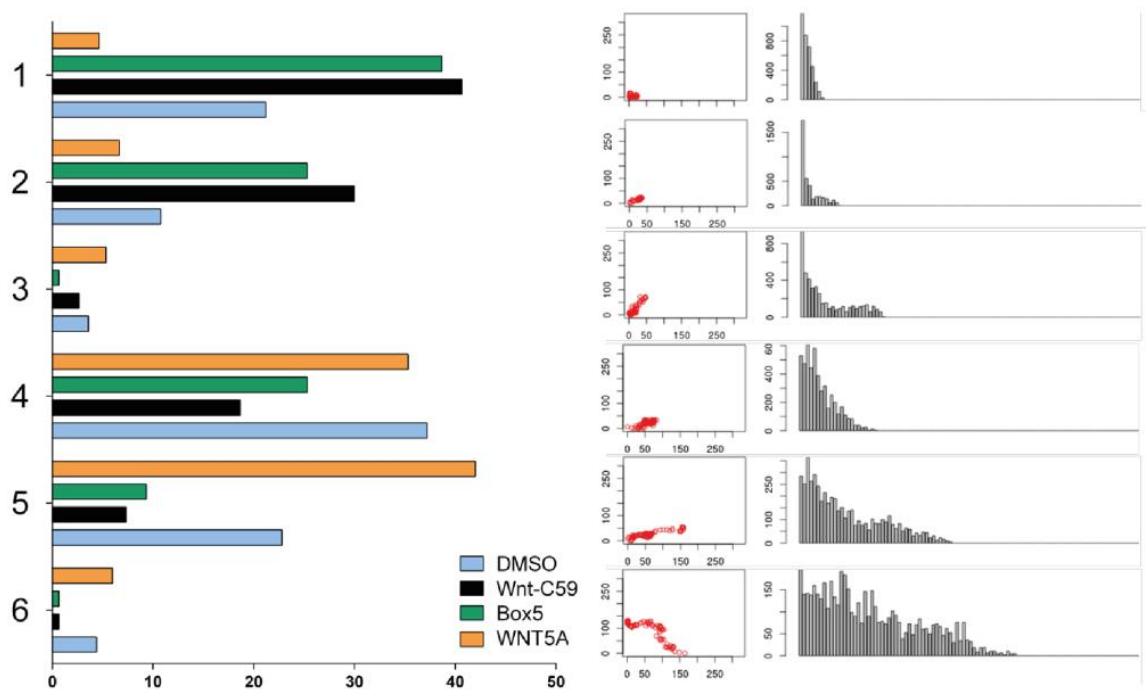

relative distribution within a group [\%]

Figure 19: L428 cell movement classes are affected by WNT5A signalling. (A) The heat map displays the results of the hierarchical clustering of movement patterns of Wnt-C59, Box5 or WNT5A-treated L428 cells based on shape fingerprints according to the form and length of each track. Exemplary fingerprints are plotted next to their corresponding position in the dendrogram and are shown as track coordinates and shape fingerprint. The $x$-axis of the heat map corresponds to the internal distances within single tracks, with short distances mapped to the left and longer distances to the right. The colour of the heat map tiles represents the number of counts for specific distances per track ('square root transformed' to enhance contrast). Experimental group membership is encoded by colours on the left side of the heat map with black (Wnt-C59), green (Box5) and orange (WNT5A). (B) Relative distribution of the six most different movement classes within each group of DMSO, Wnt-C59, Box5 or WNT5A-treated L428 cells. Corresponding Videos 1-4 can be found in the Appendix on page 151. From (Linke et al, 2016b). 


\subsubsection{FZD5 and DVL3 are required for $\mathrm{cHL}$ cell migration}

For the dissection of mechanisms required for the WNT5A-mediated $\mathrm{cHL}$ migration, selected components of the PCP pathway were analysed including FZD5. FZD5 is one of the known high-affinity WNT5A receptors (Dijksterhuis et al, 2015). Knockdown of FZD5 significantly decreased the migration rates of the two CHL cell lines, L428 and KM-H2 (Figure 20 A-B; Appendix Figure A-44 A). Therefore, FZD5 is an important PCP receptor involved in $\mathrm{CHL}$ cell migration.

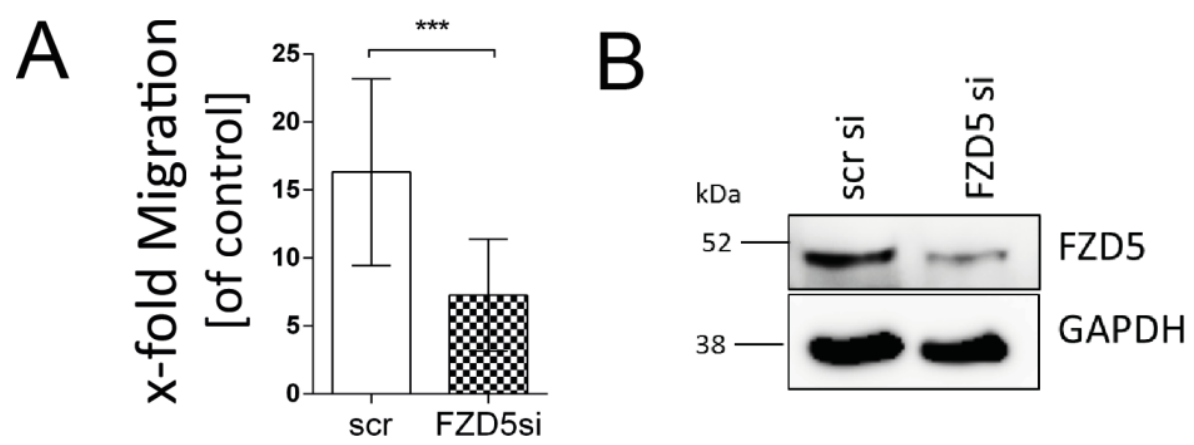

Figure 20: FZD5 knockdown impairs L428 cell migration. (A) Migration is significantly reduced in L428 cells $48 \mathrm{~h}$ after FZD5 knockdown (mean $\pm \mathrm{SD}, \mathrm{n}=3$, unpaired 2-tailed t-test with Welch's correction, $\left.{ }^{* *} P<0.001\right)$. (B) Corresponding Western Blot shows the FZD5 knockdown in L428 cells. Protein was detected using specific antibodies against FZD5 and against GAPDH as loading control. From (Linke et al, 2016b).

Next, the role of the FZD-associated cytoplasmic adaptor protein DVL was investigated. KM-H2 and L428 cells were stimulated with WNT5A and the activation status of DVL1, DVL2 and DVL3 was monitored by the existence of the second shifted activation band of DVL in immunoblots over the time (Figure $21 \mathrm{~A}$, Appendix Figure A-44 B). DVL1 was slightly active and could not be further activated by WNT5A stimulation over the time. In addition, DVL2 was almost completely activated in control cells and could not further be activated. In contrast DVL3 was specifically activated after WNT5A stimulation. The activation maximum seemed to be reached after one hour in $\mathrm{KM}-\mathrm{H} 2$ cells and after 30 minutes in $\mathrm{L} 428$ cells. As further confirmation WNT5A stimulation induced specific activation of DVL3 already after 10 minutes in all three cHL cell lines used (Figure 21 B), while 
this activation was abolished by treating cells with the WNT5A antagonist Box5 (Appendix Figure A-44 C).

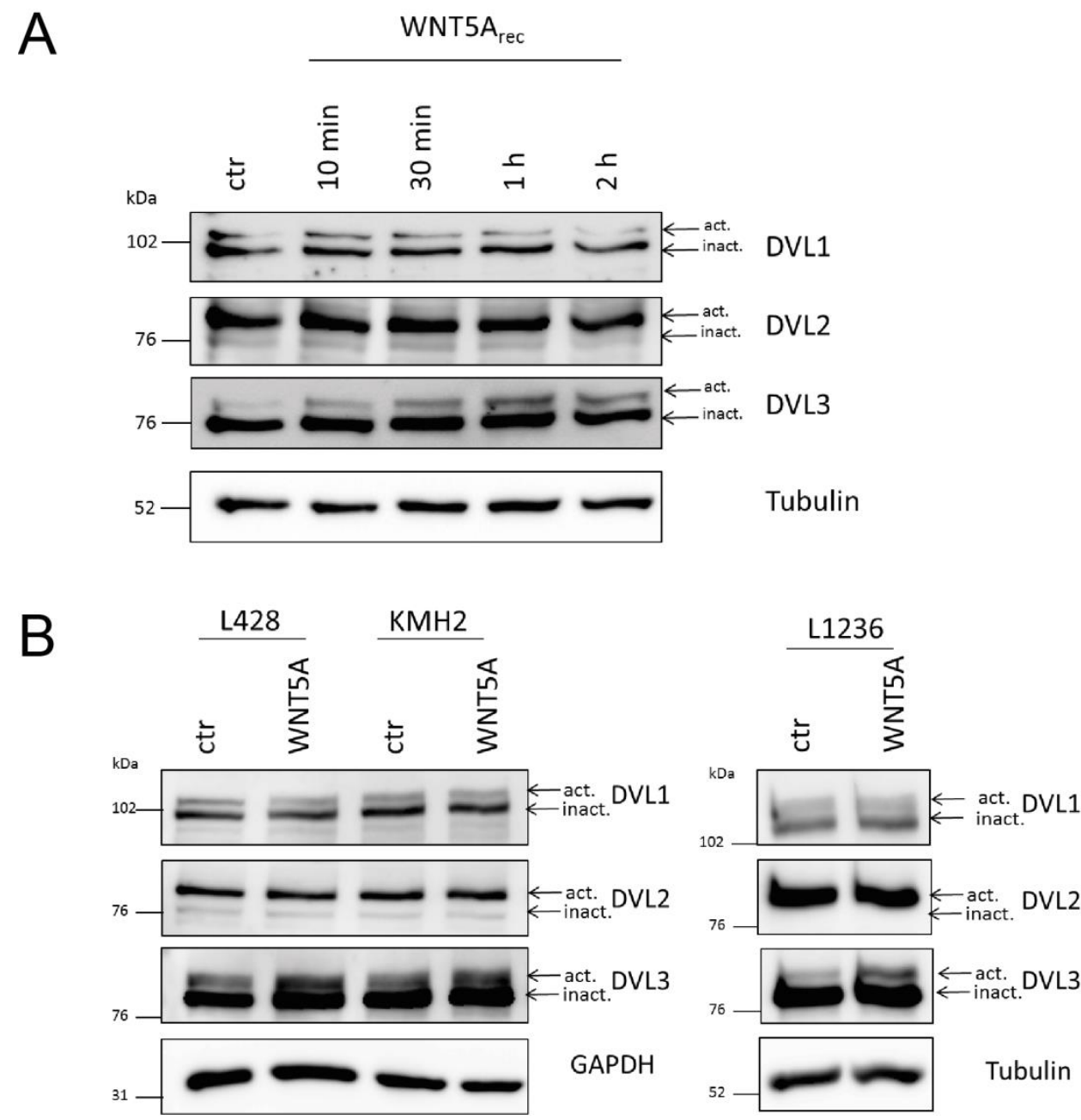

Figure 21: DVL3 is exclusively activated in a time-dependent manner after WNT5A stimulation in cHL cells. (A) Western Blot of $\mathrm{KM}-\mathrm{H} 2$ cells stimulated with $100 \mathrm{ng} / \mathrm{ml}$ recombinant WNT5A for the indicated time intervals. Note the increasing activation of DVL3 during the first hour. (B) Western blot of L428, KM-H2 and L1236 cells after stimulation with $100 \mathrm{ng} / \mathrm{ml}$ recombinant WNT5A or PBS/BSA for 10 minutes. Note the increase of active DVL3 after WNT5A stimulation. For protein detection (A, B) specific antibodies against DVL1, DVL2, DVL3 and against tubulin or GAPDH as loading control were used. Modified from (Linke et al, 2016b).

In order to further investigate the role of DVL3 for $\mathrm{cHL}$ cell migration DVL3 knockdown as well as overexpression was performed. DVL3 knockdown alone reduced L428 cell migration by up to $30 \%$ (Figure $22 \mathrm{~A}$ ). In addition, the overexpression of wildtype DVL3 enhanced L428 migration by up to $27 \%$, whereas the dominant-negative DVL3 variant (DVL3-K435M), that cannot interact with FZD 
anymore (Axelrod et al, 1998), significantly reduced L428 migration by approximately $26 \%$ (Figure 22 B). Consequently, DVL3 is an important mediator of $\mathrm{CHL}$ cell migration.

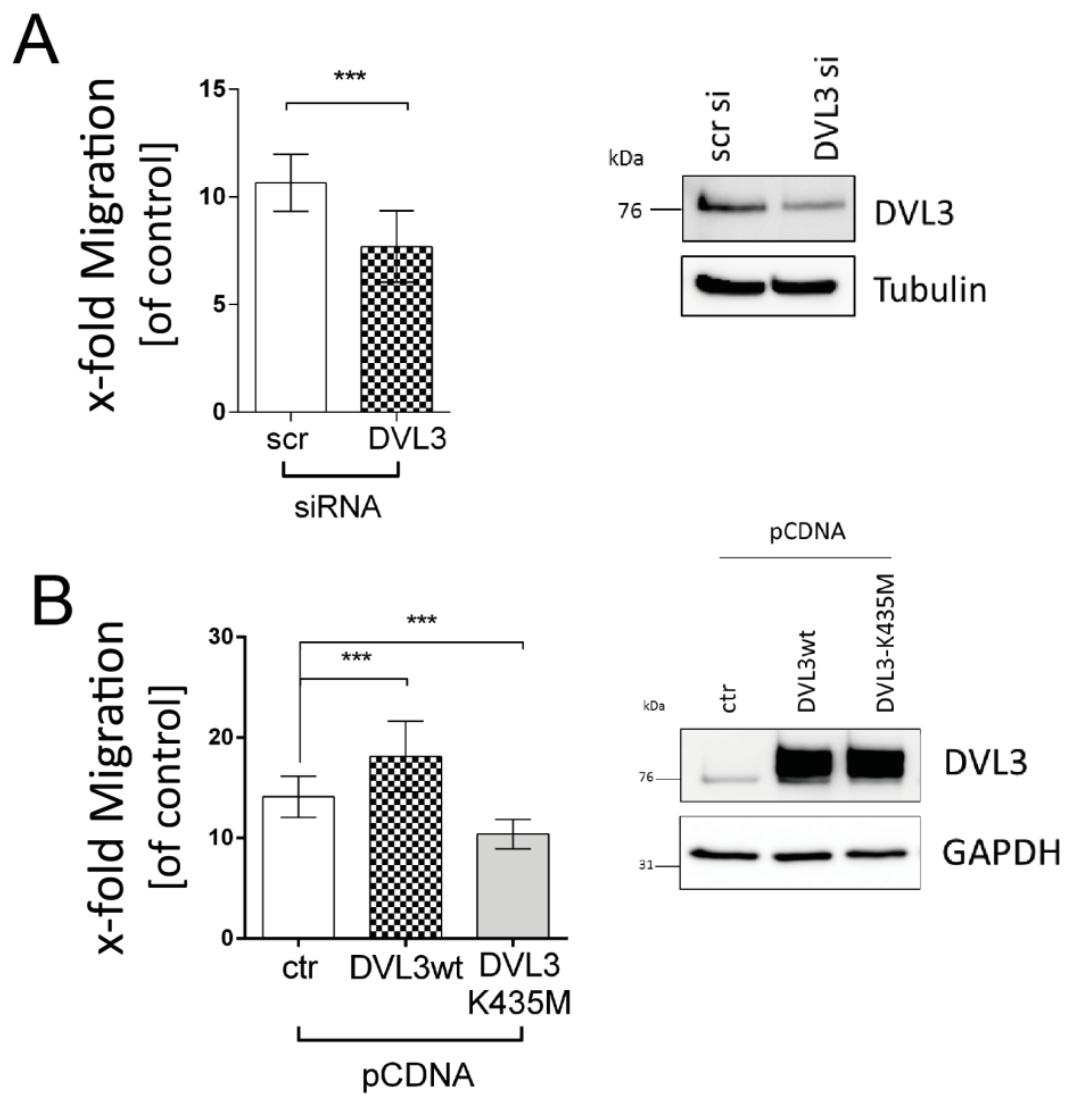

Figure 22: DVL3 expression is required for L428 cell migration. (A) Migration and Western blot of $L 428$ cells were performed $48 \mathrm{~h}$ after DVL3 knockdown. Note the inhibitory effect of the DVL3 knockdown on L428 cell migration. (mean $\pm \mathrm{SD}, \mathrm{n}=3$, unpaired 2-tailed t-test). (B) Migration and Western blot of L428 cells were shown $48 \mathrm{~h}$ after transfection with DVL3 wildtype or the dominant negative DVL3K435M variant. Note the migration-stimulating effect of DVL3 wildtype overexpression while the dominant negative DVL3K435M variant reduces $L 428$ cell migration. For protein detection $(A, B)$ specific antibodies against DVL3 and against tubulin or GAPDH as loading control were used. (mean $\pm S D, n=3,1$-way ANOVA and Bonferroni's post-hoc test) $\left({ }^{* * *} P<0.001\right)$. From (Linke et al, 2016b).

\subsubsection{WNT5A on extracellular vesicles (EVs) activates DVL3 and stimulates cHL cell migration}

Since WNT ligands can be secreted on EVs such vesicles were isolated from the supernatant of untreated $\mathrm{L} 428$ and $\mathrm{KM}-\mathrm{H} 2$ cells. WNT5A was detected in the EVs of L428 and KM-H2 cells (Figure 23 A). To further confirm that WNT5A protein is 
secreted on EVs by cHL cells, L428 cells were transfected with WNT5A-V5tagcontaining or control pCDNA plasmids. Actually, the V5-tag was detected in the EVs of the WNT5A overexpressing L428 cells (Figure 23 B). To assess whether the $\mathrm{EV}$ of $\mathrm{cHL}$ cells can induce similar pathways as recombinant WNT5A stimulation or WNT5A overexpression, $\mathrm{L} 428$ and $\mathrm{KM}-\mathrm{H} 2$ cells were stimulated with their EVs for 24 hours. Stimulation of L428 and KM-H2 cells with their EVs for 10 minutes activated DVL3 and also slightly DVL1 in the KM-H2 cells (Figure $23 \mathbf{C}$ ). Stimulation with EVs increased migration of $\mathrm{L} 428$ and $\mathrm{KM}-\mathrm{H} 2$ cells up to $30 \%$ (Figure 23 D), further confirming the autocrine migration stimulating feedback loop of cHLs.

A

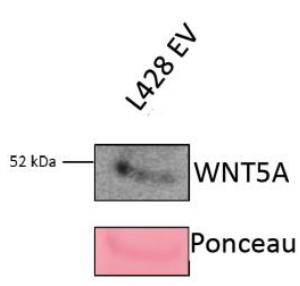

C

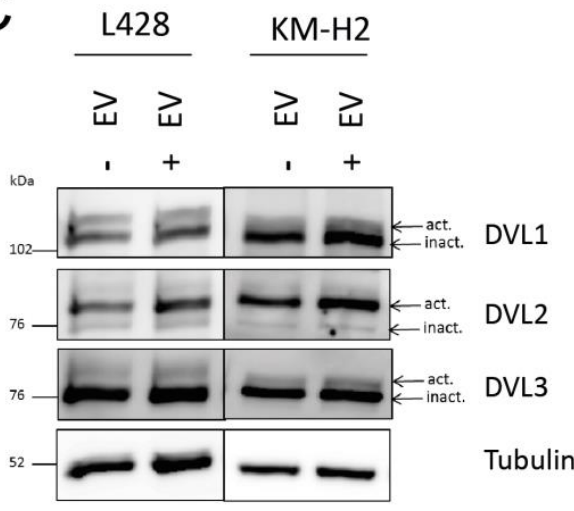

B

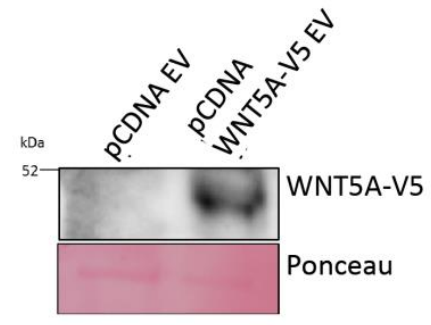

D

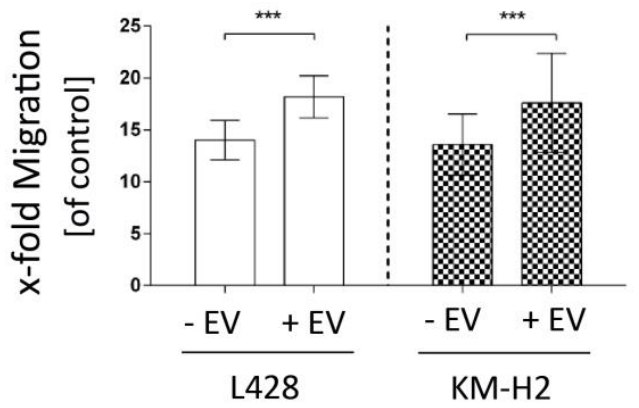

Figure 23: WNT5A of EVs activates DVL3 and stimulates cHL migration. (A) WNT5A is expressed on L428 and KM-H2 EVs. For WNT5A protein detection a specific antibody against WNT5A was used. (B) WNT5A-V5 is expressed on L428 EVs after transfecting cells with the corresponding PCDNA plasmid. For protein detection on EVs a specific antibody against the $\mathrm{V} 5$ tag was applied. (C) Western blot of L428 and KM-H2 cells after stimulation with EVs for 10 minutes. Note the increase of active DVL3 after EV stimulation. For protein detection specific antibodies against DVL1, DVL2, DVL3 and against tubulin as loading control were used. (D) Migration of L428 cells is increased after stimulation with their EVs for 24 hours. (mean $\pm S D, n=3$, unpaired 2-tailed t-test). $\left.{ }^{* * *} \mathrm{P}<0.001\right)$ 


\subsubsection{RHOA is activated after WNT5A stimulation}

Next, the activation of the small GTPase RHOA by WNT5A was investigated. Protein pulldown assays of activated RHOA were performed. WNT5A stimulation of L428 cells activated RHOA within 5 minutes and continued for at least 15 minutes on a high level (Figure 24 A). To investigate whether RHOA activation depends not only on WNT5A stimulation but also on FZD5 or DVL3 expression, the RHOA pulldown assay was repeated with L428 knockdown cells. As monitored in three independent pulldown assays knockdown of DVL3 or FZD5 abolished WNT5A-mediated RHOA activation almost completely (Figure 24 B) thereby implying that RHOA activation after WNT5A stimulation depends on FZD5 and DVL3 signalling.

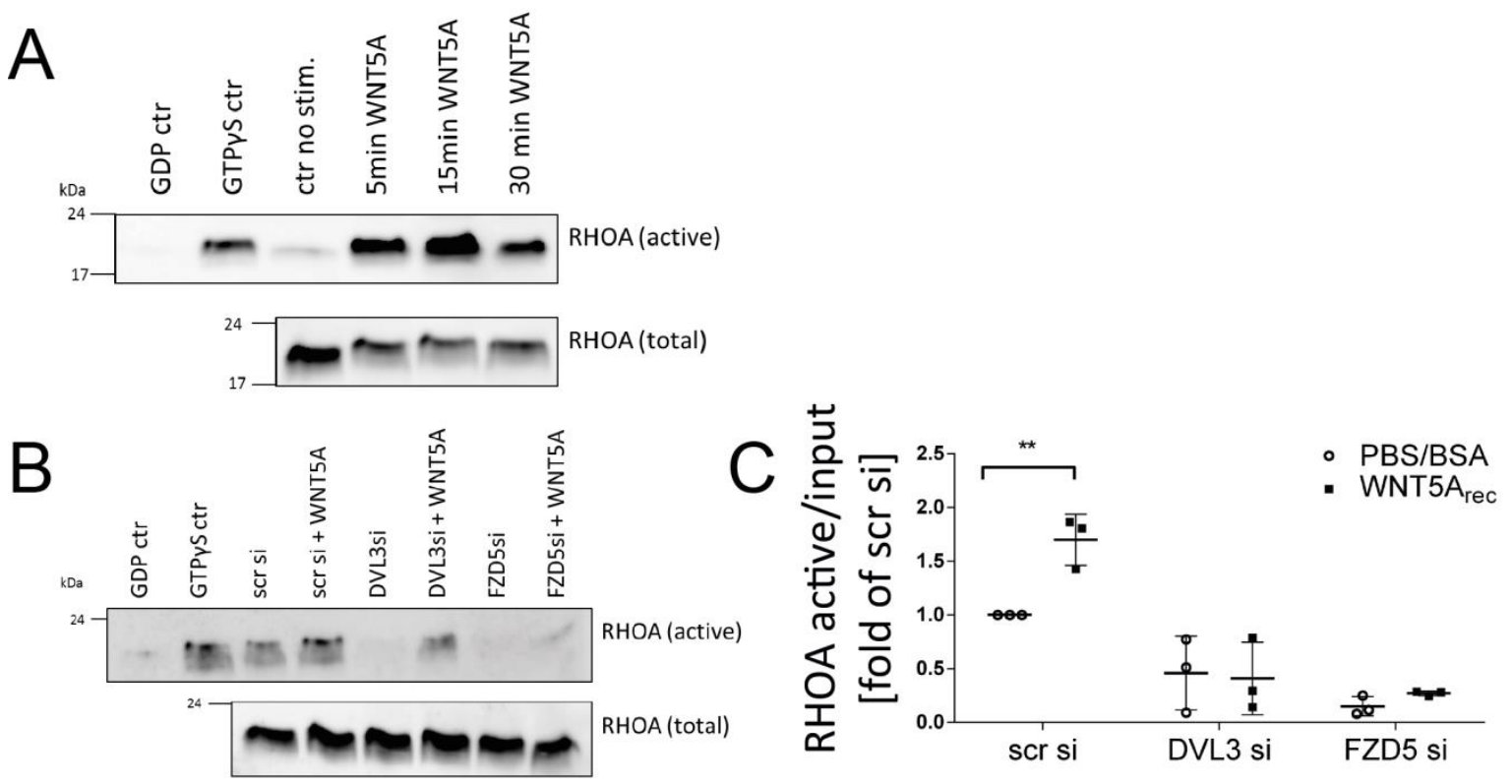

Figure 24: WNT5A stimulates RHOA in a DVL3 and FZD5-dependent manner. Western blot using specific anti-RHOA antibodies after RHOA-GTP pulldown of WNT5A-stimulated L428 cells alone (A) and after DVL3 and FZD5 knockdown (B) was performed. (C) Western blot intensities of three independent assays have been measured using ImageJ (mean $\pm S D, n=3,2$-way ANOVA and Bonferroni's post-hoc test, ${ }^{* *} P<0.01$ ). Note the increase of activated RHOA over the time that almost completely disappears under DVL3 or FZD5 knockdown. From (Linke et al, 2016b).

As RHOA activates ROCK two different ROCK inhibitors, Y-27632 and H1152P, were applied. Both ROCK inhibitors blocked migration rates of L428 cells almost 
completely without affecting cell viability (Figure 25 A-B) suggesting an important role of ROCK for cHL cell motility.
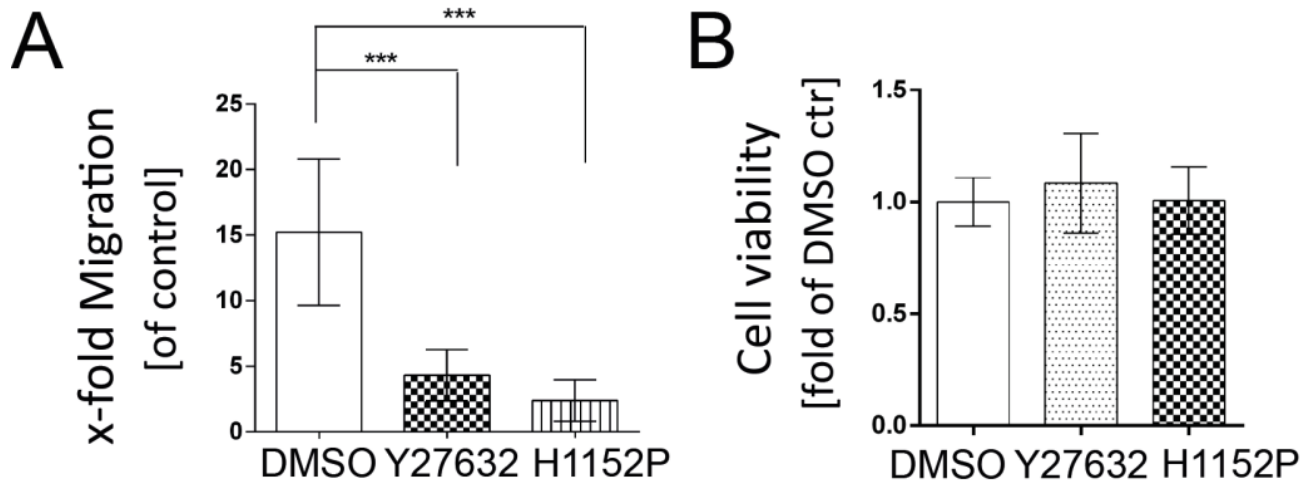

Figure 25: L428 cell migration depends on ROCK (A) Migration of L428 cells is impaired after ROCK inhibition using $5 \mu \mathrm{M}$ Y-27632 or $0.5 \mu \mathrm{M} \mathrm{H1152P} \mathrm{(mean} \pm$ SD, $\mathrm{n}=3,1$-way ANOVA and Bonferroni's post-hoc test). (B) MTT of L428 cells after treatment with $5 \mu \mathrm{M}$ Y27632 or $0.5 \mu \mathrm{M}$ $\mathrm{H} 1152 \mathrm{P}$ for 72 hours was performed. OD values of DMSO control have been set 1 (mean \pm SD, $\mathrm{n}=4$ (Y27632 $\mathrm{p}=0.4717, \mathrm{H} 1152 \mathrm{P} \mathrm{p}>0.999)$, One-way ANOVA and Bonferroni's post-hoc test) $\left({ }^{* * *} P<0.001\right)$. Modified from (Linke et al, 2016b).

\subsubsection{WNT5A expression is increased in a fraction of patients and associated with early relapse cases}

Since the in vitro results suggest a lymphoma-promoting role of WNT5A publically available microarray data of WNT5A gene expression in $\mathrm{CHL}$ was analyzed. By using the Brune Lymphoma data set WNT5A expression was compared between a subset of physiological B-cells and several lymphoma entities (Brune et al, 2008). WNT5A expression is increased in the analysed primary HRS cells of a considerable number of patients (Figure $26 \mathrm{~A}$ ). These patient's data are in line with the in vitro $\mathrm{cHL}$ cell line results on aberrant WNT5A expression by $\mathrm{CHL}$ cells.

By using a second data set by Steidl et al. WNT5A gene expression was also correlated with clinical parameters (Steidl et al, 2010a). WNT5A expression is significantly increased in patients with early relapse compared to late relapses $(\mathrm{P}=0.037)$ (Figure $26 \mathrm{~B}$ ). This implies that enhanced WNT5A expression might 
also correlate with a worse clinical outcome by contributing to early relapses of aggressive $\mathrm{CHL}$ cases.
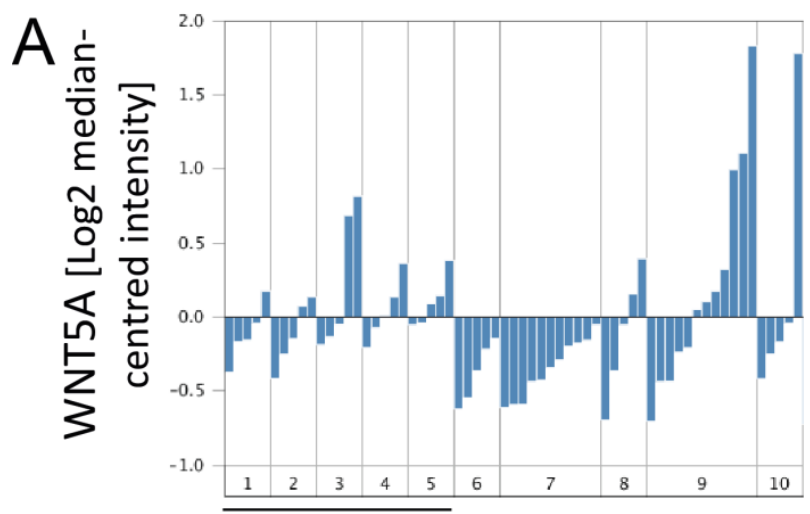

B-cell subsets BL DLBCL FL HL NLPHL

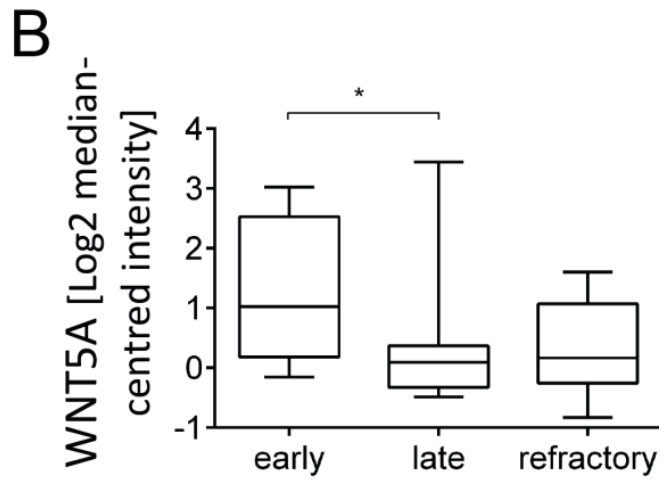

Figure 26: WNT5A expression is increased in a substantial fraction of cHL patients. (A) WNT5A expression is high in several HRS patients' samples (no. 9). WNT5A expression data was obtained by single HRS cell analysis by Brune et al. (Brune et al, 2008) (mean of single patients' data; No.1: centroblasts $n=5$; No.2: memory B-cell $n=5$; No.3: naïve pre-germinal centre B-cell $n=5$; No.4: plasma cell $n=5$; No.5: small cleaved follicle centre cell $n=5$; No.6: $B L n=5$; No.7: DLBCL $\mathrm{n}=11$; No.8: Follicular lymphoma $\mathrm{n}=5$; No.9: $\mathrm{HL} \mathrm{n}=12$; No.10: nodular lymphocyte predominant $\mathrm{HL}$ $\mathrm{n}=5$ ). (B) WNT5A expression is significantly increased in patients with early relapse compared to late relapse. WNT5A expression data obtained by Steidl et al. (Steidl et al, 2010a) (mean \pm SD, early, $n=9$; late, $n=19$; refractory, $n=10$; Mann-Whitney test) ( $\left.{ }^{\star} P<0.05\right)$. From (Linke et al, 2016b).

\subsubsection{Autocrine canonical WNT signalling is detected in $\mathrm{cHL}$ cells}

Since non-canonical WNT5A signalling has been shown to play a pivotal role for $\mathrm{CHL}$ cell motility, the question arose whether canonical WNT signalling might also be important for $\mathrm{cHL}$ cells. The activation of canonical WNT signalling can be monitored by nuclear translocation of $\beta$-catenin. Western Blot analysis of the cytosolic and nuclear localization of $\beta$-catenin revealed that albeit at low levels a substantial proportion is already localized within the nucleus (Figure 27). As control L428 cells were stimulated with a typical canonical WNT, WNT3A, which further stimulated $\beta$-catenin translocation, while the non-canonical WNT ligand WNT5A did not further increase the nuclear amount of $\beta$-catenin. Interestingly, nuclear $\beta$-catenin translocation was also enhanced after stimulation with conditioned medium of L428 cells suggesting an autocrine canonical WNT pathway activity in $\mathrm{CHL}$ cells. 


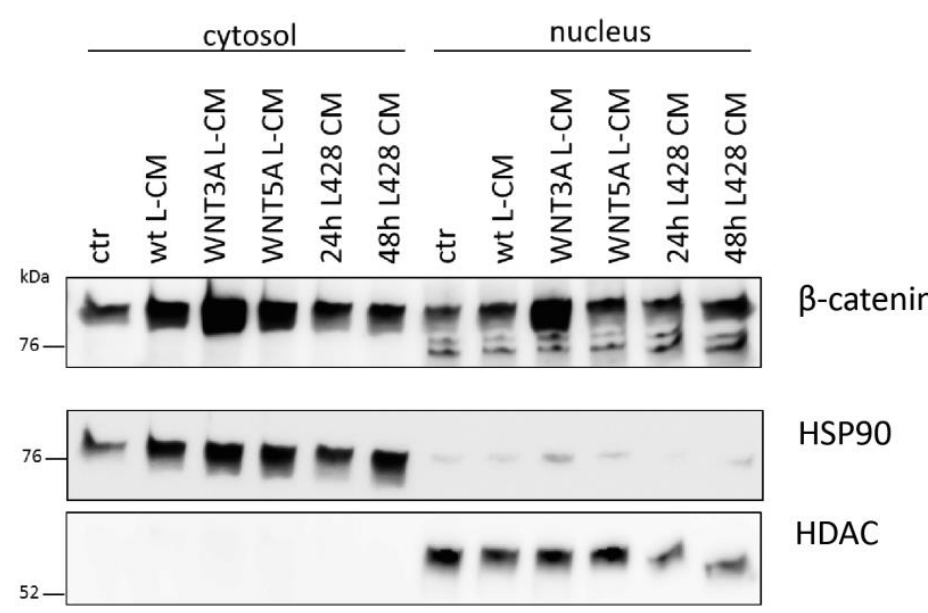

Figure 27: Low amounts of $\beta$-catenin are already located in the nucleus of L428 cells. Western Blot of cytosolic and nuclear fractions of L428 cells stimulated with $24 \mathrm{~h}$ or $48 \mathrm{~h}$ conditioned medium (CM) shows increased nuclear $\beta$-catenin fraction after $\mathrm{CM}$ stimulation. For protein detection specific antibodies against $\beta$-catenin and against HDAC as nuclear control and HSP90 as cytosolic control were used. Modified from (Linke et al, 2016a).

\subsubsection{Increased LEF-1 expression is associated with B-cell malignancies}

Since LEF-1 can form a transcription complex with $\beta$-catenin in the nucleus, the hypothesis was tested whether LEF-1 expression might be a general marker for lymphomas and especially cHLs. Interestingly, the analysis of publically available gene expression data sets showed that increased expression of $L E F-1$ in $\mathrm{cHL}$ is comparable to CLL or BL cases (Basso et al, 2005) (Figure 28 A). As the Basso data set only comprised $\mathrm{CHL}$ data of four cell lines an additional data set with patients' data was analysed. In the Brune data set it is found that cHL LEF-1 expression is significantly increased in comparison to a set of normal B-cells including memory and germinal centre B-cells (Brune et al, 2008) (Figure 28 B) suggesting an aberrant expression of LEF-1. 


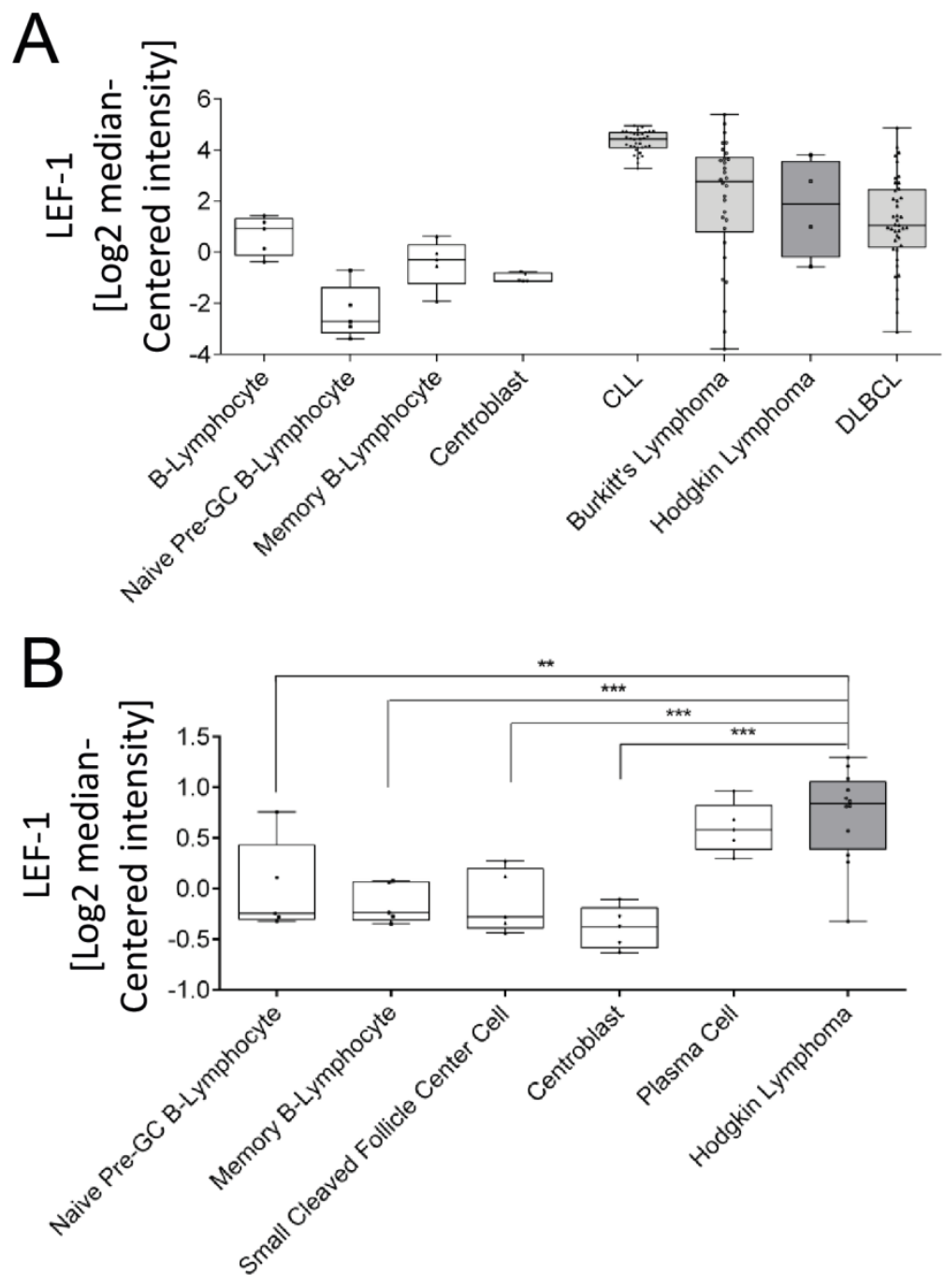

Figure 28: Aberrant LEF-1 expression in lymphoma entities compared to physiological B-cell subsets. $L E F-1$ expression data obtained by Basso et al. (Basso et al, 2005) (A) and Brune et al. (Brune et al, 2008) (B). Aberrant LEF-1 expression is increased in analysed lymphoma and leukaemia (A) and significantly higher in $\mathrm{CHL}$ patient samples compared to physiological B-cells (B) (mean \pm SD, Basso et al.: B-Lymphocyte, Naive Pre-GC B-Lymphocyte, Memory B-Lymphocyte, Centroblast, each $n=5 ; B L, n=31 ; H L, n=4$ (cell lines); DLBCL, $n=41 ; C L L, n=34$; Brune et al.: Naive Pre-GC B-Lymphocyte, Memory B-Lymphocyte, Small Cleaved Follicle Centre Cell, Centroblast, Plasma Cell, $n=5 ; \mathrm{HL}, \mathrm{n}=12$ (patients' material); 1 -way ANOVA and Bonferroni's post-hoc test, ${ }^{\star} P$ $<0.01$ and ${ }^{* * *} P<0.001$ ). From (Linke et al, 2016a).

\subsubsection{Inhibition of the canonical WNT pathway reduces $\mathrm{cHL}$ cell chemotaxis}

To test the impact of canonical WNT signalling on $\mathrm{cHL}$ cell migration the signalling cascade was inhibited at different levels of signal transduction. The antagonisation 
of WNT receptor binding with DKK1 and DKK2 reduced chemokine-mediated $\mathrm{CHL}$ cell chemotaxis to $80 \%$ in single treatments and to $68 \%$ in combination (Figure 29 A). To target the canonical $\beta$-catenin destruction complex CK1 or tankyrases were inhibited. These inhibitors prohibit the disassembly or stabilize the $\beta$-catenin destruction complex respectively, thus causing a permanent cytosolic degradation of $\beta$-catenin. For migration assays $\mathrm{cHL}$ cells were incubated with 50 nM PF670462 or $5 \mu \mathrm{M}$ XAV939 for 24 hours. As functional test nuclear and cytosolic fractions were prepared from inhibitor-treated cells. Application of CK1 or tankyrases inhibitor reduced the basal nuclear $\beta$-catenin fraction and even WNT3A stimulation did no longer stimulate $\beta$-catenin translocation under inhibitor treatment (Appendix: Figure A-45). In modified Boyden chamber assays the inhibition of CK1 or tankyrases led to a reduction of cell chemotaxis rates to $55 \%$ and $76 \%$ respectively (Figure 29 B).
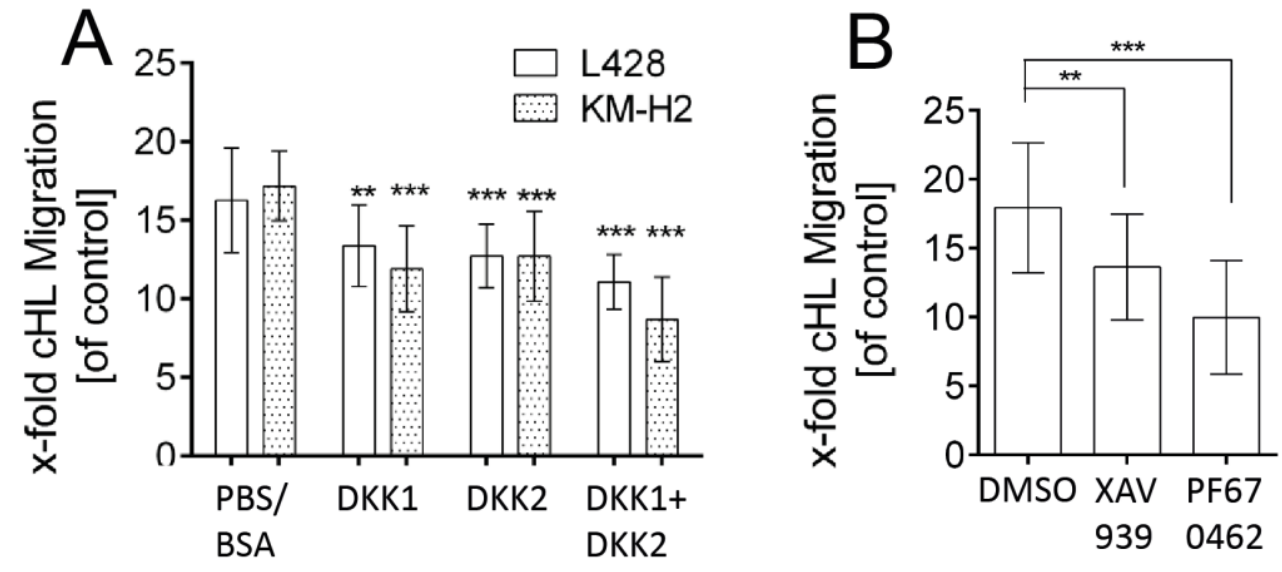

Figure 29: Inhibition of the canonical WNT signalling decreases $\mathrm{CHL}$ cell migration. (A) Migration of L428 and KM-H2 cells is decreased after $24 \mathrm{~h}$ of pre-treatment with $100 \mathrm{ng} / \mathrm{ml}$ DKK1, DKK2 or DKK1 plus DKK2. (mean $\pm S D, n=3$; 2-way ANOVA and Bonferroni's post-hoc test, significance level is shown compared to respective PBS/BSA control). (B) Migration of L428 cells is decreased after $24 \mathrm{~h}$ of pre-treatment with $5 \mu \mathrm{M}$ XAV939 or $0.05 \mu \mathrm{M}$ PF670462 (mean $\pm \mathrm{SD}$, XAV939, $n=4$; PF670462, $n=3 ; 2$-way ANOVA and Bonferroni's post-hoc test) ( ${ }^{* *} P<0.01$ and $\left.{ }^{* \star *} P<0.001\right)$. From (Linke et al, 2016a). 


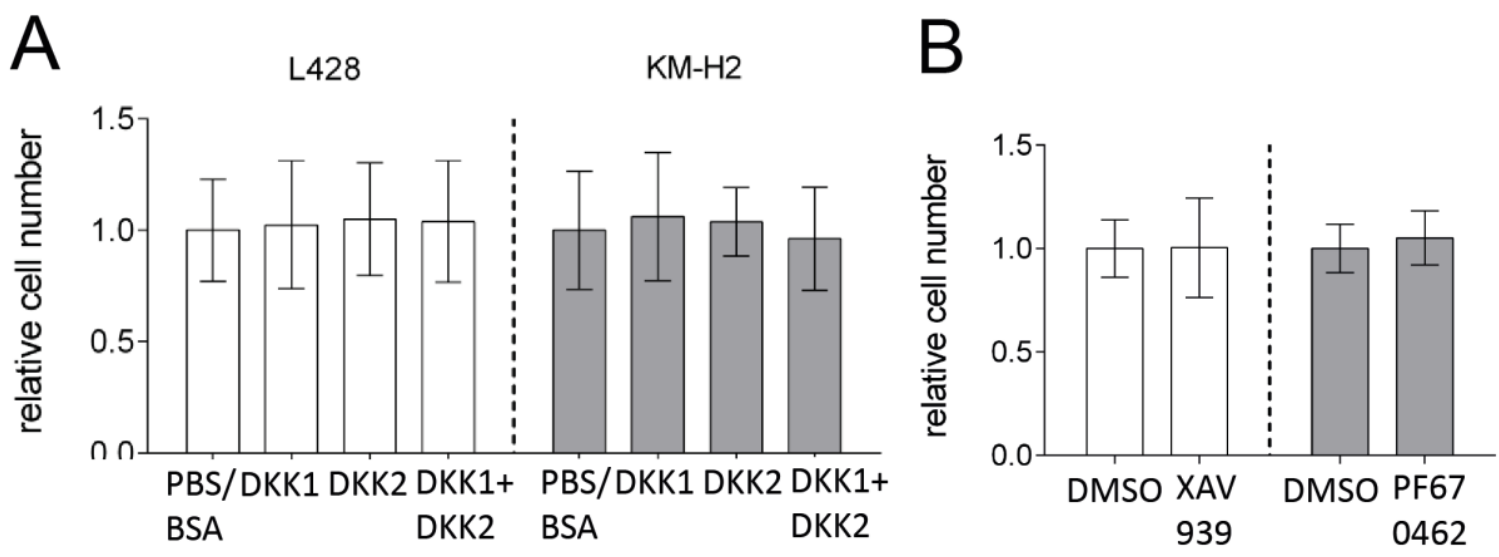

Figure 30: Inhibition of the canonical WNT pathway does not affect $\mathrm{cHL}$ cell proliferation. Relative cell numbers of $\mathrm{L} 428$ and $\mathrm{KM}-\mathrm{H} 2$ did not change after 24 hours of treatment with DKK1 and DKK2 (A), PF670462 and XAV939 (B). Of note, no significant difference in cell proliferation has been caused by inhibitor treatments (mean $\pm S D, n=3$, 2-way ANOVA with Bonferroni's posthoc test). From (Linke et al, 2016a).

To exclude potential effects of the DKK, XAV939 or PF670462 treatment on $\mathrm{cHL}$ cell proliferation, $\mathrm{cHL}$ cells were counted after the respective inhibitor treatment but no effects on cell numbers have been detected (Figure 30).

At transcription factor level both, transient and stable, knockdowns of LEF-1 as well as transient knockdown of $\beta$-catenin were performed. Migration rates were measured two days after transient nucleofection or puromycin-free culture of L428 and KM-H2 pGIPZ cell lines. Knockdowns of LEF-1 as well as $\beta$-catenin reduced $\mathrm{CHL}$ chemotaxis rates by approximately $30 \%$ (Figure 31 A-D). To exclude that reduced LEF-1 expression is compensated by the upregulation of other TCF factors RNA and protein levels of TCF7 (TCF1), TCF7L1 (TCF3) and TCF7L2 (TCF4) were controlled in LEF-1 knockdown cell lines but no clear compensation was detected (Appendix: Figure A-46).

In addition, invasion through type-I-collagen was also investigated in modified Boyden chamber assays using type-I-collagen-coated membranes. Invasion was significantly impaired by LEF-1 and $\beta$-catenin knockdown (Figure 31 E). In comparison to the migration assays with uncoated membranes the inhibition effect in the invasion assay was even bigger. These data further support the hypothesis 
that canonical WNT signalling is linked to $\mathrm{cHL}$ cell migration and invasion and therefore part of the $\mathrm{CHL}$ motility relevant signalling cascades.

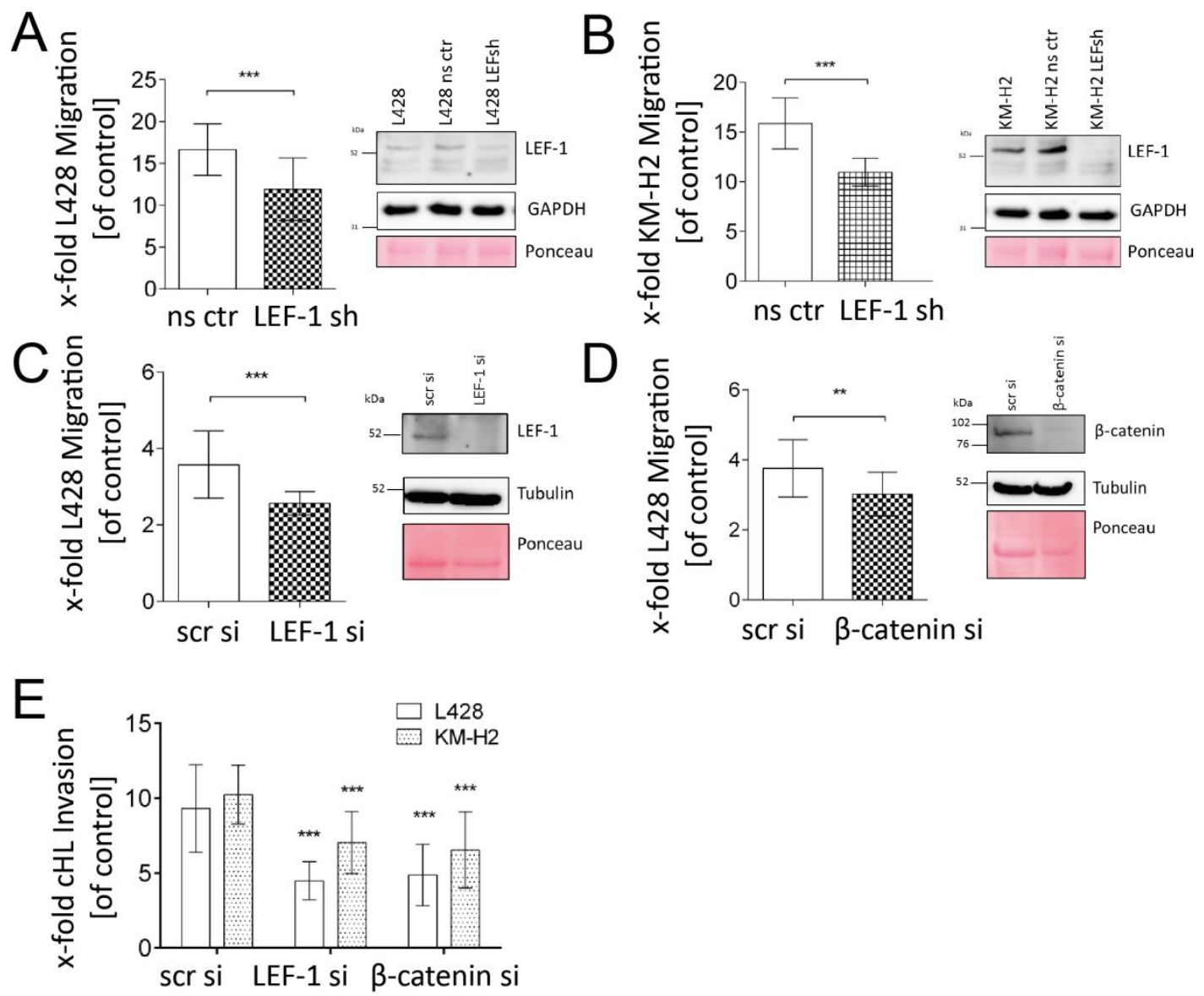

Figure 31: LEF-1 and $\beta$-catenin expression are necessary for $\mathrm{cHL}$ cell migration and invasion. Migration rates of $\mathrm{L} 428$ and $\mathrm{KM}-\mathrm{H} 2$ cells after stable (A, B) and transient LEF-1 (C) or $\beta$-catenin (D) knockdown are reduced. For protein detection specific antibodies against LEF-1, $\beta$-catenin and against GAPDH or tubulin as loading control were used. (mean \pm SD, LEF-1 si, $n=4$; $\beta$-catenin si, $n=3$; unpaired, 2-tailed t-test). (E) Invasion through type-I-collagen is decreased in L428 and KM-H2 LEF-1 and $\beta$-catenin knockdown cells. (mean \pm SD, $n=3,1$-way ANOVA and Bonferroni's post-hoc test, significance level is shown compared to respective scr si control) $\left({ }^{*} P<0.01\right.$ and $\left.{ }^{* *} P<0.001\right)$. Modified from (Linke et al, 2016a).

Since the $\mathrm{CM}$ of $\mathrm{CHL}$ cells as well as WNT5A was capable to rescue the porcupine inhibitor effect on $\mathrm{CHL}$ cell migration (Figure 7 and Figure $15 \mathrm{~B}$ ), the effect of WNT5A on $\mathrm{CHL}$ cells with an inhibited canonical WNT signalling was also tested. Of note, the simultaneous WNT5A stimulation rescued the migration impairment by the application of the canonical WNT signalling inhibitor XAV939, but not the 
Y-27632-mediated inhibition of L428 cell migration (Figure 32). This suggests that WNT5A signalling relies on functional ROCK kinases but acts independent of canonical WNT signalling.

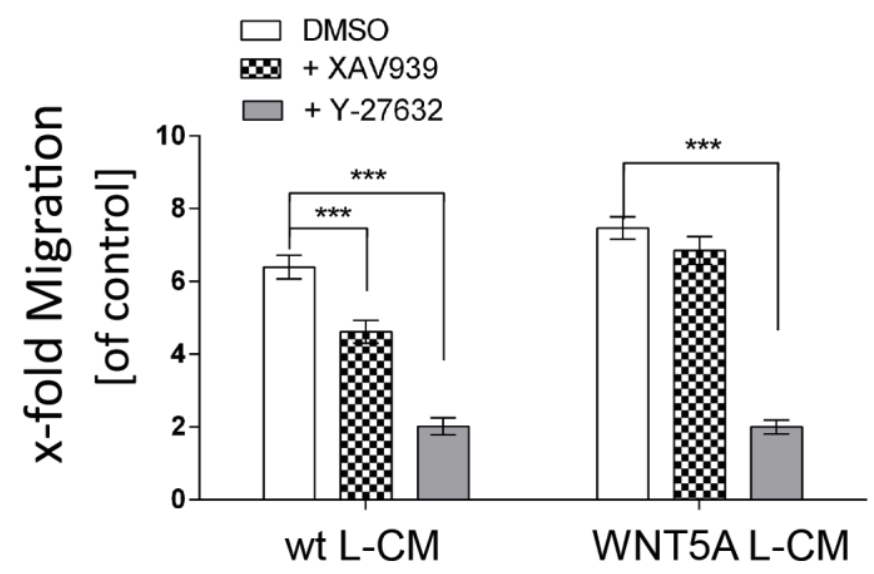

Figure 32: WNT5A can rescue inhibition of tankyrases but not ROCK. Migration of L428 cells was measured after Y-27632 or XAV939 treatment and stimulation with wildtype (wt) or WNT5A L-cell-conditioned medium (WNT5A L-CM) (mean \pm SD, $n=3,2$-way ANOVA and Bonferroni's post-hoc test). Note the rescue of XAV939-treated cells by WNT5A stimulation ( ${ }^{* *} P<0.001$ ). Modified from (Linke et al, 2016b).

\subsubsection{Migration path characteristics of $\mathrm{cHL}$ cells are impaired after LEF-1 and $\beta$-catenin knockdown}

To assess the influence of the LEF-1 or $\beta$-catenin knockdown on the typical $\mathrm{CHL}$ cell movement characteristics, siRNA-treated $\mathrm{KM}-\mathrm{H} 2$ cells were monitored over 6 hours and their corresponding cell tracks were analysed (Appendix Supplementary Videos 5-7). Fifty cells per condition were tracked in each biological experiment. Many control (scr si) $\mathrm{KM}-\mathrm{H} 2$ cells moved in an amoeboid manner and very directed towards the CCL19 gradient, while others were at least actively blebbing and turning around in the gel (Figure $33 \mathrm{~A}$ ). In contrast many LEF-1 as well as $\beta$-catenin knockdown $\mathrm{KM}-\mathrm{H} 2$ cells seemed to have difficulties to orientate correctly and squeezed in different directions before moving. Therefore, knockdown cells lacked directness in their movements (Figure 33 A). One exemplary cell for each group is shown in Figure $33 \mathrm{~A}$ below the trajectory dot plots. While control cells most often blebbed, orientated and squeezed in short 
time intervals, LEF-1 and especially $\beta$-catenin knockdown cells needed the same time interval for squeezing and turning around without moving much apart from their starting point (Figure $33 \mathrm{~A}$ red cross). The further analysis of whole group movements strengthened this impression. Cell velocities were significantly reduced from $1.1 \mu \mathrm{m} / \mathrm{min}$ to $0.6 \mu \mathrm{m} / \mathrm{min}$ and $0.4 \mu \mathrm{m} / \mathrm{min}$ due to LEF-1 and $\beta$-catenin knockdown respectively (Figure 33 B). Similarly, covered distances including euclidean and accumulated distances decreased strongly compared to control $\mathrm{KM}-\mathrm{H} 2$ cells to approximately $30 \%$ and $50 \%$ respectively (Figure $33 \mathrm{C}$ D).

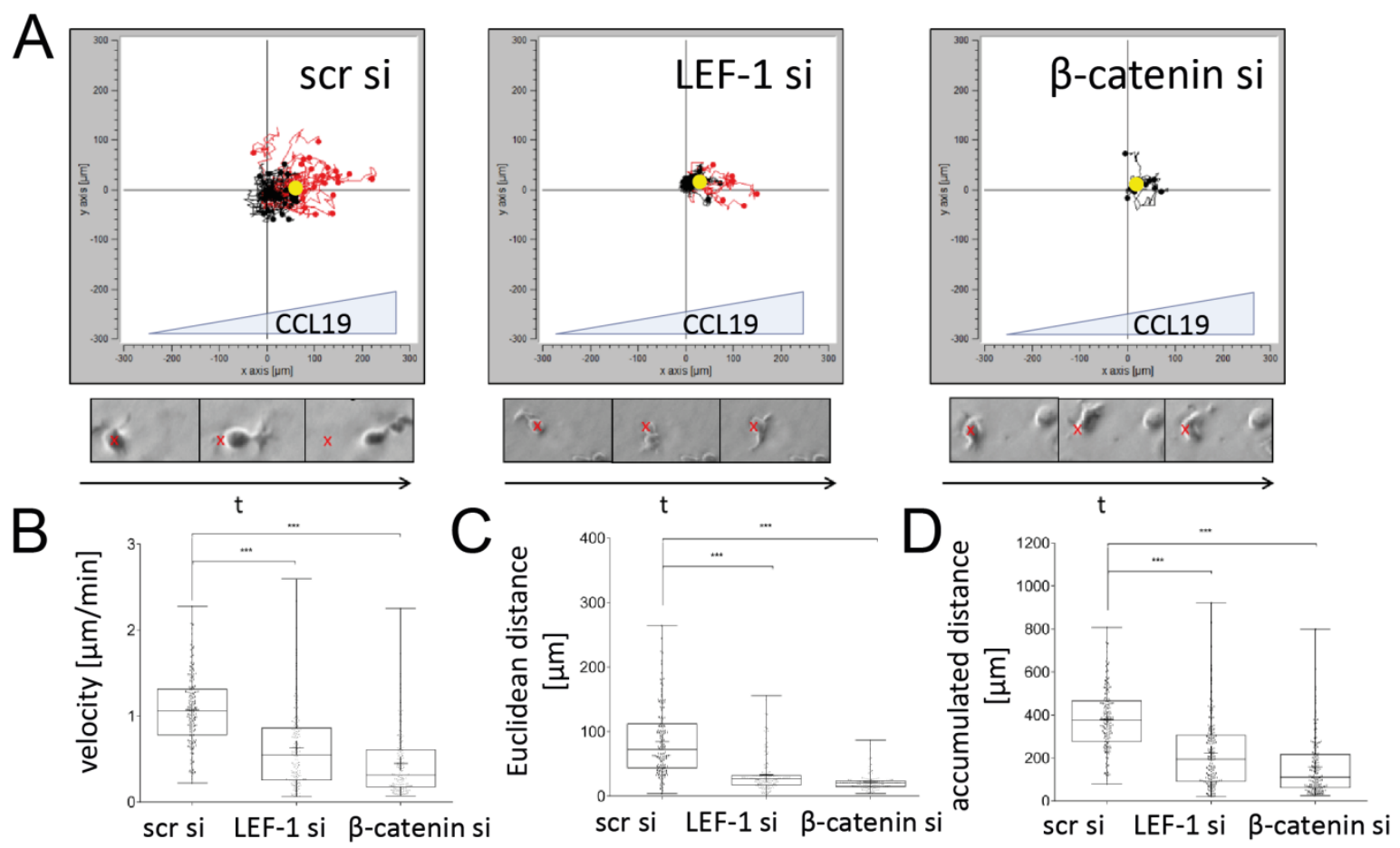

Figure 33: LEF-1 and $\beta$-catenin influence cell path characteristics of $\mathrm{cHL}$ cells in a 3D matrix. KM-H2 scr si control, LEF-1 and $\beta$-catenin knockdown cells have been embedded in type-Icollagen in $\mu$-Slide chemotaxis ${ }^{3 D}$ chambers and their cell tracks have been observed using timelapse microscopy. (A) Representative trajectory dot plots show the sector distribution of control scr si, LEF-1 and $\beta$-catenin knockdown cells. Single cell tracks covering more than $75 \mu \mathrm{m}$ euclidean distance are coloured red. For group directionality the centre of masses is shown as yellow dot. The triangle CCL19 indicates the chemokine gradient. Beneath the dot plot one representative cell movement is shown over the time. Note the impaired directionality in LEF-1 and $\beta$-catenin knockdown cells. Velocities (B), euclidean (C) and accumulated distances (D) of LEF-1 and $\beta$-catenin knockdown cells are significantly reduced compared to control scr si cells (mean \pm SD; $\mathrm{n}=3$ of each 50 trajectories; Kruskal-Wallis test, ${ }^{* * *} P<0.001$ ). Corresponding Videos $5-7$ can be found in the Appendix on page 151. From (Linke et al, 2016a). 
Next, each cell track was converted into a biostatistical fingerprint which allows the comparison of the track patterns and characteristics between control (scr si) and LEF-1 and $\beta$-catenin knockdown $\mathrm{KM}-\mathrm{H} 2$ cells in a very detailed manner for all cells tracks acquired throughout the different biological replicates. Therefore, the single cell tracks of each treatment group were hierarchically ordered according to highest similarities. In the similarity heat map the tracks of control (scr si) cells clearly separated from knockdown cells suggesting huge path differences throughout these cell groups (Appendix: Figure A-47).

By hierarchical clustering the 15 most different movement classes were calculated and analysed (Figure 34). Control $\mathrm{KM}-\mathrm{H} 2$ cells showed a particular pattern concerning the distribution throughout these 15 movement classes and the effect of LEF-1 and $\beta$-catenin knockdown on this particular distribution was investigated. The precise paths $\mathrm{KM}-\mathrm{H} 2$ cells used to move through the matrix were very divergent. Several cell tracks were composed of more or less straight and long single steps (classes 12-15) that were strikingly overrepresented by control cells. Other classes consisted almost entirely of very short steps up to halts (classes 8-11) and were predominantly represented by the LEF-1 and $\beta$-catenin knockdown cells. The third group of movement classes (1-7) contained many short steps but also already intermediate steps and were found in all cell groups. Of note classes 8-11 display tracks with several halts and short back and forth steps. These movements are not continuous and always interrupted. Since these classes were predominantly found in knockdown cells these classes might be characteristic for motility and orientation impairments. This leads to the hypothesis that canonical WNT signalling is required for directed cell movements and affects not only covered distance lengths and velocity but might also be of importance for cell paths in general. 

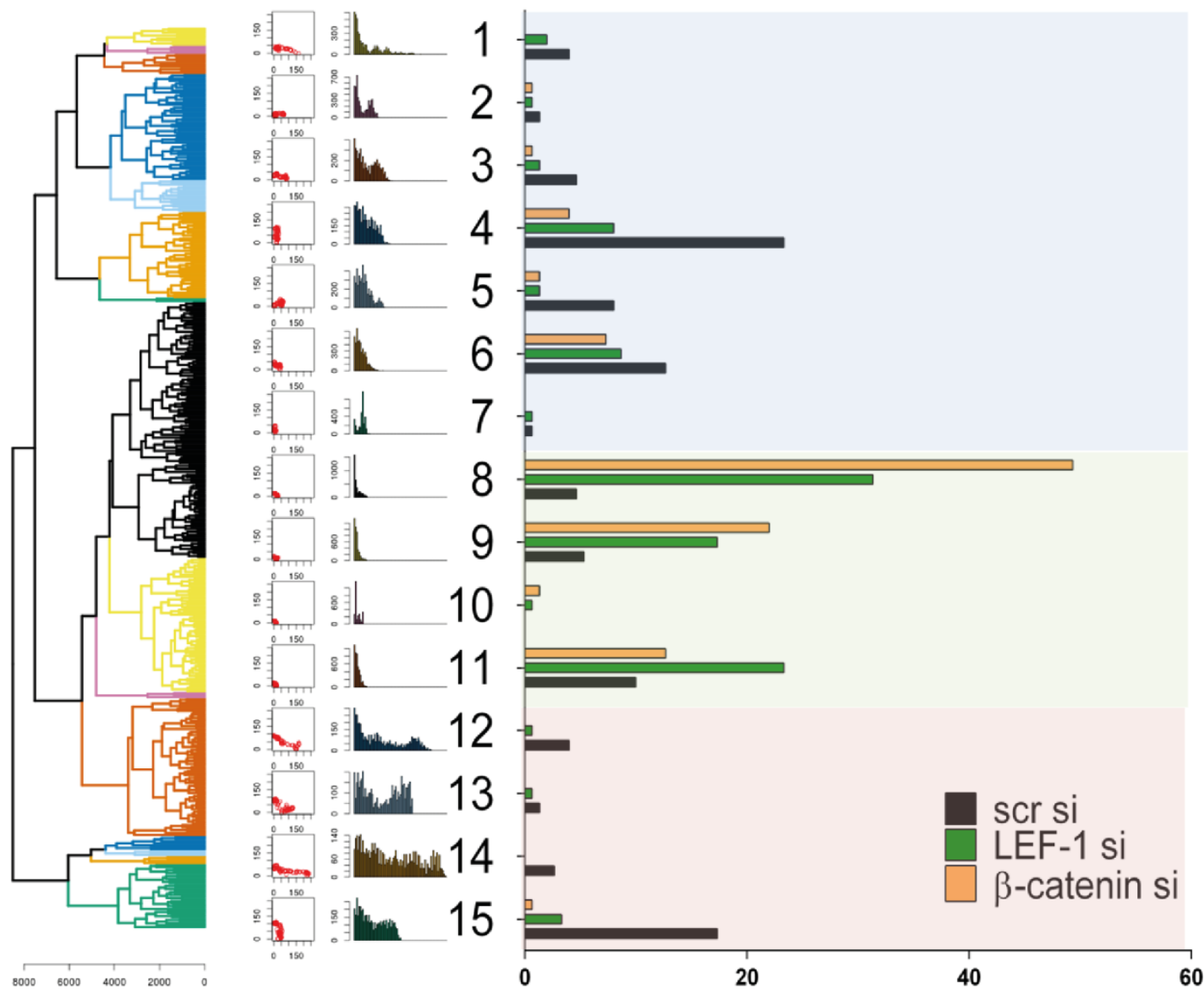

relative distribution within a group [\%]

Figure 34: LEF-1 and $\beta$-catenin influence movement classes of $\mathrm{cHL}$ cells in a 3D matrix. The 15 most different movement classes out of 450 cell tracks are shown and the corresponding distribution within each group of scr si, LEF-1 si and $\beta$-catenin si KM-H2 cells. Classes 8-11 characterized by low directionality are dominant for LEF-1 si and $\beta$-catenin si KM-H2 cells. Corresponding Videos 5-7 can be found in the Appendix on page 151. From (Linke et al, 2016a).

\section{2 $\mathrm{cHL}$ cells possess pro-angiogenic properties that depend on WNT signalling}

Since cHL cells are embedded in an infiltrate of immune and stroma cells, not only their own motility is relevant for lymphoma progression but also the direct manipulation of endothelial cells. If alterations of endothelial cells are considered as an important step in lymphoma dissemination it is important to test the influence of HRS cells on endothelial cell features. To model the initial sprouting of vessels the spheroid assay was applied. HUVEC spheroids embedded with LEF-1 
deficient cHL CM sprouted only half as often compared to control cHL CM (Figure 35 A-B). But if sprouting events occurred, neither the number of sprouting tips nor the cumulative sprout length differed between LEF-1 knockdown CM spheroids and control CM spheroids (Figure 35 C-D). This suggests that LEF-1 might regulate the secretome of $\mathrm{cHLs}$ for the initialization of the endothelial sprouting event rather than defining its characteristics.

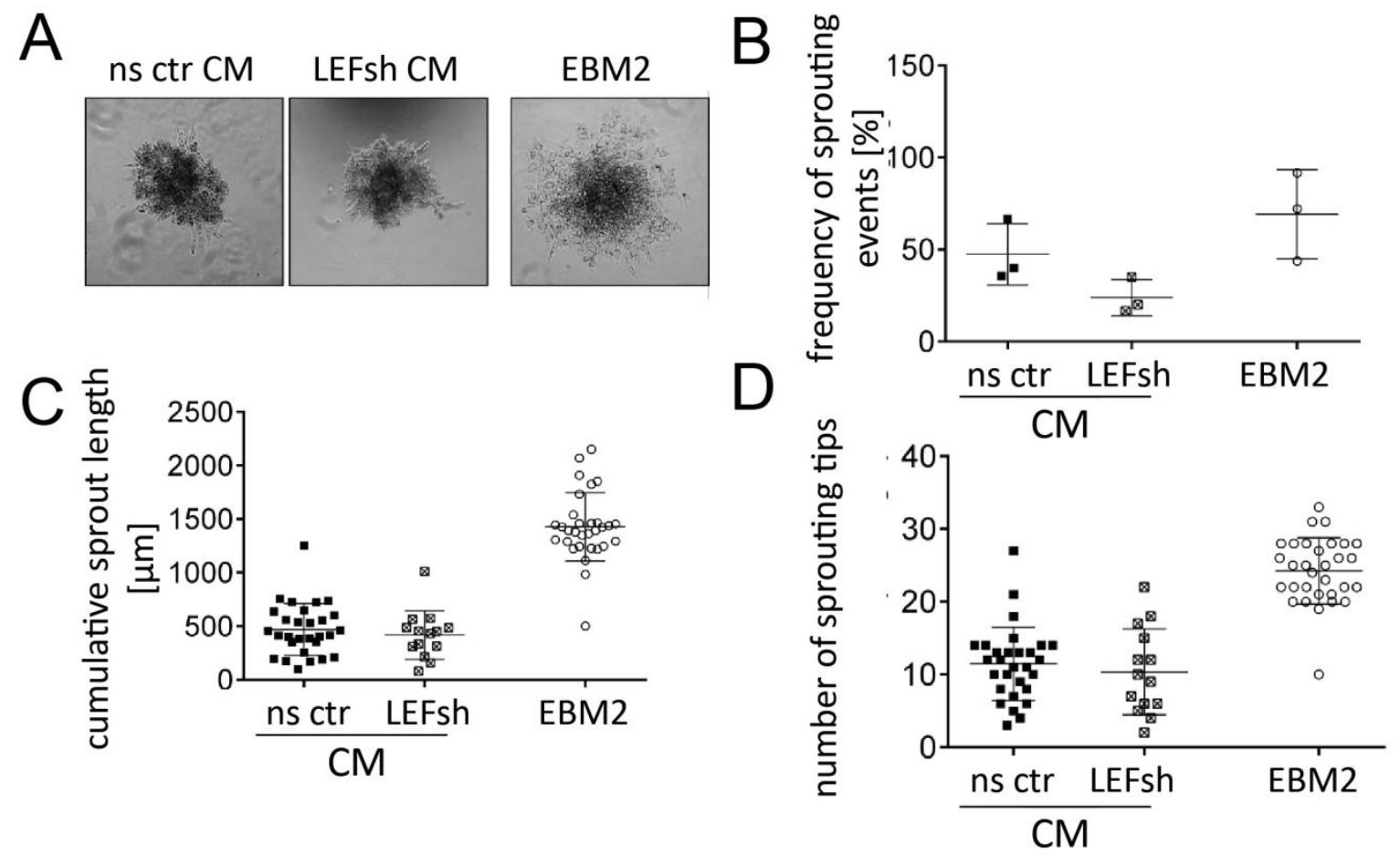

Figure 35: LEF-1 and $\beta$-catenin modify the influence of $\mathrm{cHL}$ cells on endothelial cell sprouting. (A) Representative pictures of sprouting HUVEC spheroids grown in CM of KM-H2 ns control or LEF-1 knockdown cells are shown (100-fold magnification). As positive control cell culture medium-III has been used. For analysis the frequency of sprouting events (B), the cumulative sprout lengths (C) and the number of sprouting tips (D) have been calculated. Note the only difference between control and LEF-1 knockdown CM is the sprouting frequency. Spheroids grown in RPMI medium do not sprout. (mean $\pm \mathrm{SD}, \mathrm{n}=3$ of each $12-20$ spheroids). From (Linke et al, 2016a).

In the next step of angiogenesis a lumen has to be formed by the endothelial cells. This was modelled with tube formation assays. Therefore, the HUVEC capacity to form tubes on a gel composed similar to the extracellular matrix was analysed. HUVEC cells in LEF-1 or $\beta$-catenin knockdown cHL CM formed tubes, but the tube lengths were significantly reduced compared to the control $\mathrm{cHL} \mathrm{CM}$ (Figure 
36 A-B). Thus, the LEF-1/ $\beta$-catenin-regulated secreted factors are also involved in the vessel lumen formation process.

A

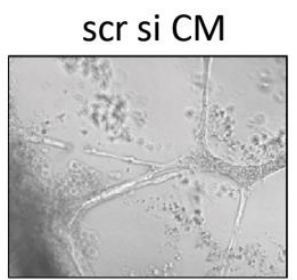

$\beta$-catenin si CM

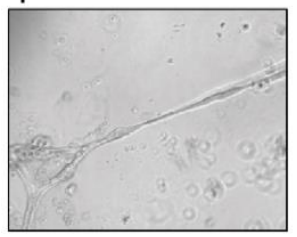

LEF si CM

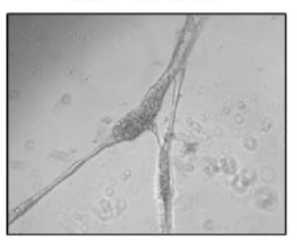

EBM2

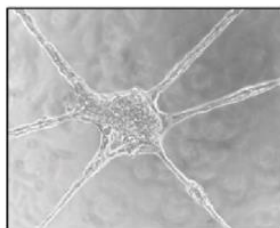

B

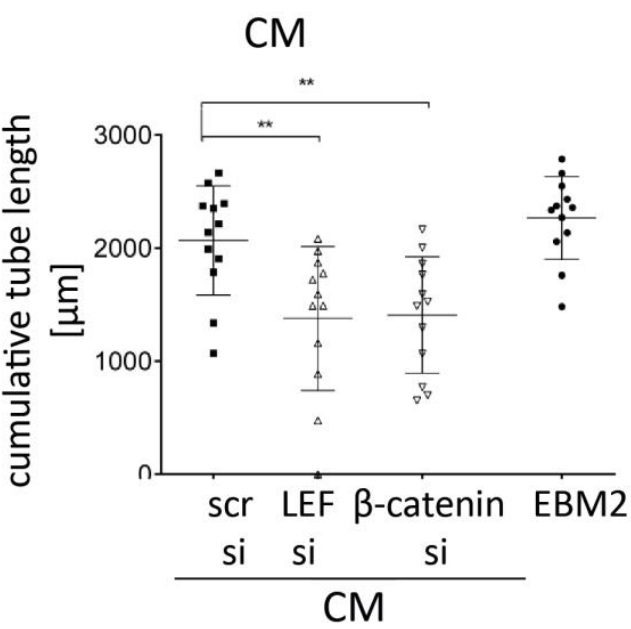

Figure 36: LEF-1 and $\beta$-catenin modify the influence of $\mathrm{cHL}$ cells on endothelial tube formation. (A) Representative pictures of HUVEC tubes formed in KM-H2 scrambled control, LEF-1 or $\beta$-catenin knockdown CM are displayed (100-fold magnification). As positive control cell culture medium-III has been used. In pure RPMI medium HUVEC cells do not form any tubes. (B) For quantification cumulative tube lengths have been measured. Cumulative tube lengths are significantly reduced in HUVEC cells treated with CM of KM-H2 LEF-1 or $\beta$-catenin knockdown cells. (mean $\pm \mathrm{SD}, \mathrm{n}=3$ of each 4 wells; 1 -way ANOVA and Bonferroni's post-hoc test, ${ }^{* *} P<0.01$ ). From (Linke et al, 2016a).

\subsubsection{Inhibition of the canonical WNT pathway impairs lymphoma outcome and vascularization in the in vivo CAM assay}

Since angiogenesis is a very complex and multi-step process, in vitro assays, which analyse single mechanisms, are limited. A very well established system to monitor the whole angiogenesis process and thus the impact of single cell components on vessel formation and destruction is the CAM assay as already described in chapter 3.1.4. The tankyrases inhibitor XAV939, which promotes the canonical destruction complex and thus inhibits nuclear $\beta$-catenin translocation, was applied to L428 cells. Exemplary L428 tumours are presented in Figure 37-A-B. Measurement of the tumour area as well as evaluation of the hemorrhages in a blinded manner revealed that tumours derived from 
inhibitor-treated cells were significantly smaller and showed less hemorrhages (Figure 37 C-D).

In addition Micro-CT technique was applied to virtually cut the tumour in order to monitor the vessel network within the whole tumour mass (Figure 38 A). DMSO-treated control tumours were interspersed with vessels and vessel residuals (Figure 38 B-C left). Interestingly, new vessels originated inside the tumour out of an already existing big CAM vessel of the tumour surface with several ramifications (Figure 38 D). In contrast, the tankyrases inhibitor-treated tumours were not able to build up such a complex vessel network inside the tumour mass (Figure $38 \mathbf{E}$ ). Consequently the results of the in vivo CAM assay are in line with the in vitro angiogenesis assays by showing a remarkable impact of canonical WNT signalling of cHLs on the endothelial vasculature.
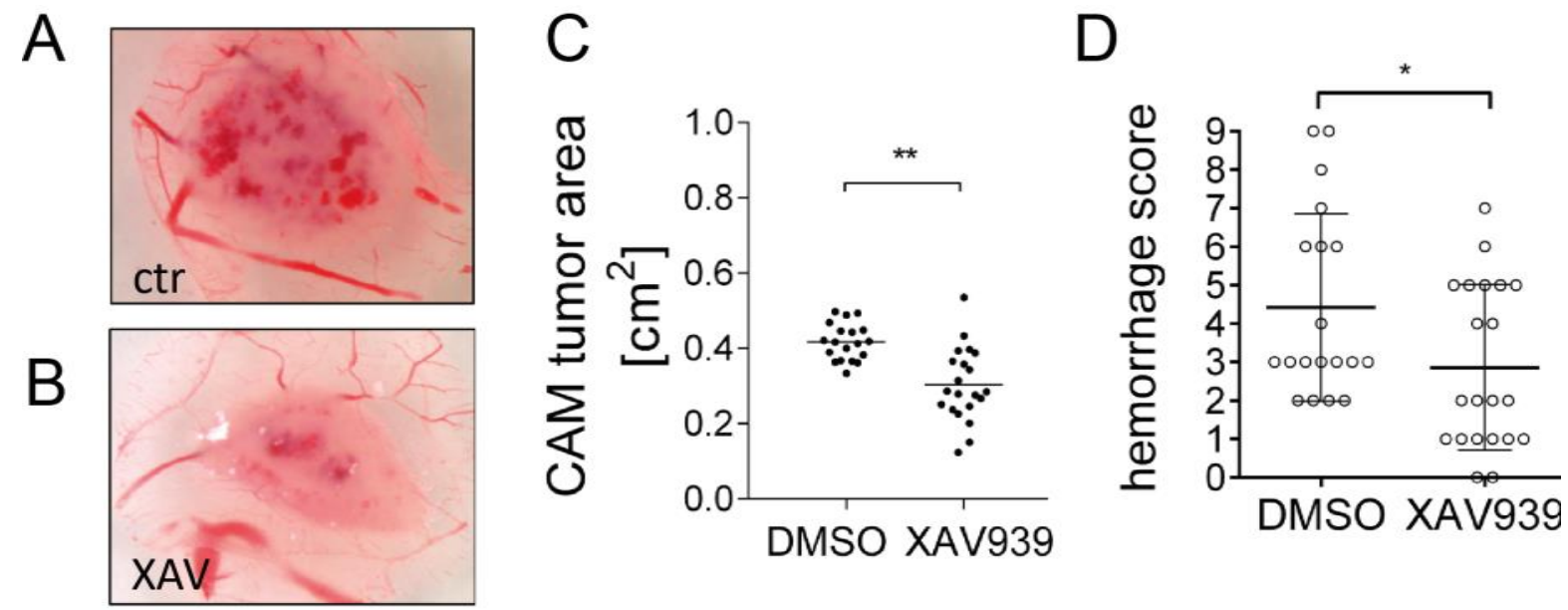

Figure 37: Impaired canonical WNT signalling by XAV939 treatment affects lymphoma outcome in the chick CAM assay. L428 cells were pre-treated for 24 hours with XAV939, inoculated on the CAM and harvested after four days of tumour growth. Representative stereo-microscopic photos (7.8 x magnification) show L428 tumours treated with DMSO (A) or XAV939 (B). Note decreased size and reduced bleedings in XAV939-treated tumours. To quantify the lymphoma outcome tumour area (C) of $L 428$ tumours and the corresponding hemorrhage score (D) have been measured (mean \pm SD, L428 DMSO, $n=19$; L428 XAV939, $n=21$; A: 2-way ANOVA and Bonferroni's post-hoc test, B: Mann-Whitney test) $\left({ }^{*} P<0.05,{ }^{* *} P<0.01\right)$. Modified from (Linke et al, 2016a). 

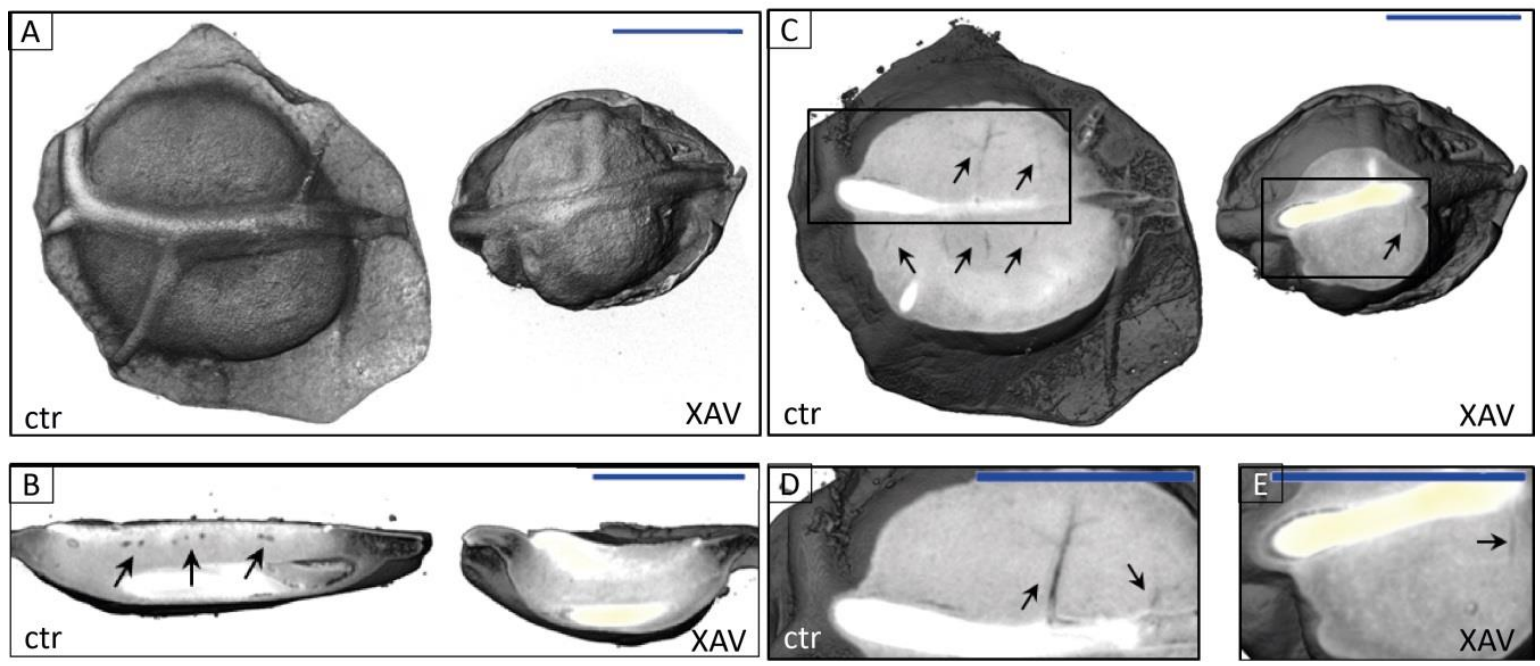

Figure 38: Impaired canonical WNT signalling by XAV939 treatment reduces lymphoma hemorrhages. (A-C) Volume rendered Micro-CT data sets show exemplary KM-H2 tumours pre-treated with DMSO (left) or XAV939 (right) (B-E: virtually cut open). Black arrows indicate vessel structure inside the tumours. In comparison to control DMSO tumours (D) the vessel network in the XAV939-treated tumour (E) is reduced despite CAM vessel access (bar=3 $\mathrm{mm}$ ). Modified from (Linke et al, 2016a).

\subsubsection{WNT5A addition enhances cHL tumour hemorrhages in the in vivo CAM model}

Porcupine inhibition as well as the inhibition of the canonical WNT pathway had a strong effect on the vasculature of in vivo cHL tumours (Figure 11 and Figure 37). Next, it was tested whether also WNT5A stimulation could affect cHL lymphoma engraftment by using WNT5A pre-stimulated CHL cells. L428 cells were stimulated with either recombinant WNT5A protein or WNT5A L-CM 24 hours prior to the inoculation. Since endogenous canonical and non-canonical WNT signalling was not blocked, the PBS and wt-L-CM controls still possessed autocrine WNT signalling. Regarding the results from the Wnt-C59 experiments (3.1.2 and 3.1.4) it was hypothesized that additional exogenous WNT5A stimulation could further promote lymphoma formation, as it was also observed for cell motility and velocity in vitro. Tumours derived from recombinant WNT5A or WNT5A L-CM pre-treated L428 cells were bigger and had increased hemorrhages compared to control tumours (Figure 39 A-B). Semi-thin sections of the corresponding CAM tumours illustrate the further increased bleeding areas induced by additional WNT5A 
stimulation (Figure 39 C-D). Although the L428 control tumours already possessed hemorrhages, the additional increase by WNT5A depicts a high potential for vessel disruption and vessel remodelling capacity.
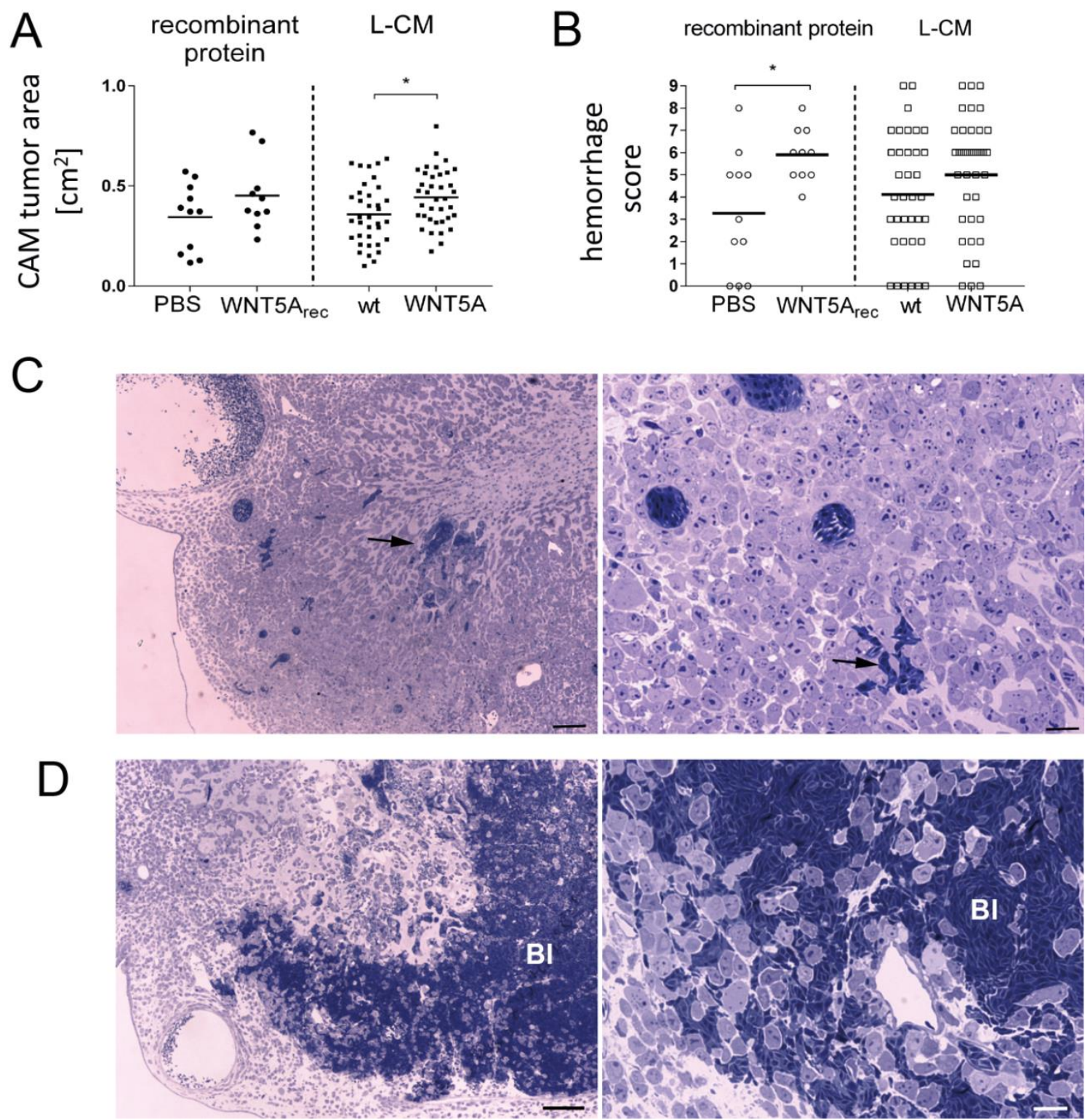

Figure 39: WNT5A pre-treatment positively affects tumour outcome in a chick CAM model. Tumour area (A) of L428 tumours and the corresponding hemorrhage scores were determined (B) after $24 \mathrm{~h}$ of pre-treatment with either WNT5A L-cell-conditioned medium (L-CM) or $100 \mathrm{ng} / \mathrm{ml}$ recombinant WNT5A protein and four days of tumour growth on the CAM. Note the increase of tumour size and hemorrhages after WNT5A stimulation (PBS, $n=11$; WNT5Arec, $n=10$; wt L-CM, $\mathrm{n}=36$; WNT5A L-CM, n=37, 2-way ANOVA and Bonferroni's post-hoc test). Representative semi-thin sections of PBS/BSA (C) or WNT5A (D) pre-treated L428 CAM tumours reveal minor hemorrhage (arrows in $\mathrm{C}$ ) in contrast to massive bleedings (BI in D) (left bar $=150 \mu \mathrm{m}$; right bar $=25$ $\mu \mathrm{m})\left({ }^{*} P<0.05\right)$. Modified from (Linke et al, 2016b). 


\subsubsection{LEF-1 and $\beta$-catenin are important for the secreted VEGFA levels of cHL cells}

Since canonical WNT signalling and especially $\beta$-catenin and LEF-1 expression in cHLs had such a strong impact on endothelial cell behaviour the underlying mechanism was investigated. The hypotheses were that the differential tumour biology may either be due to metabolic differences of the differently treated $\mathrm{cHL}$ cells themselves, or due to differences in the secretion of pro-angiogenic factors. To test the first hypothesis, NMR analyses of LEF-1 and $\beta$-catenin knockdown cells were performed (Appendix Figure A-48). However, these data revealed no major differences in content of metabolites, suggesting that the metabolic rates did not change significantly by LEF-1 or $\beta$-catenin knockdown.

The second hypothesis would suggest that LEF-1 and $\beta$-catenin knockdown cells secreted less and WNT5A pre-treated cells more pro-angiogenic factors than the control cells. One factor that can act as sprouting and lumen formation promotor on endothelial cells is VEGFA (Neufeld et al, 2001). ELISA assays of L428 and $\mathrm{KM}-\mathrm{H} 2$ control supernatants revealed VEGFA levels of 700 and $900 \mathrm{pg} / \mathrm{ml}$ respectively (Figure 40 A). Additional stimulation with WNT5A for 24 or 48 hours did not further increase these secretion levels (Figure $40 \mathrm{~A}$ ). After transfection L428 and KM-H2 control cells secreted 500 and 700 pg/ml VEGFA respectively (Figure 40 B). Importantly, under LEF-1 or $\beta$-catenin knockdown the secreted VEGFA levels dropped to $400-500 \mathrm{pg} / \mathrm{ml}$. Thus, LEF-1 as well as $\beta$-catenin expression is directly correlated with the secreted VEGFA level in cHLs.

The additional analysis of patients' microarray data revealed a clear connection between VEGFA expression and overall survival (Steidl et al, 2010a) (Figure 40 B). While approximately $90 \%$ of patients with low VEGFA expression survived 10 years or longer, only $65 \%$ with high VEGFA expression were alive after 10 years $(\mathrm{P}=.008)$. Consequently $\mathrm{cHL}$ VEGFA expression level is directly correlated with patient's survival and thus therapy success. 
A
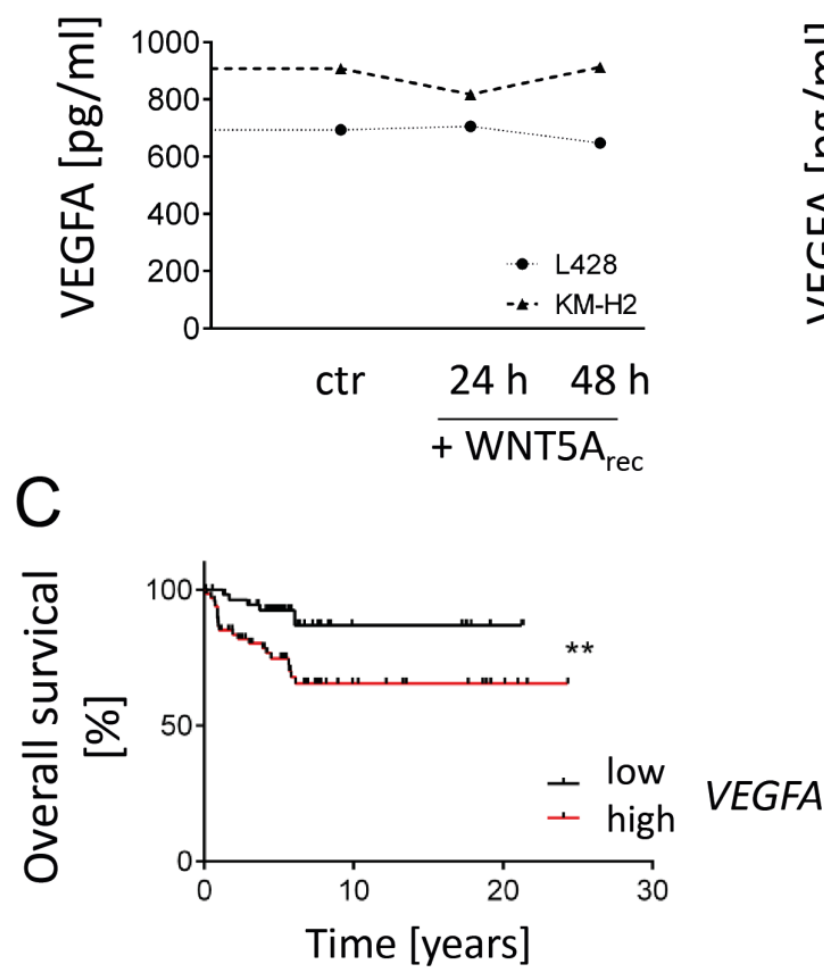

B

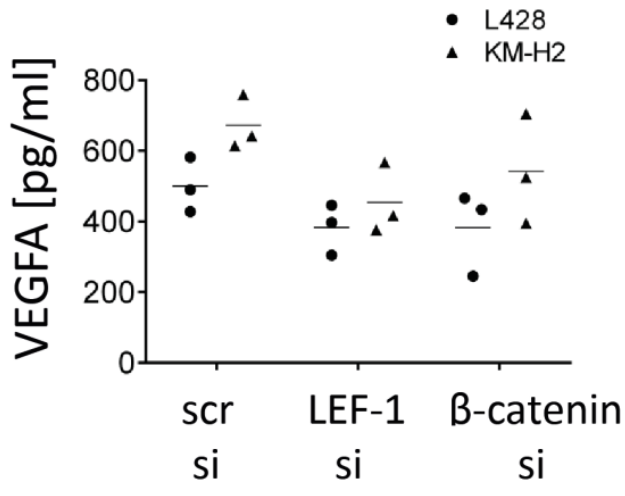

Figure 40: VEGFA secreted by cHL cells is not regulated by WNT5A but by LEF-1/ $\beta$-catenin and high VEGFA gene expression is associated with a worse overall survival in cHL patients. (A) VEGFA levels of L428 and KM-H2 cells do not clearly vary after 24 or 48 hours of recombinant WNT5A stimulation. (B) VEGFA levels of scr si control, LEF-1 si and $\beta$-catenin si L428 and $\mathrm{KM}-\mathrm{H} 2$ cell supernatants from three independent nucleofections were measured using ELISA. Note the decreased VEGFA levels after LEF-1 and $\beta$-catenin knockdown. (mean $\pm S D, n=3$ ). (C) VEGFA gene expression data obtained by Steidl et al. reveals the significantly worse overall survival in patients with high VEGFA levels (Steidl et al, 2010a) (mean $\pm S D$, low, $n=56$; high, $n=68$; Log-rank Mantel-Cox test, ${ }^{* *} P<0.01$ ). Modified from (Linke et al, 2016a). 


\section{Discussion}

Classical Hodgkin Lymphoma (cHL) is unique with respect to the fact that the malignant cells, the HRS cells, form the absolute minority of cells that are defined as the 'tumour mass' (Aldinucci et al, 2010). The infiltration with immune cells provides essential survival signals for HRS cells (Küppers, 2009; Liu et al, 2014), and it can be speculated that other mechanisms that control tumour maintenance and progression are as well regulated by interactions between HRS cells and their neighbouring cells, including the vascularized stroma.

In this thesis, it has been shown that $\mathrm{cHL}$ cell lines are characterized by a remarkable migration potential which is reflected in the efficient amoeboid type of cell migration. This cellular motility is regulated by non-canonical WNT5A and basal canonical WNT signalling. In addition, angiogenesis assays could demonstrate that $\mathrm{cHL}$ cells are able to induce vessel sprouting and tube formation of endothelial cells that also depend on CHL WNT signalling. Finally, the impact of WNT signalling was confirmed in in vivo assays and by patient's gene expression data thereby implying a role for WNT signalling in $\mathrm{CHL}$ progression.

\subsection{High migration rates are a feature of cHL cells}

$\mathrm{HL}$ dissemination is correlated with increased mortality rates (Böll et al, 2013; Guermazi et al, 2001; Introcaso et al, 2008). In HL extra-nodal involvement is seen in $10-15 \%$ of all HL cases (Guermazi et al, 2001). Meanwhile evidence has accumulated that $\mathrm{HL}$ dissemination occurs by haematogenous and lymphatic spread (Gharbaran et al, 2014). Although the mechanisms for $\mathrm{cHL}$ dissemination mostly remained to be studied, this thesis provides a first detailed description of $\mathrm{cHL}$ cell movements as well as insights into underlying signalling cascades.

One general consensus for lymphoma dissemination is the similarity to the original lymphocyte tissue-specific homing patterns. B-cells need to modify their homing signature depending on their present maturation stage. Thus, sites of B-cell dissemination might be predictable with special regard to the originating B-cell 
stage (Cyster et al, 2002). Currently two homing receptors are discussed to play a role in lymphoma dissemination: CCR7 and $\alpha 4 \beta 3$. There are observations that, for example, subsets of MCLs express the intestinal homing receptor $\alpha 4 \beta 7$ like naïve B-cells and are associated with a multifocal involvement of the gastrointestinal tract while primary MCLs with only nodal involvement lack $\alpha 4 \beta 7$ expression (Pals et al, 1994; Geissmann et al, 1998). In addition expression of the receptor chemokine (C-C Motif) receptor 7 (CCR7), which is required for B-cell entry into secondary lymphoid tissues, is down-regulated during plasma cell differentiation and is also not detected in Multiple Myeloma (Trentin et al, 2007). In contrast CLLs and MCLs with high CCR7 expression also show widespread nodal dissemination (Lopez-Giral et al, 2004). Interestingly, also cHL but not NLPHL cells express high levels of CCR7 but lack the expression of the corresponding ligands (Höpken et al, 2002). In addition, microarray data from Brune et al. show that the CCR7 expression of $\mathrm{HL}$ cells is even higher than in physiological B-cells (Appendix; Figure A-49) (Brune et al, 2008). Thus the CCR7 overexpression of $\mathrm{CHL}$ cells might be one explanation why HRS cells are found in the interfollicular zone of lymph nodes and not at their original site of derivation, the germinal centres. Nevertheless Höpken et al. already discussed the limitations of this dissemination pattern hypothesis: HRS cells in the follicular mantle zone also express CCR7 thus implying that other interactions might also contribute to the distribution of tumour cells (Höpken et al, 2002). Consequently, cHL dissemination patterns might be regulated by additional chemokines, chemokine receptors, pathway deregulations or crosstalks like WNT signalling.

This thesis provides a more detailed analysis of cHL cell movements in a CCL19 gradient over the time for the first time. The amoeboid type of migration is reflected in the high $\mathrm{CHL}$ cell migration rates compared to $\mathrm{BL}, \mathrm{DLBCL}$ and even $\mathrm{MCL}$ cell lines. Since the $\mathrm{CHL}$ cell lines L428, KM-H2 and L1236 have been established from late-stage/relapsed HL patients, it could be suggested that highly efficient motility processes might also be linked to advanced $\mathrm{CHL}$ stages. HL cells represent a highly heterogeneous group of cells concerning the classes of cell movements, with constantly turning cells, as well as slow to fast migrating cells 
that cover short to longer distances. The characteristic formation of short blebs and long protrusions will have to be investigated further with special regard to its precise function e.g. for orientation or obstacle assessment by the $\mathrm{CHL}$ cell. Further investigations should also clarify the dynamics of bleb formations and the responsible molecular composition. Moreover, $\mathrm{cHL}$ cell movements appear to be also influenced by other surrounding $\mathrm{cHL}$ cells that seem to affect the direction of movements occasionally through cell-cell contacts. Those intercellular mechanisms need to be analysed in future studies regarding their function and modifying capacity for $\mathrm{cHL}$ group movements because they might also contribute to the distribution of tumour cells as discussed by Höpken et al.(Höpken et al, 2002)

Although chemokine receptor expression patterns can determine the direction of movements a highly dynamic actin cytoskeleton is a first indispensable prerequisite for amoeboid cell migration (Miao et al, 2003; Yamazaki et al, 2005). Therefore, there is a need in understanding signalling cascades that contribute to the high dynamics of $\mathrm{cHL}$ cell movements. Next to the analysed $\mathrm{cHL}$ movement patterns and characteristics this study aimed at investigating the WNT signalling cascade that contributes to $\mathrm{cHL}$ cell motility by providing and preserving high actin dynamics.

\subsection{WNT signalling is a regulator of $\mathrm{cHL}$ cell migration and invasion}

Notably, WNT signalling has been identified as important regulator of $\mathrm{CHL}$ cell motility. As highlighted in the introduction, CLL cells are characterized by an aberrant LEF-1 expression and their migration is strongly associated with WNT/PCP signalling (Erdfelder et al, 2010; Gutierrez et al, 2010; Kaucká et al, 2013). These studies on CLL motivated us to investigate the underlying signalling mechanisms also in cHLs. Herein, the new role of canonical and non-canonical WNT signalling is highlighted as autocrine pathways for cHL cell motility and invasion. 


\subsubsection{Autocrine secreted WNT5A is an enhancer of cHL cell motility}

One major finding of this thesis is that autocrine WNTs and especially WNT5A are major drivers of $\mathrm{HL}$ cell migration and invasion in vitro. WNT5A positively affects general motility as well as the directed migration towards a chemokine and invasion rates.

WNTs have been identified as key players in early stages of haematopoiesis underlining the physiological role of WNTs in B-cell differentiation (Malhotra et al, 2008; Reya et al, 2000). Nevertheless, the role of WNTs for mature B-cells during the germinal centre reaction is still unclear. Germinal centre B-cells are the proposed cells of origin of $\mathrm{cHL}$ and aggressive NHLs like BLs or DLBCLs. Interestingly, WNT5A secreted by follicular dendritic cells is able to protect germinal centre B-cells from apoptosis thus permitting survival and maturation (Kim et al, 2012). Whether WNT5A might also affect motility of B-cells during the germinal centre reaction has not been investigated yet. Our data on the role of WNT5A in HLs would support the view that, for example, cHL cells might be able to create a corresponding morphogen gradient which thus supports the spread from the germinal centre to interfollicular sites and functional neighbouring lymph nodes. The herein described aberrant expression of WNT5A is a new feature of cHL cells.

In CML WNT5A signalling maintains CML survival upon Bcr-Abl inhibition (Gregory et al, 2010). In addition, cell survival of B-cell precursor acute lymphoblastic leukaemia is enhanced by WNT5A supporting the view of WNT5A as a protooncogene (Thiago et al, 2010). However, it also has to be noticed that under certain conditions WNT5A can act as a tumour suppressor (Roman-Gomez et al, 2007). The discovery of two WNT5A isoforms with different functions on tumour cells might be one assumption to explain the diverse and context-dependent role of WNT5A in cancer cells (Bauer et al, 2013). However, all these analysis were focused on cell survival but not cell migration behaviour. 
In CLL, an indolent NHL, PCP WNT signalling was shown to be important for CLL cell motility although the ligands are still unknown (Kaucká et al, 2013). In breast cancer WNT5A showed highest expression in the invasive mammary carcinoma cells thus serving as prominent factor for breast cancer invasiveness (MacMillan et al, 2014). Accordingly, our data for cHLs demonstrates how enhanced autocrine WNT5A secretion increases cellular motility including blebbing and velocity thus probably facilitating tumour progression and relapse. Therefore, it is reasonable to suggest that WNT5A signalling changes pathophysiological parameters of $\mathrm{cHL}$ cells to a more aggressive behaviour.

In cHL cells WNT5A mediated cell migration and invasion through FZD5, DVL3 and RHOA activation. Thus, the observation of FZD5-mediated WNT5A effects in $\mathrm{CHL}$ cells corresponds well with the recent description of a high WNT5A-FZD5 binding affinity (Dijksterhuis et al, 2015). Nevertheless also other WNTs might be able to bind to FZD5 in $\mathrm{CHL}$ cells, and also WNT5A might be able to interact additionally with other FZDs. More comprehensive expression studies of all autocrine WNTs as well as receptors will be needed for clarification. However, WNT10A, WNT10B and WNT16 could not enhance cHL cell migration under the applied experimental conditions. Mechanistically, DVL proteins have already been proven to connect FZD/G-protein signalling thereby acting as central regulators of the signalling cascade (Kilander et al, 2014). The DVL isoforms DVL1, DVL2 and DVL3 are apparently able to integrate multiple WNT signals but are also specifically able to mediate branching of WNT signalling as shown best in Xenopus laevis (Gentzel et al, 2015). Nevertheless little is known about the distinct functions of the different DVL variants in cancer. In all analysed $\mathrm{CHL}$ cell lines the interaction of WNT5A and FZD5 involves DVL3 as central mediator for cHL cell migration. Importantly, all three DVL isoforms are constitutively active in the investigated cell lines. Interestingly, the DVL2 activation is independent of porcupine, which suggests that DVL2 is independent of WNT signalling in $\mathrm{CHL}$ cells. Considering the knockdown experiments and overexpression of a dominant negative DVL3 variant DVL3 most probably has a dominant role in WNT5Amediated cHL cell migration. Recently increased expression of DVL1 and DVL3 
could be shown in brain metastases of lung cancer thus connecting DVL expression with tumour progression (Kafka et al, 2014). Consequently, DVL3 activation in $\mathrm{CHL}$ cells might be also important for lymphoma progression and future clinical studies will have to clarify whether aberrant DVL3 expression or activation is involved in $\mathrm{CHL}$ progression.

Moreover, the thesis shows the essential contribution of RHOA activation to the motility and amoeboid type of migration of $\mathrm{cHL}$ cells. It is well-known that amoeboid migration depends on $\mathrm{RHOA} / \mathrm{ROCK}$ signalling as prerequisite of motility rather than on Ras-Related C3 Botulinum Toxin Substrate 1 (Rho Family, Small GTP Binding Protein Rac1) (RAC) (Sahai \& Marshall, 2003). Nevertheless, it cannot be excluded so far that $\mathrm{CHL}$ cell movements also require activation of RAC or Cell Division Cycle 42 (CDC42). Several cancer cells are able to switch between the RAC-dependent mesenchymal and the RHOA-dependent amoeboid type of migration depending on the particular circumstances (Friedl, 2004). Similar mechanisms should also be analysed for $\mathrm{cHL}$ cells. Comparable activity measurements as performed for RHOA (chapter 3.1.10) will also be of interest for RAC and CDC42 with porcupine-inhibited or WNT5A-stimulated CHL cells. In addition, the effect of CCL19 on small GTPases like RHOA, RAC or CDC42 will have to be investigated in comparison to WNT5A stimulation.

Another approach might be the analysis of potential WNT5A target genes. WNT5A-mediated PCP signalling was of central interest in this thesis, nevertheless, it cannot be excluded that WNT5A can also activate calciumdependent NFAT-mediated WNT target genes or C-Jun N-Terminal Kinase 1/JUN (JNK/JUN)-mediated target genes. In addition the direct regulation of small G-proteins by WNT5A could not be proven in qRT-PCR assays (Zaunig, unpublished thesis). Nevertheless, it will be subject to future assays to test whether WNT5A might be able to regulate other targets e.g. of the canonical WNT pathway. Therefore, RNA interference, specific inhibitors or genome editing could be applied to test, for example, JNK-regulated gene expression changes following WNT5A signalling. 


\subsubsection{Canonical WNT signalling modifies especially collagen-induced $\mathrm{cHL}$ motility}

In addition to the WNT5A-mediated PCP signalling of $\mathrm{cHL}$ cells also canonical WNT signalling has been studied. Since WNT5A was unable to rescue porcupine inhibited $\mathrm{CHL}$ cells completely and stimulation with supernatant of $\mathrm{CHL}$ cells could further increase the already existing basal nuclear fraction of $\beta$-catenin, the rationale of an autocrine canonical WNT signalling in $\mathrm{CHL}$ cells evolved. Canonical WNT signalling of $\mathrm{CHL}$ cells has been blocked at different levels of the pathway, which constantly resulted in reduced chemotactic migration in Boyden chamber assays. Interestingly, the migratory deficiencies induced by LEF-1- or $\beta$-cateninknockdown, were even more obvious in invasion assays with type-I-collagen, and the most obvious in 3D-chemotaxis chambers, where the cells are completely embedded in type-I-collagen. These observations suggest a specific role for canonical WNT signalling in collagen-mediated $\mathrm{cHL}$ cell movements, and indicate functions for the expression of molecules that interact with collagen, e.g. of the Discoidin Domain Receptor Tyrosine Kinase 2 (DDR2) signalling pathway (Afonso et al, 2013). DDR2 is a collagen receptor which is specifically activated by type-I and type-III-collagen (Vogel et al, 1997; Shrivastava et al, 1997). Renné et al. showed that approximately $65 \%$ of patients with the nodular sclerosis and $25 \%$ patients of the mixed cellularity subtype express DDR2 (Renné et al, 2005). Conceivable LEF-1/ß-catenin targets might comprise the DDR2 receptor regulation pathway or direct signalling members and need to be investigated.

In a medical doctor thesis it was analysed whether LEF-1/B-catenin regulate PCP target genes like WNT5A or FZD5 directly but no correlation has been found so far (Harenberg; unpublished thesis). Nevertheless LEF-1/ $\beta$-catenin target genes might directly or indirectly affect general secretion mechanisms. To test this hypothesis a general secretome analysis of untreated $\mathrm{cHL}$ cells in comparison to porcupineinhibited, LEF-1/ß-catenin knockdown and WNT5A-stimulated $\mathrm{CHL}$ cells would clarify the effect of WNT signalling on the $\mathrm{CHL}$ secretome. 


\section{3 $\mathrm{cHL}$ cells possess pro-angiogenic properties that rely on WNT signalling}

In this thesis the angiogenic potential of $\mathrm{CHL}$ cells has been assessed with various in vitro assays and the in vivo CAM assay. Angiogenic properties have not yet been evaluated for $\mathrm{CHL}$ cells, although such studies including CAM assays had been proposed by Marinaccio et al. (Marinaccio et al, 2014). Importantly, cHL cells are able to induce the capacity of endothelial cells to sprout and to form tubes thus promoting angiogenesis processes. Moreover, in our group it has been shown, that $\mathrm{CHL}$ cells can also attract endothelial cells and increase their migration capacities (Harenberg; unpublished thesis).

The dissemination patterns of HL have been discussed since the 1960s but initially focused on the lymphatics as route for the spread to contiguous lymph node chains (Rosenberg \& Kaplan, 1966; Kaplan, 1971; Smithers et al, 1974; Mann et al, 1986). The involvement of the spleen and other distant tissues like the bones has been discussed as hints for the additional haematogenous spread of $\mathrm{HL}$ (Horan, 1969; Halie et al, 1972b; Vockerodt et al, 1998). In 5-10\% of HL cases dissemination occurs via the haematogenous route (Guermazi et al, 2001). Moreover, the presence of abnormal cells, that are believed to be circulating $\mathrm{HL}$ cells by now, supports the view of a haematogenous route in addition to the spread via the lymphatics (Halie et al, 1972a; Zucker-Franklin et al, 1983; Sitar et al, 1994). Furthermore, the $\mathrm{cHL}$ cell line $\mathrm{L} 1236$ has been established from circulating peripheral blood mononuclear cells of an advanced stage $\mathrm{HL}$ patient (Wolf et al, 1996; Kanzler et al, 1996a).

Therefore, it is reasonable to conclude that $\mathrm{HL}$ progression involves interactions with endothelial cells as well as manipulations of endothelial cell behaviour. The migration and adhesion of lymphoma cells to HUVECs is a model to study the dissemination process of the tumour cells, which has a major impact on the outcome of the disease. Although not investigated for $\mathrm{cHL}$, the adherence to HEVs has been associated with the dissemination potential of Non-Hodgkin lymphomas, which has been confirmed in lymphoma mouse models (Stauder et al, 1993; 
Bargatze et al, 1987). Therefore, endothelium-mediated chemotaxis and adherence of lymphoma cells to endothelial cells can be regarded as parameters for $\mathrm{cHL}$ progression. Given this, the question arises if $\mathrm{cHL}$ cells gain an additional benefit from their proximity to endothelial cells, despite the apparent induction of angiogenesis and facilitation of dissemination. One hint comes from the studies by Fhu et al. (Fhu et al, 2014), who have shown that cHL cells actively secrete lymphotoxin- $\alpha$, which caused the upregulation of adhesion molecules in endothelial cells thereby recruiting $\mathrm{CD}^{+}$naïve T-cells. This suggests that endothelial cells can actively participate in the recruitment of lymphoma-supporting T-cells, and thereby shape the $\mathrm{cHL}$ microenvironment towards a pro-tumourigenic niche. The secretion of VEGF-A by $\mathrm{cHL}$ cells additionally fits into this scenario, but suggests an additional function for endothelial cells in $\mathrm{cHL}$ progression. In a previous study, $70.6 \%(41 / 61)$ of immunostained $\mathrm{cHL}$ samples were positive for VEGF-A (Doussis-Anagnostopoulou et al, 2002). The reevaluation of published patient's data shows that high VEGF-A levels correlate with a significantly worse overall survival (Figure $40 \mathrm{C}$ ) (Steidl et al, 2010a). In this thesis evidence is provided for WNT-regulated signalling mechanisms of VEGF-A secretion in $\mathrm{CHL}$ cells. VEGF-A has been identified as a factor secreted in a LEF-1- and $\beta$-catenindependent manner by $\mathrm{cHL}$ cells. Nevertheless, it cannot be ruled out that the secretion of other endothelial modulating factors is regulated by canonical WNT signalling in cHL cells. To assess the complete effects of LEF-1 and $\beta$-catenin signalling also in relation to WNT signalling interventions in $\mathrm{cHL}$, a broad secretome analysis must be performed in future experiments. However, it cannot be excluded that autocrine secreted WNTs that activate WNT signalling in $\mathrm{CHL}$ cells also influence endothelial cells. Activated canonical WNT signalling in HUVEC cells has already been proven to induce endothelial cell invasion and thus may contribute to the complex effects of $\mathrm{cHL}$ supernatants on endothelial cells (Planutiene et al, 2011).

In this thesis HUVECs were used as model system to analyse the influence of $\mathrm{CHL}$ cells on blood vessel structures. However, it is obvious that the effect of $\mathrm{cHL}$ cells on lymphatic vessels has to be clarified by using, for example, lymphatic 
microvascular endothelial cells (LECs). It will be of interest whether $\mathrm{CHL}$ cells are also able to induce lymphangiogenesis or whether their influence is specifically concentrated on endothelial cells.

In summary, autocrine activated WNT signalling contributes to the pro-angiogenic properties of $\mathrm{cHL}$ cells at least by mediating VEGFA secretion through LEF-1/ß-catenin. Interestingly, $\mathrm{CHL}$ cells are able to migrate towards ECs in response to chemokines and also attract ECs via VEGFA secretion. Importantly, for both processes particularly canonical WNT signalling in lymphoma cells is a prerequisite.

\subsection{In vivo Lymphoma engraftment is significantly affected by both, canonical and non-canonical, WNT signalling}

In addition to the autocrine role of WNT5A and canonical WNT signalling in the regulation of $\mathrm{CHL}$ cell migration, invasion and adhesion evidence accumulated for additional paracrine effects of WNTs. In the chick chorio-allantoic assay lymphoma development is WNT dependent. Inhibition of $\mathrm{CHL}$ WNT secretion and the canonical WNT pathway impaired lymphoma outcome while WNT5A stimulation increased lymphoma development. Regarding the in vitro analyses of $\mathrm{CHL}$ cell interaction with HUVECs WNT signalling might also be important in the regulation of vessel integrity in lymphomas. Vascularization of lymphoma depends on canonical WNT signalling and also on WNT5A.

Recently, angiogenic activity of WNTs has been observed in non-small-cell lung cancer (NSCLC) and malignant melanoma (Yao et al, 2014; Ekström et al, 2014). In NSCLC high WNT5A expression is associated with higher microvessel density, vascular mimicry and worse clinical outcome (Yao et al, 2014). However, in absence of reliable mouse models for $\mathrm{HL}$ we used the CAM assay to assess $\mathrm{CHL}$ engraftment in vivo. The massive bleeding in WNT5A-stimulated cHL is obviously a result of vessel disruption illustrating the high vessel dynamics within the lymphoma. Whether the vessel destructive activity is directed against pre-existing 
or newly generated vessels still needs to be investigated. Nevertheless, it is reasonable to conclude that WNTs affect both angiogenesis and vessel integrity in cHLs. The hemorrhages may open up an additional haemogenic route for dissemination. As $\mathrm{cHL}$ cells are characterized by an amoeboid migration it is interesting to note that also several non-small-cell lung cancer cell lines are characterized by this migration type (Carragher et al, 2006). Although in vitro WNT5A is unable to stimulate migration and proliferation of endothelial cells (Samarzija et al, 2009) and WNT5A stimulation could not enhance VEGFA secretion, the data suggest that WNT5A is not only promoting adhesion to endothelial cells (HUVEC), but it may also induce new vessels. In malignant melanoma it has been shown that the secretion of pro-angiogenic factors like VEGFA or IL-6 is mediated by WNT5A (Ekström et al, 2014). As HL cells secrete IL-6 it is reasonable to study the interaction of this cytokine with WNTs in the subsequent assays.

Additionally, inhibition of canonical WNT signalling reduced lymphoma outcome, namely lymphoma size and hemorrhages, in vivo. Obviously, parts of these observations can be explained by reduced VEGF-A secretion as observed after LEF-1 and $\beta$-catenin knockdown. However, as discussed in chapter 4.4, other targets of canonical WNT signalling of $\mathrm{cHL}$ cells might contribute to the WNTdependent lymphoma outcome in $\mathrm{CHL}$. As inhibition of canonical/non-canonical WNT signalling did not inhibit $\mathrm{cHL}$ cell proliferation nor did LEF-1/ $\beta$-catenin knockdown change metabolite's turnover a different lymphoma outcome due to proliferation seems not very likely. But another hypothesis might involve the affected chemotaxis and invasion of $\mathrm{CHL}$ cells after WNT signalling inhibition. It will have to be tested whether the reduced ability to adhere and invade impedes already the initial settling on the CAM and the subsequent invasion through the chorionic epithelium. In that case WNT-inhibited lymphomas would have a survival disadvantage from the very beginning of tumour development that could probably account for the drastic differences in tumour outcome after four days of tumour growth on the CAM. In support of this scenario also the impaired chemotaxis of the $\mathrm{cHL}$ cells themselves towards CAM blood vessels could contribute to worse 
nutrient supply of the tumour and therefore limit tumour growth. Those considerations could be investigated by more comprehensive CAM assays at different time points and by using immunohistochemistry, electron microscopy as well as Micro-CT.

\subsection{Therapy of $\mathrm{cHL}$ and future prospects}

Besides the advantages of CAM assays to monitor $\mathrm{cHL}$ engraftment in vivo there are obvious limitations before these results can be extrapolated to human beings. In order to bridge the gap towards the clinic we cooperated with the working group of Prof. Klapper (Section Haematopathology, UKSH Campus Kiel) during the time of the thesis. Based on the promising results from the analysis of $\mathrm{HL}$ patient's microarray data of publically available data bases, we decided to stain tissue microarrays of HL patients for LEF-1. In total $27 \mathrm{cHL}$ samples have been stained whereof 18 samples were of the nodular sclerosis type and 9 of the mixed cellularity type. LEF-1 positive HRS cells were found in 3/9 (33\%) mixed cellularity type and 1/18 (6 \%) nodular sclerosis subtype of $\mathrm{cHL}$ (Linke et al, 2016a, submitted) (Figure 41). Since LEF-1 expression within the HRS cells is observed in a proportion of mixed cellularity type $\mathrm{cHL}$ canonical WNT signalling might play a role for that subgroup of patients.

In general the therapy of $\mathrm{cHL}$ comprises chemotherapeutic regimens, but has not until recently focused on the lymphoma-endothelium interplay as a potential target. Currently, a single group study (NCT00722865) investigates the effects of anti-VEGFA monoclonal antibodies (bevacizumab) in combination with the ABVD chemotherapeutic regimen, and may provide new insights into the clinical use of bevacizumab for $\mathrm{cHL}$ by the end of 2016. In an earlier study the effects of bevacizumab in five patients with refractory and multiple-relapsed Hodgkin lymphoma were investigated (Reiners et al, 2009). The combined treatment of bevacizumab with the chemotherapeutic agent gemcitabine led to partial or complete remission in 3 of 5 patients. Biological effects like tumour size or serum CD30 levels were affected under bevacizumab therapy only in patients with 
reduced serum VEGFA levels. This first promising result needs to be further investigated in larger studies in comparison with a control group. Our immunohistochemistry results would additionally suggest a further discrimination between the nodular-sclerosis and mixed cellularity subtypes of $\mathrm{cHL}$ for the stratification of such studies.
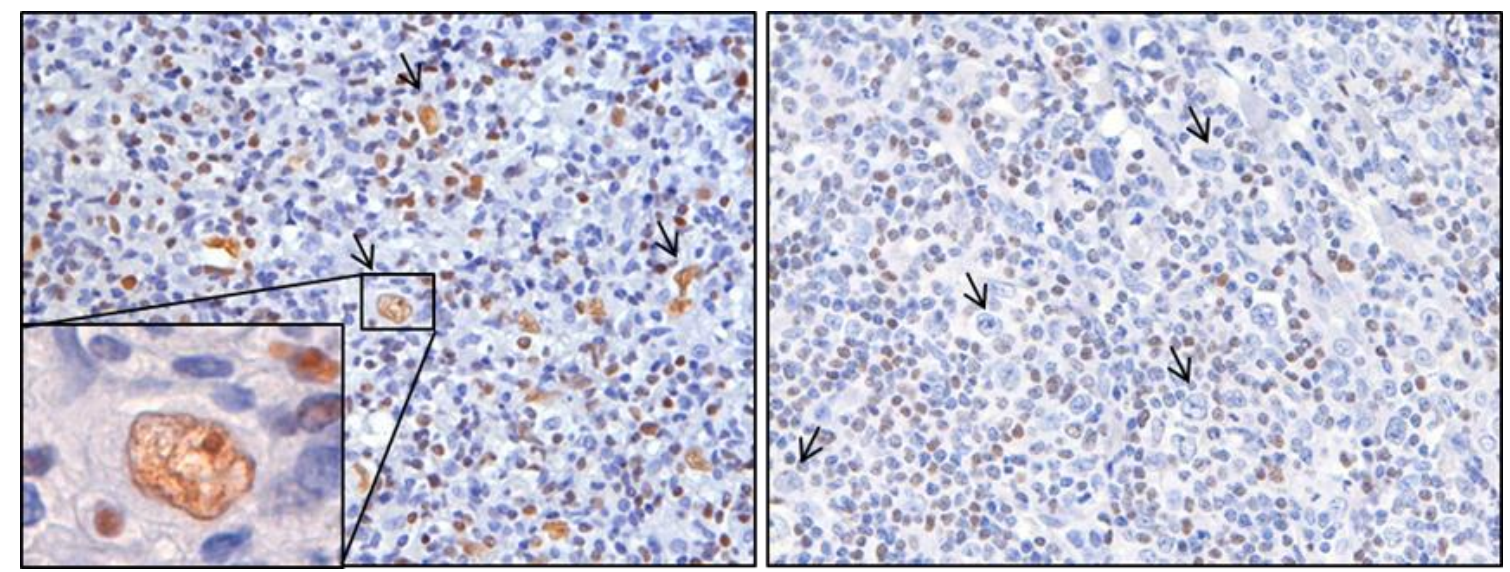

Figure 41: Positive LEF-1 staining was found in 3/9 (33\%) mixed cellularity cHL samples. Immunohistochemical staining of LEF-1-positive (left) and negative (right) HRS cells of mixed cellularity type patients. HRS cells show nuclear LEF-1 staining only in the left case (inlet).In some bystander cells also the nuclear LEF-1 staining can be observed. Adopted from (Linke et al, 2016a).

Another up-to-date therapy strategy concentrates on the highly important $\mathrm{cHL}$ microenvironment (see chapter 1.1.3) by targeting immune checkpoints. Antiprogrammed cell death 1 (PD-1) antibodies like nivolumab abolish the lymphomamediated T-cell blockade thereby inducing T-cell-anti-tumour-activity (Okazaki \& Honjo, 2007; Ribas, 2012). Nivolumab treatment of $\mathrm{cHL}$ patients with several therapy failures, including relapses after autologous stem-cell transplantation and BV treatment, still caused a remarkable progression-free survival rate of $86 \%$ (95\% Cl 62-95) at 24 weeks (Ansell et al, 2015). As consequence of these successful and new approaches new trials plan to combine BV-based treatment strategies with other drugs like nivolumab to treat $\mathrm{HL}$ patients with high response rates but manageable drug toxicities thereby probably changing the standard of care of HL patients (Stathis \& Younes, 2015). Of note, drugs targeting the HRS cells' motility or migration capacity are not yet discussed but might also be 
candidates for combination therapies as it is increasingly discussed also as add-on to standard therapies for solid cancers (Wells et al, 2013). Porcupine might be, for example, one interesting target since an enzyme might be easier to address than protein-protein interactions and an additional combination with the anti-CD30 antibody would assure extra-specificity. Targeting molecular mechanisms involved in $\mathrm{cHL}$ chemotaxis might therefore be used to target the $\mathrm{cHL}$ dissemination potential as add-on therapy. 


\section{Summary and Conclusions}

Cancer cell motility is one feature associated with cancer progression, metastasis and therapy resistance. Especially movements towards endothelial cells and the general lymphoma-endothelial interplay are of particular interest for an improved understanding of lymphoma dissemination. In this thesis the motility of cHL cells and their ability to influence endothelial cells were investigated with special regard to the WNT signalling.

Amoeboid $\mathrm{HL}$ cell migration, invasion and adhesion capacities depend specifically on autocrine WNT signalling. Therefore, a model is proposed in which $\mathrm{CHL}$ cells secrete WNT ligands at least partly on EVs to induce autocrine signalling cascades in cHL cells. One very important autocrine function has been identified for the WNT5A-FZD5-DVL3-RHOA signalling cascade that is central to modify the $\mathrm{cHL}$ cytoskeleton. Secreted WNT5A of $\mathrm{cHL}$ cells is able to induce $\mathrm{cHL}$ cell migration and invasion by enhancing motility parameters. While WNT5A protein was present on EVs of $\mathrm{CHL}$ cell lines evidence accumulated that $\mathrm{CHL}$ cells also secrete at least one not yet identified canonical WNT ligand to sustain a basal canonical WNT pathway activity in the cells. Canonical WNT signalling of $\mathrm{CHL}$ cells via $\beta$-catenin and LEF-1 mediates $\mathrm{CHL}$ cell migration possibly through target genes involved in cytoskeleton rearrangement and perhaps in the regulation of the noncanonical pathway. Since canonical WNT signalling inhibition had the strongest effects in collagen-based assays it is also reasonable to investigate target genes in collagen-induced chemotaxis signalling cascades.

Furthermore, by using a chick CAM xenograft $\mathrm{CHL}$ model a new paracrine mode of interaction of $\mathrm{CHL}$ cells with the vasculature has been revealed. Inhibition of WNT secretion reduces $\mathrm{CHL}$ lymphoma size and affects the whole vasculature of the tumours. While additional WNT5A stimulation further increased tumour hemorrhages, inhibition of canonical WNT signalling caused a remarkable impairment of the lymphoma vasculature network. These pro-lymphomagenic effects further strengthen the important role of WNT signalling for HL pathophysiology. One possible mechanistic explanation of the paracrine WNT 
effect is the regulation of VEGFA secretion. LEF-1 and $\beta$-catenin but apparently not WNT5A mediate the secretion of VEGFA thus influencing endothelial cell migration, sprouting and vessel tube formation. Since LEF-1 expression can be observed in $33 \%$ of mixed cellularity type $\mathrm{HL}$ and high VEGFA expression is associated with a worse overall survival in $\mathrm{CHL}$ patients, the data support the concept that basal canonical WNT signalling plays a critical role for lymphoma progression in a subset of $\mathrm{cHL}$. Whether targeting WNT or VEGFA signalling might become a promising target for the treatment of patients will remain to be elucidated in corresponding clinical trials. An overview scheme of all herein analysed WNT effects is provided in Figure 42. All in all, a deeper understanding of the regulators of lymphoma dissemination may provide new targets to prevent progression, and failures from currently used treatment modalities. WNT signalling might be a promising diagnostic and therapeutic target for $\mathrm{cHL}$ in late stages and relapses, and should be investigated in corresponding clinical trials.

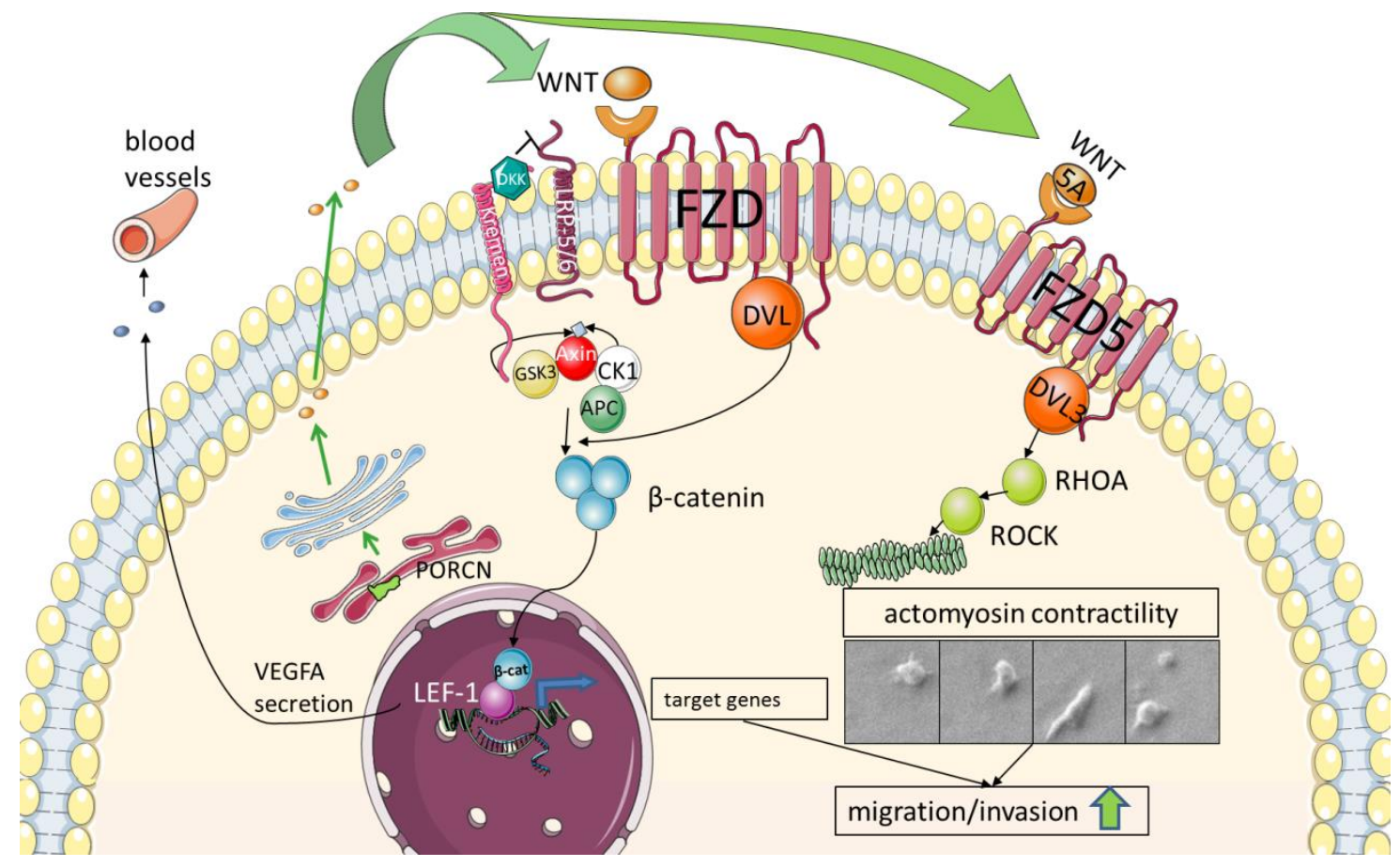

Figure 42: Scheme of autocrine WNT5A signalling loop and canonical WNT signalling in cHLs. The scheme is composed of porcupine-dependent WNT secretion and autocrine WNT5A signalling via FZD5, DVL3 and RHOA to stimulate $\mathrm{CHL}$ migration as well as autocrine canonical WNT signalling that stimulates migration possibly through target gene regulation but also VEGFA secretion. Secreted VEGFA levels influence blood vessel characteristics like sprouting or tube formation. 


\section{Bibliography}

Afonso P V, McCann CP, Kapnick SM \& Parent CA (2013) Discoidin domain receptor 2 regulates neutrophil chemotaxis in $3 \mathrm{D}$ collagen matrices. Blood 121: $1644-1650$

Agur A, Amir G, Paltiel O, Klein M, Dann EJ, Goldschmidt H \& Goldschmidt N (2015) CD68 staining correlates with the size of residual mass but not with survival in classical Hodgkin lymphoma. Leuk. Lymphoma 56: 1315-1319

Alber G, Kim K-M, Weiser P, Riesterer C, Carsetti R \& Reth M (1993) Molecular mimicry of the antigen receptor signalling motif by transmembrane proteins of the Epstein-Barr virus and the bovine leukaemia virus. Curr. Biol. 3: 333-339

Aldinucci D, Gloghini A, Pinto A, De Filippi R \& Carbone A (2010) The classical Hodgkin's lymphoma microenvironment and its role in promoting tumour growth and immune escape. J. Pathol. 221: 248-263

Aldinucci D, Lorenzon D, Cattaruzza L, Pinto A, Gloghini A, Carbone A \& Colombatti A (2008) Expression of CCR5 receptors on Reed-Sternberg cells and Hodgkin lymphoma cell lines: involvement of CCL5/Rantes in tumor cell growth and microenvironmental interactions. Int. J. Cancer 122: 769-776

Aleman BMP, van den Belt-Dusebout AW, Klokman WJ, van't Veer MB, Bartelink H \& van Leeuwen FE (2003) Long-Term Cause-Specific Mortality of Patients Treated for Hodgkin's Disease. J. Clin. Oncol. 21: 3431-3439

Annunziata CM, Safiran YJ, Irving SG, Kasid UN \& Cossman J (2000) Hodgkin disease: pharmacologic intervention of the CD40-NF kappa B pathway by a protease inhibitor. Blood 96: 2841-2848

Ansell SM, Lesokhin AM, Borrello I, Halwani A, Scott EC, Gutierrez M, Schuster SJ, Millenson MM, Cattry D, Freeman GJ, Rodig SJ, Chapuy B, Ligon AH, Zhu L, Grosso JF, Kim SY, Timmerman JM, Shipp MA \& Armand P (2015) PD-1 Blockade with Nivolumab in Relapsed or Refractory Hodgkin's Lymphoma. N. Engl. J. Med. 372: 311-319

Aprelikova O, Palla J, Hibler B, Yu X, Greer YE, Yi M, Stephens R, Maxwell GL, Jazaeri A, Risinger JI, Rubin JS \& Niederhuber J (2013) Silencing of miR$148 \mathrm{a}$ in cancer-associated fibroblasts results in WNT10B-mediated stimulation of tumor cell motility. Oncogene 32: 3246-3253

Armitage JO (1993) Treatment of non-Hodgkin's lymphoma. N. Engl. J. Med. 328: 1023-1030 
Armitage JO (2010) Early-Stage Hodgkin's Lymphoma. N. Engl. J. Med. 363: 653662

Axelrod JD, Miller JR, Shulman JM, Moon RT \& Perrimon N (1998) Differential recruitment of Dishevelled provides signaling specificity in the planar cell polarity and Wingless signaling pathways. GENES Dev. 12: 2610-2622

Baekkevold ES, Yamanaka T, Palframan RT, Carlsen HS, Reinholt FP, von Andrian UH, Brandtzaeg P \& Haraldsen G (2001) The CCR7 ligand elc (CCL19) is transcytosed in high endothelial venules and mediates $T$ cell recruitment. J. Exp. Med. 193: 1105-1112

Bargatze RF, Wu NW, Weissman IL \& Butcher EC (1987) High Endothelial Venule Binding As A Predictor Of The Dissmenination Of Passaged Murine Lymphomas. J. Exp. Med. 166: 1125-1131

Barth TFE, Martin-Subero JI, Joos S, Menz CK, Hasel C, Mechtersheimer G, Parwaresch RM, Lichter P, Siebert R \& M??ller P (2003) Gains of 2p involving the REL locus correlate with nuclear $c-R e l$ protein accumulation in neoplastic cells of classical Hodgkin lymphoma. Blood 101: 3681-3686

Basso K, Margolin AA, Stolovitzky G, Klein U, Dalla-Favera R \& Califano A (2005) Reverse engineering of regulatory networks in human B cells. Nat. Genet. 37: 382-390

Bauer M, Bénard J, Gaasterland T, Willert K \& Cappellen D (2013) WNT5A encodes two isoforms with distinct functions in cancers. PLoS One 8: 1-14

Behrens J, von Kries JP, Kühl M, Bruhn L, Wedlich D, Grosschedl R \& Birchmeier W (1996) Functional interaction of $\beta$-catenin with the transcription factor LEF1. Nature 382: 638-642

van den Berg A, Visser L \& Poppema S (1999) High Expression of the CC Chemokine TARC in Reed-Sternberg Cells. Am. J. Pathol. 154: 1685-1691

Bernatík O, Šedová K, Schille C, Ganji RS, Červenka I, Trantírek L, Schambony A, Zdráhal Z \& Bryja V (2014) Functional analysis of dishevelled-3 phosphorylation identifies distinct mechanisms driven by casein kinase $1 \epsilon$ and frizzled5. J. Biol. Chem. 289: 23520-23533

Berthold MR, Cebron N, Dill F, Gabriel T, Kötter T, Meinl T, Ohl P, Sieb C, Thiel K \& Wiswedel B (2007) KNIME: The Konstanz Information Miner, In Studies in Classification, Data Analysis, and Knowledge Organization GfKL 2007. Springer International Publishing 
Bertrand S, Berger R, Philip T, Bernheim A, Bryon P-A, Bertoglio J, Doré J-F, Brunat-Mentigny $M$ \& Lenoir GM (1981) Variant translocation in a non endemic case of Burkitt's lymphoma: $t(8 ; 22)$ in an Epstein-Barr virus negative tumour and in a derived cell line. Eur. J. Cancer 17: 577-581

Bhatt PM, Lewis CJ, House DL, Keller CM, Kohn LD, Silver MJ, McCall KD, Goetz DJ \& Malgor R (2012) Increased Wnt5a mRNA Expression in Advanced Atherosclerotic Lesions, and Oxidized LDL Treated Human Monocyte-Derived Macrophages. open Circ. Vasc. J. 5: 1-7

Blagodatski A, Poteryaev D \& Katanaev VL (2014) Targeting the Wnt pathways for therapies. Mol. Cell. Ther. 2: 28

Boutros M \& Mlodzik M (1999) Dishevelled: At the crossroads of divergent intracellular signaling pathways. Mech. Dev. 83: 27-37

Brabletz T, Jung A, Dag S, Hlubek F \& Kirchner T (1999) $\beta$-Catenin Regulates the Expression of the Matrix Metalloproteinase-7 in Human Colorectal Cancer. Am. J. Pathol. 155: 1033-1038

Brandt J, Dietrich S, Meissner J, Neben K, Ho AD \& Witzens-Harig M (2010) Quality of life of long-term survivors with Hodgkin lymphoma after high-dose chemotherapy, autologous stem cell transplantation, and conventional chemotherapy. Leuk. Lymphoma 51: 2012-2020

Brune V, Tiacci E, Pfeil I, Döring C, Eckerle S, van Noesel CJM, Klapper W, Falini B, von Heydebreck A, Metzler D, Bräuninger A, Hansmann M-L \& Küppers R (2008) Origin and pathogenesis of nodular lymphocyte-predominant Hodgkin lymphoma as revealed by global gene expression analysis. J. Exp. Med. 205: 2251-2268

Butcher EC \& Picker LJ (1996) Lymphocyte Homing and Homeostasis. Science. 272: $60-67$

Cabannes E, Khan G, Aillet F, Jarrett RF \& Hay RT (1999) Mutations in the IkBa gene in Hodgkin's disease suggest a tumour suppressor role for IkappaBalpha. Oncogene 18: 3063-3070

Canellos GP, Rosenberg S a., Friedberg JW, Lister TA \& DeVita VT (2014) Treatment of Hodgkin lymphoma: A 50-Year perspective. J. Clin. Oncol. 32: 163-168 
Carbone A, Gloghini A, Gruss HJ \& Pinto A (1995) CD40 ligand is constitutively expressed in a subset of $T$ cell lymphomas and on the microenvironmental reactive $T$ cells of follicular lymphomas and Hodgkin's disease. Am. J. Pathol. 147: 912-922

Carmeliet P \& Jain RK (2011) Molecular Mechanisms and and clinical applications of angiogenesis. Nature 473: 298-307

Carragher NO, Walker SM, Scott Carragher L a, Harris F, Sawyer TK, Brunton VG, Ozanne BW \& Frame MC (2006) Calpain 2 and Src dependence distinguishes mesenchymal and amoeboid modes of tumour cell invasion: a link to integrin function. Oncogene 25: 5726-5740

Chen B, Dodge ME, Tang W, Lu J, Ma Z, Fan C-W, Wei S, Hao W, Kilgore J, Williams NS, Roth MG, Amatruda JF, Chen C \& Lum L (2009) Small molecule-mediated disruption of Wnt-dependent signaling in tissue regeneration and cancer. Nat. Chem. Biol. 5: 100-107

Chen W, ten Berge D, Brown J, Ahn S, Hu LA, Miller WE, Caron MG, Barak LS, Nusse R \& Lefkowitz RJ (2003) Dishevelled 2 Recruits -Arrestin 2 to Mediate Wnt5A-Stimulated Endocytosis of Frizzled 4. Science. 301: 1391-1394

Christman MA, Goetz DJ, Dickerson E, McCall KD, Lewis CJ, Benencia F, Silver MJ, Kohn LD \& Malgor R (2008) Wnt5a is expressed in murine and human atherosclerotic lesions. AJP Hear. Circ. Physiol. 294: H2864-H2870

Clavio M, Garrone A, Pierri I, Michelis G, Balocco M, Albarello A, Varaldo R, Canepa P, Miglino M, Ballerini F, Canepa L \& Gobb M (2005) Ifosfamide, epirubicin, etoposide (IEV) and autologous peripheral blood progenitor cell transplant: A feasible and effective salvage treatment for lymphoid malignancies. Oncol. Rep. 14: 933-940

Clements WM, Wang J, Sarnaik A, Kim OJ, MacDonald J, Fenoglio-Preiser C, Groden J \& Lowy AM (2002) beta-Catenin mutation is a frequent cause of Wnt pathway activation in gastric cancer. Cancer Res. 62: 3503-3506

Clevers H (2006) Wnt/beta-catenin signaling in development and disease. Cell 127: $469-480$

Cogle CR, Goldman DC, Madlambayan GJ, Leon RP, Al Masri A, Clark HA, Asbaghi SA, Tyner JW, Dunlap J, Fan G, Kovacsovics T, Liu Q, Meacham A, Hamlin KL, Hromas RA, Scott EW \& Fleming WH (2014) Functional integration of acute myeloid leukemia into the vascular niche. Leukemia 28: 1978-1987 
Comito G, Giannoni E, Segura CP, Barcellos-de-Souza P, Raspollini MR, Baroni G, Lanciotti M, Serni S \& Chiarugi P (2014) Cancer-associated fibroblasts and M2-polarized macrophages synergize during prostate carcinoma progression. Oncogene 33: 2423-2431

Coombs GS, Yu J, Canning C a, Veltri C a, Covey TM, Cheong JK, Utomo V, Banerjee N, Zhang ZH, Jadulco RC, Concepcion GP, Bugni TS, Harper MK, Mihalek I, Jones CM, Ireland CM \& Virshup DM (2010) WLS-dependent secretion of WNT3A requires Ser209 acylation and vacuolar acidification. J. Cell Sci. 123: 3357-3367

Curtin JC \& Lorenzi M V (2010) Drug Discovery Approaches to Target Wnt Signaling in Cancer Stem Cells. Oncotarget 1: 563-566

Cyster JG, Ansel KM, Ngo VN, Hargreaves DC \& Lu TT (2002) Traffic patterns of B cells and plasma cells. Adv Exp Med Biol 512: 35-41

Dabdoub A \& Kelley MW (2005) Planar cell polarity and a potential role for a Wnt morphogen gradient in stereociliary bundle orientation in the mammalian inner ear. J. Neurobiol. 64: 446-457

Danielson KG, Pillarisetti J, Cohen IR, Sholehvar B, Huebner K, Ng LJ, Nicholls JM, Cheah KS \& lozzo R V (1995) Characterization of the complete genomic structure of the human WNT-5A gene, functional analysis of its promoter, chromosomal mapping, and expression in early human embryogenesis. $J$. Biol. Chem. 270: 31225-31234

Darlavoix T, Seelentag W, Yan P, Bachmann A \& Bosman FT (2009) Altered expression of CD44 and DKK1 in the progression of Barrett's esophagus to esophageal adenocarcinoma. Virchows Arch. 454: 629-637

Darnay BG, Haridas V, Ni J, Moore PA \& Aggarwal BB (1998) Characterization of the intracellular domain of receptor activator of NF-kB (RANK). J. Biol. Chem. 273: 20551-20555

Development Core Team, R: A language and environment for statistical computing. R Foundation for Statistical Computing, Vienna, Austria (2011)

Dietmair S, Timmins NE, Gray PP, Nielsen LK \& Krömer JO (2010) Towards quantitative metabolomics of mammalian cells: development of a metabolite extraction protocol. Anal. Biochem. 404: 155-164 
Dijksterhuis JP, Baljinnyam B, Stanger K, Sercan HO, Ji Y, Andres O, Rubin JS, Hannoush RN \& Schulte G (2015) Systematic Mapping of WNT-FZD Protein Interactions Reveals Functional Selectivity by Distinct WNT-FZD Pairs. J. Biol. Chem. 290: 6789-6798

Dolcetti R, Boiocchi M, Gloghini A \& Carbone A (2001) Pathogenetic and histogenetic features of HIV-associated Hodgkin's disease. Eur. J. Cancer 37: $1276-1287$

Doussis-Anagnostopoulou IA, Talks KL, Turley H, Debnam P, Tan DC, Mariatos G, Gorgoulis V, Kittas C \& Gatter KC (2002) Vascular endothelial growth factor (VEGF) is expressed by neoplastic Hodgkin-Reed-Sternberg cells in Hodgkin's disease. J. Pathol. 197: 677-683

DuBridge RB, Tang P, Hsia HC, Leong PM, Miller JH \& Calos MP (1987) Analysis of mutation in human cells by using an Epstein-Barr virus shuttle system. Mol Cell Biol 7: 379-387.

Dutton A, Reynolds GM, Dawson CW, Young LS \& Murray PG (2005) Constitutive activation of phosphatidyl-inositide 3 kinase contributes to the survival of Hodgkin's lymphoma cells through a mechanism involving Akt kinase and mTOR. J. Pathol. 205: 498-506

Dyer MJS, Fischer P, Nacheva E, Labastide W \& Karpas A (1990) A new human B-cell non-Hodgkin's lymphoma cell line (Karpas 422) exhibiting both $t(14 ; 18)$ and $\mathrm{t}(4 ; 11)$ chromosomal translocations. Blood 75: 709-714

Eichenauer D a, Engert A, André M, Federico M, Illidge T, Hutchings M \& Ladetto M (2014) Hodgkin's lymphoma: ESMO Clinical Practice Guidelines for diagnosis, treatment and follow-up. Ann. Oncol. 25 Suppl 3: iii70-5

Ekström EJ, Bergenfelz C, von Bülow V, Serifler F, Carlemalm E, Jönsson G, Andersson T \& Leandersson K (2014) WNT5A induces release of exosomes containing pro-angiogenic and immunosuppressive factors from malignant melanoma cells. Mol. Cancer 13: 88

Engert A, Diehl V, Franklin J, Lohri A, Dörken B, Ludwig WD, Koch P, Hänel M, Pfreundschuh M, Wilhelm M, Trümper L, Aulitzky WE, Bentz M, Rummel M, Sezer O, Müller-Hermelink HK, Hasenclever D \& Löffler M (2009) Escalateddose BEACOPP in the treatment of patients with advanced-stage Hodgkin's lymphoma: 10 Years of follow-up of the GHSG HD9 study. J. Clin. Oncol. 27: 4548-4554 
Erdfelder F, Hertweck M, Filipovich A, Uhrmacher S \& Kreuzer K-A (2010) High lymphoid enhancer-binding factor-1 expression is associated with disease progression and poor prognosis in chronic lymphocytic leukemia. Hematol. Rep. 2: e3

Ferlay J, Steliarova-Foucher E, Lortet-Tieulent J, Rosso S, Coebergh JWW, Comber H, Forman D \& Bray F (2013) Cancer incidence and mortality patterns in Europe: Estimates for 40 countries in 2012. Eur. J. Cancer 49: 1374-1403

Fhu CW, Graham AM, Yap CT, Al-Salam S, Castella A, Chong SM \& Lim Y-C (2014) Reed-Sternberg cell-derived lymphotoxin- $\alpha$ activates endothelial cells to enhance T-cell recruitment in classical Hodgkin lymphoma. Blood 124: 2973-2982

Fiumara P, Snell V, Li Y, Mukhopadhyay A, Younes M, Gillenwater a M, Cabanillas F, Aggarwal BB \& Younes A (2001) Functional expression of receptor activator of nuclear factor kappaB in Hodgkin disease cell lines. Blood 98: 2784-2790

Foss HD, Reusch R, Demel G, Lenz G, Anagnostopoulos I, Hummel M \& Stein H (1999) Frequent expression of the B-cell-specific activator protein in ReedSternberg cells of classical Hodgkin's disease provides further evidence for its B-cell origin. Blood 94: 3108-3113

Francis K, Palsson B, Donahue J, Fong S \& Carrier E (2002) Murine Sca-1+/Lincells and human KG1a cells exhibit multiple pseudopod morphologies during migration. Exp. Hematol. 30: 460-463

Francisco JA, Cerveny CG, Meyer DL, Mixan BJ, Klussmann K, Chace DF, Rejniak SX, Gordon KA, DeBlanc R, Toki BE, Law C-L, Doronina SO, Siegall CB, Senter PD \& Wahl AF (2003) cAC10-vcMMAE, an anti-CD30monomethyl auristatin $\mathrm{E}$ conjugate with potent and selective antitumor activity. Blood 102: 1458-1465

Friedl P (2004) Prespecification and plasticity: shifting mechanisms of cell migration. Curr. Opin. Cell Biol. 16: 14-23

Friedl P, Borgmann S \& Bröcker EB (2001) Amoeboid leukocyte crawling through extracellular matrix: lessons from the Dictyostelium paradigm of cell movement. J. Leukoc. Biol. 70: 491-509

Friedl P \& Wolf K (2003a) Proteolytic and non-proteolytic migration of tumour cells and leucocytes. Biochem. Soc. Symp. 285: 277-285 
Friedl P \& Wolf K (2003b) Tumour-cell invasion and migration: diversity and escape mechanisms. Nat. Rev. Cancer 3: 362-374

Gandhirajan RK, Staib PA, Minke K, Gehrke I, Plickert G, Schlösser A, Schmitt EK, Hallek M \& Kreuzer K-A (2010) Small molecule inhibitors of Wnt/betacatenin/lef-1 signaling induces apoptosis in chronic lymphocytic leukemia cells in vitro and in vivo. Neoplasia 12: 326-335

Gao C \& Chen Y-G (2010) Dishevelled: The hub of Wnt signaling. Cell. Signal. 22: 717-727

Gavin BJ, McMahon J a \& McMahon a P (1990) Expression of multiple novel Wnt/int related genes during fetal and adult mouse development. Genes Dev. 4: 2319-2332

Ge X \& Wang X (2010) Role of Wnt canonical pathway in hematological malignancies. J. Hematol. Oncol. 3: 33

Geissmann F, Ruskoné-Fourmestraux A, Hermine O, Bourquelot P, Belanger C, Audouin J, Delmer A, Macintyre E a., Varet B \& Brousse N (1998) Homing Receptor $\alpha 4 \beta 7$ Integrin Expression Predicts Digestive Tract Involvement in Mantle Cell Lymphoma. Am. J. Pathol. 153: 1701-1705

Gelebart P, Anand M, Armanious H, Peters AC, Bard JD, Amin HM, Lai R, Dien Bard J, Amin HM \& Lai R (2008) Constitutive activation of the Wnt canonical pathway in mantle cell lymphoma. Blood 112: 5171-5179

Gentzel M, Schille C, Rauschenberger V \& Schambony A (2015) Distinct functionality of dishevelled isoforms on $\mathrm{Ca2}+$ /calmodulin-dependent protein kinase 2 (CamKII) in Xenopus gastrulation. Mol. Biol. Cell 26: 966-977

Gharbaran R, Park J, Kim C, Goy A \& Suh KS (2014) Circulating tumor cells in Hodgkin's lymphoma-A review of the spread of $\mathrm{HL}$ tumor cells or their putative precursors by lymphatic and hematogenous means, and their prognostic significance. Crit. Rev. Oncol. Hematol. 89: 404-417

Gonzalez-Sancho JM, Brennan KR, Castelo-soccio LA \& Brown AMC (2004) Wnt Proteins Induce Dishevelled Phosphorylation via an LRP5 / 6- Independent Mechanism, Irrespective of Their Ability To Stabilize b-Catenin. Mol. Cell. Biol. 24: 4757-4768

Goodrich L V. (2008) The Plane Facts of PCP in the CNS. Neuron 60: 9-16

Gospodarowicz MK \& Sutcliffe SB (1995) The extranodal lymphomas. Semin. Radiat. Oncol. 5: 281-300 
Graeber SH \& Hülser DF (1998) Connexin transfection induces invasive properties in HeLa cells. Exp. Cell Res. 243: 142-149

Graham F, Smiley R, Russell WC \& Nairn R (1977) Characteristics of a Human Cell Line Transformed by D N A from Human Adenovirus Type 5. J. Gen. Virol. 36: 59-74

Gravanis I, Tzogani K, van Hennik P, de Graeff P, Schmitt P, Mueller-Berghaus J, Salmonson T, Gisselbrecht C, Laane E, Bergmann L \& Pignatti F (2016) The European Medicines Agency Review of Brentuximab Vedotin (Adcetris) for the Treatment of Adult Patients With Relapsed or Refractory CD30+ Hodgkin Lymphoma or Systemic Anaplastic Large Cell Lymphoma: Summary of the Scientific Assessment of the Committee. Oncologist 21: 102-109

Gregory MA, Phang TL, Neviani P, Alvarez-Calderon F, Eide CA, O'Hare T, Zaberezhnyy V, Williams RT, Druker BJ, Perrotti D \& Degregori J (2010) Wnt/Ca2+/NFAT signaling maintains survival of $\mathrm{Ph}+$ leukemia cells upon inhibition of Bcr-Abl. Cancer Cell 18: 74-87

Groden J, Thliveris A, Samowitz W, Carlson M, Gelbert L, Albertsen H, Joslyn G, Stevens J, Spirio L \& Robertson M (1991) Identification and characterization of the familial adenomatous polyposis coli gene. Cell 66: 589-600

Gross JC, Chaudhary V, Bartscherer K \& Boutros M (2012) Active Wnt proteins are secreted on exosomes. Nat. Cell Biol. 14: 1036-1045

Guermazi A, Brice P, Kerviler E de, Fermé C, Hennequin C, Meignin V \& Frija J (2001) Extranodal Hodgkin Disease: Spectrum of Disease. RadioGraphics 1: $161-179$

Gutierrez A, Tschumper RC, Wu X, Shanafelt TD, Eckel-Passow J, Huddleston PM, Slager SL, Kay NE \& Jelinek DF (2010) LEF-1 is a prosurvival factor in chronic lymphocytic leukemia and is expressed in the preleukemic state of monoclonal B-cell lymphocytosis. Blood 116: 2975-2983

Habas $R$, Kato $Y$ \& He $X$ (2001) Wnt/Frizzled activation of Rho regulates vertebrate gastrulation and requires a novel formin homology protein Daam1. Cell 107: 843-854

Halie MR, Eibergen R \& Nieweg HO (1972a) Observations on abnormal cells in the peripheral blood and spleen in Hodgkin's disease. Br. Med. J. 2: 609-611

Halie MR, Seldenrath JJ, Stam HC \& Nieweg HO (1972b) Curative radiotherapy in Hodgkin's disease: significance of haematogenous dissemination established by examination of peripheral blood and spleen. Br. Med. J. 2: 611-613 
Hanahan D \& Weinberg RA (2011) Hallmarks of cancer: the next generation. Cell 144: $646-674$

Hanamoto H, Nakayama T, Miyazato H, Takegawa S, Hieshima K, Tatsumi Y, Kanamaru A \& Yoshie O (2004) Expression of CCL28 by Reed-Sternberg cells defines a major subtype of classical Hodgkin's disease with frequent infiltration of eosinophils and/or plasma cells. Am. J. Pathol. 164: 997-1006

Harenberg M unpublished thesis. Clinic of Haematology and Medical Oncology, University Medical Centre of the Georg-August University of Göttingen.

Hartmann C \& Tabin CJ (2000) Dual roles of Wnt signaling during chondrogenesis in the chicken limb. Development 127: 3141-3159

Hausmann G, Bänziger C \& Basler K (2007) Helping Wingless take flight: how WNT proteins are secreted. Nat. Rev. Mol. Cell Biol. 8: 331-336

Hay ED (1990) Role of cell-matrix contacts in cell migration and epithelialmesenchymal transformation. Cell Differ. Dev. 32: 367-375

Hayashida Y, Honda K, Idogawa M, Ino Y, Ono M, Tsuchida A, Aoki T, Hirohashi $S$ \& Yamada $T$ (2005) E-cadherin regulates the association between betacatenin and actinin-4. Cancer Res. 65: 8836-8845

Hodgkin T (1832) On some Morbid Appearances of the Absorbent Glands and Spleen. Med. Chir. Trans. 17: 68-114

Hodgson DC, Gilbert ES, Dores GM, Schonfeld SJ, Lynch CF, Storm H, Hall P, Langmark F, Pukkala E, Andersson M, Kaijser M, Joensuu H, Fosså SD \& Travis LB (2007) Long-term solid cancer risk among 5-year survivors of Hodgkin's lymphoma. J. Clin. Oncol. 25: 1489-1497

Höpken UE, Foss H-D, Meyer D, Hinz M, Leder K, Stein H \& Lipp M (2002) Upregulation of the chemokine receptor CCR7 in classical but not in lymphocytepredominant Hodgkin disease correlates with distinct dissemination of neoplastic cells in lymphoid organs. Blood 99: 1109-1116

Horan FT (1969) Bone involvement in hodgkin's disease a survey of 201 cases. Br. J. Surg. 56: 277-281

Horie R, Watanabe T, Morishita Y, Ito K, Ishida T, Kanegae Y, Saito I, Higashihara M, Mori S \& Kadin ME (2002) Ligand-independent signaling by overexpressed CD30 drives NF-kappaB activation in Hodgkin-Reed-Sternberg cells. Oncogene 21: 2493-2503 
Hovanes K, Li TW, Munguia JE, Truong T, Milovanovic T, Lawrence Marsh J, Holcombe RF \& Waterman ML (2001) Beta-catenin-sensitive isoforms of lymphoid enhancer factor-1 are selectively expressed in colon cancer. Nat. Genet. 28: 53-57

Hsieh J-C (2004) Specificity of WNT-receptor interactions. Front. Biosci. 9: 13331338

Hsieh M, Boerboom D, Shimada M, Lo Y, Parlow AF, Luhmann UFO, Berger W \& Richards JS (2005) Mice Null for Frizzled4 (Fzd4-/-) Are Infertile and Exhibit Impaired Corpora Lutea Formation and Function. Biol. Reprod. 73: 11351146

Huang H-C \& Klein PS (2004) The Frizzled family: receptors for multiple signal transduction pathways. Genome Biol. 5: 234

Huang S-MA, Mishina YM, Liu S, Cheung A, Stegmeier F, Michaud GA, Charlat O, Wiellette E, Zhang Y, Wiessner S, Hild M, Shi X, Wilson CJ, Mickanin C, Myer V, Fazal A, Tomlinson R, Serluca F, Shao W, Cheng $H$, et al (2009) Tankyrase inhibition stabilizes axin and antagonizes Wnt signalling. Nature 461: $614-620$

Ishizaki T, Naito M, Fujisawa K, Maekawa M, Watanabe N, Saito Y \& Narumiya S (1997) p160(ROCK), a Rho-associated coiled-coil forming protein kinase, works downstream of Rho and induces focal adhesions. FEBS Lett. 404: 118-124

Jain RK (2005) Normalization of tumor vasculature: an emerging concept in antiangiogenic therapy. Science 307: 58-62

Janda CY, Waghray D, Levin a. M, Thomas C \& Garcia KC (2012) Structural Basis of Wnt Recognition by Frizzled. Science. 337: 59-64

Jenei V, Sherwood V, Howlin J, Linnskog R, Säfholm A, Axelsson L \& Andersson $T$ (2009) A t-butyloxycarbonyl-modified Wnt5a-derived hexapeptide functions as a potent antagonist of Wnt5a-dependent melanoma cell invasion. Proc. Natl. Acad. Sci. U. S. A. 106: 19473-19478

Jeon HJ, Kim CW, Yoshino T \& Akagi T (1998) Establishment and characterization of a mantle cell lymphoma cell line. Br.J.Haematol. 102: 1323-1326

Joos S, Küpper M, Ohl S, Cells CDH, Ku M, Bonin F Von, Mechtersheimer G, Bentz M, Marynen P, Mo P, Pfreundschuh M, Tru L \& Lichter P (2000) Genomic Imbalances Including Amplification of the Tyrosine Kinase Gene JAK2 in CD30 + Hodgkin Cells. Cancer Res. 60: 549-552 
Joos S, Menz CK, Wrobel G, Siebert R, Gesk S, Ohl S, Mechtersheimer G, Trümper L, Moller P, Lichter P \& Barth TF (2002) Classical Hodgkin lymphoma is characterized by recurrent copy number gains of the short arm of chromosome 2. Blood 99: 1381-1387

Jundt F, Anagnostopoulos I, Bommert K, Emmerich F, Müller G, Foss HD, Royer HD, Stein H \& Dörken B (1999) Hodgkin/Reed-Sternberg cells induce fibroblasts to secrete eotaxin, a potent chemoattractant for $\mathrm{T}$ cells and eosinophils. Blood 94: 2065-2071

Kafka A, Tomas D, Beroš V, Pećina HI, Zeljko M \& Pećina-Šlaus N (2014) Brain metastases from lung cancer show increased expression of DVL1, DVL3 and beta-catenin and down-regulation of E-cadherin. Int. J. Mol. Sci. 15: 1063510651

Kamesaki H, Fukuhara S, Tatsumi E, Uchino H, Yamabe H, Miwa H, Shirakawa S, Hatanaka M \& Honjo T (1986) Cytochemical, Immunologic, Chromosomal, and Molecular Genetic Analysis of a Novel Cell Line derived from Hodgkin's Disease. Blood 68: 285-292

Kamper P, Bendix K, Hamilton-Dutoit S, Honoré B, Nyengaard JR \& D\&apos;Amore $F$ (2011) Tumor-infiltrating macrophages correlate with adverse prognosis and Epstein-Barr virus status in classical Hodgkin's lymphoma. Haematologica 96: 269-276

Kanzler H, Hansmann ML, Kapp U, Wolf J, Diehl V, Rajewsky K \& Küppers R (1996a) Molecular single cell analysis demonstrates the derivation of a peripheral blood-derived cell line (L1236) from the Hodgkin/Reed-Sternberg cells of a Hodgkin's lymphoma patient. Blood 87: 3429-3436

Kanzler H, Küppers R, Hansmann M \& Rajewsky K (1996b) Hodgkin and ReedSternberg cells in Hodgkin's disease represent the outgrowth of a dominant tumor clone derived from (crippled) germinal center B cells. J. Exp. Med. 184: 1495-1505

Kapatai G \& Murray P (2006) Contribution of the Epstein Barr virus to the molecular pathogenesis of Hodgkin lymphoma. J. Clin. Pathol. 60: 1342-1349

Kaplan HS (1971) Contiguity and progression in Hodgkin's disease. Cancer Res.

31: 1811-1813 
Kapp U, Yeh WC, Patterson B, Elia AJ, Kägi D, Ho A, Hessel A, Tipsword M, Williams A, Mirtsos C, Itie A, Moyle M \& Mak TW (1999) Interleukin 13 is secreted by and stimulates the growth of Hodgkin and Reed-Sternberg cells. J. Exp. Med. 189: 1939-1946

Kato M, Sanada M, Kato I, Sato Y, Takita J, Takeuchi K, Niwa A, Chen Y, Nakazaki K, Nomoto J, Asakura Y, Muto S, Tamura A, lio M, Akatsuka Y, Hayashi Y, Mori H, Igarashi T, Kurokawa M, Chiba S, et al (2009) Frequent inactivation of A20 in B-cell lymphomas. Nature 459: 712-716

Katoh M \& Katoh M (2009) Transcriptional mechanisms of WNT5A based on NF$\mathrm{KB}$, Hedgehog, TGF $\beta$, and Notch signaling cascades. Int. J. Mol. Med. 23: 837-843

Katz J, Janik JE \& Younes A (2011) Brentuximab vedotin (SGN-35). Clin. Cancer Res. 17: 6428-6436

Kaucká M, Plevová K, Pavlová S, Janovská P, Mishra A, Verner J, Procházková J, Krejcí $P$, Kotasková J, Ovesná $P$, Tichy $B$, Brychtová $Y$, Doubek M, Kozubík A, Mayer J, Pospísilová S \& Bryja V (2013) The planar cell polarity pathway drives pathogenesis of chronic lymphocytic leukemia by the regulation of $B$ lymphocyte migration. Cancer Res. 73: 1491-1501

van Kempen LC, van den Oord JJ, van Muijen GN, Weidle UH, Bloemers HP \& Swart GW (2000) Activated leukocyte cell adhesion molecule/CD166, a marker of tumor progression in primary malignant melanoma of the skin. Am. J. Pathol. 156: 769-774

Kikuchi A, Yamamoto H, Sato A \& Matsumoto S (2011) New Insights into the Mechanism of Wnt Signaling Pathway Activation. In International Review of Cell and Molecular Biology pp 21-71.

Kilander MBC, Petersen J, Andressen KW, Ganji RS, Levy FO, Schuster J, Dahl N, Bryja V \& Schulte G (2014) Disheveled regulates precoupling of heterotrimeric G proteins to Frizzled 6. FASEB J. 28: 2293-2305

Kilger E, Kieser A, Baumann M \& Hammerschmidt W (1998) Epstein-Barr virusmediated B-cell proliferation is dependent upon latent membrane protein 1, which simulates an activated CD40 receptor. EMBO J. 17: 1700-1709

Kim J, Kim DW, Chang W, Choe J, Kim J, Park C-S, Song K \& Lee I (2012) Wnt5a is secreted by follicular dendritic cells to protect germinal center $B$ cells via Wnt/Ca2+/NFAT/NF-kB-B cell lymphoma 6 signaling. J. Immunol. 188: 182189 
Kimelman D \& Xu W (2006) Beta-Catenin Destruction Complex: Insights and Questions From a Structural Perspective. Oncogene 25: 7482-7491

Kinzler K \& Vogelstein B (1996) Lessons from Hereditary Colorectal Cancer. Cell 87: $159-170$

Kinzler KW, Nilbert MC, Su LK, Vogelstein B, Bryan TM, Levy DB, Smith KJ, Preisinger a $C$, Hedge $P$ \& McKechnie $D$ (1991) Identification of FAP locus genes from chromosome 5q21. Science. 253: 661-665

Kishida S, Yamamoto H, Hino S, Ikeda S, Kishida M \& Kikuchi a (1999) DIX domains of Dvl and axin are necessary for protein interactions and their ability to regulate beta-catenin stability. Mol. Cell. Biol. 19: 4414-4422

Klein JL, Nguyen TT, Bien-Willner GA, Chen L, Foyil K V., Bartlett NL, Duncavage EJ, Hassan A, Frater JL \& Kreisel F (2014) CD163 immunohistochemistry is superior to CD68 in predicting outcome in classical Hodgkin lymphoma. Am. J. Clin. Pathol. 141: 381-387

Klemm F, Bleckmann a., Siam L, Chuang HN, Rietk̈tter E, Behme D, Schulz M, Schaffrinski M, Schindler S, Trümper L, Kramer F, Beissbarth T, Stadelmann C, Binder C \& Pukrop T (2011) $\beta$-catenin-independent WNT signaling in basal-like breast cancer and brain metastasis. Carcinogenesis 32: 434-442

Kramps T, Peter O, Brunner E, Nellen D, Froesch B, Chatterjee S, Murone M, Züllig S \& Basler K (2002) Wnt/Wingless Signaling Requires BCL9/LeglessMediated Recruitment of Pygopus to the Nuclear $\beta$-Catenin-TCF Complex. Cell 109: 47-60

Krappmann D, Emmerich F, Kordes U, Scharschmidt E, Dörken B \& Scheidereit C (1999) Molecular mechanisms of constitutive NF-kappaB/Rel activation in Hodgkin/Reed-Sternberg cells. Oncogene 18: 943-953

Krüger A, Soeltl R, Sopov I, Kopitz C, Arlt M, Magdolen V, Harbeck N, Gänsbacher B \& Schmitt M (2001) Hydroxamate-type matrix metalloproteinase inhibitor batimastat promotes liver metastasis. Cancer Res. 61: $1272-1275$

Kube D, Holtick U, Vockerodt M, Ahmadi T, Haier B, Behrmann I, Heinrich PC, Diehl V \& Tesch H (2001) STAT3 is constitutively activated in Hodgkin cell lines. Blood 98: 762-771

Kube D, Platzer C, von Knethen A, Straub H, Bohlen H, Hafner M \& Tesch H (1995) Isolation of the Human Interleukin 10 Promotor. Characterization of the Promotor Activity in Burkitt's Lymphoma Cell Lines. Cytokine 7: 1-7 
Kunkel EJ \& Butcher EC (2002) Chemokines and the tissue-specific migration of lymphocytes. Immunity 16: 1-4

Küppers R (2009) The biology of Hodgkin's lymphoma. Nat. Rev. Cancer 9: 15-27

Küppers R, Engert A \& Hansmann M-L (2012) Hodgkin lymphoma. J. Clin. Invest. 122: $3439-3447$

Küppers R, Rajewsky K, Zhao M, Simons G, Laumann R, Fischer R \& Hansmann ML (1994) Hodgkin disease: Hodgkin and Reed-Sternberg cells picked from histological sections show clonal immunoglobulin gene rearrangements and appear to be derived from B cells at various stages of development. Proc. Natl. Acad. Sci. U. S. A. 91: 10962-10966

Kurayoshi M, Oue N, Yamamoto H, Kishida M, Inoue A, Asahara T, Yasui W \& Kikuchi A (2006) Expression of Wnt-5a is correlated with aggressiveness of gastric cancer by stimulating cell migration and invasion. Cancer Res. 66: 10439-10448

Kurayoshi M, Yamamoto H, Izumi S \& Kikuchi A (2007) Post-translational palmitoylation and glycosylation of Wnt-5a are necessary for its signalling. Biochem. J. 402: 515-523

Laemmli UK (1970) Cleavage of structural proteins during the assembly of the head of bacteriophage T4. Nature 227: 680-685

Lai R, McDonnell TJ, O'Connor SL, Medeiros LJ, Oudat R, Keating M, Morgan MB, Curiel TJ \& Ford RJ (2002) Establishment and characterization of a new mantle cell lymphoma cell line, Mino. Leuk. Res. 26: 849-855

Lamprecht B, Kreher S, Anagnostopoulos I, Jöhrens K, Monteleone G, Jundt F, Stein H, Janz M, Dörken B \& Mathas S (2008) Aberrant expression of the Th2 cytokine IL-21 in Hodgkin lymphoma cells regulates STAT3 signaling and attracts Treg cells via regulation of MIP-3alpha. Blood 112: 3339-3347

Lau T, Chan E, Callow M, Waaler J, Boggs J, Blake RA, Magnuson S, Sambrone A, Schutten M, Firestein R, Machon O, Korinek V, Choo E, Diaz D, Merchant M, Polakis P, Holsworth DD, Krauss S \& Costa M (2013) A novel tankyrase small-molecule inhibitor suppresses APC mutation-driven colorectal tumor growth. Cancer Res. 73: 3132-3144

Lehtiö L, Chi N-W \& Krauss S (2013) Tankyrases as drug targets. FEBS J. 280: 3576-93 
Linke F, Harenberg M, Nietert MM, Zaunig S, von Bonin F, Szczepanowski M, Weich HA, Lutz S, Dullin C, Janovská P, Klapper W, Beissbarth T, Alves F, Bryja V, Trümper L, Wilting J \& Kube D (2016a) Microenvironmental interactions between endothelial and lymphoma cells- a role for the canonical WNT pathway in Hodgkin's disease. Cancer Res.: submitted

Linke F, Zaunig S, Nietert MM, von Bonin F, Lutz S, Dullin C, Janovská P, Beissbarth T, Alves F, Bryja V, Pukrop T, Trümper L, Wilting J \& Kube D (2016b) WNT5A - a motility promoting factor in Hodgkin Lymphoma. Oncogene: in revision

Liu P, Wakamiya M, Shea MJ, Albrecht U, Behringer RR \& Bradley A (1999) Requirement for Wnt3 in vertebrate axis formation. Nat. Genet. 22: 361-365

Liu W, Dong X, Mai M, Seelan RS, Taniguchi K, Krishnadath KK, Halling KC, Cunningham JM, Qian C, Christensen E, Roche PC, Smith DI \& Thibodeau SN (2000) Mutations in AXIN2 cause colorectal cancer with defective mismatch repair. Nat. Genet. 26: 146-147

Liu Y, Sattarzadeh A, Diepstra A, Visser L \& van den Berg A (2014) The microenvironment in classical Hodgkin lymphoma: an actively shaped and essential tumor component. Semin. Cancer Biol. 24: 15-22

Long A, Giroux V, Whelan K a., Hamilton KE, Tetreault M-P, Tanaka K, Lee J-S, Klein-Szanto a. J, Nakagawa H \& Rustgi a. K (2015) WNT10A promotes an invasive and self-renewing phenotype in esophageal squamous cell carcinoma. Carcinogenesis 36: 598-606

Lopez-Giral S, Quintana NE, Cabrerizo M, Alfonso-perez M, Sala-Valdes M, Gomez Garcia de Soria V, Fernandez-Ranada JM, Fernandes-Ruiz E \& Munoz C (2004) Chemokine receptors that mediate B cell homing to secondary lymphoid tissues are highly expressed in B cell chronic lymphocytic leukemia and non-Hodgkin lymphomas with widespread nodular dissemination. J. Leukoc. Biol. 76: 462-471

Luhmann UFO, Meunier D, Shi W, Lüttges A, Pfarrer C, Fundele R \& Berger W (2005) Fetal loss in homozygous mutant Norrie disease mice: A new role of Norrin in reproduction. Genesis 42: 253-262

Lukes RJ \& Butler JJ (1966) The pathology and nomenclature of Hodgkin's disease. Cancer Res. 26: 1063-1083 
MacDonald BT, Hien A, Zhang X, Iranloye O, Virshup DM, Waterman ML \& He X (2014) Disulfide Bond Requirements for Active Wnt Ligands. J. Biol. Chem. 289: $18122-18136$

MacMillan CD, Leong HS, Dales DW, Robertson AE, Lewis JD, Chambers AF \& Tuck AB (2014) Stage of Breast Cancer Progression Influences Cellular Response to Activation of the WNT/Planar Cell Polarity Pathway. Sci. Rep. 4: 6315

Maggio E, Berg A Van Den, Diepstra A, Kluiver J, Visser L \& Poppema S (2002) Chemokines, cytokines and their receptors in Hodgkin's lymphoma cell lines and tissues. Ann. Oncol. 13: 52-56

Malhotra S, Baba Y, Garrett KP, Staal FJT, Gerstein R \& Kincade PW (2008) Contrasting Responses of Lymphoid Progenitors to Canonical and Noncanonical Wnt Signals. J. Immunol. 181: 3955-3964

Mann JL, Hafez GR \& Longo WL (1986) Role of the spleen in the transdiaphragmatic spread of Hodgkin's disease. Am. J. Med. 81: 959-961

Mao B \& Niehrs C (2003) Kremen2 modulates Dickkopf2 activity during Wnt/IRP6 signaling. Gene 302: 179-183

Marafioti T, Hummel M, Foss HD, Laumen H, Korbjuhn P, Anagnostopoulos I, Lammert H, Demel G, Theil J, Wirth T \& Stein H (2000) Hodgkin and reedsternberg cells represent an expansion of a single clone originating from a germinal center B-cell with functional immunoglobulin gene rearrangements but defective immunoglobulin transcription. Blood 95: 1443-1450

Marinaccio C, Nico B, Maiorano E, Specchia G \& Ribatti D (2014) Insights in Hodgkin Lymphoma angiogenesis. Leuk. Res. 38: 857-861

Matasar MJ \& Zelenetz AD (2008) Overview of Lymphoma Diagnosis and Management. Radiol. Clin. North Am. 46: 175-198

Menck K, Klemm F, Gross JC, Pukrop T, Wenzel D \& Binder C (2013) Induction and transport of Wnt 5 a during macrophage-induced malignant invasion is mediated by two types of extracellular vesicles. Oncotarget 4: 2057-2066

Miao L, Vanderlinde O, Stewart M \& Roberts TM (2003) Retraction in amoeboid cell motility powered by cytoskeletal dynamics. Science 302: 1405-1407

Mikels AJ \& Nusse R (2006) Purified Wnt5a protein activates or inhibits b-cateninTCF signaling depending on receptor context. PLoS Biol. 4: 570-582 
Mizuno H, Nakayama T, Miyata Y, Saito S, Nishiwaki S, Nakao N, Takeshita K \& Naoe T (2012) Mast cells promote the growth of Hodgkin's lymphoma cell tumor by modifying the tumor microenvironment that can be perturbed by bortezomib. Leukemia 26: 2269-2276

Mo ML, Li MR, Chen Z, Liu XW, Sheng Q \& Zhou HM (2013) Inhibition of the Wnt palmitoyltransferase porcupine suppresses cell growth and downregulates the Wnt/b-catenin pathway in gastric cancer. Oncol. Lett. 5: 1719-1723

Molin D, Fischer M, Xiang Z, Larsson U, Harvima I, Venge P, Nilsson K, Sundstrom C, Enblad G \& Nilsson G (2001) Mast cells express functional CD30 ligand and are the predominant CD30L-positive cells in Hodgkin's disease. Br. J. Haematol. 114: 616-623

Morin PJ, Sparks AB, Korinek V, Barker N, Clevers H, Vogelstein B \& Kinzler KW (1997) Activation of beta-catenin-Tcf signaling in colon cancer by mutations in beta-catenin or APC. Science 275: 1787-1790

Murakami T, Toda S, Fujimoto M, Ohtsuki M, Byers HR, Etoh T \& Nakagawa H (2001) Constitutive activation of Wnt/beta-catenin signaling pathway in migration-active melanoma cells: role of LEF-1 in melanoma with increased metastatic potential. Biochem. Biophys. Res. Commun. 288: 8-15

Müschen M, Rajewsky K, Bräuninger A, Baur AS, Oudejans JJ, Roers A, Hansmann ML \& Küppers R (2000) Rare occurrence of classical Hodgkin's disease as a T cell lymphoma. J. Exp. Med. 191: 387-394

Nagaraj SRM, Shilpa P, Rachaiah K \& Salimath BP (2015) Crosstalk between VEGF and MTA1 signaling pathways contribute to aggressiveness of breast carcinoma. Mol. Carcinog. 54: 333-350

Nagel S, Burek C, Venturini L, Scherr M, Quentmeier H, Meyer C, Rosenwald A, Drexler HG, Macleod RAF \& Dc W (2007) Comprehensive analysis of homeobox genes in Hodgkin lymphoma cell lines identifies dysregulated expression of HOXB9 mediated via ERK5. Blood 109: 3015-3023

Najdi R, Proffitt K, Sprowl S, Kaur S, Yu J, Covey TM, Virshup DM \& Waterman ML (2012) A uniform human Wnt expression library reveals a shared secretory pathway and unique signaling activities. Differentiation. 84: 203-213

Nemeth MJ, Topol L, Anderson SM, Yang Y \& Bodine DM (2007) Wnt5a inhibits canonical Wnt signaling in hematopoietic stem cells and enhances repopulation. 2007: 1-6 
Neufeld G, Kessler O, Vadasz Z \& Gluzman-Poltorak Z (2001) The contribution of proangiogenic factors to the progression of malignant disease: role of vascular endothelial growth factor and its receptors. Surg. Oncol. Clin. N. Am. 10: 339-356, ix

Nguyen DX, Chiang AC, Zhang XH-FF, Kim JY, Kris MG, Ladanyi M, Gerald WL \& Massagué J (2009) WNT/TCF signaling through LEF1 and HOXB9 mediates lung adenocarcinoma metastasis. Cell 138: 51-62

Niehrs C (2006) Function and biological roles of the Dickkopf family of Wnt modulators. Oncogene 25: 7469-7481

Niehrs C (2012) The complex world of WNT receptor signalling. Nat. Rev. Mol. Cell Biol. 13: 767-779

Nishisho I, Nakamura Y, Miyoshi Y, Miki Y, Ando H, Horii A, Koyama K, Utsunomiya J, Baba S \& Hedge P (1991) Mutations of chromosome 5q21 genes in FAP and colorectal cancer patients. Science. 253: 665-669

Nübler-Jung K (1987) Insect epidermis: disturbance of supracellular tissue polarity does not prevent the expression of cell polarity. Roux's Arch. Dev. Biol. 196: 286-289

Nusse R \& Varmus HE (1982) Many tumors induced by the mouse mammary tumor virus contain a provirus integrated in the same region of the host genome. Cell 31: 99-109

Ohshima K, Tutiya T, Yamaguchi T, Suzuki K, Suzumiya J, Kawasaki C, Haraoka S \& Kikuchi M (2002) Infiltration of Th1 and Th2 lymphocytes around Hodgkin and Reed-Sternberg (HRS) cells in Hodgkin disease: Relation with expression of CXC and CC chemokines on HRS cells. Int. J. Cancer 98: 567-572

Okazaki T \& Honjo T (2007) PD-1 and PD-1 ligands: From discovery to clinical application. Int. Immunol. 19: 813-824

Otto C, Giefing M, Massow A, Vater I, Gesk S, Schlesner M, Richter J, Klapper W, Hansmann ML, Siebert R \& Küppers R (2012) Genetic lesions of the TRAF3 and MAP3K14 genes in classical Hodgkin lymphoma. Br. J. Haematol. 157: 702-708

Pals ST, Drillenburg P, Dragosics B, Lazarovits Al \& Radaszkiewicz T (1994) Expression of the mucosal homing receptor $\alpha 4 \beta 7$ in malignant lymphomatous polyposis of the intestine. Gastroenterology 107: 1519-1523

Pals ST, de Gorter DJJ \& Spaargaren M (2007) Lymphoma dissemination: the other face of lymphocyte homing. Blood 110: 3102-3111 
Pals ST, Horst E, Scheper RIKJ \& Meijer CJLM (1989) Mechanisms of Human Lymphocyte Migration and their Role in the Pathogenesis of Disease. Immunol. Rev. 108: 111-133

Peifer M (1993) Cancer, catenins, and cuticle pattern: a complex connection. Science. 262: 1667-1668

Petropoulos K, Arseni N, Schessl C, Stadler CR, Rawat VPS, Deshpande AJ, Heilmeier B, Hiddemann W, Quintanilla-Martinez L, Bohlander SK, FeuringBuske M \& Buske C (2008) A novel role for Lef-1, a central transcription mediator of Wnt signaling, in leukemogenesis. J. Exp. Med. 205: 515-522

Philip I, Philip T, Favrot M, Vuillaume M, Fontaniere B, Chamard D \& Lenoir GM (1984) Establishment of lymphomatous cell lines from bone marrow samples from patients with Burkitt's lymphoma. J. Natl. Cancer Inst. 73: 835-840

Pinto A, Aldinucci D, Gloghini A, Zagonel V, Degan M, Improta S, Juzbasic S, Todesco M, Perin V, Gattei V, Herrmann F, Gruss HJ \& Carbone A (1996) Human eosinophils express functional CD30 ligand and stimulate proliferation of a Hodgkin's disease cell line. Blood 88: 3299-3305

Piotto M, Saudek V \& Sklenár V (1992) Gradient-tailored excitation for singlequantum NMR spectroscopy of aqueous solutions. J. Biomol. NMR 2: 661665

Planutiene M, Planutis K \& Holcombe RF (2011) Lymphoid enhancer-binding factor 1, a representative of vertebrate-specific Lef1/Tcf1 sub-family, is a Wntbeta-catenin pathway target gene in human endothelial cells which regulates matrix metalloproteinase-2 expression and promotes endothelial cell inva. Vasc Cell 3: 28

Polakis P (1999) The oncogenic activation of beta catenin. Curr Opin Genet Dev 9: $15-21$

Proffitt KD, Madan B, Ke Z, Pendharkar V, Ding L, Lee MA, Hannoush RN \& Virshup DM (2013) Pharmacological inhibition of the Wnt acyltransferase PORCN prevents growth of WNT-driven mammary cancer. Cancer Res. 73: 502-507

Proffitt KD \& Virshup DM (2012) Precise regulation of porcupine activity is required for physiological Wnt signaling. J. Biol. Chem. 287: 34167-34178

Qiang Y, Walsh K, Yao L, Kedei N, Blumberg PM, Rubin JS, Jr JS \& Rudikoff S (2005) Wnts induce migration and invasion of myeloma plasma cells. Blood 106: $1786-1794$ 
Qin L, Yin Y, Zheng F, Peng L, Yang C, Bao Y-N, Liang Y-Y, Li X-J, Xiang Y-Q, Sun R, Li A-H, Zou R-H, Pei X-Q, Huang B-J, Kang T-B, Liao D-F, Zeng Y-X, Williams BO \& Qian C-N (2015) WNT5A promotes stemness characteristics in nasopharyngeal carcinoma cells leading to metastasis and tumorigenesis. Oncotarget 6: 10239-10252

Qin X, Zhang H, Zhou X, Wang C, Zhang H, Zhang X \& Ye L (2007) Proliferation and migration mediated by Dkk-1/Wnt/beta-catenin cascade in a model of hepatocellular carcinoma cells. Transl. Res. 150: 281-294

Reed D (1902) On the pathological changes in Hodgkin's disease with special reference to its relation to tuberculosis. John Hopkins Hosp. Reports 10: 133

Reiners KS, Gossmann A, Von Strandmann EP, Böll B, Engert A \& Borchmann P (2009) Effects of the anti-VEGF Monoclonal antibody bevacizumab in a preclinical model and in patients with refractory and multiple relapsed hodgkin lymphoma. J. Immunother. 32: 508-512

Renné C, Willenbrock K, Küppers R, Hansmann ML \& Bräuninger A (2005) Autocrine- and paracrine-activated receptor tyrosine kinases in classic Hodgkin lymphoma. Blood 105: 4051-4059

Reya T, Duncan AW, Ailles L, Domen J, Scherer DC, Willert K, Hintz L, Nusse R \& Weissman IL (2003) A role for Wnt signalling in self-renewal of haematopoietic stem cells. Nature 423: 409-414

Reya T, O'Riordan M, Okamura R, Devaney E, Willert K, Nusse R \& Grosschedl R (2000) Wnt signaling regulates $B$ lymphocyte proliferation through a LEF-1 dependent mechanism. Immunity 13: 15-24

Rhodes DR, Yu J, Shanker K, Deshpande N, Varambally R, Ghosh D, Barrette T, Pandey A \& Chinnaiyan AM (2004) ONCOMINE: A Cancer Microarray Database and Integrated Data-Mining Platform1. Neoplasia 6: 1-6

Ribas A (2012) Tumor Immunotherapy Directed at PD-1. N. Engl. J. Med. 366: 2517-2519

Rizzatti EG, Falcão RP, Panepucci RA, Proto-Siqueira R, Anselmo-Lima WT, Okamoto OK \& Zago MA (2005) Gene expression profiling of mantle cell lymphoma cells reveals aberrant expression of genes from the PI3K-AKT, WNT and TGFbeta signalling pathways. Br. J. Haematol. 130: 516-526 
Roman-Gomez J, Jimenez-Velasco A, Cordeu L, Vilas-Zornoza A, San JoseEneriz E, Garate L, Castillejo J a., Martin V, Prosper F, Heiniger A, Torres A \& Agirre X (2007) WNT5A, a putative tumour suppressor of lymphoid malignancies, is inactivated by aberrant methylation in acute lymphoblastic leukaemia. Eur. J. Cancer 43: 2736-2746

Rosenberg SA \& Kaplan HS (1966) Evidence for an orderly progression in the spread of Hodgkin's disease. Cancer Res. 26: 1225-1231

Rüffer JU, Flechtner H, Tralls P, Josting a., Sieber M, Lathan B \& Diehl V (2003) Fatigue in long-term survivors of Hodgkin's lymphoma; A report from the German Hodgkin Lymphoma Study Group (GHSG). Eur. J. Cancer 39: 21792186

Sahai E \& Marshall CJ (2003) Differing modes of tumour cell invasion have distinct requirements for Rho/ROCK signalling and extracellular proteolysis. Nat. Cell Biol. 5: 711-719

Sahin U, Neumann F, Türeci Ö, Schmits R, Perez F \& Pfreundschuh M (2002) Hodgkin and Reed-Sternberg cell-associated autoantigen CLIP-170/restin is a marker for dendritic cells and is involved in the trafficking of macropinosomes to the cytoskeleton, supporting a function-based concept of Hodgkin and Reed-Stemberg cells. Blood 100: 4139-4145

Sakai Y \& Kobayashi M (2015) Lymphocyte 'homing' and chronic inflammation. Pathol. Int. 65: 344-354

Samarzija I, Sini P, Schlange T, Macdonald G \& Hynes NE (2009) Wnt3a regulates proliferation and migration of HUVEC via canonical and noncanonical Wnt signaling pathways. Biochem. Biophys. Res. Commun. 386: 449-454

Saneyoshi T, Kume S, Amasaki Y \& Mikoshiba K (2002) The Wnt/calcium pathway activates NF-AT and promotes ventral cell fate in Xenopus embryos. Nature 417: 295-299

Santoro A, Magagnoli M, Spina M, Pinotti G, Siracusano L, Michieli M, Nozza A, Sarina B, Morenghi E, Castagna L, Tirelli U \& Balzarotti M (2007) Ifosfamide, gemcitabine, and vinorelbine: a new induction regimen for refractory and relapsed Hodgkin's lymphoma. Haematologica 92: 35-41 
Satoh S, Daigo Y, Furukawa Y, Kato T, Miwa N, Nishiwaki T, Kawasoe T, Ishiguro $\mathrm{H}$, Fujita M, Tokino T, Sasaki Y, Imaoka S, Murata M, Shimano T, Yamaoka Y \& Nakamura Y (2000) AXIN1 mutations in hepatocellular carcinomas, and growth suppression in cancer cells by virus-mediated transfer of AXIN1. Nat. Genet. 24: 245-250

Schaadt M, Fonatsch C, Kirchner H \& Diehl V (1979) Establishment of a Malignant, Epstein-Barr-Virus (EBV)-negative Cell-Line from the Pleura Effusion of a Patient with Hodgkin's Disease*. Blut 38: 185-190

Scheeren FA, Diehl SA, Smit LA, Beaumont T, Naspetti M, Bende RJ, Blom B, Karube K, Ohshima K, Noesel CJM Van \& Spits H (2008) IL-21 is expressed in Hodgkin lymphoma and activates STAT5 : evidence that activated STAT5 is required for Hodgkin lymphomagenesis. Blood 111: 4706-4716

Schellong G, Riepenhausen M, Ehlert K, Brämswig J, Dörffel W, Schmutzler RK, Rhiem K \& Bick U (2014) Breast cancer in young women after treatment for Hodgkin's disease during childhood or adolescence--an observational study with up to 33-year follow-up. Dtsch. Arztebl. Int. 111: 3-9

Schmidt A, Schmitz R, Giefing M, Martin-Subero JI, Gesk S, Vater I, Massow A, Maggio E, Schneider M, Hansmann M-L, Siebert R \& Küppers R (2010) Rare occurrence of biallelic CYLD gene mutations in classical Hodgkin lymphoma. Genes. Chromosomes Cancer 49: 803-809

Schneider G, Neidhart W, Giller T \& Schmid G (1999) 'Scaffold-Hopping' by topological pharmacophore search: A contribution to virtual screening. Angew. Chemie - Int. Ed. 38: 2894-2896

Schreck S, Friebel D, Buettner M, Distel L, Grabenbauer G, Young LS \& Niedobitek G (2009) Prognostic impact of tumour-infiltrating Th2 and regulatory T cells in classical Hodgkin lymphoma. Hematol. Oncol. 27: 31-39

Schreiber E, Matthias P, Müller MM \& Schaffner W (1989) Rapid detection of octamer binding proteins with 'mini-extracts', prepared from a small number of cells. Nucleic Acids Res. 17: 6419

Schulte G \& Bryja V (2007) The Frizzled family of unconventional G-proteincoupled receptors. Trends Pharmacol. Sci. 28: 518-525

Schwering I, Bräuninger A, Klein U, Jungnickel B, Tinguely M, Diehl V, Hansmann M, Dalla-Favera R, Rajewsky K \& Küppers R (2003) Loss of the B-lineagespecific gene expression program in Hodgkin and Reed-Sternberg cells of Hodgkin lymphoma. Blood 101: 1505-1512 
Seitz V, Hummel M, Marafioti T, Anagnostopoulos I, Assaf C \& Stein H (2000) Detection of clonal T-cell receptor gamma-chain gene rearrangements in Reed-Sternberg cells of classic Hodgkin disease. Blood 95: 3020-3024

Semënov M V, Tamai K, Brott BK, Kühl M, Sokol S \& He X (2001) Head inducer Dickkopf-1 is a ligand for Wnt coreceptor LRP6. Curr. Biol. 11: 951-961

Sen M, Lauterbach K, El-Gabalawy H, Firestein GS, Corr M \& Carson D a (2000) Expression and function of wingless and frizzled homologs in rheumatoid arthritis. Proc. Natl. Acad. Sci. U. S. A. 97: 2791-2796

Sheldahl LC, Park M, Malbon CC \& Moon RT (1999) Protein kinase C is differentially stimulated by Wnt and Frizzled homologs in a G-proteindependent manner. Curr. Biol. 9: 695-698

Shetty S, Bruns T, Weston CJ, Stamataki Z, Oo YH, Long HM, Reynolds GM, Pratt G, Moss P, Jalkanen S, Hubscher SG, Lalor PF \& Adams DH (2012) Recruitment mechanisms of primary and malignant $B$ cells to the human liver. Hepatology 56: 1521-1531

Shrivastava A, Radziejewski C, Campbell E, Kovac L, McGlynn M, Ryan TE, Davis S, Goldfarb MP, Glass DJ, Lemke G \& Yancopoulos GD (1997) An Orphan Receptor Tyrosine Kinase Family Whose Members Serve as a Nonintegrin Collagen Receptors. Mol. Cell 1: 25-34

Shtutman M, Zhurinsky J, Simcha I, Albanese C, D'Amico M, Pestell R \& BenZe'ev A (1999) The cyclin D1 gene is a target of the beta-catenin/LEF-1 pathway. Proc. Natl. Acad. Sci. U. S. A. 96: 5522-5527

Simon M, Grandage VL, Linch DC \& Khwaja A (2005) Constitutive activation of the Wnt/beta-catenin signalling pathway in acute myeloid leukaemia. Oncogene 24: $2410-20$

Sitar G, Santamaria AB, Rosti V, Shaskin P, Blago R, Santamaria L \& Ascari E (1994) Giant cell formation in Hodgkin's disease. Res. Immunol. 145: 499515

Skinnider BF, Elia AJ, Gascoyne RD, Patterson B, Trümper L, Kapp U \& Mak TW (2002) Signal transducer and activator of transcription 6 is frequently activated in Hodgkin and Reed-Sternberg cells of Hodgkin lymphoma. Blood 99: 618626

Smithers DW, Lillicrap SC \& Barnes A (1974) Patterns of lymph node involvement in relation to hypotheses about the modes of spread of Hodgkin's disease. Cancer 34: 1779-1786 
Spaulding C, Reschly EJ, Zagort DE, Yashiro-Ohtani Y, Beverly LJ, Capobianco A, Pear WS \& Kee BL (2007) Notch1 co-opts lymphoid enhancer factor 1 for survival of murine T-cell lymphomas. Blood 110: 2650-2658

Stathis A \& Younes A (2015) The new therapeutical scenario of Hodgkin lymphoma. Ann. Oncol.: 1-8

Stauder R, Hamader S, Fasching B, Kemmler G, Thaler J \& Huber H (1993) Adhesion to high endothelial venules: a model for dissemination mechanisms in non-Hodgkin's lymphoma. Blood 82: 262-267

Steidl C, Lee T, Shah SP, Farinha P, Han G, Nayar T, Delaney A, Jones SJ, Iqbal J, Weisenburger DD, Bast MA, Rosenwald A, Muller-Hermelink H-K, Rimsza LM, Campo E, Delabie J, Braziel RM, Cook JR, Tubbs RR, Jaffe ES, et al (2010a) Tumor-Associated Makrophages and Survival in Classic Hodgkin's Lymphoma. N. Engl. J. Med. 362: 875-885

Steidl C, Telenius A, Shah SP, Farinha P, Barclay L, Boyle M, Connors JM, Horsman DE \& Gascoyne RD (2010b) Genome-wide copy number analysis of Hodgkin Reed-Sternberg cells identifies recurrent imbalances with correlations to treatment outcome. Blood 116: 418-427

Stein H, Gerdes J, Schwab U, Lemke H, Diehl V, Mason DY, Bartels H \& Ziegler A (1983) Evidence for the detection of the normal counterpart of Hodgkin and Sternberg-Reed cells. Hematol. Oncol. 1: 21-29

Stein H, Marafioti T, Foss HD, Laumen H, Hummel M, Anagnostopoulos I, Wirth T, Demel G \& Falini B (2001) Down-regulation of BOB.1/OBF.1 and Oct2 in classical Hodgkin disease but not in lymphocyte predominant Hodgkin disease correlates with immunoglobulin transcription. Blood 97: 496-501

Stein H, Mason DY, Gerdes J, O'Connor N, Wainscoat J, Pallesen G, Gatter K, Falini B, Delsol G \& Lemke H (1985) The expression of the Hodgkin's disease associated antigen $\mathrm{Ki}-1$ in reactive and neoplastic lymphoid tissue: evidence that Reed-Sternberg cells and histiocytic malignancies are derived from activated lymphoid cells. Blood 66: 848-858

Sternberg C (1897) Über eine eigenartige, unter dem Bilde der Pseudoleukämie verlaufende Tuberkulose des lymphat. Apparates. Ztschr. f. Heilkd.

Strutt DI, Weber U \& Mlodzik M (1997) The role of RhoA in tissue polarity and Frizzled signalling. Nature 387: 292-295

Su LK, Vogelstein B \& Kinzler KW (1993) Association of the APC tumor suppressor protein with catenins. Science. 262: 1734-1737 
Swerdlow SH, Campo E, Harris NL, Jaffe ES, Pileri SA \& Stein H (2008) WHO Classification of Tumours of Haematopoietic and Lymphoid Tissues IARC Press, 2008

Takada R, Satomi Y, Kurata T, Ueno N, Norioka S, Kondoh H, Takao T \& Takada $S$ (2006) Monounsaturated fatty acid modification of Wnt protein: its role in Wnt secretion. Dev. Cell 11: 791-801

Takahashi H, Hideshima K, Kawazoe K, Tsuda N, Fujita S, Shibata Y, Okabe H \& Yamabe S (1995) Immunophenotypes of Reed-Sternberg cells and their variants: a study of 68 cases of Hodgkin's disease. Tohoku J. Exp. Med. 177: 193-211

Tamai K, Semenov M, Kato Y, Spokony R, Liu C, Katsuyama Y, Hess F, SaintJeannet J-P \& He X (2000) LDL-receptor-related proteins in Wnt signal transduction. Nature 407: 530-535

Tandon B, Peterson L, Gao J, Nelson B, Ma S, Rosen S \& Chen Y-H (2011) Nuclear overexpression of lymphoid-enhancer-binding factor 1 identifies chronic lymphocytic leukemia\&sol;small lymphocytic lymphoma in small B-cell lymphomas. Mod. Pathol. 24: 1433-1443

Teichmann M, Meyer B, Beck A \& Niedobitek G (2005) Expression of the interferon-inducible chemokine IP-10 (CXCL10), a chemokine with proposed anti-neoplastic functions, in Hodgkin lymphoma and nasopharyngeal carcinoma. J. Pathol. 206: 68-75

Thiago LS, Costa ES, Lopes DV, Otazu IB, Nowill AE, Mendes F a., Portilho DM, Abreu JG, Mermelstein CS, Orfao A, Rossi MID \& Borojevic R (2010) The Wnt signaling pathway regulates Nalm-16 b-cell precursor acute lymphoblastic leukemic cell line survival and etoposide resistance. Biomed. Pharmacother. 64: 63-72

Thomas RK, Re D, Zander T, Wolf J \& Diehl V (2002) Epidemiology and etiology of Hodgkin's lymphoma. Ann. Oncol. 13: 147-152

Tiacci E, Döring C, Brune V, van Noesel CJM, Klapper W, Mechtersheimer G, Falini B, Küppers R \& Hansmann M-L (2012) Analyzing primary Hodgkin and Reed-Sternberg cells to capture the molecular and cellular pathogenesis of classical Hodgkin lymphoma. Blood 120: 4609-4620

Till KJ, Lin K, Zuzel M \& Cawley JC (2002) The chemokine receptor CCR7 and alpha4 integrin are important for migration of chronic lymphocytic leukemia cells into lymph nodes. Blood 99: 2977-2984 
Torre LA, Bray F, Siegel RL, Ferlay J, Lortet-tieulent J \& Jemal A (2015) Global Cancer Statistics, 2012. CA a cancer J. Clin. 65: 87-108

Travis A, Amsterdam A, Belanger C \& Grosschedl R (1991) LEF-1, a gene encoding a lymphoid-specific with protein, an HMG domain, regulates T-cell receptor a enhancer function. Genes Dev. 5: 880-894

Trentin L, Miorin M, Facco M, Baesso I, Carraro S, Cabrelle A, Maschio N, Bortoli M, Binotto G, Piazza F, Adami F, Zambello R, Agostini C \& Semenzato G (2007) Multiple myeloma plasma cells show different chemokine receptor profiles at sites of disease activity. Br. J. Haematol. 138: 594-602

Trümper L, Brady G, Bagg A, Gray D, Loke SL, Griesser H, Wagman R, Braziel R, Gascoyne RD \& Vicini S (1993) Single-cell analysis of Hodgkin and ReedSternberg cells: molecular heterogeneity of gene expression and p53 mutations. Blood 81: 3097-3115

Tweeddale ME, Lim B, Jamal N, Robinson J, Zalcberg J, Lockwood G, Minden MD \& Messner HA (1987) The Presence of Clonogenic Cells in High-Grade Malignant Lymphoma: A Prognostic Factor. Blood 69: 1307-1314

Vacca A, Ribatti D, Roncali L \& Dammacco F (1995) Angiogenesis in B cell lymphoproliferative diseases. Biological and clinical studies. Leuk. Lymphoma 20: $27-38$

Veeman MT, Axelrod JD \& Moon RT (2003) A Second Canon: Functions and Mechanisms of $\beta$-Catenin-Independent Wnt Signaling. Dev. Cell 5: 367-377

Verdelis K, Lukashova L, Atti E, Mayer-Kuckuk P, Peterson MGE, Tetradis S, Boskey a. L \& van der Meulen MCH (2011) MicroCT morphometry analysis of mouse cancellous bone: Intra- and inter-system reproducibility. Bone 49: 580-587

Vockerodt M, Pinkert D, Smola-Hess S, Michels A, Ransohoff RM, Tesch H \& Kube D (2005) The Epstein-Barr virus oncoprotein latent membrane protein 1 induces expression of the chemokine IP-10: Importance of mRNA half-life regulation. Int. J. Cancer 114: 598-605

Vockerodt M, Soares M, Kanzler H, Küppers R, Kube D, Hansmann ML, Diehl V \& Tesch H (1998) Detection of clonal Hodgkin and Reed-Sternberg cells with identical somatically mutated and rearranged $\mathrm{VH}$ genes in different biopsies in relapsed Hodgkin's disease. Blood 92: 2899-2907

Vogel W, Gish GD, Alves F \& Pawson T (1997) The Discoidin Domain Receptor Tyrosine Kinases Are Activated by Collagen. Mol. Cell 1: 13-23 
Wallingford JB, Fraser SE \& Harland RM (2002) Convergent extension: The molecular control of polarized cell movement during embryonic development. Dev. Cell 2: 695-706

Walther N, Ulrich A, Vockerodt M, von Bonin F, Klapper W, Meyer K, Eberth S, Pukrop T, Spang R, Trümper L \& Kube D (2013) Aberrant lymphocyte enhancer-binding factor 1 expression is characteristic for sporadic Burkitt's lymphoma. Am. J. Pathol. 182: 1092-1098

Wang J \& Wynshaw-Boris A (2004) The canonical Wnt pathway in early mammalian embryogenesis and stem cell maintenance/differentiation. Curr. Opin. Genet. Dev. 14: 533-539

Wang W, Ji P, Steffen B, Metzger R, Schneider PM, Halfter H, Schrader M, Berdel WE, Serve H \& Müller-Tidow C (2005) Alterations of lymphoid enhancer factor-1 isoform expression in solid tumors and acute leukemias. Acta Biochim. Biophys. Sin. (Shanghai). 37: 173-180

Wang W, Wyckoff JB, Frohlich VC, Wang W, Wyckoff JB, Frohlich VC, Oleynikov Y, Hu S, Zavadil J, Cermak L, Bottinger EP, Singer RH, White JG, Segall JE \& Condeelis JS (2002) Single Cell Behavior in Metastatic Primary Mammary Tumors Correlated with Gene Expression Patterns Revealed by Molecular Profiling Single Cell Behavior in Metastatic Primary Mammary Tumors Correlated with Gene Expression Patterns Revealed by Molecular Pro. Cancer Res. 62: 6278-6288

Wang Z, Dabrosin C, Yin X, Fuster MM, Arreola A, Rathmell WK, Generali D, Nagaraju GP, El-Rayes B, Ribatti D, Chen YC, Honoki K, Fujii H, Georgakilas AG, Nowsheen S, Amedei A, Niccolai E, Amin A, Ashraf SS, Helferich B, et al (2015) Broad targeting of angiogenesis for cancer prevention and therapy. Semin. Cancer Biol.: 1-20

Weeraratna AT, Jiang Y, Hostetter G, Rosenblatt K, Duray P, Bittner M \& Trent JM (2002) Wnt5a signaling directly affects cell motility and invasion of metastatic melanoma. Cancer Cell 1: 279-288

Wells A, Grahovac J, Wheeler S, Ma B \& Lauffenburger D (2013) Targeting tumor cell motility as a strategy against invasion and metastasis. Trends Pharmacol. Sci. 34: 283-289

Weniger M a, Melzner I, Menz CK, Wegener S, Bucur a J, Dorsch K, Mattfeldt T, Barth TFE \& Möller P (2006) Mutations of the tumor suppressor gene SOCS-1 in classical Hodgkin lymphoma are frequent and associated with nuclear phospho-STAT5 accumulation. Oncogene 25: 2679-2684 
Willert K, Brown JD, Danenberg E, Duncan AW, Weissman IL, Reya T, Yates JR \& Nusse R (2003) Wnt proteins are lipid-modified and can act as stem cell growth factors. Nature 423: 448-452

Winter CG, Wang B, Ballew A, Royou A, Karess R, Axelrod JD \& Luo L (2001) Drosophila Rho-associated kinase (Drok) links Frizzled-mediated planar cell polarity signaling to the actin cytoskeleton. Cell 105: 81-91

Wolf J, Kapp U, Bohlen H, Kornacker M, Schoch C, Stahl B, Mucke S, von Kalle C, Fonatsch C, Schaefer H-E, Hansmann M-L \& Diehl V (1996) Peripheral Blood Mononuclear Cells of a Patient With Advanced Hodgkin's Lymphoma Give Rise to Permanently Growing Hodgkin-Reed Sternberg Cells. Blood 87: 3418-3428

Wolf K, Mazo I, Leung H, Engelke K, Von Andrian UH, Deryugina El, Strongin AY, Bröcker EB \& Friedl P (2003) Compensation mechanism in tumor cell migration: Mesenchymal-amoeboid transition after blocking of pericellular proteolysis. J. Cell Biol. 160: 267-277

Wong H-C, Bourdelas A, Krauss A, Lee H, Shao Y, Wu D, Mlodzik M, Shi D \& Zheng J (2003) Direct Binding of the PDZ Domain of Dishevelled to a Conserved Internal Sequence in the C-Terminal Region of Frizzled. Mol. Cell 12: $1251-1260$

Wood SL, Pernemalm M, Crosbie PA \& Whetton AD (2014) The role of the tumormicroenvironment in lung cancer-metastasis and its relationship to potential therapeutic targets. Cancer Treat. Rev. 40: 558-566

Wright K, Wilson P, Morland S, Campbell I, Walsh M, Hurst T, Ward B, Cummings M \& Chenevix-Trench G (1999) Beta-Catenin Mutation and Expression Analysis in Ovarian Cancer: Exon 3 Mutations and Nuclear Translocation in 16\% of Endometrioid Tumours. Int. J. Cancer 82: 625-629

Wu B, Crampton SP \& Hughes CCW (2007) Wnt Signaling Induces Matrix Metalloproteinase Expression and Regulates T Cell Transmigration. Immunity 26: 227-239

Wu G, Xu G, Schulman BA, Jeffrey PD, Harper JW \& Pavletich NP (2003) Structure of a b-TrCP1-Skp1- b -Catenin Complex: Destruction Motif Binding and Lysine Specificity of the SCF b -TrCP1 Ubiquitin Ligase. Mol. Cell 11: 1445-1456 
Wu W, Glinka A, Delius H \& Niehrs C (2000) Mutual antagonism between dickkopf1 and dickkopf2 regulates $W n t / \beta$-catenin signalling. Curr. Biol. 10: 1611-1614

Xargay-Torrent S, López-Guerra M, Montraveta A, Saborit-Villarroya I, Rosich L, Navarro A, Pérez-Galán P, Roué G, Campo E \& Colomer D (2013) Sorafenib inhibits cell migration and stroma-mediated bortezomib resistance by interfering B-cell receptor signaling and protein translation in mantle cell lymphoma. Clin. Cancer Res. 19: 586-597

Xu Q, Wang Y, Dabdoub A, Smallwood PM, Williams J, Woods C, Kelley MW, Jiang L, Tasman W, Zhang K \& Nathans J (2004) Vascular development in the retina and inner ear: Control by Norrin and Frizzled-4, a high-affinity ligand-receptor pair. Cell 116: 883-895

Yamamoto W, Tomita N, Watanabe R, Hattori Y, Nakajima Y, Hyo R, Hashimoto C, Motomura $S$ \& Ishigatsubo $Y(2010)$ Central nervous system involvement in diffuse large B-cell lymphoma. Eur. J. Haematol. 85: 6-10

Yamazaki D, Kurisu S \& Takenawa T (2005) Regulation of cancer cell motility through actin reorganization. Cancer Sci. 96: 379-386

Yang Y, Topol L, Lee H \& Wu J (2003) Wnt5a and Wnt5b exhibit distinct activities in coordinating chondrocyte proliferation and differentiation. Development 130: 1003-1015

Yao L, Sun B, Zhao X, Zhao X, Gu Q, Dong X, Zheng Y, Sun J, Cheng R, Qi H \& An $J$ (2014) Overexpression of Wnt5a promotes angiogenesis in NSCLC. Biomed Res. Int. 2014: 832562

Yeh J-RJ \& Peterson RT (2009) Novel Wnt antagonists target porcupine and Axin. Nat. Chem. Biol. 5: 74-75

Yochum GS (2011) Multiple Wnt/B-catenin responsive enhancers align with the MYC promoter through long-range chromatin loops. PLoS One 6: e18966

Yochum GS, Cleland R \& Goodman RH (2008) A genome-wide screen for betacatenin binding sites identifies a downstream enhancer element that controls c-Myc gene expression. Mol. Cell. Biol. 28: 7368-7379 
Younes A, Gopal AK, Smith SE, Ansell SM, Rosenblatt JD, Savage KJ, Ramchandren R, Bartlett NL, Cheson BD, De Vos S, Forero-Torres A, Moskowitz CH, Connors JM, Engert A, Larsen EK, Kennedy DA, Sievers EL \& Chen R (2012) Results of a pivotal phase II study of brentuximab vedotin for patients with relapsed or refractory Hodgkin's Iymphoma. J. Clin. Oncol. 30: 2183-2189

Yu B, Yang X, Xu Y, Yao G, Shu H, Lin B, Hood L, Wang H, Yang S, Gu J, Fan J \& Qin W (2009) Elevated expression of DKK1 is associated with cytoplasmic/nuclear $\beta$-catenin accumulation and poor prognosis in hepatocellular carcinomas. J. Hepatol. 50: 948-957

Zaunig $S$ unpublished thesis. Clinic of Haematology and Medical Oncology, University Medical Centre of the Georg-August University of Göttingen

Zecca M, Basler K \& Struhl G (1996) Direct and long-range action of a wingless morphogen gradient. Cell 87: 833-844

Zeng X, Huang H, Tamai K, Zhang X, Harada Y, Yokota C, Almeida K, Wang J, Doble B, Woodgett J, Wynshaw-Boris A, Hsieh J-C \& He X (2008) Initiation of Wnt signaling: control of Wnt coreceptor Lrp6 phosphorylation/activation via frizzled, dishevelled and axin functions. Development 135: 367-375

Zepeda-Moreno A, Taubert I, Hellwig I, Hoang V, Pietsch L, Lakshmanan VK, Wagner W \& Ho AD (2014) Innovative method for quantification of cell-cell adhesion in 96-well plates. Cell Adh. Migr. 5: 215-219

Zhang J, Ye J, Ma D, Liu N, Wu H, Yu S, Sun X, Tse W \& Ji C (2013) Cross-talk between leukemic and endothelial cells promotes angiogenesis by VEGF activation of the Notch/DII4 pathway. Carcinogenesis 34: 667-677

Zhang X, Gaspard JP \& Chung DC (2001) Regulation of Vascular Endothelial Growth Factor by the Wnt and K-ras Pathways in Colonic Neoplasia. Cancer Res. 61: 6050-6054

Zhao J, Kim K-A \& Abo A (2009) Tipping the balance: modulating the Wnt pathway for tissue repair. Trends Biotechnol. 27: 131-136

Zheng B, Flumara P, Li Y V., Georgakis G, Snell V, Younes M, Vauthey JN, Carbone A \& Younes A (2003) MEK/ERK pathway is aberrantly active in Hodgkin disease: A signaling pathway shared by CD30, CD40, and RANK that regulates cell proliferation and survival. Blood 102: 1019-1027 
Zhu J, Zhang S, Gu L \& Di W (2012) Epigenetic silencing of DKK2 and Wnt signal pathway components in human ovarian carcinoma. Carcinogenesis 33: 23342343

Zucker-Franklin D, Grusky G \& Baez L (1983) Reed-Sternberg cells cultured from morphologically unidentifiable precursors in the blood of patients with Hodgkin's disease. Hematol. Oncol. 1: 127-138

Zurawel RH, Chiappa SA, Allen C \& Raffel C (1998) Sporadic medulloblastomas contain oncogenic $\beta$-catenin mutations. Cancer Res. 58: 896-899 


\section{Appendix}

\section{Additional figures}

A
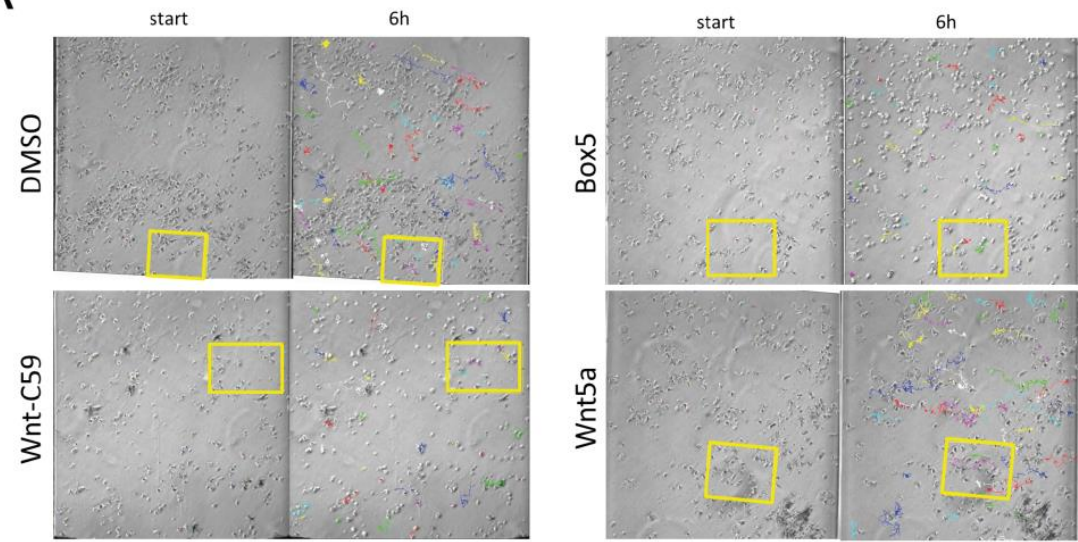

B
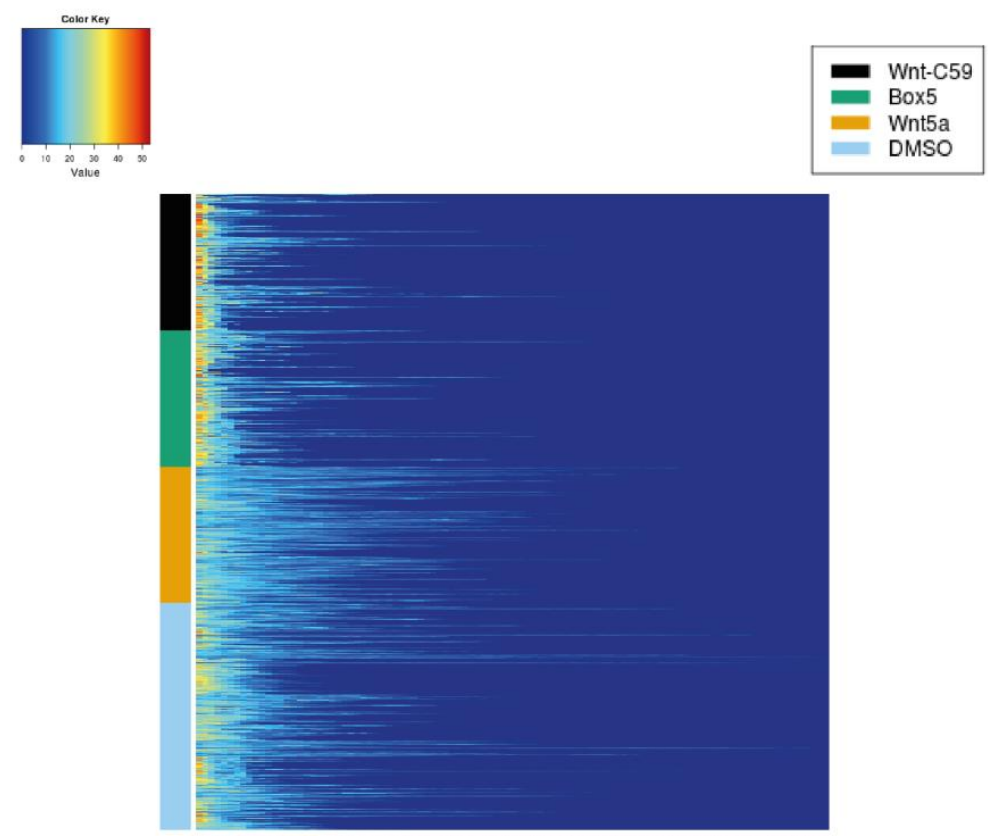

Figure A-43: Additional data to time-lapse microscopy of Wnt-C59, Box5 or WNT5A pretreated L428 cells using the IBIDI 3D chemotaxis chamber. (A) Exemplary trajectories of 50 cells per experiment at the starting point and after 6 hours are shown in coloured lines. (Yellow square visualizes the area observed in Figure 17). (B) Complete heat map shows all fingerprints of DMSO (light blue), Wnt-C59 (black), Box5 (green) or WNT5A (orange)-treated L428 cells without clustering (addition to Figure 19).

These additional data belongs to chapter 3.1.7. 
A

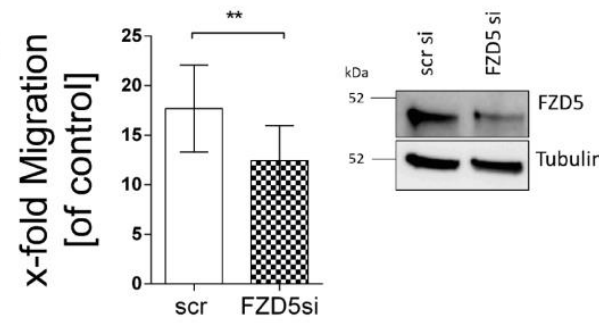

B

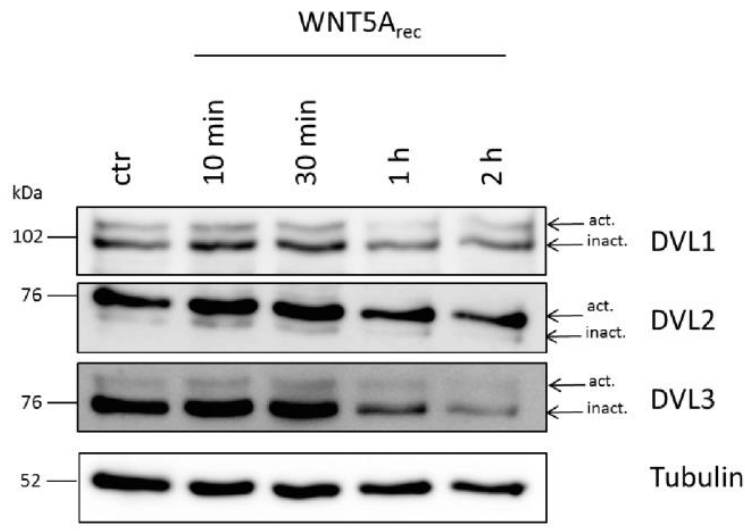

C

\begin{tabular}{|c|c|c|c|c|c|c|c|c|c|c|c|c|}
\hline \multicolumn{4}{|c|}{ L428 } & \multicolumn{4}{|c|}{$\mathrm{KMH} 2$} & \multicolumn{4}{|c|}{ L1236 } & \multirow[b]{2}{*}{ DMSO } \\
\hline+ & . & + & . & + & 1 & + & ' & + & ' & + & . & \\
\hline ' & + & 1 & + & ' & + & 1 & + & ' & + & ' & + & Box5 \\
\hline , & , & + & + & , & , & + & + & ' & , & , & + & Wnt5a \\
\hline
\end{tabular}

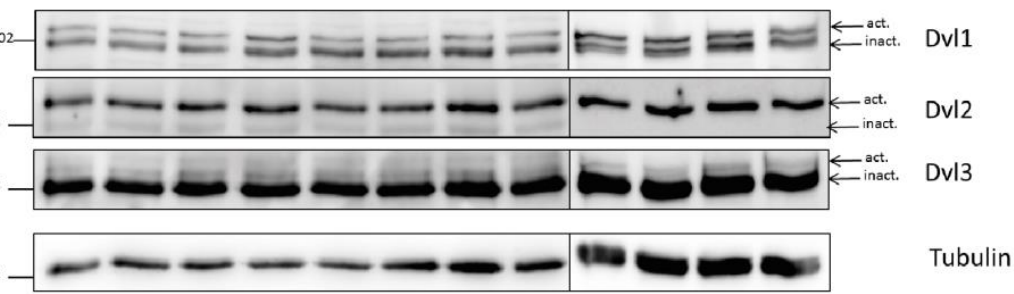

Figure A-44: KM-H2 migration depends on FZD5 and Box5 abolishes DVL3 activation in HL cell lines. (A) Migration and Western Blot were performed 48 hours after FZD5 knockdown in $\mathrm{KM}-\mathrm{H} 2$ cells. For protein detection specific antibodies against FZD5 and against tubulin as loading control were used (mean $\pm S D, n=3$, Mann Whitney test, ${ }^{* *} P<0.01$ ). (B) Western Blot shows $L 428$ cells stimulated with $100 \mathrm{ng} / \mathrm{ml}$ recombinant WNT5A for the indicated time intervals. Note the increasing activation of DVL3 during the first 30 minutes. (C) Western Blot shows DMSO or Box5 $(100 \mu \mathrm{M})$ pre-treated L428, KM-H2 and L1236 cells after stimulation with $100 \mathrm{ng} / \mathrm{ml}$ recombinant WNT5A for 10 minutes. For protein detection (B, C) specific antibodies against DVL1, DVL2, DVL3 and against tubulin as loading control were used. Modified from (Linke et al, 2016b).

These immunoblots are controls for chapter 3.1.8. 

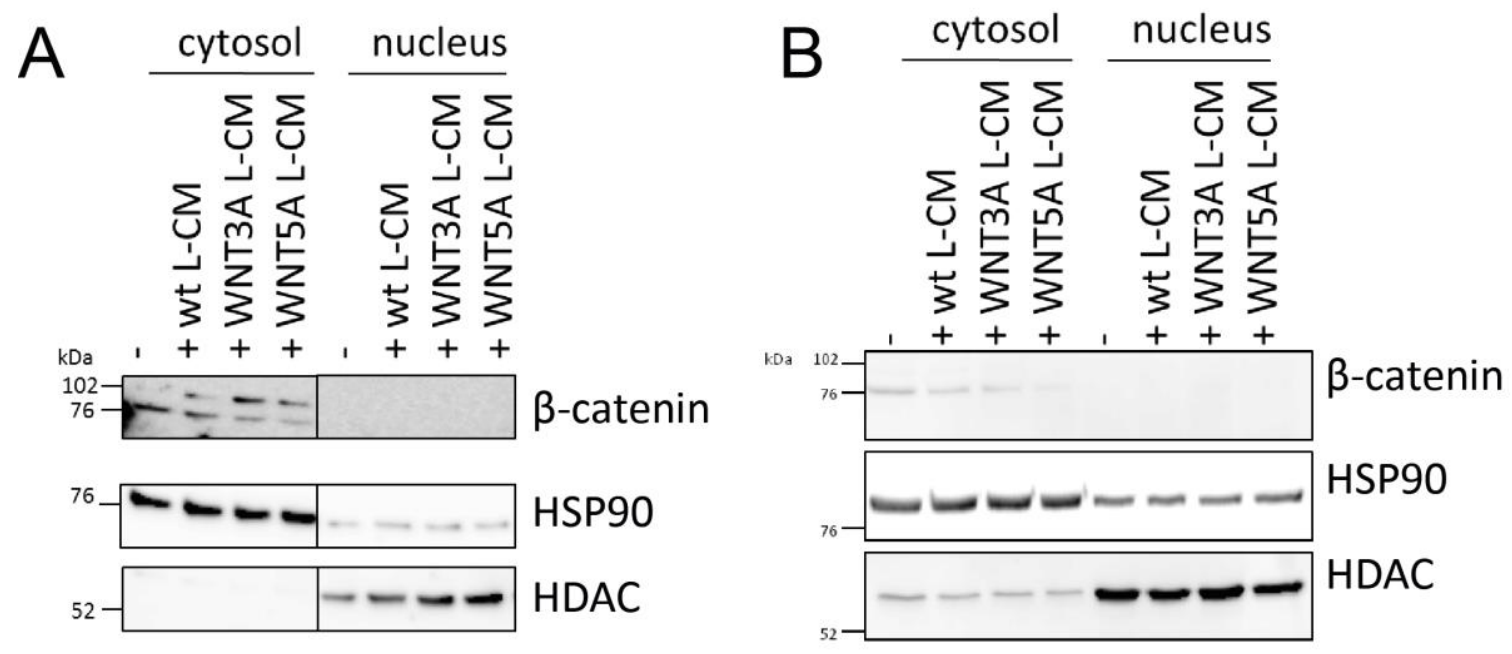

Figure A-45: Treatment with XAV939 or PF670462 abolishes nuclear $\beta$-catenin fraction. Western Blot was performed with cytosolic and nuclear fractions of L428 cells stimulated with wildtype, WNT3A or WNT5A L-cell conditioned medium (CM) after treatment with XAV939 (A) or PF670462 (B). For protein detection specific antibodies against $\beta$-catenin and against HDAC as nuclear control and HSP90 as cytosolic control were used.

This immunoblot is a control for the efficacy of the XAV939 and PF670462 inhibitors used in chapter 3.1.13 and 3.2.1. 
A

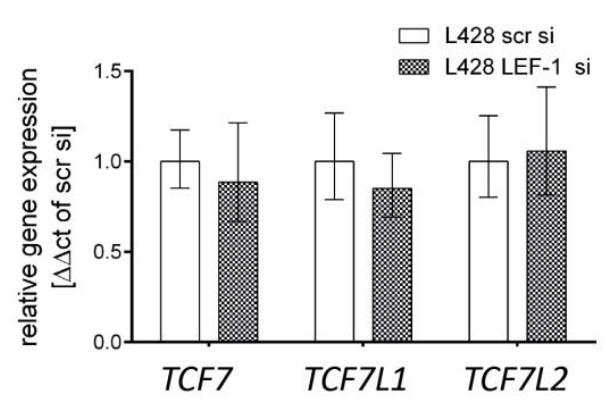

C

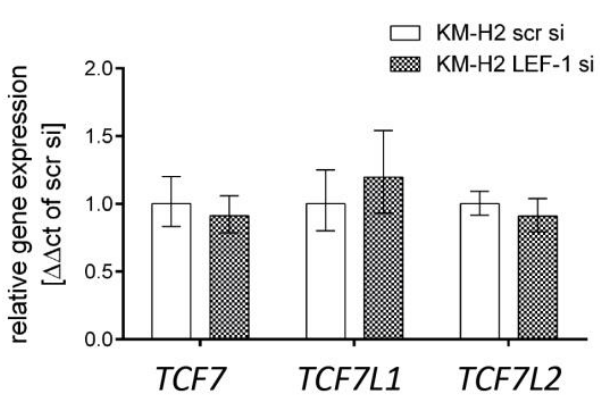

E

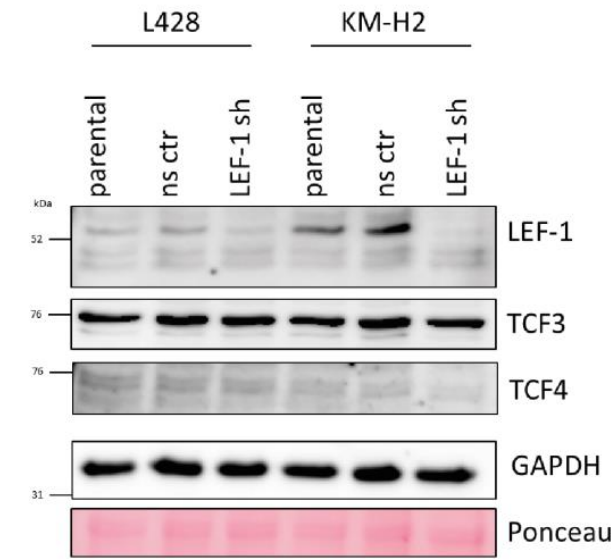

B

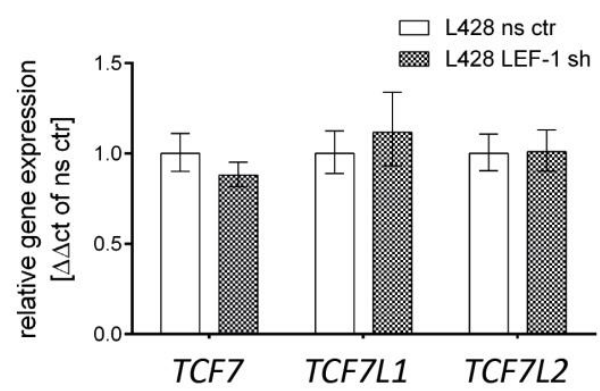

$\mathrm{D}$

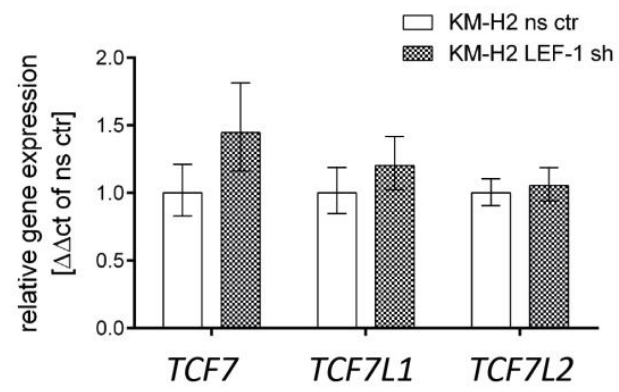

Figure A-46: TCF RNA and protein level are not influenced by the LEF-1 knockdown. QRT results of L428 cells as well as $\mathrm{KM}-\mathrm{H} 2$ cells with transient $(\mathbf{A} ; \mathbf{C})$ and stable (B; D) LEF-1 knockdown show no strong influence of LEF-1 knockdown on TCF7, TCF7L1 or TCF7L2 gene expression. Only $\mathrm{KM}-\mathrm{H} 2$ cells with stable LEF-1 knockdown show slightly increased TCF7 gene expression levels. (mean \pm error; KM-H2 LEF-1 si $n=1$; L428 LEF-1 si, L428 LEF-1 sh KM-H2 LEF-1 sh $n=3$ ) (E) Western Blot of L428 and KM-H2 cells shows no influence of the LEF-1 knockdown on TCF3 protein (protein of TCF7L1) level and just slight effects on the TCF4 (protein of TCF7L2) level in KM-H2 LEF-1 knockdown cells. For protein detection specific antibodies against LEF-1, TCF3, TCF4 and against GAPDH as loading control were used.

This immunoblot serves as control of the other TCF expression levels for LEF-1 knockdown cell lines. 


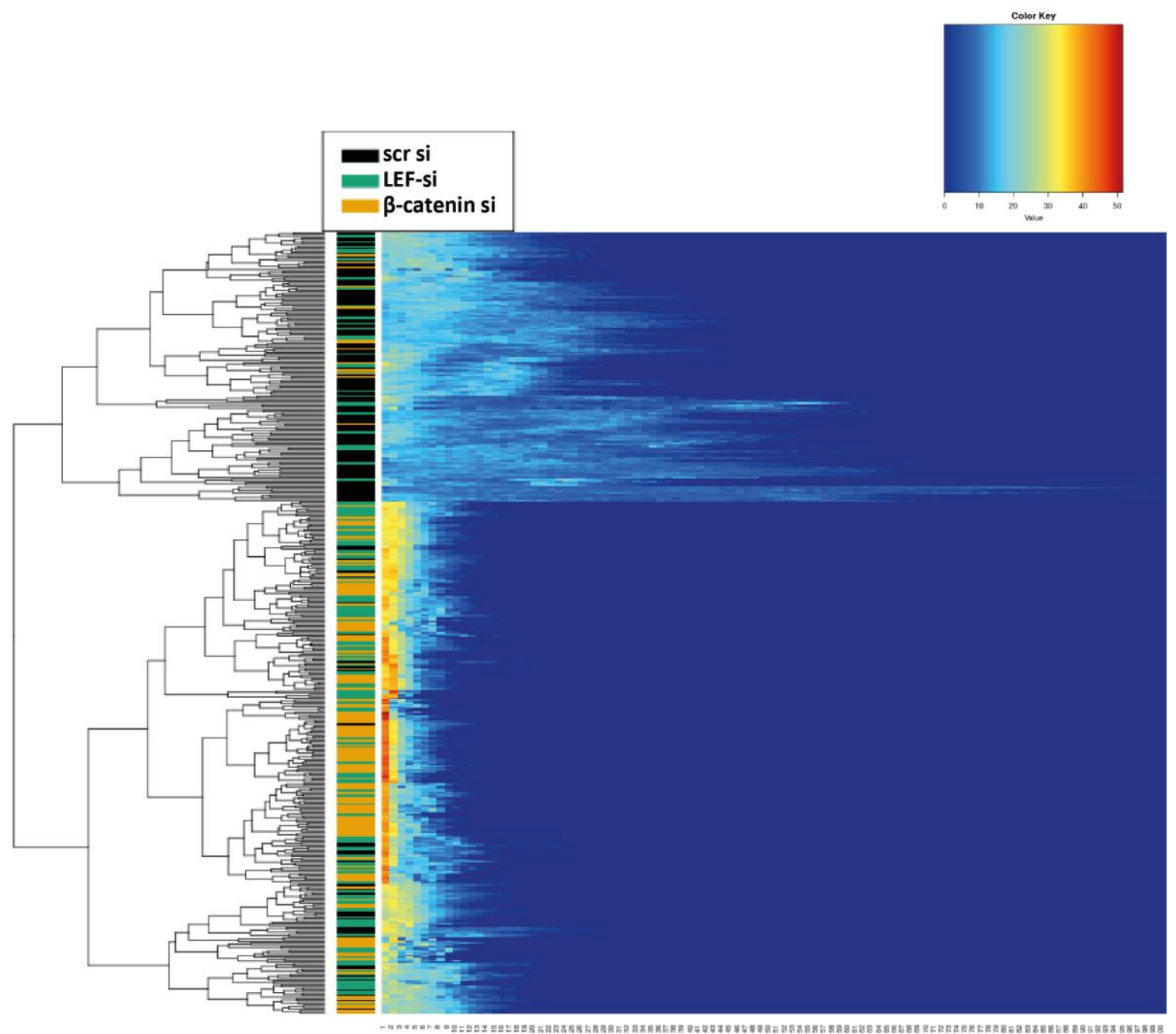

Figure A-47: Cell tracks of KM-H2 LEF-1 si and $\beta$-catenin si cluster separately from scr control cells. Heat map displays the results of the hierarchical clustering of movement patterns of scr si, LEF-1 si and $\beta$-catenin si KM-H2 cells based on shape fingerprints according to the form and length of each track. The $x$-axis of the heat map corresponds to the internal distances within single tracks, with short distances mapped to the left and longer distances to the right. The colour of the heat map tiles represents the number of counts for specific distances per track ('square root transformed' to enhance contrast). Experimental group membership is encoded by colours on the left side of the heat map with black (scr si), green (LEF-1 si) and orange ( $\beta$-catenin si). From (Linke et al, 2016a).

This heat map shows the clustering scr si, LEF-1 si and $\beta$-catenin si KM-H2 cell path fingerprints described in chapter 3.1.1. 
Case Processing Summary ${ }^{\mathrm{a}, \mathrm{b}, \mathrm{c}}$

\begin{tabular}{|c|c|c|c|c|c|}
\hline \multicolumn{6}{|c|}{ Cases } \\
\hline \multicolumn{2}{|c|}{ Valid } & \multicolumn{2}{|c|}{ Missing } & \multicolumn{2}{|c|}{ Total } \\
\hline $\mathrm{N}$ & Percent & $\mathrm{N}$ & Percent & $\mathrm{N}$ & Percent \\
\hline 40 & 88,9 & 5 & 11,1 & 45 & 100,0 \\
\hline
\end{tabular}

a. Protein factor $=1$

b. Squared Euclidean Distance used

c. Average Linkage (Between Groups)

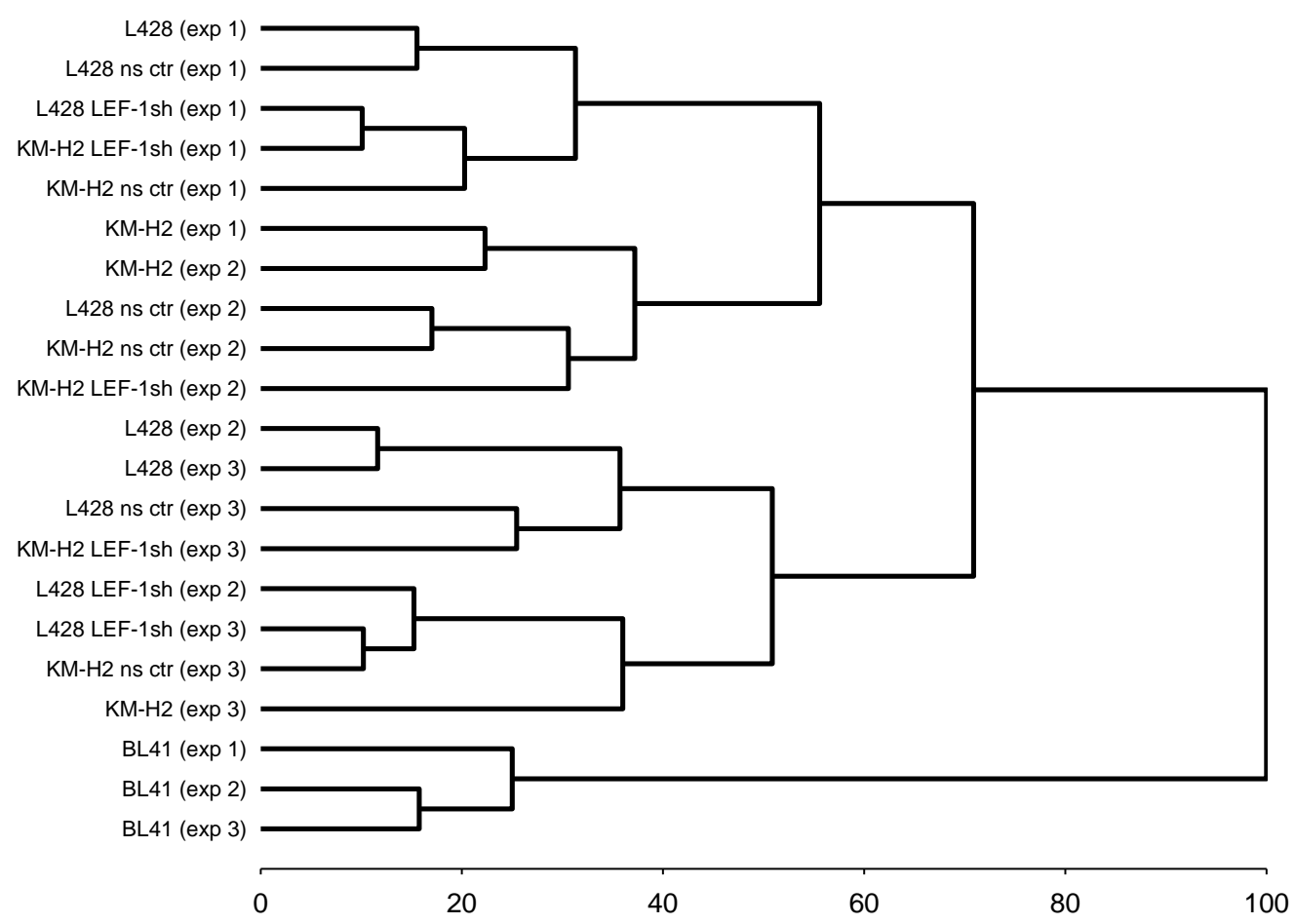

Figure A-48: Metabolites of L428 and KM-H2 pGIPZ LEF-1 sh cells are not different from control cells. Metabolomics NMR analysis data from three independent experimental sets (KM-H2/L428; parental, LEF-1 sh, ns ctr) were normalized by total protein amount in each sample and their metabolic profile (based on 25 metabolites) was analysed using Cluster analysis (Euclidean distance; Ward's method; link distance scaled as percentage of maximal link distance). The LEF-1 knockdown does not cause any obvious change in the metabolism of cHL cell lines KM$\mathrm{H} 2$ and L428. BL cell line BL41 was used as an external control. From (Linke et al, 2016a).

These additional data belong to chapter 3.2.3. 


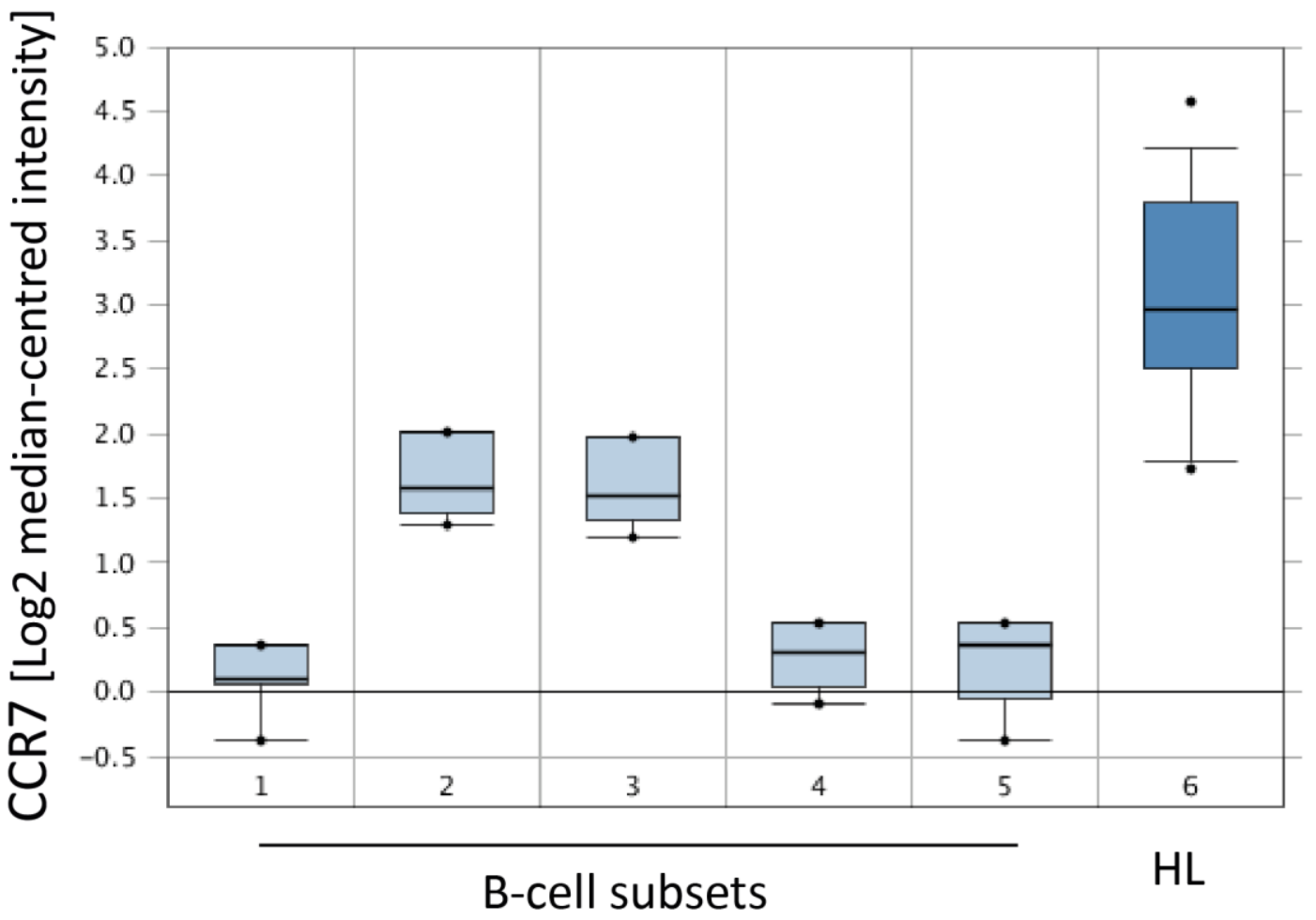

Figure A-49: CCR7 expression is increased in $\mathrm{CHL}$ patients compared to physiological B-cell subsets. CCR7 expression is high in several HRS patients' samples (no. 6). CCR7 expression data was obtained by single HRS cell analysis by Brune et al. (Brune et al, 2008) (mean of single patients' data; No.1: centroblasts $n=5$; No.2: memory B-cell $n=5$; No.3: naïve pre-germinal centre B-cell $n=5$; No.4: plasma cell $n=5$; No.5: small cleaved follicle centre cell $n=5$; No.6: $H L n=12$ ) 


\section{Supplementary Videos}

Video 1: L428 cells, DMSO-treated for 72 hours

Video 2: L428 cells, Wnt-C59-treated for 72 hours

Video 3: L428 cells, Box5-treated for 24 hours

Video 4: L428 cells, WNT5A-stimulated for 24 hours

Video 5: KM-H2 cells, scr siRNA

Video 6: KM-H2 cells, LEF-1 siRNA

Video 7: KM-H2 cells, $\beta$-catenin siRNA 


\section{Additional Methods}

Cell track analysis using shape fingerprint descriptors by Manuel M. Nietert

To derive a condensed depiction for the observed track space, we performed an analysis using 2D shape fingerprints, which were derived from the internal distance distribution for each track, like it is common for the shape description of chemical compounds in cheminformatics (Schneider et al, 1999).

\section{Software}

We used KNIME version 2.11.3 (Berthold et al, 2007) to organize the analysis of cell tracks and perform preprocessing, the final analysis steps like deriving the fingerprints, hierarchical clustering and plotting where done with corresponding R-nodes in KNIME using $R$ version 3.0.2. (Development Core Team, $R$ : $A$ language and environment for statistical computing. R Foundation for Statistical Computing, Vienna, Austria, 2011).

Deriving cell track fingerprints

To derive the individual track fingerprint we implemented the following steps as an R function:

1. Generating intra-track distance matrices per track $\rightarrow$ we transformed the xy-coordinate collection for each track into an individual distance matrix representation, thus mapping the occurring internal distances of each track.

2. Estimating the binning parameters $\rightarrow$ To achieve a comparable scaled binning of the resulting correlation vectors we scanned the individual track distance matrices for the global max distance reported, then we used the global maximum of intra-track distances to set the binning algorithms required max distance to be used for all tracks. The number of bins was set to $n=100$; which seems a reasonable choice given that 50 time steps were recorded per track and the global max distance was $\approx 250 \mu \mathrm{m}$, while a typical eukaryotic cell diameter is $\approx 10 \mu \mathrm{m}$. 
3. Deriving the shape fingerprints $\rightarrow$ The use of a binning vector function (using a range [0; global_max_distance], and \#_of_bins = 100) allowed to transform each distance matrix into a correlation vector representation. For each occurring distance within a track the corresponding bin position to count up in the n-dimensional correlation vector can be simply calculated using: bin_position = floor((current_distance-global_minimal_distance) / (global_max_ distance-global_minimal_distance) ${ }^{*}$ \#_of_bins).

4. Resulting correlation vector table containing fingerprints $\rightarrow$ having derived the shape fingerprint vector for each track we used the vector representations for our similarity calculations; e.g., hierarchical clustering, heat map representations

Similarity analysis using cell track fingerprints

We used the fingerprints to explore the track space. The analysis can be divided into the following sequential steps:

1. Hierarchical clustering of the tracks $\rightarrow$ We used the fingerprints to derive dendrogram representations of the track space using Manhattan distance for all distance calculations and complete linkage method for the tree construction.

2. Identifying the main clusters $\rightarrow$ we used the cut-tree function to derive the main clusters in track space.

3. Identifying cluster representatives $\rightarrow$ for each cluster we derived the representative track by identifying the track fingerprint with the smallest cumulative distance to the other cluster members.

4. Mapping tracks from different experiments to the clusters $\rightarrow$ after successful inspection of the cluster representatives to represent the required distinction level, we mapped the tracks respective experiment type to the dendrogram leafs. Extracting the cluster group members we thus could derive the count of the tracks per experiment per cluster. Finally, scaling the count per experiment resulted in the relative distribution of track types per experiment. 


\section{Curriculum Vitae}

Franziska Linke

\section{Personal Information}

Date of birth

Place of birth

Nationality

Email
July $19^{\text {th }}, 1987$

Cottbus (Germany)

German

franziska.linke@med.uni-goettingen.de

\section{Education}

10/2012 till present

Doctoral thesis at the University Medical Centre of the Georg-August University of Göttingen:

"WNT signalling affects cell migration, invasion and the lymphoma-endothelial interplay in Hodgkin Lymphoma" (Clinic of Haematology and Medical Oncology, project team of Prof. Dr. Kube)

09/2010-09/2012 Master course Medical Biology at the University of Duisburg-Essen

Title of the Master thesis:

"Irreversible inhibition of the epidermal growth factor receptor by BIBW2992 (Afatinib) - New aspects on apoptosis-induction and acquired resistance in non-small cell lung cancer" (Department of Medical Oncology at the Essen University Hospital, project team of Prof. Dr. Schuler)

09/2007-09/2010 Bachelor course Medical Biology at the University of Duisburg-Essen 
Title of the Bachelor thesis:

„Influence of Adenosine on Migration and Proliferation of HCASMCs and Adenosine-induced upregulation of the HAS-1" (Institute for Pharmacology at the Essen University Hospital, project team of Prof. Dr. Fischer)

09/2000 - 07/2007 Abitur (A-levels)

European School Humboldt Grammar School Cottbus

\section{Internships}

$06 / 2013$

Method course on chromatin immunoprecipitation (ChIP) at the Charité Berlin, project team of Prof. Dr. Hummel

01/2012 - 02/2012 Laboratory internship „Stroma-mediated resistance of nonsmall-cell lung cancer (NSCLC) against cytotoxic drugs with special respect to EGFR TKIs" at the Essen University Hospital, Clinic for Internal Medicine (Tumor research), project team of Dr. Breitenbücher

11/2011-12/2011 Laboratory internship „Analysis of the pathobiological function of the nuclear protease Taspase 1" at the Mainz University Hospital, Molecular and Cellular Oncology, project team of Prof. Dr. Stauber

09/2011-10/2011 Laboratory internship „Molecular characterization of the translocation 8;22 on the basis of B-ALL patient samples and lymphoma cell lines" at the Charité Berlin, campus Benjamin-Franklin, project team of Dr. Burmeister 


\section{Congress Participations}

Annual Meeting of the German Society for Hematology \& Oncology, 2015, Basel (Switzerland)

Oral presentation: "Wnt5a signaling mediates cell migration and invasion of Hodgkin Lymphoma in vitro and in xenograft models"; Linke F., Zaunig S., von Bonin F., Wilting J., Bryja V., Pukrop T., Trümper L., Kube D.

18th International AEK Cancer Congress, 2015, Heidelberg (Germany)

Poster Presentation: "A Role for Wht signaling in Hodgkin's Lymphoma cell migration"; Linke F., Zaunig S., von Bonin F., Wilting J., Trümper L., Pukrop T., Kube D.

Wnt symposium at the German Cancer Centre, 2013, Heidelberg (Germany) Poster presentation: "A Role For WNT Signaling in Hodgkin's Lymphoma"; Linke F., Schoof N., Sieben O.M., von Bonin F., Hengst S., Wilting J., Trümper L., Pukrop T., Kube D.

\section{Additional Skills}

Language skills: German native speaker

English fluent (spoken and written)

French intermediate

EDV skills: Microsoft Office (Word, Excel, PowerPoint), Graph Pad, Adobe Photoshop/lllustrator, Pymol, Gene Construction Kit, Bio Edit

\section{Awards and Honours}

2011/12 Scholarship of Germany

2004 "National Competition in Foreign Languages": 1. Brandenburg Regional Prize for English, group competition \& 3. Brandenburg Regional Prize for English, single competition 